\title{
DISCLAIMER
}

This report was prepared as an account of work sponsored by an agency of the United States

Government. Neither the United States Government nor any agency thereef, nor any of their employees, makes any warranty, express or implied, or assumes any legal liability or responsibility for the accuracy, completeness, or usefulness of any information, apparatus, product, or process disclosed, or represents that its use would not infringe privately owned rights. Refer-

UC-38

Issued: August 1985 ence herein to any specific commercial product, process, or service by trade name, trademark, manufacturer, or otherwise does not necessarily constitute or imply its endorsement, recommendation, or favoring by the United States Government or any agency thereof. The views and opinions of authors expressed herein do not necessarily state or reflect those of the Uniied States Government or any agency thereof.

\section{Progress in Radiation Immune Thermionic Integrated Circuits}

LA- -10466 -MS

DE 36003286
Compiled by

D. K. Lynn

J. B. McCormick

\section{Contributors}
A. Cowan
N. Kruse
R. Dooley
M. MacRoberts
D. Hamilton*
G. Messengert
D. Holtkamp
T. Springer
L. Hong **
R. Tallon‡
W. Kerwin*
D. Wilde
E. Knight

-Consultant at Los Alamos. Department of Electrical Engineering, University of Arizona,

Tucson, AZ 85721.

-"Department of Electrical Engineering. University of Arizona, Tucson, AZ 85721.

†Consultant at Los Alamos.

†Air Force Weapons Laboratory, Albuquerque, NM 87117.

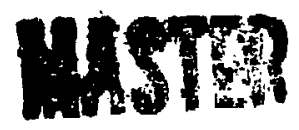


CONTENTS

ABSTRACT . . . . . . . . . . . . . . . . . . . . . . 1

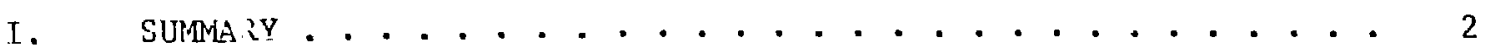

4. Background . . . . . . . . . . . . . . . . . 2

B. Objective. . . . . . . . . . . . . . . . . 5

C. Approach . . . . . . . . . . . . . . . . . . 5

D. Symopsis of Conclusions . . . . . . . . . . . . . 6

l. Applications (Discusstons/Conclusions) . . . . . . 5

2. Technical Accomplishruents . . . . . . . . . . 9 9

E. Programatic Recommendations . . . . . . . . . . . . 10

I l . Vulnerabllity . . . . . . . . . . . . . . . . . . . 12

A. Statemant of Wurk from Proposal (March 1982) . . . . . . . 12

B. Temperature Tests... . . . . . . . . . . . . . 13

C. Radiation Test Summary . . . . . . . . . . . . . . . 13

D. Gamma Dose Rate Response . . . . . . . . . . . . . . 15

l. Analysis of Mechanisms . . . . . . . . . . . . 16

a. Phaton Interactions . . . . . . . . . . 16

b. Radiation-Induced Conductivity . . . . . . . . 19

2. Initial $\dot{\gamma}$ Tests . . . . . . . . . . . . . . . 22

3. Verification Tests . . . . . . . . . . . . . 27

E. Dose Rate Response of the flip-Flop............ . 39

l. Simplified Analysis of Flip-Flop Sensitivity to

Radiation . . . . . . . . . . . . . . 39

2. Flip-Flop Proton Dose Rate Tests . . . . . . . . 42

3. Projecced Inprovements . . . . . . . . . . . 49

F. Conclusions . . . . . . . . . . . . . . . . . . . . 51

G. Reccmmendations... . . . . . . . . . . . . 53

III. LEVEL OF LNTEGRATION . • . . . . . . . . . . . . . . . . 53

A. Statement of Work from Proposal (March 1982) . . . . . . 53

B. Modification to the Statement of Work . . . . . . . . . 59

C. Process Dependent Factors Influencing Level of

Integration . . . . . . . . . . . . . . . 59

1. Resistive Leakage . . . . . . . . . . . . . . 59

2. Resistive Leakage - Impruvements to Date . . . . . 62 
3. Resistive Leakage - Future Improvements . . . . . . 67

4. Spurious Emission... . . . . . . . . . . . . . 67

5. Conclusions on Process Dependent Factors

Influencing Level of Integration . . . . . . . . 69

D. Process Independent Factors Influencing Level

of Integration . . . . . . . . . . . . . . . 70

1. Device and Circuit Modeling/Verification of Effects . . 70

2. Device Interactions. . . . . . . . . . . . 73

3. Projected Level of Integration - Current Technology . . 81

4. Design/Fabrication of an Integrated Circuit. . . . . 90

a. Initial Design of an Integrated Flip-Flop . . . . 90

b. An Infroved Flip-Flop Layout . . . . . . . . . . 94

5. Level Shifting in a Single Device (a feasibility experiment) . . . . . . . . . . . . 97

6. Current Source Devices . . . . . . . . . . 100

E. Conclusions . . . . . . . . . . . . . . . . 102

F. Recommendations . . . . . . . ....... 105

IV. POWER REQUIREMENTS . . . . . . . . . . . . . . . . . . 105

A. Statement of Work from Proposal (March 1982) . . . . . . 105

B. Theoretical Analysis and Experimental Results . . . . . . 106

C. Conclusions.................... . 110

D. Recommendations. . . . . . . . . . . . . . . 111

V. DEVICE SPEED/BANDWIDTH . . . . . . . . . . . . . . . . 111

A. Statement of Work from Proposal (March 1982) . . . . . . 111

B. Modifications to the Statement of Work . . . . . . . 112

C. Theoretical Analys is of GBP . . . . . . . . . . . . 112

D. Enhanced Processing . . . . . . . . . . . 120

E. Conclusions... . . . . . . . . . . . . . . 123

F. Recommendations .................. 123

VI. LIFE AND RELIABILITY. . . . . . . . . . . . . . . . . . . . 124

A. Statement of Work from Proposal (March 1982) . . . . . 124

B. Experimental Program for Another Sponsor - High

Current Density Cathodes. . . . . . . . . . . . 124

C. Conclusions . . . . . . . . . . . . . . . . . 125

D. Recommendations ................... 128 
VII. POWER DEVICES . . . . . . . . . . . . . . . . . . 128

A. Background . . . . . . . . . . . . . . . . . . 128

B. Analysis of Two Configurations. . . . . . . . . . . . 128

C. Conclusions. . . . . . . . . . . . . . . . 132

D. Recommendations . . . . . . . . . . . . . . . 132

VIII. APPLICATIONS . . . . . . . . . . . . . . . . . . . . 133

A. Approach . . . . . . . . . . . . . . . . . 133

B. Discussions/Presentations/Meetings . . . . . . . . . 133

C. Conclustons . . . . . . . . . . . . . . . 137

D. Recommendations . . . . . . . . . . . . . . . 139

IX. REFERENCES . . . . . . . . . . . . . . . . . . . . 139

X. APPENDIX . . . . . . . . . . . . . . . . . . 140

TIC Speed/Bandwidth Test Structure and Plans . . . . . . . . 140 
PROGRESS IN RADIATTON IMMUNE THERMIONIC INTEGRAIED CIRCUITS

Compiled by

D. K. Lynn and J. B. McCormick

\begin{abstract}
This report describes the results of a program directed at evaluating the thermionic integrated circuit (TIC) technology for applicability to military systems. Previous programs under the sponsorship of the Department of Energy, Office of Basic nnergy Sciences, have developed an Initial TIC technology base and demonstrated operation in hightemperature and high-radiation environments. The program described in this report has two parts: a technical portion in with experiments and analyses were conducted to refine perceptions of nearterm as well as ultimate performance levels of the TIC technology and (2) an applications portion in which the technical conclusions were to be evaluated against potential military applications. This report draws several conclusions that strongly suggest that (1) useful radiation-hard/high-temperature operable integrated circuits can be developed using the TIC technology; (2) because of their ability to survive and operate in hostile environments, a variety of potential military applications have been projected for this technology; and (3) based on the above two conclusions, an aggressive TIC development program should be initlated to provide the designers of future systems with integrated circuits and devices with the unique features of the TICs.
\end{abstract}




\section{SUMMARY}

\section{A. Background}

The nature, mission, tactics, and capability of military systems derive from available technology. In the last 25 years, the trend has been toward "smarter" weapuns systems with more built-in functionality and capability for autonomous action and with the ability to communicate at higher rates and process roore information. This tcend, of course, has derived from progress in semiconductor and integrated circuit technology, which has provided increasing miniaturization and lower-power and higher-speed electronic components and integrated circuits. The resultant increase in system capability has been dramatic. Modern weapons systems such as cruise missiles and satellite system. would be virtually impossible without solid-state device technology. Ulifortunately, one of the penalties in the solid-state evolution has been an icreasing susceptibility to nuclear weapon and space radiation effects.

Thermionic integrated circuits (TICs), on the other hand, derive from vacuum tube techrology. They are manufactured with the use of photolfthographic and farrication techniques developed for conventional integrated circuits, and they yield thin-film microminiature devices produced simultaneously by the thousands on the same substrate in the form of integrated circuits. Figures $I-1,-2$, and -3 depict current TIC device structures and fabrication process sequence. The TIC technology has been developed at Los Alamos National Laboratory principally under the sponsorship of the Department of Energy, Office of Basic Energy Sciences, for application in high-temperature environments. TIC devices and circuits have shown a high degree of resistance to nuclear radiation and high-temperature environments.

The program reported on in this document was initiated under DARPA sponsorship to evaiuate the TIC technology for its applicability to future military systems. 


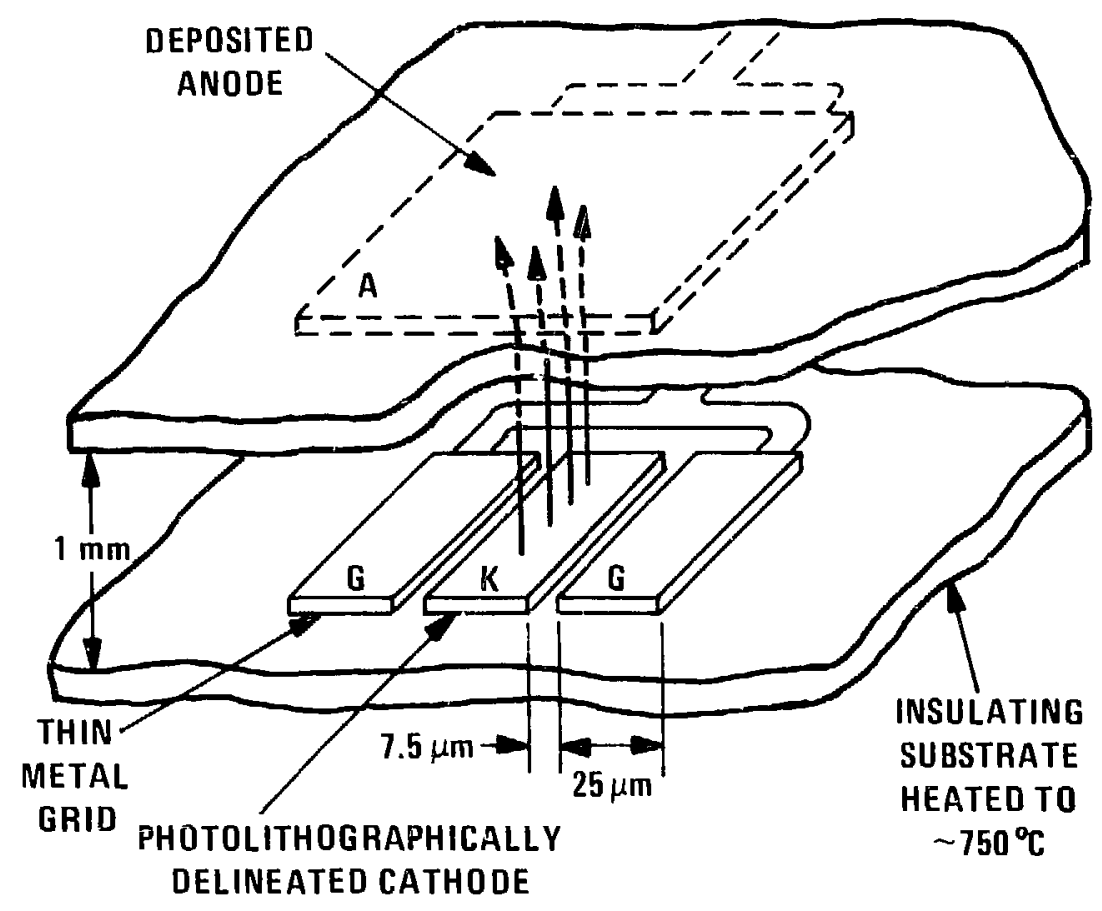

Fig. I-1. Vertical TIC gain device.

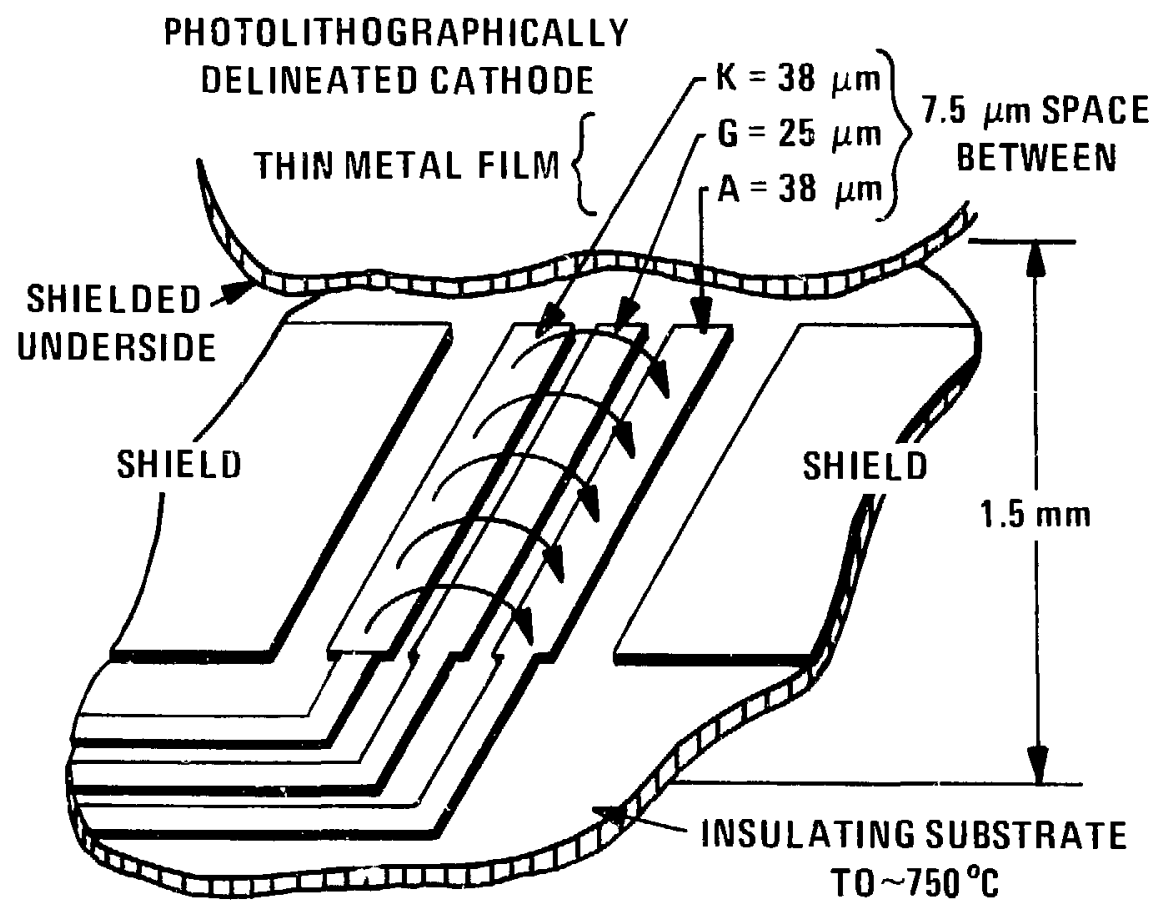

F1g. I-2. Coplanar TIC gain dev1ce. 
THIN FILM DEFOSITION - CIRCUIT SIDE

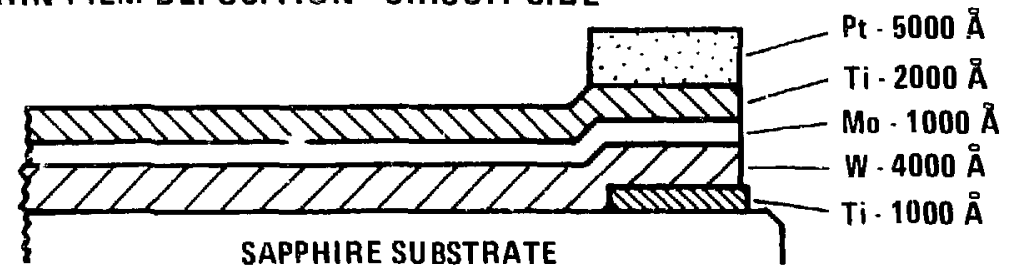

PATTERN DEFINITION - RF PLASMA ETCHED

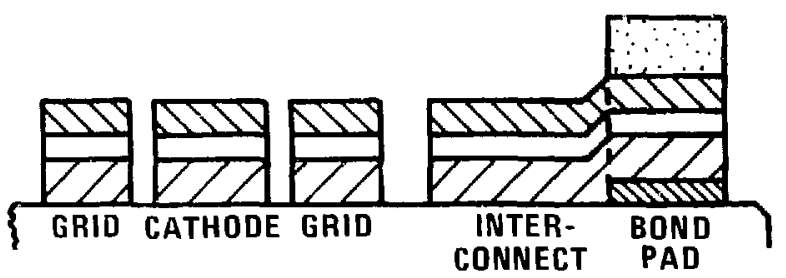

Ti - Mo REMOVED FROM CATHODE BY CHEMICAL ETCH

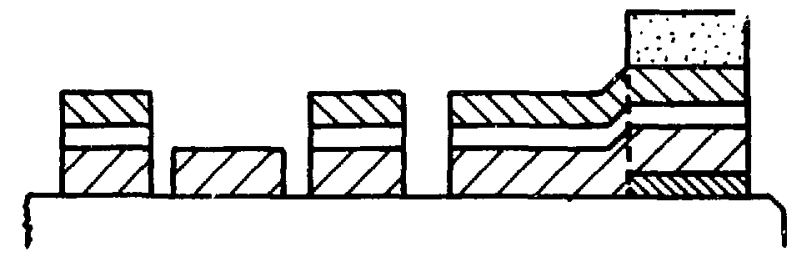

CATHODE COATING APPLIED AND DEFINED PHOTOGRAPHICALLY

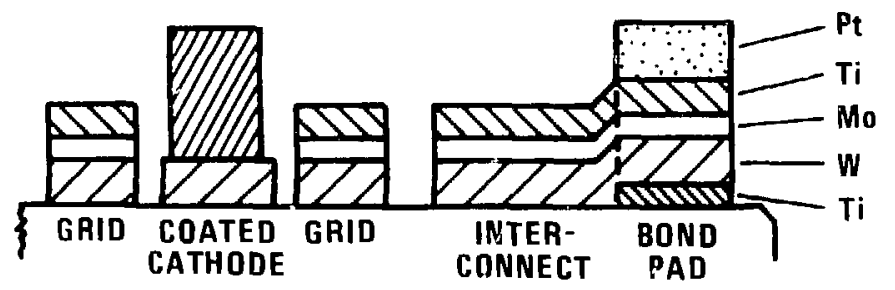

F1g. I-3. TIC metalization and photolithography processes. 
B.

Objective

As stated in the March 1982 proposal to DARPA,* "The objective of the 1 -year program is to verify the applicability of the TIC technology for milltary radiation-hardened applications. The key concepts here are verification and applications; the program is directed at enhancing present estimates of performance and refining perceptions of those applications for which the technology appears most appropriate and derives the largest benefits. The technical issues to be addressed are

- device bandwidth/speed,

- power requirements,

- level of integration,

- vulnerability, and

- life and rellability."

Additional guidance from the sponsor suggests the importance of the applications portion of this study and that the space reactor environment in particular should be carefully evaluated.

The experiments and analyses performed on these flve technical issues are described in detall in Sections II-VI.

C. Approach

It was recognized from the outset that the level of funding for this project was inadequate to answer definitively the many questions regarding both TIC technology and potential applications and to perform the required in-depth experiments or analyses. Therefore, since the general rationale for this project is to evaluate applicability of TIC technology to weapons systems and concurrently to develop insights for guiding future TIC development programs, broad discussions with both governmental agencies and industry (Seciton VIII.B) have been initiated, and based on those discussions, varying emphasis has been given to the types and depth of the technical evaluations performed. Based on sponsor guidance suggesting the Importance of applications, a small amount of the DARPA orogram funding augmented by Los Alamos funding in an approximately equal amount has been set aside for a contract with one of several companies

* Since there was a delay of nearly a year between the funding approval at DARPA and receipt of funds at Los Alamos, portions of the results described in the following sections were performed between March 82 and February 83 in anticipation of and for the DARPA-sponsored program. 
to perform an independent evaluation of the TIC technology vs applications. Aiter the competitive RFP process, $R$ \& D Associates has been selected to carry out this analysis. Also, since beam weapons represent an important possible threat in the future, Dr. George Messenger has been retalned by Los Alamos as a consultant to evaluate and report upon the threat posed to electronics by beam wapons and to evaluate the TIC technology as related to that emerging weapons concept.

The major portion of this report (Sections II-VII) contains results of numerous calculations and experiments that have been conducted as part of the DARPA-sponsored project to provide a sound basis for making future programmatic decisions and suggests directions for future programs based on technological and applications insights developed to date.

D. Synopsis of Conclusions

1. Applications (Discussions/Conclusions). There is growing industrial and governmental interest in the TIC technology as evidenced by the 1ist of discussions conducted to date (Section VIJ.I.B). It should be roted that a maiority of the discussions with industry have been initlated by industry. A few of the possibie applications discussed to date include the following:

- Launch control for hard mobile missile - BMO

- Selective hardening of satellites - Hughes Alrcraft, Air Force Space Command

- Hardened RPVs (remotely piloted vehicles) and battlefield sensors Air Force Systems Command, Hughes Aircraft, Mission Research Corp.

o Reactor safety, military, and nonmilitary - GA Technologies*

- Arming, fuzing, and terminal guidance - Sandia National Laboratories, Naval Weapons Systems Center

- Hardened controls/power devices for both space and terrestrial reactors - JPL, GA Technologles, Lockheed, Martin Marletta, General Electric

o Hardened $C^{3} I$ - Defense Communications Agency, Strateglc Alr Command, JPL

*Former1y General Atomic. 
- Jet engine instrumentation/control ("fly by wire") - Strategic Air Command, a jet engine manufacturer*

A general conclusion from these discussions is that TICs can affect future weapons systems by increasing the tolerance of their electronic systems to environments in which the electronics must operate and survive. That is to say that systems and, therefore, military missions are designed to accommodate the limitations of existing technology. The TIC technology is receiving its best rcsponse from personnel working on new systems at the conceptual stage. For example, SP-100 and hard mobile missiles represent important applications for which total dose survivability well beyond that of current techrologies would be extremely desirable. In many cases, the definition of the miostor of a particular system would be expanded based on improved hardening, e.g., ballistic missile terminal guidance. In still other cases, new threats are emerging (e.g., beam weapons) as are new scenarios such as flexible response during nuclear conflict, for which improved radiation hardness may be required.

Based on the discussions held to date, several conclusions regarding technological issues may be drawn.

o Use of TICs in concert with silicon or gallium arsenide irtegrated circuitry is universally cecommended as the appropriate method for utilizing the TIC technology (Figs. I-4 and -5 ).

c Many applications appear for TICs at the small- or medium-scale integration levels (20-1000 devices).

- Because of the selected use of this technology, powers of $2 \mathrm{~mW}$ per device (as projected later in this report) are acceptable, even for satellite systems.

- Many potential applications exist at the speed/bandwidth projected.

- Concern about electromagnetic pulse (EMP) is large; and in a followon program, thorough EMP testing should be undertaken.

- The high-temperature capability of these devices could be advantageous to a number of military systems.

o Power devices should be investigated.

*The company is not named because it is in the process of contracting with Los Alamos to evaluate this application in more detail. 


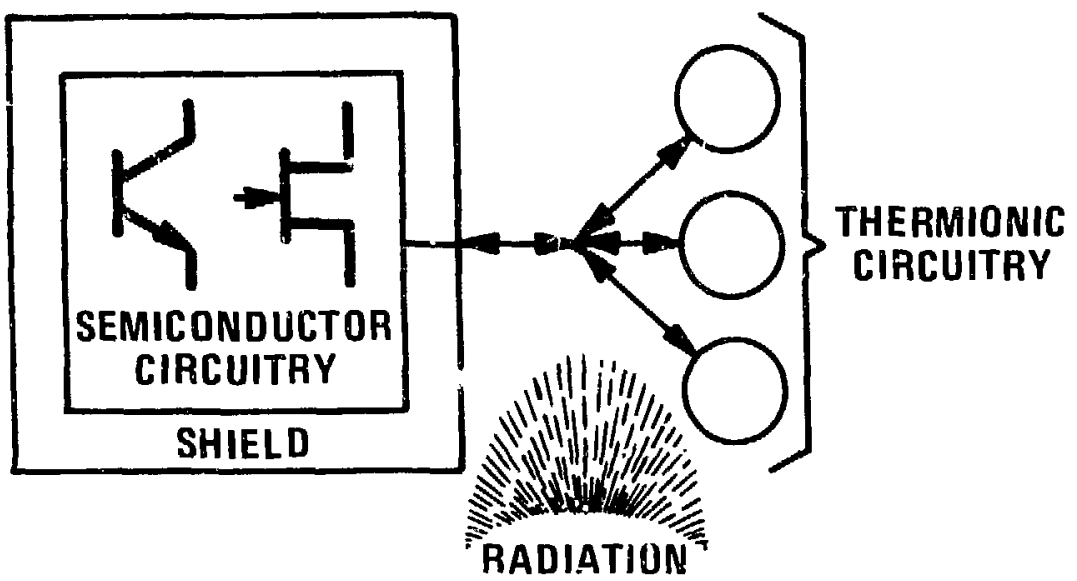

F1g. I-4. Hyb:id approach using TIC's and semiconductors.

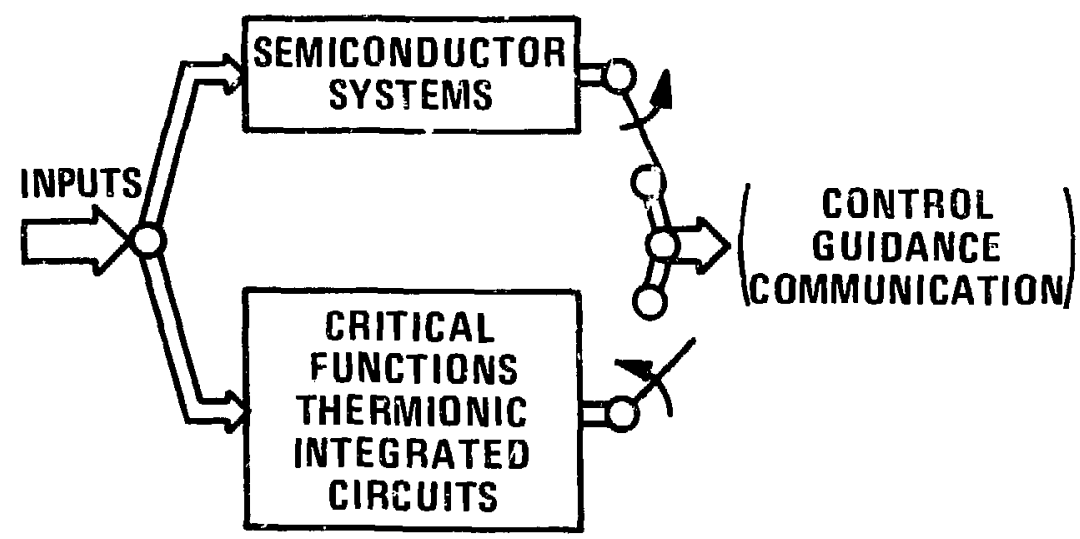

Fig. I-5. arallel approach using TICs and semiconductors. TICs would be activated upon failure of the semiconductor system. 
Concern for timeliness in availability of this technology has been expressed by several parties, particularly with regard to validation for military systeas.

Although the IIC technology is new to most of the personnel involved in recent discussions, the level of interest has been high in spite of the novelty. This strongly suggests the perceived benefit of a technology such as TICs that complements silicon and GaAs integrated circuits by providing additional radiation hardness and high-temperature operability.

2. Technical Accomplishments. The following is a list of technical milestones accomplished ciring this program.

- The first fully integrated thermionic circuit has been designed and tested, demonstrating the feasibility of the TIC concept (Section III). *

- Device speed has been analyzed, and it has heen found that devices with gain handwidths of a few tens to a couple of hundred megahertz are possible with existing technology (depending on current density drawn from the cathode) and that gain bandvidth products approaching a gigahertz may be possible with enlanced processing (Sectior: V).

- Theury and experiment have been correlated and have shown that with a properly desisned package at a level of integration of 1000 devices/in ${ }^{2}$, required heater powers will he as low as $2 \mathrm{~mW} /$ device. At 10,000 devices $/ \mathrm{in}^{2}$, this will drop to $0.2 \mathrm{~mW} /$ device (Section IV).

- Fabrication process improvements have been developed and verified so that resistive leakage and spurious emissions have been reduced to a level in all devices tested where cathode current is at least three orders of magnitude larger than parasitic emission and resistive leakage currents. This suggests that no problem should he encouncered at levels of integration currently envisioned (Section III).

- The transient radiation $(\dot{i})$ response of a single flip-flop has been analyzed. It has been predicted theoretically and confirmed experimentally that the substrate of present-day devices is the major contributor to the transient radiation response. For a 30 -mil-thick substrate and the current flip-flop layout, the analysis predicts an

\footnotetext{
* Both DARPA and DOE funding were used in accomplishing these tasks.
} 
upset level of $2 \times 10^{y} \mathrm{rad}(\mathrm{Si}) / \mathrm{s}$. However, an improved substrate and circuit layout is projected to achieve $4 \times 10^{11} \mathrm{rad}(\mathrm{Si}) / \mathrm{s}$ for upset levels, with levels greater than $10^{12} \mathrm{rad}(\mathrm{Si}) / \mathrm{s}$ perhaps being possible in the long term (Section II).

- Based on the integrated circuit designed and demonstrated and the process improvements achieved* and on computer analyses, TICs at integration levels of 1000 devices/in ${ }^{2}$ or better (perhaps uf to 10,000) appear likeiy in the near term (Section ITI).

- Under sponsorship of a major computer manufacturer, experiments aimed at determining factors influencing lifetime have been initiated (aimed at a product of unique interest to that corporation) (Section VII).

E. Programmatic Recommendations

From the discussions with industry and government agencies to date, it is evident that there is a need for a technology with radiation-hardened characteristics such as the TICs to complement the capabilities/limitations of silicon and gallium arsenide. A major recommendation of this program, therefore, is to proceed with a long-term program. However, such a program shauld include the continued evaluation of applications and discussions with possible users so that $(1)$ the user community can evaluate applicability and timing of the TIC technology to respond to the needs of their particular systems and (2) the TIC technology program can be effectively directed at the requirenents of important applications.

From a technical point of view, many specific recommendations have emerged from the current program.

Vulnerability

o Improved substrates must be developed to improve transient gamma and charged particle response.

o EMP tests must be conducted.

- Continuous radiation tests must be conducted throughout the program to expedite validation and fielding of TIC circuitry.

ॠBoth DARPA and DOE funding were used in accomplishing these tasks. 
o More thorough total dose tests must be conducted to determine failure levels.

Level of Integration

- A major investmeur in circult technology is required, including Investigation of ways to take advantage of and effectively ut11Ize electrostatj.c interactions.

- CAD tools including 3D Laplace and variable mesh Poisson codes must be developed and current state-of-the-art CAD mask-making and circuit analysis tools must be modified to support TIC development.

- Advanced device structures including current sources and high offset devices should be investigated.

- Perhaps most important, an investment must be made in atatistical data taking, characterizing many devices o: many substrates so that design rules can be derived for circuitry producible at high ylelds (developing this data is more difflcult in TIC technology than it is in conventional solid-state integrated circuits because the vacuum package isolates the devices, making them difficult or impossible to probe).

- Improvements in processing must be investigated including continued evolution of lower leakage, lowex spurious emission processes, as well as finer 1ithography.

- Improved cathode structures should be investigated, including those that yleld higher current density and/or finer geometry as well as those with enhanced tolerance to gases that may contaminate the vacuum.

- Additional fabrication techniques must be inirestigated, includIng the development of crossovers, resistors, and capacitors.

- Near-term simple functional circuits must be designed and tested, starting with an analog circuit (operational amplifier), and simple digital circuits (gates and flip-flops). These simple circuits must then be refined to begin the evolution toward analogto-digital converters, registers, arithmetic logic units, etc.

Heater Power

- Materials for reflective coatings must be investigated, and methods for applying them to the package must be developed. 
o Reflective coatings directly on the substrate must be investigated.

\section{Jevice Speed/Bandwidth}

- Tests of current density vs 11fetime on cathodes must be continued.

- Advanced, higher-current density cathodes should be investigated.

- Processes ylelding finer lithography should be investigated.

- "Grooved" substrates to reduce grid-to-cathode capacitance should be developed.

Life and Rellaw:11ty

- Thorough life and rellability tests should be initiated.

- Degradation mechanisms in cathodes should be investigated.

- Improved packaging, including "gettering" techniques to minimize gas evolution into the vacuum, and more rugged pin seals and welds should be investigäted.

Package

- Practical and useful TIC packages must be designed and developed with appropriate thermal. characteristics and with the ability to withstand high temperatures, shock, and vibration.

\section{Power Devices}

- Power device structures should be designed and tested.

The following sections describe in detall the technical basis for these conclusions and prellminary analyses and experiments performed under the current DARPA program (In concert with DOE-sponsored research), which underlies the recommendations made above.

\section{VULNERABILITY*}

A. Statement of Work from Proposal (March 1982)

"Single devices have been tested to the following levels: $1 \times 10^{17}$ neutrens $/ \mathrm{cm}^{2} ; 2.5 \times 10^{8} \mathrm{rad}(\mathrm{S} 1) ; 1.4 \times 10^{16}$ neutrons $/ \mathrm{cm}^{2} \mathrm{~s}$; and $1.2 \times 10^{7}$

\footnotetext{
* Because there was a delay of nearly a year between the funding approval at DARPA and recelpt of funds at Los Alamos, portions of the results described in the following sections were performed between March 82 and February 83 in anticipation of and for the DARPA-sponsored program.
} 
$\operatorname{rad}(\mathrm{S} 1) / \mathrm{s}$. During these tests, negligible change of device dc characteristics was observed. These tests, it must be emphasized, were 'quick and dirty' tests to verify feasibility of the technology for radiation-hardened app.lications. However, even though the results of these tests were limited by the capability of the particular reactor used (100-kW TRIGA), In all cases except gamma flux, the resultant levels exceed current silicon performance levels. In the gamma rai:e case, tests with earlier vacuum tubes such as NUVISTORS have shown capab: 11 ties exceeding $10^{11} \mathrm{rad}(\mathrm{S} 1) / \mathrm{s}$.

"Another important parameter in determining the effectiveness of a particular technology in a high-radiation environment is recovery time; that is the time required for a device co return to acceptable operation after an upset.

"Individual devices and simple circults will be radiation tested on a continuing basis during the second half of the l-year program. Since it is expected that gamma flux is of most fundamental importance for envisioned military applications, device response as a function of gamma flux and recovery time from upset will be measured. No total dose tests beyond those previously conducted are currently plarsad for the 1-year program."

\section{B. Temperature Tests}

TIC devices have been operated successfully in high-temperature environments. A device has been operated continuously at $500^{\circ} \mathrm{C}$ ambient temperature for 13,000 hours with no degradation in device characteristics. After 13,000 hours a pin seal falled, allowing air to leak into the package. In addition, a Hartley oscillator was operated successfully in a $500^{\circ} \mathrm{C}$ environment. These tests were performed before the DARPA-sponsored program; the results are summarized for reference.

\section{Radiation Test Summary}

A number of test.s have been performed on single TIC devices. The first iests were performed at the University of Arizoria (U of A) in July 1979 and are included here for completeness. Next, as part of the current DARPA program, a series of gamma dose rate test.s were performed at the Alr Force Weapons Laboratory (AFWL) Febetron facility in Albuquerque, New Mexico. Finally, devices were tested in the proton beam at the Weapons Neutron Research (WNR) facility 
at Los Alamos. Devices have been tested to the levels shown in Table II-1 with no observable change in characteristics.

TABLE I I-I

SINGLE-DEVICE RADIATION TESTS

\begin{tabular}{|c|c|c|c|c|}
\hline Total Dose & Dose Rate & $\begin{array}{l}\text { Pulse } \\
\text { Duration }\end{array}$ & Type & Facility \\
\hline $1 \times 10^{17} \mathrm{n} ! \mathrm{cm}^{2}$ & & & neutron & $\begin{array}{l}\text { U of A TRIGA, } \\
100 \mathrm{~kW} \text {, continuous }\end{array}$ \\
\hline $2.5 \times 10^{8} \operatorname{rad}(\mathrm{Si})$ & & & gamma & $\begin{array}{l}\text { U of A TRIGA, } \\
100 \mathrm{~kW}, \text { continuous }\end{array}$ \\
\hline & $1.4 \times 10^{16} \mathrm{n} / \mathrm{cm}^{2} \mathrm{~s}$ & $20 \mathrm{~ms}$ & neutron & $\begin{array}{l}\text { U of A TRIGA, } \\
750 \mathrm{MW} \text {, pulsed }\end{array}$ \\
\hline $899 \mathrm{rad}(\mathrm{Si}) / \mathrm{pulse}$ & $4.5 \times 10^{10} \mathrm{rad}(\mathrm{Si}) / \mathrm{s}$ & $20 \mathrm{~ns}$ & gamma & AFWL Febetron \\
\hline $960 \mathrm{rad}\left(\mathrm{Si}_{i}\right) / \mathrm{pulse} \mathrm{a}^{-}$ & $2 \therefore 0^{8} \mathrm{rad}\left(\mathrm{Si}_{i}\right) / \mathrm{s}^{\mathrm{b}}$ & 4.8 is & proton & WNR \\
\hline
\end{tabular}

The $U$ of A tests were performed with a TRIGA reactor from Gulf General Atomic, capable of 100-kW continuous and 750-MW pulser operation. During these tests, the devices were active and were continuously monitored for changes in characteristics. The total dose tests produced no effect on the device characteristics. When the reactor was pulsed at $750 \mathrm{MW}$, the triode characteristics showed an instantaneous shift during the pulse with an almost immediate recovery.

Tests with the AFWL Febetron show that the TIC devices with their cur-rent structure show a response for gamma dose rates above $10^{8} \mathrm{rad}(\mathrm{S} i) / \mathrm{s}$. As nearly as can be determined, this response iasts only for the length of the gamma pulse. At dose rates as high as $4.5 \times 10^{10} \mathrm{rad}(\mathrm{Si}) / \mathrm{s}$, the devices recover quickly and show no permanent effects. Both tests and analyses indicate that the transient gamma response is dominated by the sapphire substrate. An improved substrate structure, already tested in a preliminary Form, is proposed that would reduce the gamma dose rate response by orders of inagnitude. 
Devices were tested in the $800-\mathrm{MeV}$ proton beam at WNR to a level of $2 \times 10^{8} \mathrm{rad}(\mathrm{Si}) / \mathrm{s}$. At this level, the devices showed a response, but again, this response lasted only for the duration of the pulse.

In addition, a TIC flip-flop was tested in the proton beam. The pulse width of the beam was adjusted until the flip-flop was at the threshold of upset. It was found that the flip-flop's upset threshold is $28 \mathrm{rad}(\mathrm{Si})$ delivered in $200 \mathrm{~ns}$, a rate of $1.4 \times 10^{8} \mathrm{rad}(\mathrm{Si}) / \mathrm{s}$. [The calculated $\dot{\gamma}$ upset level of this flip-flop is $2.2 \times 10^{9} \mathrm{rad}(\mathrm{Si}) / \mathrm{s}$ for $20 \mathrm{~ns}$, or a total dose of 45 $\operatorname{rad}(S i)$.

The proton upset mechanisu should be somewhat different than the $\dot{\gamma}$ mechanism. The protons impart less energy to the electrons, and the electron motion is much less directional. The number of ejected electrons will be lower, but the number of electron-hole pairs generated and the associated conductivity effects will be greater for protons. The substrate improvements geared to improve the $\dot{\gamma}$ tolerance, particularly the measures to reduce the radiationInduced conductivity, should also improve the proton dose rate tolerance. However, aditional measurements must be made to determine the proton-induced conductivity affects in different substrate materials.

D. Gamma Dose Rate Response

Because the total dose tests produced no observable degradation in the TIC characteristics and because the initial dose rate tests indicated that the TIC devices showed a response for gamma dose rates above $10^{8} \mathrm{rad}(\mathrm{S} 1) / \mathrm{s}$, the effort during this program was concentrated on measuring and understandii_o dose rate response. Specifically, the goals were to

- Gain an understanding of the dose rate response mechanisms by analyzing a number of device and electrrde configurations and then conducting measurements to verify the analyses.

- Design structures that would have reduced responses and then verify that the responses are indeed reduced.

- Determine how TIC device response affects circuit performance by calculating and measuring the effect of dose rate on a logic inverter and a flip-flop.

- Project the dose rate tolerance of the flip-flop when improved substrate and device structures are used. 
1. Analysis of Mechanisms. Two important effects that can contribute to the dose rate response of the TICs are photon-electron interactions and radiation-induced conductivity. How these mechanisms affect TIC circult performance is analyzed in Sections a and $h$ below.

a. Photon Interactions. The photon energies produced by the AFWL Fehetron are in the $1-\mathrm{MeV}$ range. In this energy range, the dominant interaction mechanism is Compton scattering of photons h; electrons. Compton scattering imparts energy to the electrons; the average motion of these electrons is in the direction ,f the incident photons. Thus, there is a net transport of negative charge in the direction of the photons. It is this motion of charge that produces the dose rate response.

The number of photons removed from the incident beam, $\Delta p$, in distance $\Delta \mathrm{x}$ is

$$
\Delta p=p \mu \Delta x \quad \text { photons } / \mathrm{cm}^{2},
$$

where

$$
\begin{aligned}
& \Delta \mathrm{p}=\text { photons removed } / \mathrm{cm}^{2}, \\
& \mathrm{p}=\text { incident photons } / \mathrm{cm}^{2}, \\
& \mu=\text { photon absorption coefficient (cross section), } \mathrm{cm}^{-1}, \text { and } \\
& \Delta \mathrm{x}=\text { distance traversed, cm. }
\end{aligned}
$$

For a thin sample of material of thickness $x$ ( $\mu x$ less than about 0.1 ), the total number of photons removed from the sample is

$$
\Delta p=p \mu x \quad \text { photons } / \mathrm{cm}^{2} \text {. }
$$

For a thin sample, approximately one eiectron is ejected for each captured photon. Then the number of ejected electrons is

$$
\mathrm{N}_{\mathrm{e}}=\mathrm{p} \mu \mathrm{x} \quad \text { electrons } / \mathrm{cm}^{2}
$$

and the ejected charge is

$$
q=\operatorname{efux} \quad \mathrm{c} / \mathrm{cm}^{2}
$$


where

$\mathrm{e}=1.602 \times 10^{-19} \quad \mathrm{C}$.

Gamma radiation levels are generally expressed in $\mathrm{rads}(1 \mathrm{rad}=100$

ergs/gram absorhed). The energy absorbed hy the mat ial is

$$
E_{a}=\mu_{p} E_{p A} \quad e V
$$

or

$$
\mathrm{E}_{\mathrm{a}} / \mathrm{m}=\operatorname{ep}(\mu / \mathrm{p}) \mathrm{E}_{\mathrm{p}} \times 10^{7} \quad \text { ergs/gram, }
$$

where

$$
\begin{aligned}
& E_{p}=\text { energy of incident photons, } \mathrm{eV}, \\
& A=\text { area of naterial, } \mathrm{cm}^{2}, \\
& \mathrm{~m}=\text { mass of riaterial, grams, and } \\
& \rho=\text { density of material, grams } / \mathrm{cm}^{3} \text {. The } n \\
& \mathrm{p}=\frac{10^{-5}}{\mathrm{e} \mathrm{E}_{\mathrm{p}}(\mu / \rho)} \gamma \quad \text { photons } / \mathrm{cm}^{2},
\end{aligned}
$$

where $\gamma=$ rads. If units of rads are selected for the purposes of comparison, with material 1 being the reference (e.g., silicon) and material 2 being the material under test, then the ejected charge is

$$
q=\frac{\mu_{2} x_{2} \gamma_{1}}{E_{p}\left(\mu_{1} / \rho_{1}\right)} ! 0^{-5} \quad \mathrm{c} / \mathrm{cm}^{2},
$$

and the current density is 


$$
\begin{aligned}
& J=\frac{\mu_{2} x_{2} \dot{\gamma}_{1}}{E_{p}\left(\mu_{1} / \rho_{1}\right)} 10^{-5} \quad \mathrm{~A} / \mathrm{cm}^{2}, \\
& \dot{\gamma}_{1}=\text { dose rate, } \mathrm{rad} / \mathrm{s}
\end{aligned}
$$

Table II 2 gives several radiation parameters for some of the materials of interest. In the calculations that follow, for purposes of comparison with current silicon IC technology, $\gamma_{1}=\operatorname{rad}\left(S_{1}\right)$ and $\dot{\gamma}_{1}=\operatorname{rad}\left(\mathrm{Si}_{1}\right) / \mathrm{s}$.

TABLE II $\cdot 2$

\begin{tabular}{|c|c|c|c|c|c|c|c|}
\hline Material & $\begin{array}{c}\rho \\
\left(\mathrm{g} / \mathrm{cm}^{3}\right)\end{array}$ & $\begin{array}{c}{ }_{P}^{E}= \\
p=1 \\
\mu \\
\left(\mathrm{cm}^{-1}\right)\end{array}$ & $\begin{array}{l}=0.6 \times 1 \\
\begin{array}{c}12.92 \times 1 \\
\text { E1ectron } \\
\text { Range } \\
(\mathrm{cm})\end{array}\end{array}$ & $\begin{array}{l}0^{6} \mathrm{eV} \\
0^{8} \gamma \text { photons } / \mathrm{cm}^{2} \\
\mathrm{q} / \mathrm{xR} \\
\left(\mathrm{c} / \mathrm{cm}^{2}\right) / \mathrm{cm} \mathrm{rad}\end{array}$ & $\begin{array}{c}p=9 \\
u \\
\left(\mathrm{~cm}^{-1}\right)\end{array}$ & $\begin{array}{c}83 \times 10 \\
\text { Electro } \\
\text { Range } \\
(\mathrm{cm})\end{array}$ & $\begin{array}{l}8 \gamma \text { photons } / \mathrm{cm}^{2} \\
\mathrm{q} / \mathrm{xR} \\
\left(\mathrm{c} / \mathrm{cm}^{2}\right) / \mathrm{cm} \mathrm{rad}\end{array}$ \\
\hline A1 & 2.70 & 0.210 & 0.0822 & $43.5 \times 10^{-12}$ & 0.166 & 0.160 & $26.1 \times 10^{-12}$ \\
\hline $\mathrm{Si}$ & 2.33 & 0.188 & 0.0984 & $38.9 \times 10^{-12}$ & 0.148 & 0.192 & $23.3 \times 10^{12}$ \\
\hline $\mathrm{Ti}$ & 4.5 & 0.339 & 0.0470 & $70.2 \times 10^{-12}$ & 0.263 & 0.0914 & $41.4 \times 10^{-12}$ \\
\hline $\mathrm{Ni}$ & 8.9 & 0.682 & 0.0247 & $141 \times 10^{-12}$ & 0.548 & 0.0480 & $86.3 \times 10^{-12}$ \\
\hline Mo & 10.2 & 0.794 & 0.0198 & $164 \times 10^{-12}$ & 0.593 & 0.0385 & $93.3 \times 10^{-12}$ \\
\hline W & 19.3 & 2.03 & 0.00962 & $420 \times 10^{-12}$ & 1.26 & 0.0187 & $199 \times 10^{-12}$ \\
\hline $\mathrm{Pt}$ & 21.45 & 2.40 & 0.00859 & $497 \times 10^{-12}$ & 1.45 & 0.0167 & $228 \times 10^{-12}$ \\
\hline $\mathrm{Pb}$ & 11.34 & 1.35 & 0.0161 & $279 \times 10^{-12}$ & 0.797 & 0.0313 & $126 \times 10^{-12}$ \\
\hline $\mathrm{Al}_{2} \mathrm{O}_{3}$ & 3.965 & 0.314 & 0.0570 & $65.0 \times 10^{-12}$ & 0.248 & 0.111 & $39.0 \times 10^{-12}$ \\
\hline
\end{tabular}

RADIATION PARAMETERS FOR SOME MATERIALS OF INTEREST FOR THE TICS

Normally, the incident photon beam has some energy distribution, and as can be seen from Table II-2, $\mu$ is a function of energy. In general, accounting for the energy distribution would require numerical solutions necessarily done on a computer. In order to provide an approximate analytic solution, the above 
aquations will be applied assuming a single photon energy. Normally, the photon energy used will be the average energy of the photon beam (about $1 \mathrm{MeV}$ for the AFWL Febetron).

When more acsuracy was required, a computer code* for the solution of coupled electron/photon transport through multimaterial configurations was ised. In addition, the code was used to verify that the above equations provide reasonable approximations, at least for thin materials. Figure II-1 compares Eq. (II-3) with the results of the computer code for 1-MeV incident photons. The agreement is good for sapphire less than 10 mils thick. Above 10 mils, Eq. (II-3) gives a pessimistic result.

b. Radiation-Induced Conductivity. Insulating materials can undergo an increase in electrical conductivity when subjected to ionizing radiation. 1 A large erough change in the conductivity of a TIC substrate could also affect the radiation tolerance of the TIC.

Radiation-induced conductivity (RIC) is strongly influenced by temperature and dose rate. In addition, the RIC of sapphire can be altered drastically by doping $\sim r$ by changing the crystal structure. Figure II-2 shows data from Refs. 1 and 2 for two undoped samples of sapphire, samples doped with $0.0004 \mathrm{wt} \% \mathrm{Cr}_{2} \mathrm{O}_{3}$ and $0.03 \mathrm{wt} \% \mathrm{Cr}_{2} \mathrm{O}_{3}$, and a neutron-irradiated sample, all at $1000 \mathrm{~K}$. The RIC varies by more than three orders of magnitude. Thus, the use of doped or neutron-irradiated sapphire or polycrystalline alumina for the TIC substrate can greatly reduce the RIC. However, the data shown in FIg. II-2 are for radiation levels only up to $6.6 \times 10^{4} \mathrm{rad} / \mathrm{s}$. RIC measurements need to be made for much higher radiation levels.

It was shown in the previous section that the charge ejected by photons from a thin material is proportional to tie thickness of the material. However, the current or charge induced in an insulator by an electrode above a ground plane will be inversely proportional to the insulator thickness. Ther, if the insulator is made thinner, there will be a point at which the current in the insulator caused by RIC is equal to the current caused by photon-ejected electrons.

*The code is a version of CYLTRAN, developed at Sandia National Laboratories and modified and extended at Los Alamos. 

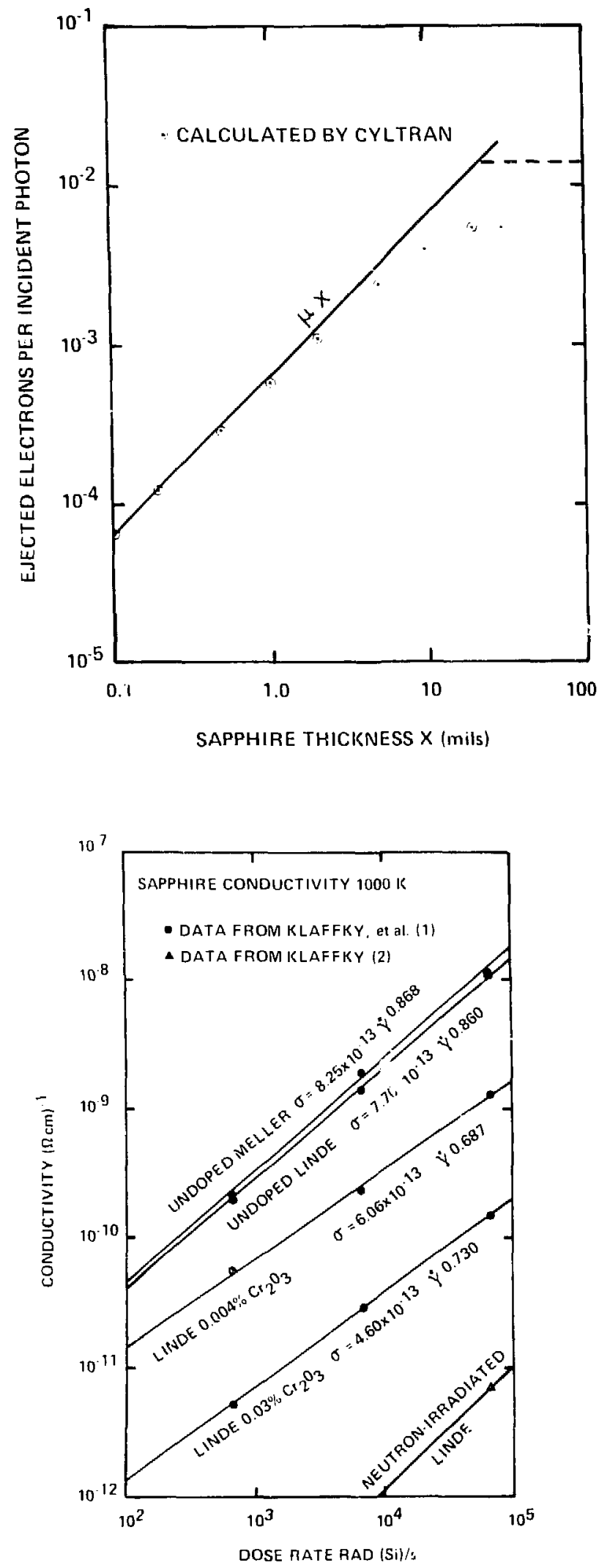

FIg. II-1. Electrons ejected from sapphire per incident $1-\mathrm{MeV}$ photon.
Fig. II-2. Sapphire conductivity as a function of radiation dose rate. 
For a node with a high impedance to ground, the change in node voltage caused by RIC in a short period of time $\Delta t$ is

$$
\Delta v_{\sigma}=-\frac{V \Delta t}{R C}=-\frac{V \Delta t \sigma A}{l C}
$$

where $V$ is the node voltage, $\sigma$ is the conductivity of the insulator, $C$ is the node capacitance, and $A$ is the electrnde area. An approximate relation hetween RIC and dose rate ${ }^{1}$ is

$$
\sigma=\mathrm{K} \dot{\gamma}^{\delta}
$$

where typically, $\delta \leq 1$. Figure $I I-2$ gives values of $K$ and $\delta$ calculated fron the data in Ref. 1 .

The change in node voltage causod by electrons ejected by 1 -MeV photons for sap phire is

$$
\Delta v_{p}=\frac{Q_{p}}{C}=\frac{39 \times 10^{-12} \ln A}{2 C},
$$

where the factor of 2 in the denominator appears hecause the ground plane supplies about half of the replacement electrons.

The two effects are about equal when $\Delta v_{p}=-\Delta v_{\sigma}$ or

$$
\mathrm{V}=\frac{19.5 \times 10^{-12} \ell^{2} \dot{\Psi}}{\sigma}
$$

If $\sigma_{0}$ is known for some radiation level $\gamma_{0}$, but the radiation level of interest is

$$
\dot{\gamma}=\dot{\gamma}_{0}+\dot{\gamma}_{1},
$$

then

$$
\sigma=k\left(\dot{\gamma}_{0}+\dot{\gamma}_{1}\right)^{\delta}=\sigma_{0}\left(1+\frac{\dot{\gamma}_{1}}{\dot{\gamma}_{0}}\right)^{\delta} \text {. }
$$


Since $\delta \leq 1$, a conservative expression for the RIC is

$$
\sigma=\sigma_{0}\left(1+\frac{\dot{\gamma}_{1}}{\dot{\gamma}_{0}}\right)
$$

and

$$
\mathrm{V}=\frac{19.5 \times 10^{-12} \ell^{2} \dot{\mathrm{y}}_{0}}{\sigma_{0}}
$$

This equation can be used to estimate either the maximum voltage at a high impedance node for a glven thickness or the minimum thickness for a given voltage, for which RIC effects become as important as photon-ejected charge. What is required is an RIC value, $\sigma_{0}$, near the radiation level of interest.

2. Initial $\dot{\gamma}$ Tests. The initial $\dot{\gamma}$ tests were conducted on TIC gain devices in both metal and glass envelopes. In addition, tests were conducted on a dummy package (package and pins but without triode and wire bonds) in order to separate package effects irom device effects. Figure II-3 shows the grid-cathode structure of the gain device; the two triodes are connected in parallel. The triode package configuration is shown in Fig. II-4. A schematic of the test fixture used is shown in Fig. II-5.

The first tests were conducted with the tube envelope touching $t$ he Febetron faceplate and with the bond pads, bond wires, and package pins exposed to the radiation. The measured radiation levels are shown in Table II- 3 .

TABLE II -3

DOSE RATES AT PACKAGE AND SURFACE OF DEVICE

\begin{tabular}{ll} 
Tota1 Dose & Dose Rate \\
{$[\operatorname{rad}(\mathrm{Si})]$} & {$[\operatorname{rad}(\mathrm{Si}) / \mathrm{s}]$} \\
\hline
\end{tabular}
At envelope surface
2278
At plane of cathode
899
$1.1 \times 10^{11}$
$4.5 \times 10^{10}$ 


\begin{tabular}{lrl}
\multicolumn{4}{c}{ Total area (sq mils) } \\
Sapphire & 442 & 000 \\
Grid & 16 & 400 (2200 active) \\
Cathode & 18 & 400 (3000 active) \\
Shleld & 122 & 000
\end{tabular}

Pt surface area (bond pads)

$2000 \mathrm{sq}$ mils on each leg.

Balance of metal is

T1 surface.

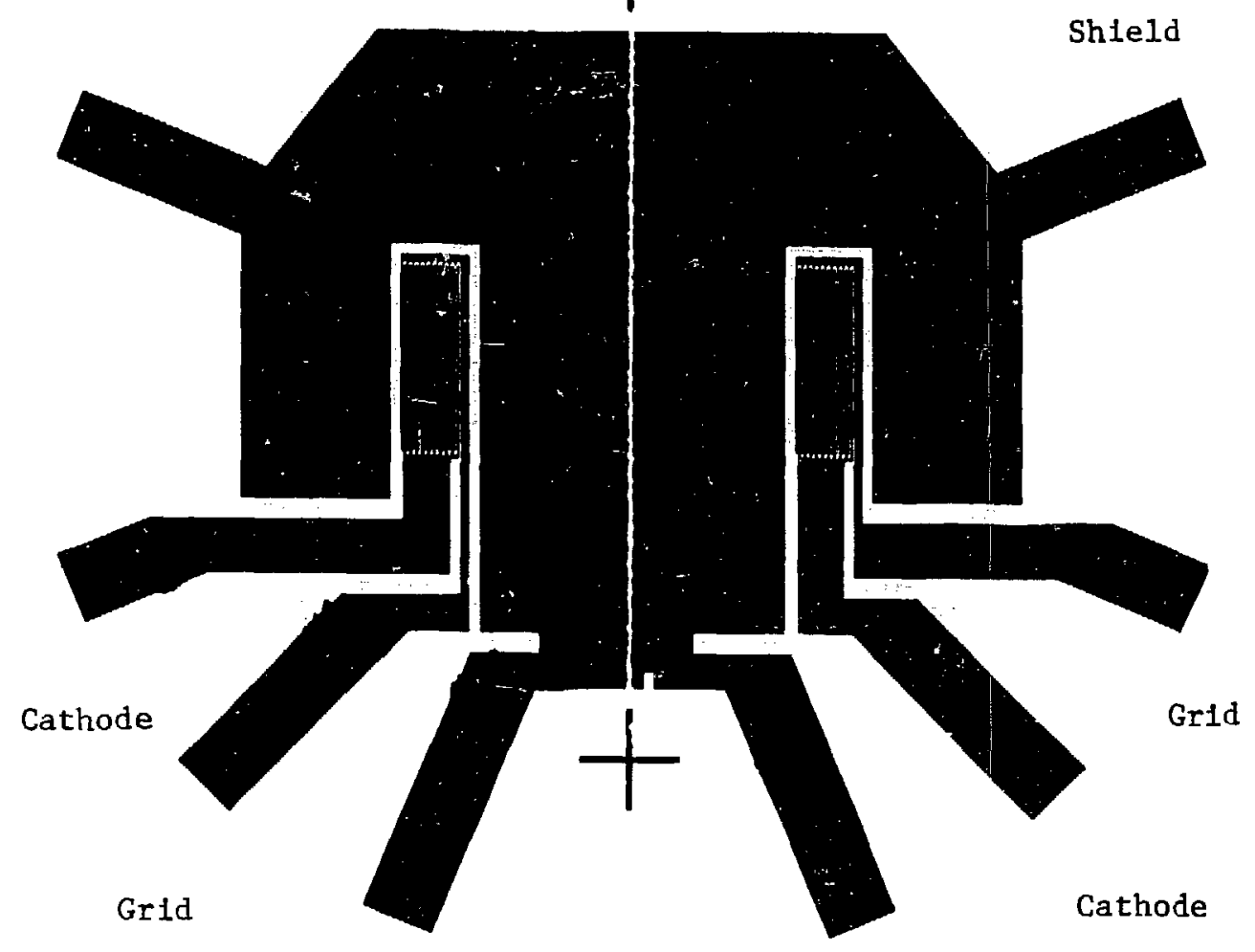

FIg. II-3. Dual triode TIC gain device for radiation tests. Substrate containing grid and cathode structures. 
Anodes $0.010 \times 0.125$ $x 0.25$ in. $\mathrm{T} i$ on $\mathrm{Ta}$ support wire

0.25-in.-diam. Ta supports with $0.005-$ $x 0.040-$ x 0.25-in. Pt straps to substrate

0.040-in.-diam. Mo pins 2.220 in. above ceramic

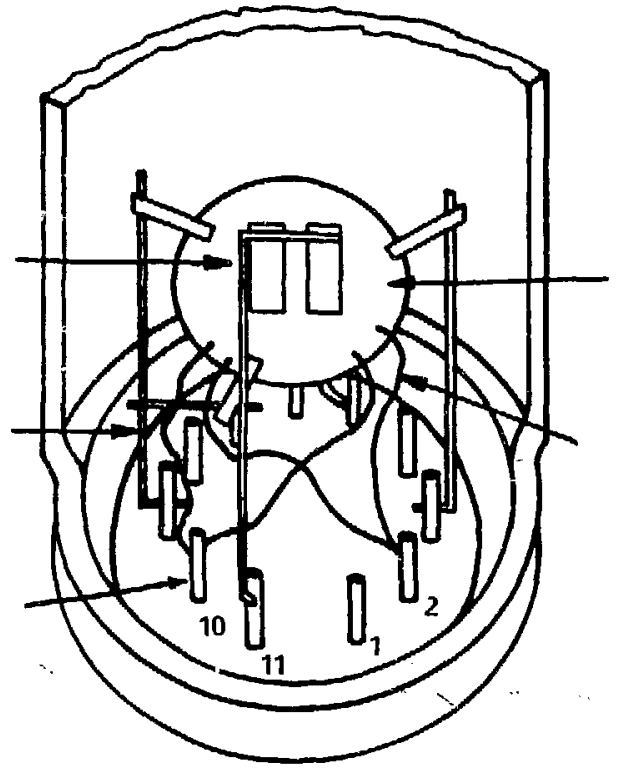

Sapphire $\sim 2 \mathrm{~cm}$ above bottom of Kovar ring

$0.005-1$. Pt grid and cathode wires

F1g. II-4. Radiation test triode package configuration. PIn connections during test: 1--not used; 2--cathode through $1 \mathrm{k} \Omega$; 3--shield through $1 \mathrm{k} \Omega$; 4--not used; 5--heater ground; 6--heater +33 V; 7--not used; 8--not used; 9--shield pin floating; $10--g r i d$ through $1 \mathrm{k} \Omega$; 11 --anode to $+60 \mathrm{~V}$.

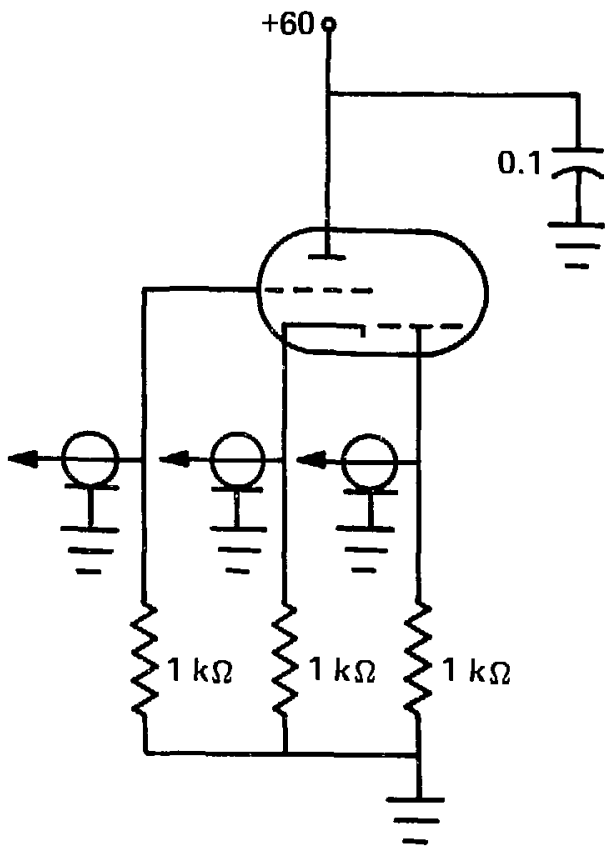

Fig. II-5. Circuit for triode radiation tests. 
The response of the dummy glass package is shown in Fig. II-6, while the response of the dual triode in a glass package is shown in Fig. II-7. A dual triode in a metal package was also tested with the results shown in Fig. II-8. The package with its pins is a substantial contributor to the total response, while the total response does not appear to depend on whether the package is glass or metal. The peak measured currents and total displaced charges are shown in Table II-4.

\section{TABLE II-4}

PEAK CURRENT AND CHARGE DISPLACED FOR PACKAGE AND PACKAGE PLUS DEVICE

\begin{tabular}{|c|c|c|c|c|c|c|}
\hline & \multicolumn{2}{|c|}{ Grid } & \multicolumn{2}{|c|}{ Cathode } & \multicolumn{2}{|c|}{ Shield } \\
\hline & $I(m A)$ & $Q(p C)$ & $\underline{I(m A)}$ & $Q(p C)$ & $\mathrm{I}(\mathrm{mA})$ & $Q(p C)$ \\
\hline Empty Envelope & 6 & 600 & 3 & 360 & 4 & 440 \\
\hline Dual Triode (Glass) & 8 & 800 & 7 & 840 & 13 & 1320 \\
\hline Dual Triode (Metal) & 8 & 1040 & 7.5 & 1000 & 10 & 1700 \\
\hline
\end{tabular}

The time constant of the response is about $80 \mathrm{~ns}$. The capacitance of the coax between the $1-\mathrm{k} \Omega$ sense resistor and line driver is about $50 \mathrm{pF}, \mathrm{giv}-$ ing a time constant of about $50 \mathrm{~ns}$. It is then possible that the response of the TIC device plus package lasts only for the 20-ns duration of the radiation pulse.

Table II-2 and Figs. II-3 ana -4 can be used to estimate displaced charge (Table II-5) for some of the elements at $899 \operatorname{rad}(\mathrm{Si})$ (1-MeV photons).

TABLE II-5

CALCULATED CHARGE DISPLACEMENT FOR TIC AND PACKAGE ELEMENTS

Element

0.04-in.-diam, 0.220-in.-high Mo pin

0.005-in.-diam Pt bond wire

$20000-\mathrm{mil}^{2}, 0.7-\mu \mathrm{m}-\mathrm{thick} \mathrm{W} \in$ lectrode

$20000-\mathrm{mil}^{2}$ of 0.030 -in.-thick sapphire

under $\mathrm{W}$ electrode
Charge Displaced

$95 \mathrm{pC}$

$66 \mathrm{pC} / \mathrm{in}$.

$1.6 \mathrm{pC}$

$250 \mathrm{pC}$ 


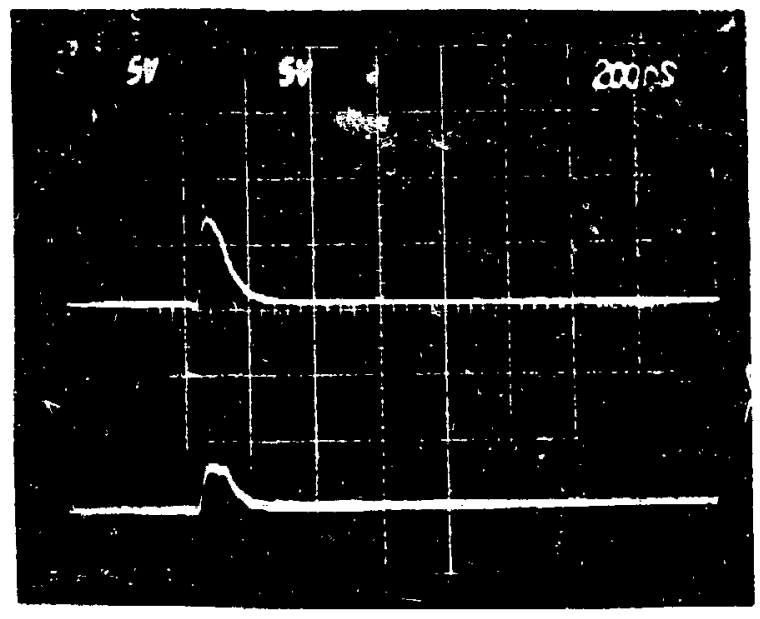

(a)

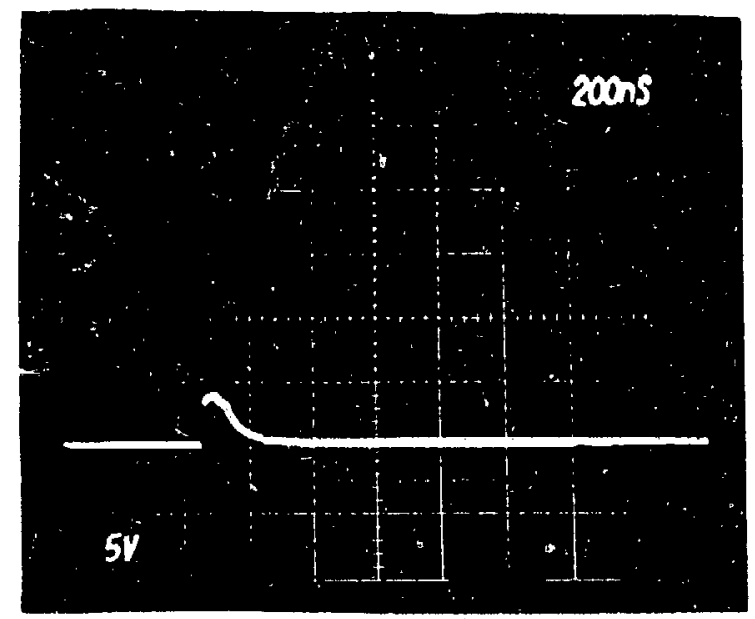

(b)

Fig. II-6. Dumny glass envelope (no tube) touching the Febetron faceplate. Anode $=60 \mathrm{~V}$; heater $=33 \mathrm{~V}$. (a) Top trace is the grid pin voltage; bottom trace is the cathode pin voltage. (b) Shield pin voltage.

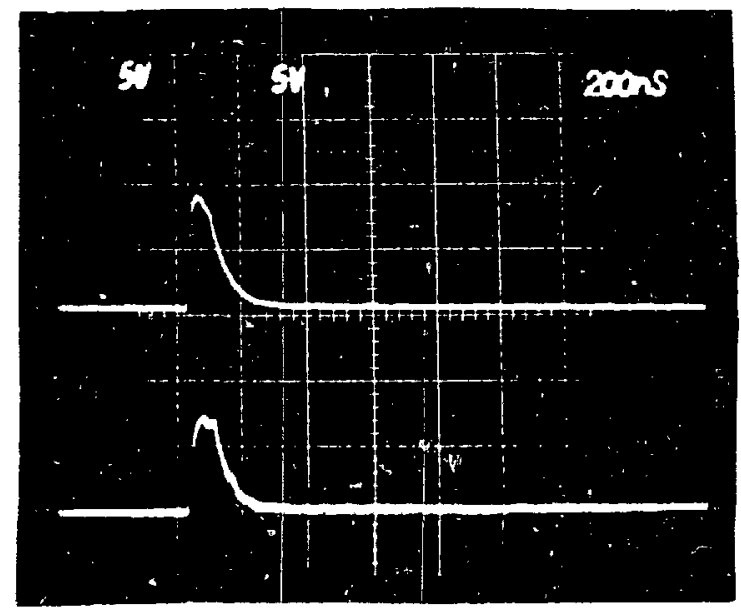

(a)

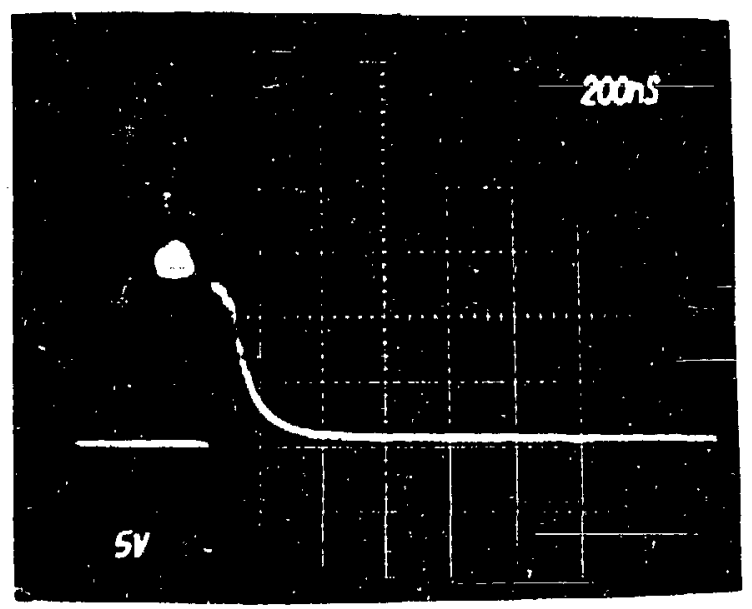

(b)

Fig. II-7. Triode in a glass envelope touching the Febetron faceplate. (a) Top trace is the grid voltage; bottom trace is the cathode voltage. (b) Shield voltage. 
(The average energy of a Compton electron from a 1-MeV photon is $0.6 \mathrm{MeV}$. The diameters of the molybdenum $p i n$ and the sapphire thickness are both greater than the range of an electron at $0.6 \mathrm{MeV}$. The charge displaced was estimated by using the electron range for the thickness, x.)

The calculated charge agrees reasonably well with the measured charge, particularly since the TIC devices were in the noisy environment of the Febetron room (rather than in the screen room). Further, the calculations indicate that the response of the device electrode $(1.6 \mathrm{pC})$ is negligible compared with the responses of the molybdenum pins, bond wires, and sapphire substrate. That is, the photoresponse is dominated by the support structure rather than by the intrinsic TIC device.

3. Verification Tests. The next sequence of tests was performed to verify $\dot{\gamma}$ response mechanisms and to develop TIC structures that would have reduced $\dot{\gamma}$ response. Tests were performed on active TIC devices and on a series of selected electrode structures. In these tests, the package, pins, and bond wires were shielded from the radiation so that only the actual device response was measured. In addition, these tests were performed in the screen room in order to reduce the noise level.

First, the dual triodes were retested in the screen room. The triodes were shielded by a lead brick with a 3/8-in.-diam hole. This arrangement a1lowed exposure of all devices and some of the interconnect metal but shielded the bond pads, bond wires, and package from the radiation. The areas exposed to the radiation are given below.
Grid
$8700 \mathrm{mil}^{2}$ tota 1
(2200 $\mathrm{mil}^{2}$ active)
Cathode
$11300 \mathrm{mil}^{\overline{2}}$ total
(3000 $\mathrm{mil}^{2}$ active)
Shield
$95000 \mathrm{mil}^{2}$ total

Total dose for the $20-n s$ pulse measured $6.38 \mathrm{rad}(\mathrm{Si})$. The results are shown in Fig. II -9 . 


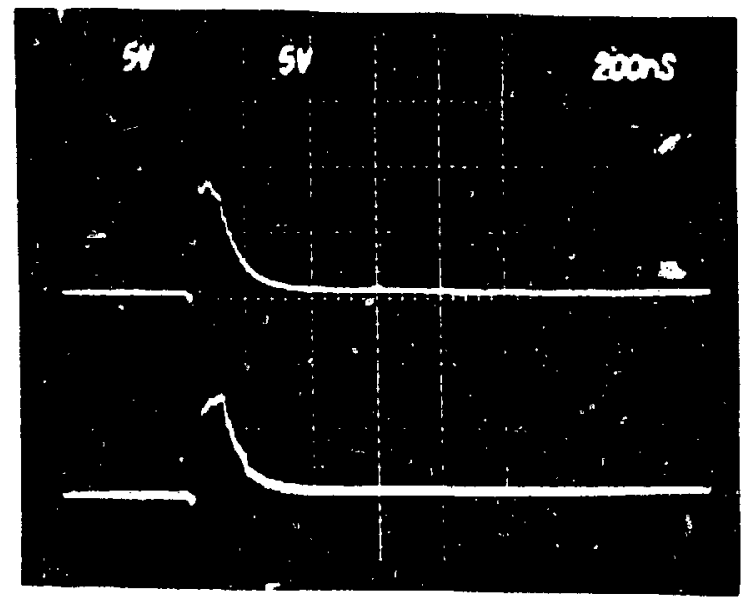

(a)

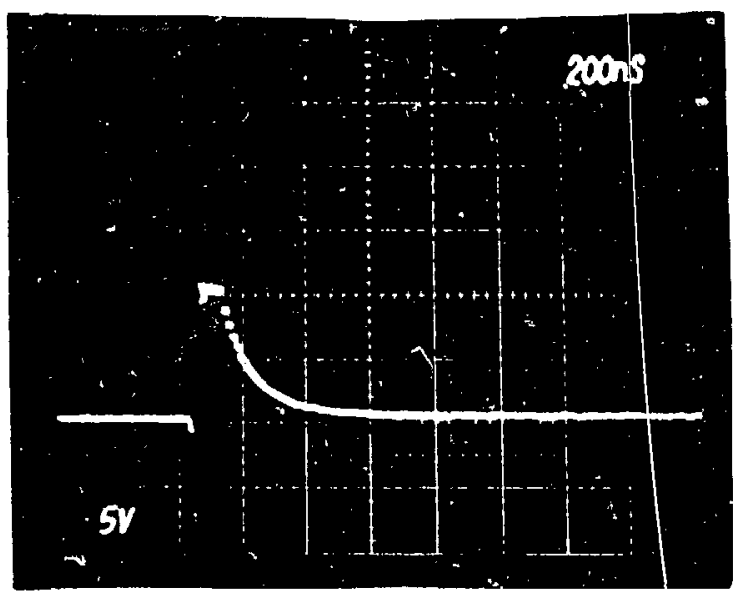

(b)

Fig. II-8. Triode in a metal envelope touching the Febetron faceplate " (a) Top trace is the grid voltage; botton trace is the cathode voltage. (b) Shield voltage.

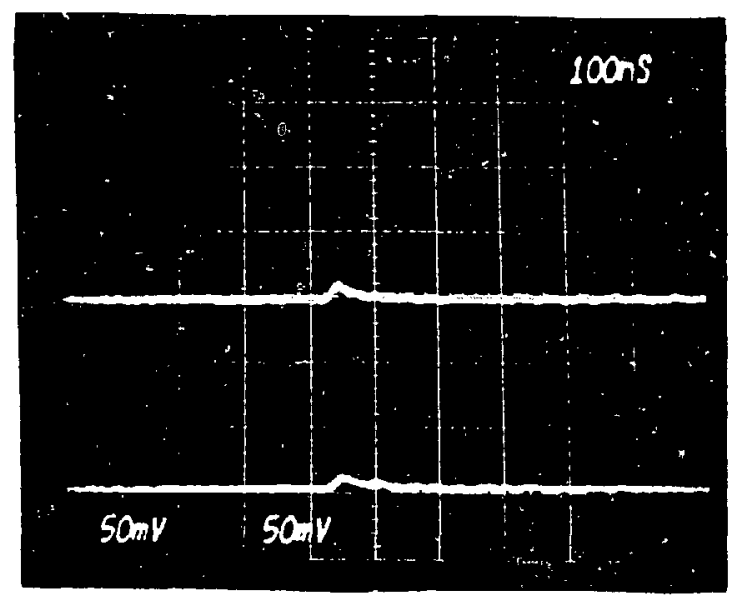

(a)

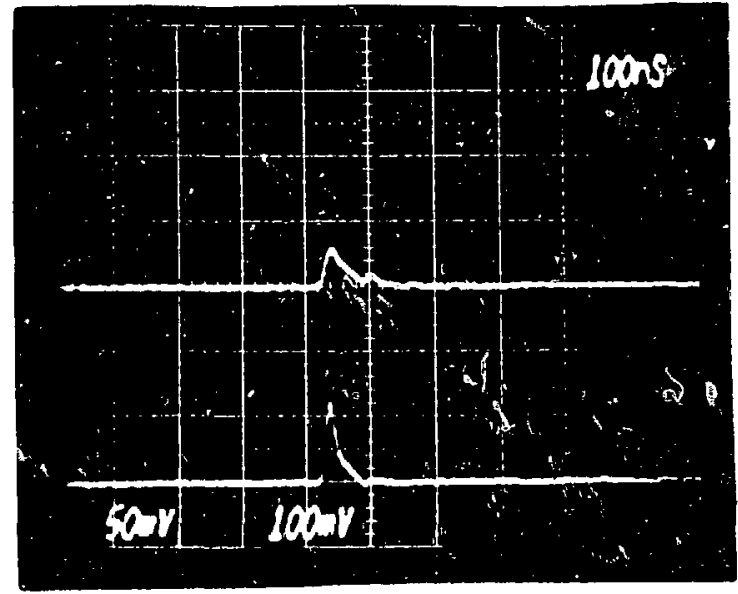

(b)

Fig. II-9. Dual triode with package, bond wires and bond pads shielded from radiation. (a) Top trace is the grid voltage; bottom trace is the cathode voltage. (b) Top trace is the shield voltage; bottom trace is the pin diode response. 
The displaced charge for the electrodes can be determined from this figure (although not very accuratelly for the grid and cathode). The measured charge and calculated charge displaced from 30-mil sapphire for 1-MeV photons are given in Table II-6. $\left(Q_{G}, Q_{K}, Q_{S}\right.$ are the charges displaced from the grid, cathode, and shield respectively.) Again, the 0.6-MeV electron range of 22 mils is used for the sapphire thickness in making the calculation for charge displaced. The calculated charge from the metal electrode is again insignificant, because for the 7000-A-thick tungsten film, the ratio of charge displaced from the metal to the charge displaced from the sapphire is

$$
\frac{{ }^{\mathrm{q}} \mathrm{W}}{{ }_{\mathrm{A} 1_{2} \mathrm{O}_{3}}}=\frac{199 \times 0.7 \times 10^{-4}}{39 \times 0.0570}=6 \times 10^{-3}
$$

In addition, Table II-6 indicates that displaced charge scales with electrode area.

TABLE II-6

MEASURED AND CALCULATED DISPLACEMENT CHARGE FOR THE DUAL TRIODE (The measured values for $Q_{G}$ and $Q_{K}$ are not very accurate.)

\begin{tabular}{lcc}
\cline { 2 - 3 } & Measured & Calculated \\
$Q_{G}$ & $21.2 \mathrm{pC}$ & $0.8 \mathrm{pC}$ \\
$Q_{\mathrm{K}}$ & $21.2 \mathrm{pC}$ & $1.0 \mathrm{pC}$ \\
$\mathrm{Q}_{\mathrm{S}}$ & $9.0 \mathrm{pC}$ & $8.7 \mathrm{pC}$ \\
$\mathrm{Q}_{\mathrm{S}} / \mathrm{Q}_{\mathrm{G}}$ & 27.5 & 10.9 \\
$\mathrm{Q}_{\mathrm{S}} / \mathrm{Q}_{\mathrm{K}}$ & 27.5 & 8.7
\end{tabular}

Two additional devices were fabricated to test the response of thin metal electrodes on sapphire substrates. Each device consisted of a large and a small electrode as shown in Fig. II-10. Titanium was used for the electrodes on one device and tungsten was used for the other because of their widely differing $Z$ numbers. In both cases, the sapphire was $30 \mathrm{mils}$ thick and the e?ectrodes were 5000 \& thick.

The calculated displacement charges for the tungsten, titanium, and sapphire for a total dose of 6.38 rads are shown below. 


$$
\begin{aligned}
& \mathrm{q}_{\mathrm{W}}=199 \times 0.5 \times 10^{-4} \times 6.38=63 \times 10^{-3} \mathrm{pC} / \mathrm{cm}^{2} \\
& \mathrm{q}_{\mathrm{T} 1}=45.4 \times 0.5 \times 10^{-4} \times 6.38=14 \times 10^{-3} \mathrm{pC} / \mathrm{cm}^{2} \\
& \mathrm{q}_{\mathrm{Al}_{2} \mathrm{O}_{3}}=39 \times 0.057 \times 6.38=14 \mathrm{pC} / \mathrm{cm}^{2}
\end{aligned}
$$

The response of the tungsten should be 4.5 times greater than that of the titanium, but both responses are negligible compared with that of the sapphire.

The responses of the tungsten and titanium films are shown in Figs. II-11 and -12 , and the measured charge and calculated charge for each electrode are given in Table II-7. While the calculated value is low by a factor of 2 , the charge scales with area as expected, and the high $\mathrm{Z}$ material does not produce more charge. Further, it appears that the response of metal electrode test structures on a sapphire sutstrate is the same as the response of the electrodes in an operating TIC gain device.

These tests indicate that the dominant mechanisms in the TIC $\dot{Y}$ photoresponse are the Compton scattering of electrons in the sapphire substrate. These electrons are replaced by charge flowing from electrode to substrate; this charge produces the response seen in the $\dot{y}$ tests. The sapphire dominates the response because its volume is much larger than that of the electrodes.

The obvious way to reduce the $\dot{\gamma}$ resporise is to reduce the substraice thickness. Further, a ground plane on the back of the sapphire should supply about half of the replacement electrons and so should reduce the $\dot{\gamma}$ response by adout a factor of 2 . In order to verify this, the test structure shown in Fig. II-13 was designed with a metal back plane that could serve as a ground plane for one of the two electrodes. Three such devices were fabricated: one with 30-mil sapphire, one with 10-mil sapphire, and one with 25 -mil alumina. 


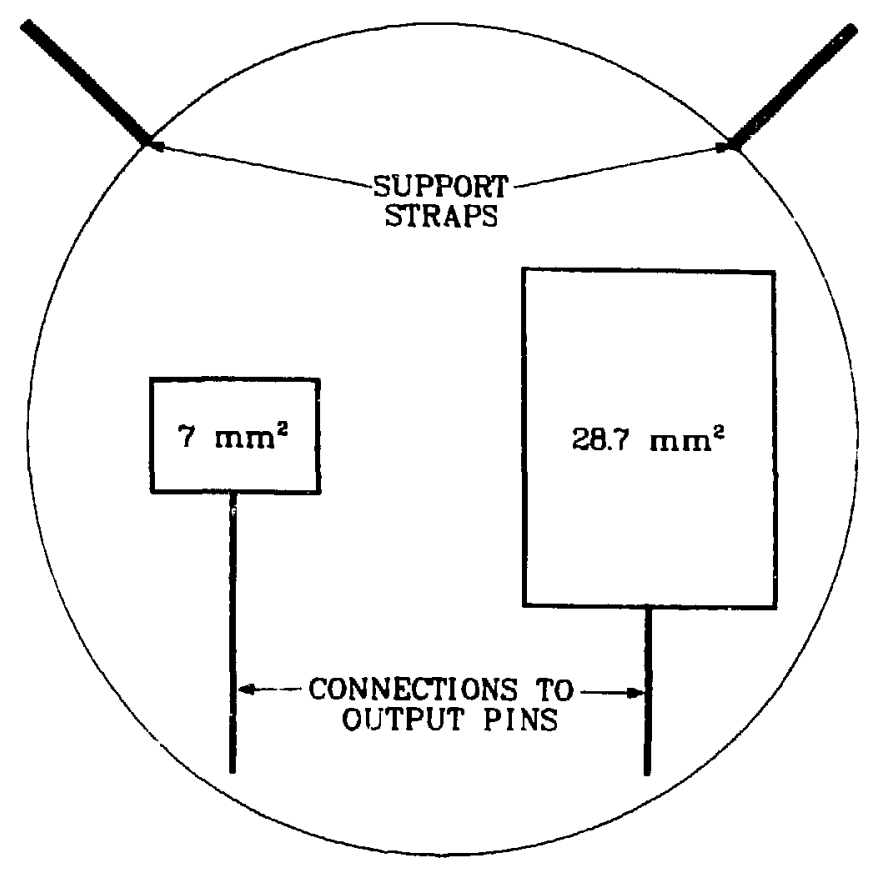

F1g. II-10. Device schematic for testing response as a function of area. One area is $\sim 4$ times the other.

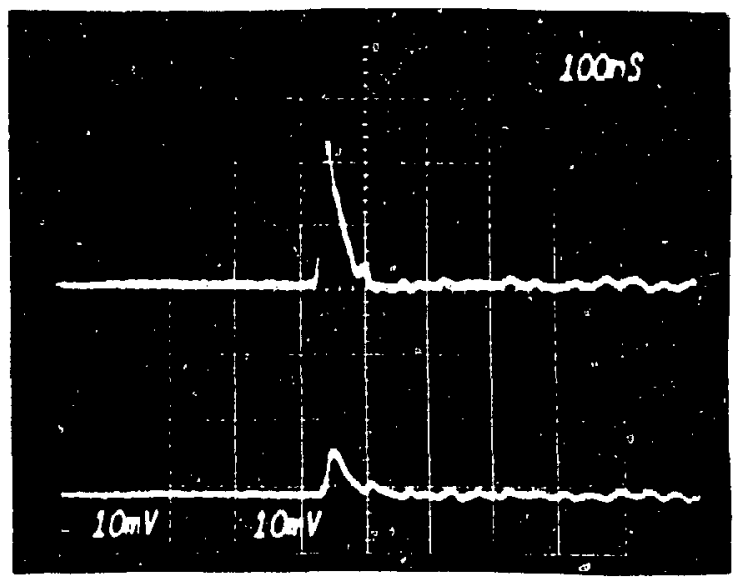

Fig. II-11. Test results for different area devices using tungsten films. Top trace is the large area device, and bottom trace is the small area device. 


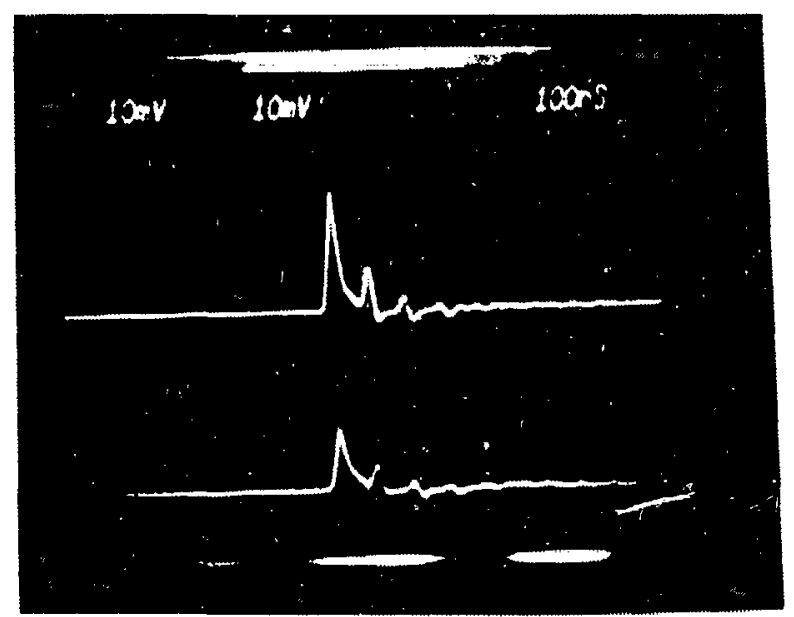

Fig. II-12. Test results for different area devices using titanium films. Top trace is the large area device, and bottom trace is the small area device.

A

B

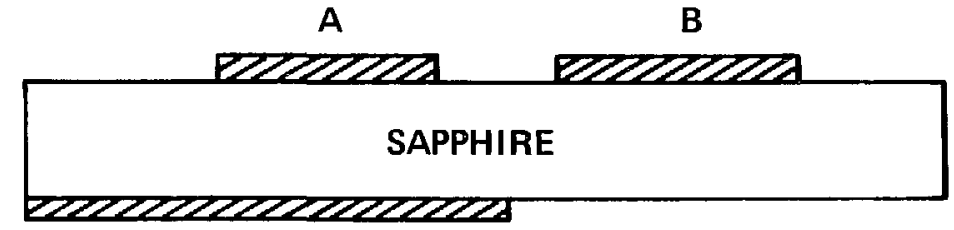

METAL BACK PLANE

Fig. II-13. Ground plane test structure. Each electrode is $0.318 \mathrm{~cm}^{2}$. 
TABLE II-7

MEASURED AND CALCULATED DISPLACEMENT CHARGE FOR TUNGSTEN AND TITANIUM ELECTRODES

(Large electrode is $28.7 \mathrm{~mm}^{2}$; small electrode is $7 \mathrm{~mm}^{2}$.)

Tungsten Electrodes

$$
\text { Alarge } / A_{\text {smal1 }}=4.1
$$

\begin{tabular}{|c|c|c|}
\hline & Measured & Calculated \\
\hline $\begin{array}{l}\text { Tungsten Electrodes } \\
\text { Q } \\
\text { large }\end{array}$ & $7.8 \mathrm{pC}$ & $4.0 \mathrm{pC}$ \\
\hline$Q_{\text {sma11 }}$ & $1.8 \mathrm{pC}$ & $0.98 \mathrm{pC}$ \\
\hline$Q_{\text {large }} / Q_{\text {small }}$ & 4.3 & 4.1 \\
\hline
\end{tabular}

Titanium Electrodes

$\begin{array}{lll}Q_{\text {1arge }} & 8.5 \mathrm{pC} & 4.0 \mathrm{pC} \\ Q_{\text {sma11 }} & 2.0 \mathrm{pC} & 0.98 \mathrm{pC} \\ Q_{\text {large }} Q_{\text {smal1 }} & 4.3 & 4.1\end{array}$

A second purpose of this test structure was to determine whether or not the single crystal sapphire became conductive during the radiation pulse. This could be determined by applying a bias voltage to the back plane. The 25-mil alumina test device was fabricated because it was felt that polycrystall.ine (amorphous) alumina (or radiation-damaged sapphire) was much less likely to become conductive.

The test results are shown in Figs. II-14 through -16 . Table II-8 shows the measured and calculated charges with no bias between the electrodes and back plane. As can te seen, the response is reduced by roughly a factor of 2 , and the agreement between measured and calculated values is reasonable.

Each test was rerun with $+100-v,-100-v$, and $+500-v$ blases between the back plane and the electrodes; the results are also shown in Figs. II-14 through -16 . The sapphire does indeed become conductive during the radiation pulse. The peak response of the electrode with a back plane is increased by a factor of 7 for the 30-mil sapphire and by a factor of 24 for the 10-m11 sapphire when $100-\mathrm{V}$ bias is applied. However, the alumina shows no increase for $100 \mathrm{~V}$ and only an increase of $50 \%$ with a $500-\mathrm{V}$ bias. 


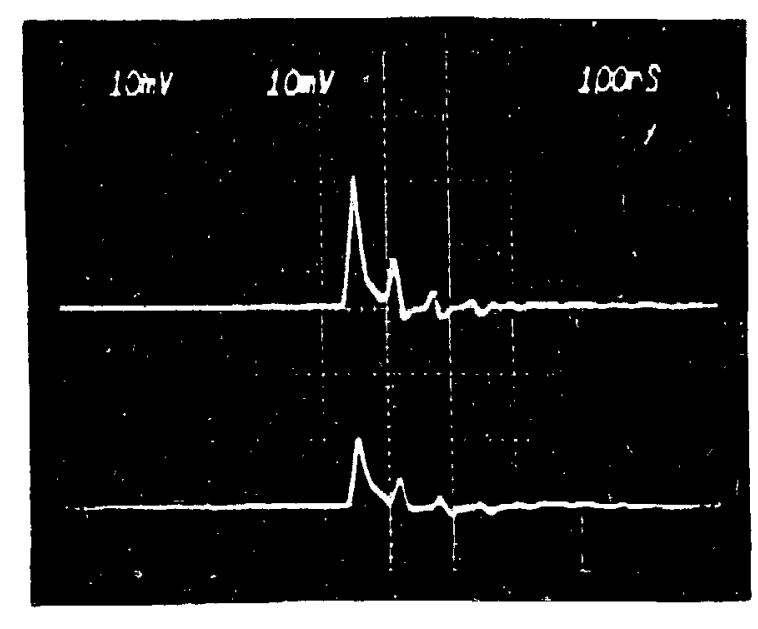

(a)

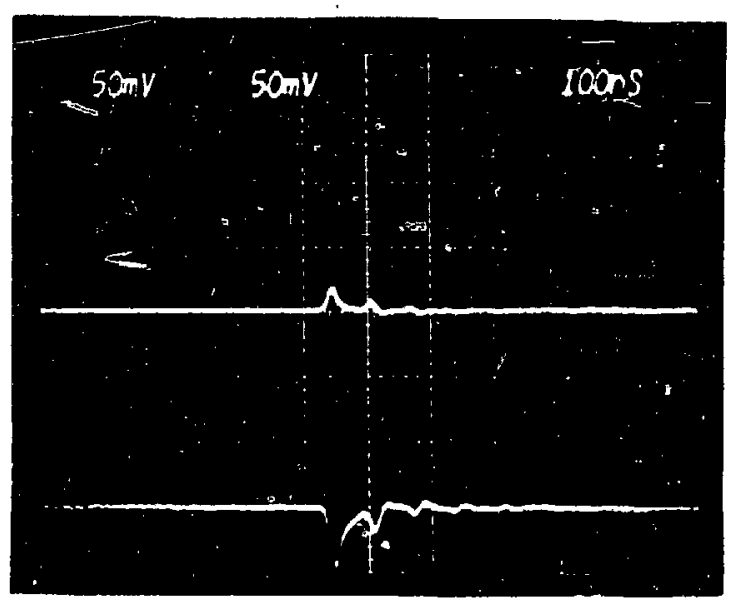

(c)

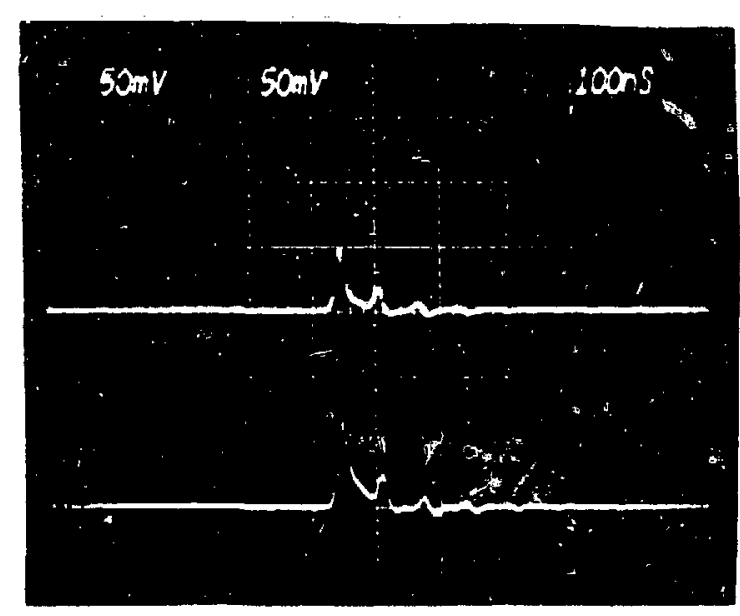

(b)

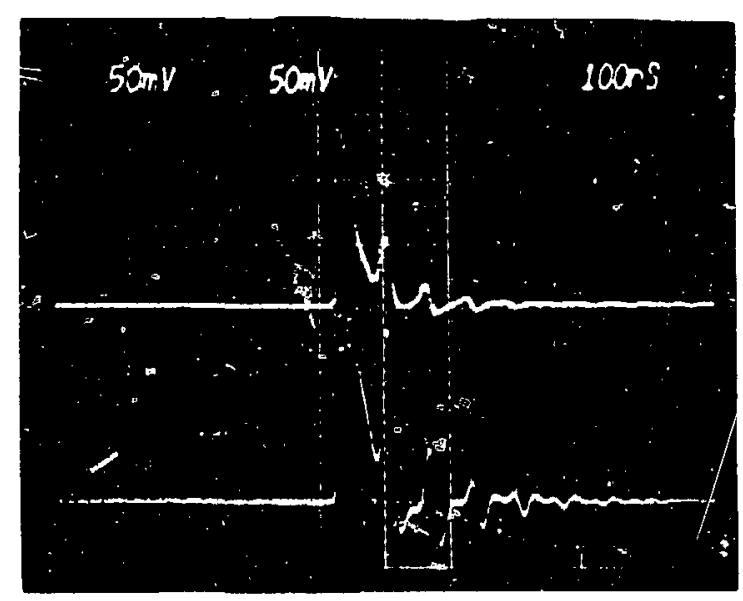

(a)

Fig. II-14. Ground plane test structure results using 30-nil-thick sapphire substrate. In all cases electrode $B$ is the top trace, and electrode A is the bottom trace. The potential difference between the ground plane and the electrodes is (a) $0.0 \mathrm{~V}$, (b) $+100 \mathrm{~V}$, (c) $-100 \mathrm{v}$, (d) $+500 \mathrm{~V}$. 


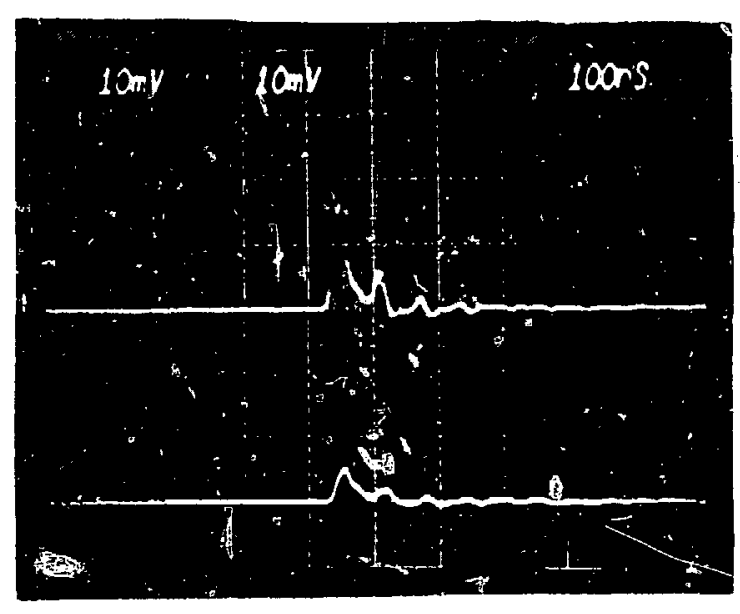

(a)

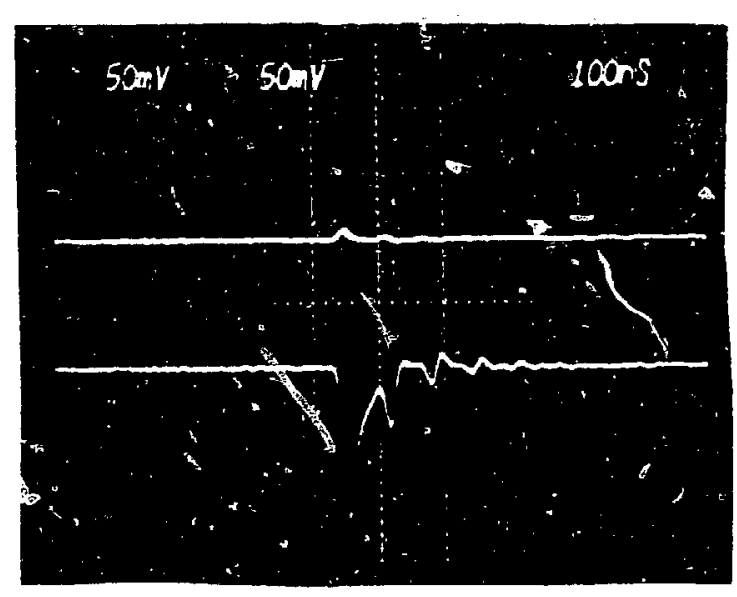

(c)

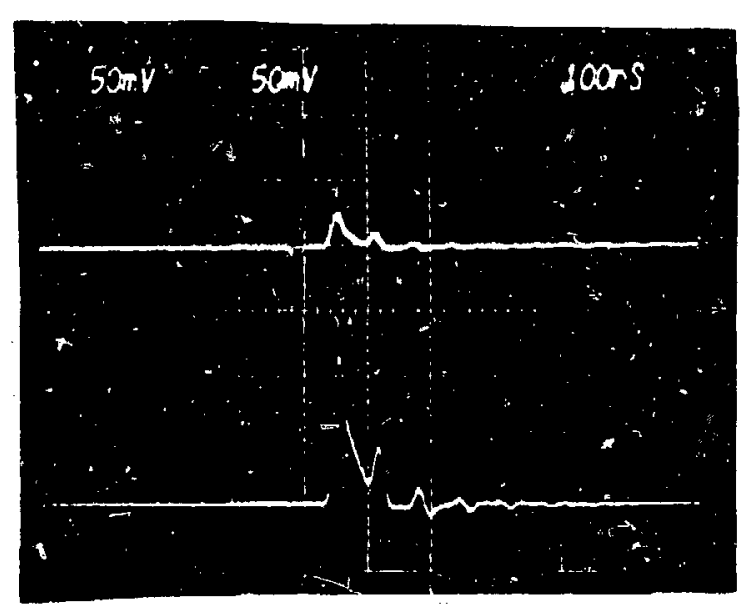

(b)

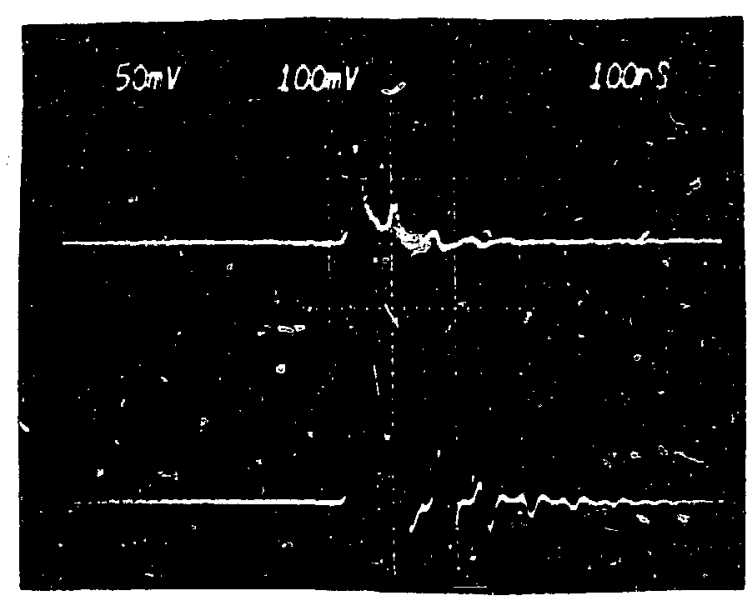

(d)

Fig. II-15. Ground plane test structure results using 10-m11-thick sapphire substrate. In all cases electrode $B$ is the top trace, and electrode $A$ is the bottom trace. 'ine potential difference between the ground plane and the electrodes is (a) $0.0 \mathrm{~V}$, (b) $+100 \mathrm{~V}$, (c) $-100 \mathrm{v}$, (d) $+500 \mathrm{v}$. 


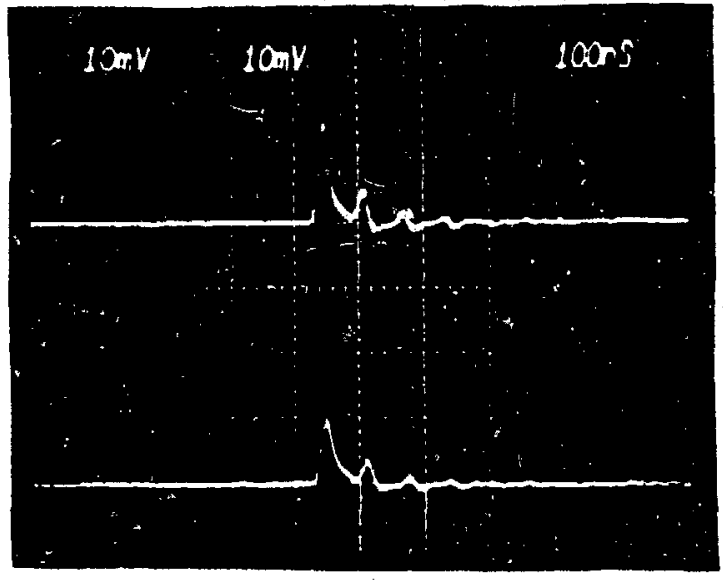

(a)

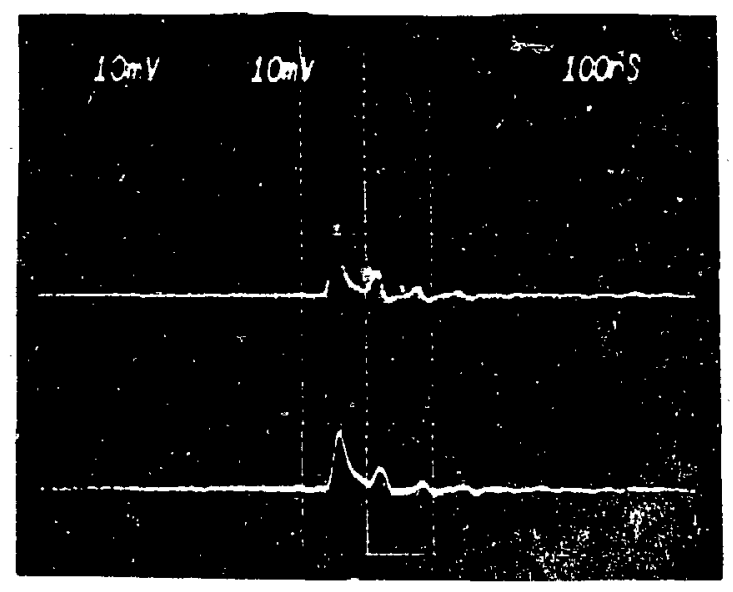

(c)

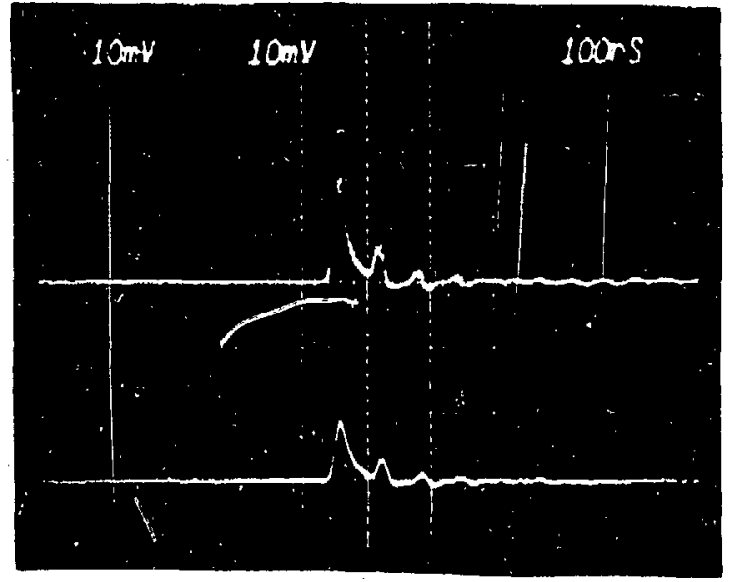

(b)

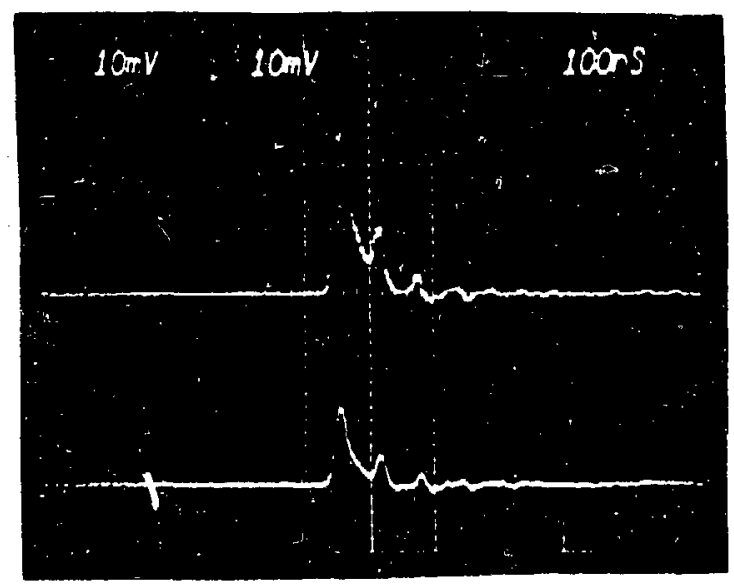

(d)

Fig. II-16. Ground $r$ ane test structure results using 25-mi1-thick alumina substrate. In all cases electrode B is the top trace, and electrode $A$ is the bottom trace. The potential difference between the ground plane and the electrodes is (a) $0.0 \mathrm{~V},(\mathrm{~b})+100 \mathrm{~V}$, (c) $-100 \mathrm{~V}$, (d) $+500 \mathrm{~V}$. 
TABLE II-8

MEASURED AND CALCULATED RESPONSE OF THE GROUND PLANE TEST STRUCTURES

\section{Structure}

30-mil aapphire without ground plane with ground plane ratio

10-mil sapphire without ground plane with ground plane ratio

25-mil alumina without ground plane with ground plane ratio

$\begin{array}{ll}\text { Charge }(\mathrm{pC}) \\ \underline{\text { Measured }} & \underline{\text { Calculated }}\end{array}$

4.4

5.7

2.4

3.9

1.8

1.5

3.2

2.6

1.1

2.9

1.3

2

$\begin{array}{ll}3.3 & 5.7 \\ 1.8 & 3.2 \\ 1.8 & 1.8\end{array}$

Because the single crystal sapphire becomes conductive during the radiation pulse, the radiation response of a circuit w11l be increased under normal blas conditions. However, the use of loped sapphire, neutron-irradiated sapphire, or alumina will greatly reduce this effect. The responses shown in Figs. II-14 through -16 were used to estimate the RIC for the $30-$ and 10-mil sapphire substrates and the 25-m11 alumina substrate; these values are shown In FIg. II-17. For reference, the extrapolated values of the room temperature RIC [from (1)] for the undoped and doped sapphire are between the dashed lines In Fig. II-17. (The extrapolation is over much too large a range to be useful. Values of RIC for potential TIC substrate materials need to be measured in the $10^{8} \mathrm{rad} / \mathrm{s}$ range and up.)

The estimated values of conductivity can be used in Eq. (II-18) to calculate the point at which RIC effects are about the same as Compton effects. The results, plotted in Fig. II-18, indicate that RIC effects may dominate in undoped sapphire for thicknesses in the 5- to 10-mil range. On the other hand, 1-mIl alumina may have lower RIC effects than 10-mil sapphire. This emphasizes the importance of evaluating doped sapphire, neutron-1rradiated sapphire, and alur:ina for TIC substrates.

It. orfer to substantially reduce the response of the substrate, a structure such as that shown in FIg. II-19 could be used. This structure lessens 

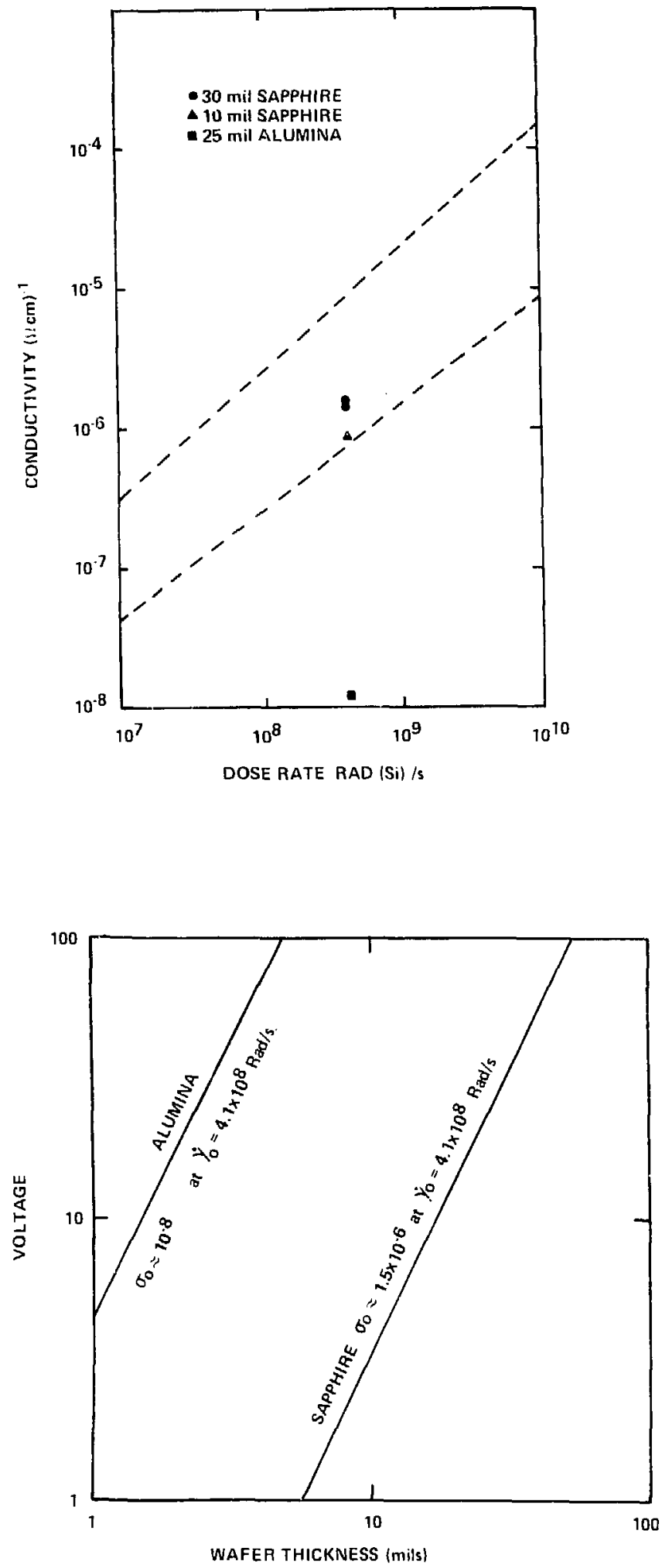

F1g. II-17. Estimated (dashed) and measured substrate conductivity as a function of dose rate. $\mathrm{T}=294 \mathrm{~K}$.
Fig. II-18. Voltage as a function of wafer thickness for which RIC effects are approximately the same as Compton scattering effects. 
the mass of insulator used for device isolation and, with ground plane and heater, shields the large volune portiun of the: substrate used for mechanical support. Such a structure might be fabricated by brazing two sapphire wafers together and then grinding and polishing one wafer to a thickness of about 1 mil. A second method might be to deposit a film of insulator on top of a ground plane.

In order to test this structure, $3000 \AA$ of $\mathrm{S}_{2} \mathrm{O}_{2}$ were deposited on a metalized 30-mil sapphire wafer. Then, $t$ wo $0.25-\mathrm{cm}^{2}$ electrodes were fabricaced on the $\mathrm{SIO}_{2}$. The test results are shown in FIg. II-20. The response appears to be noise with maximum amplitude of $30 \mu \mathrm{A}(3-\mathrm{mV}, 100-\Omega$ sense resistor $)$ for $\dot{\gamma}=4.1$ $x 10^{8} \mathrm{rad}(\mathrm{S} 1) / \mathrm{s}$. This test verifies that the structure proposed $1 \mathrm{n}$ Fig. II-19 could substantially reduce the effect of displaced charge from the substrate in a TIC circuit or device. It must be noted, however, that the test structure using glass at room temperature only demonstrates feasibility. A structure using appropriate refractory materials must be developed as part of a follow-on program.

E. Dose Rate Response of the Flip-Flop

The gamma dose rate response of the flip-flop has been calculated and measured to determine how photocurrents Induced in TIC devices affect the performance of a complete clrcult. Then, the dose rate tolerance of a flip-flop utilizing 1mproved substrates and device structures is calculated. The radiation tolerance of the flip-flop is projected to Improve from the current $2 \mathrm{x}$ $10^{9} \mathrm{rad}(\mathrm{S} 1) / \mathrm{s}$ to $4 \times 10^{11} \mathrm{rad}(\mathrm{Si}) / \mathrm{s}$ with improved devices, narrower metal interconnects, and a substrate consisting of a 1-mil insulator on a ground plane on a 30-mil sapphire wafer. The effects of radiation-induced conductivity are not included in the projection since it appears that radiation-induced conductivity can be minimized by doping the sapphire, radiation-damaging the sapphire, or by using the alumina as the substrate.

1. Simplified Analysis of Flip-Flop Sensitivity to Radiation. A schematic of the fully connected flip-flop is shown in Fig. II-2l. Neglecting RIC, the most sensitive nodes will be the output-1nput cross-coupling nodes (A and $B$ ) and the nodes at the output of the gain stages ( $C$ and $D$ ). Since the associated electrodes must replace electrons ejected from the sapphire, the node potentials w11l increase by an amount 


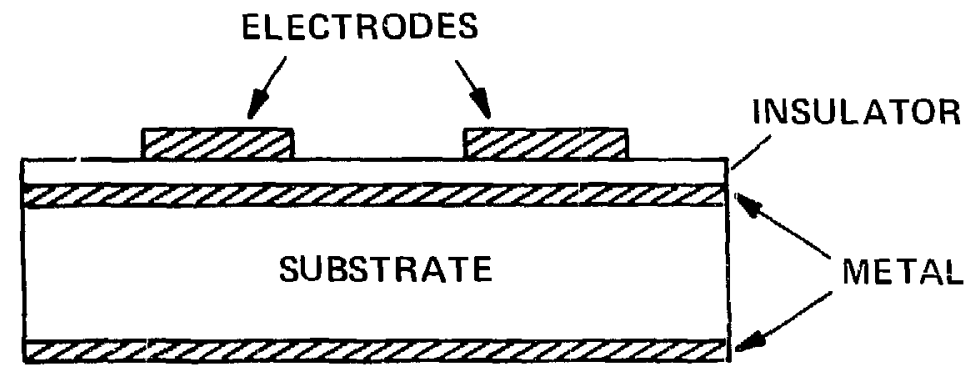

Fig. II-19. Thin insilator on metal ground plane as an Improved transient radiation substrate.

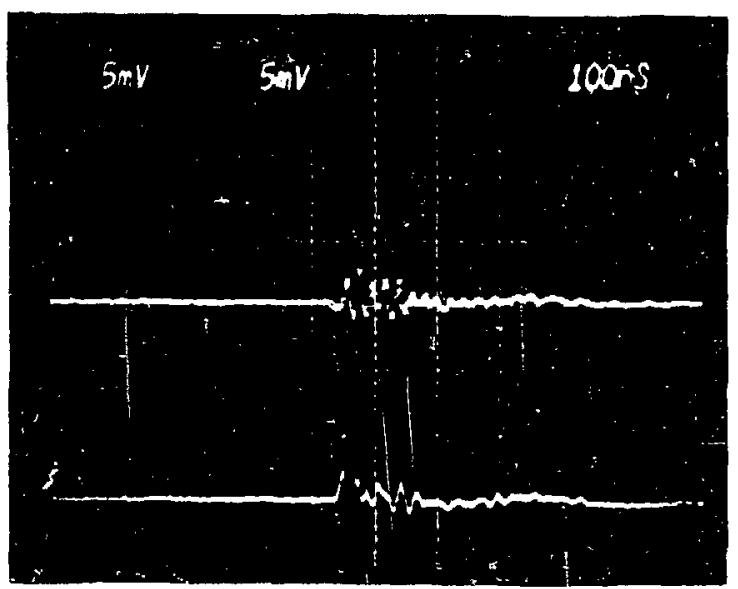

Fig. II-: 0. Response of improved transient radiation substrate.

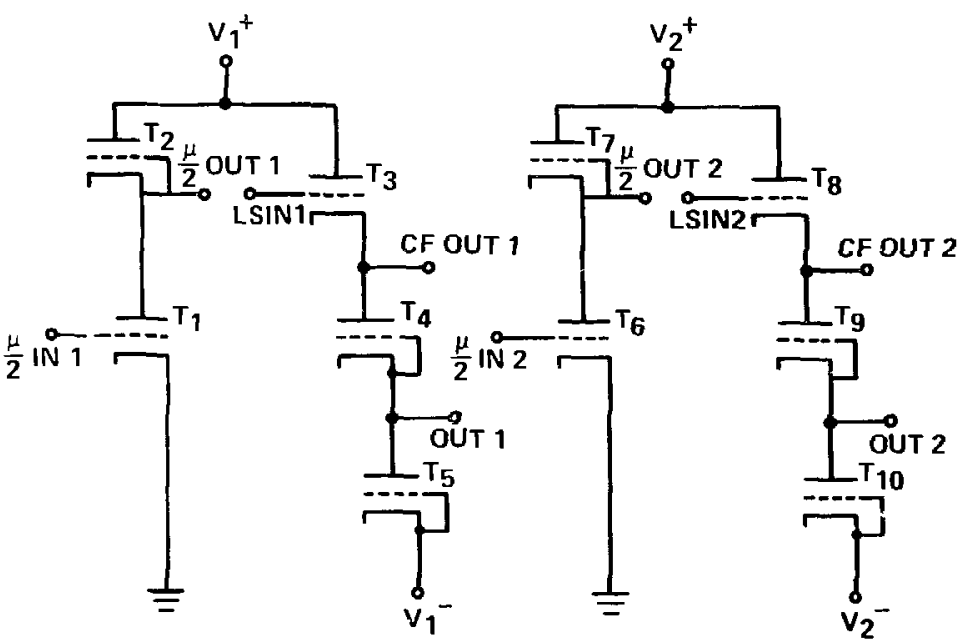

Fig. II-21. Circult diagram of the fully interconnected flip-flop: 


$$
\Delta v_{n}=\frac{-\Delta Q_{n}}{C_{n}} \text {, }
$$

where $\Delta Q_{n}$ is the total replacement charge supplied by node $n$ and $C_{n}$ is the total capacitance associated with node $n$. The most sensitive nodes should be the output-input nodes because an increase of $3-4 \mathrm{~V}$ (the logic swing of this particular inverter) will turn on both inverters and the state of the flip-flop will be lost.

If RIC is important: then any signal node that is at a voltage substantially different from ground could be affected; in this case, the output nodes of the gain stages (nodes $C$ and D, Fig. II-21) could well be the most sensitive. However, since it has been shown that substrates can be developed with substantially reduced RIC, the effects of RIC will not be included in this analysis.

In order to calculate the upset leve! of the flip-flop, it will be assumed that the critical nodes are the ottput-input nodes. Then from Eq. (II-20), the photon-induced charge and capacitance of these nodes must be calculated. The calculations will include the grid of the gain device Tl (or T6), the grid-cathode-cathode shield (G-K-KS) structure of the level shift diode T9 (or T4), the anode of the level shift diode T10 (or T5), plus the interconnect metal. Because the circuit is symmetrical and because the area of the interconnect metal is the same for both nodes, the $\dot{\gamma}$ response will be the same for either node.

In calculating the replacement charge for an electrode, it is assumed that the electrode must replace the charge in the sapphire below it and half the charge in the sapphire between it and the next electrode or ground plane. The effective area for radiation effects, $A_{R}$, includes the area of the electrode and half of the area between 1 t and next electrode. The equations in Section II.D are used to calculate the replacement charge per rad(S1) when radiation occurs in a time that is short compared with the circuit response time.

In Table II-9 the actual area $A$, the effective area $A_{R}$, the displaced charge per rad $Q / \gamma$, and the calculated capacitance to ground $C$ are shown for each electrode as well as the totals. In addition, the rads required to increase the voltage at each electrode and output-input node by $2 \mathrm{~V}$ are calculated (an increase of about $2 \mathrm{~V}$ would drive both inverters on and upset the flip-flop). In this calculation the entire radiation pulse is assumed to be 
delivered in a time that is short compared with the response time for the circuit. The last row shows the corresponding dose rate for a pulse width of 20 ns. The salculations indicate that the flip-flop could withstand $45 \operatorname{rad}(\mathrm{Si})$ in a short period or a dose rate of $2 \times 10^{9} \mathrm{rad}(\mathrm{si}) / \mathrm{s}$ in $20 \mathrm{~ns}$.

\section{TABLE II-9}

GAMMA/GAMMA-RATE-INDUCED RESPONSE IN TIC FLIP-FLOP TEST STRUCTURE

\begin{tabular}{|c|c|c|c|c|c|}
\hline & Grid & $\mathrm{G}-\mathrm{K}-\mathrm{KS}$ & Anode & Interconnect & Total \\
\hline$A\left(m 11^{2}\right)$ & 485 & 4567 & 3960 & 3400 & 12412 \\
\hline$A_{R}\left(m 11^{2}\right)$ & 903 & 6232 & 4480 & 6800 & 18415 \\
\hline$Q / \gamma\left[C / \operatorname{rad}\left(S_{i}\right)\right]$ & $17.4 \times 10^{-15}$ & $120 \times 10^{-15}$ & $85.9 \times 10^{-15}$ & $130 \times 10^{-15}$ & $353 \times 10^{-15}$ \\
\hline$C(p F)$ & 2.01 & 0.60 & 0.52 & 2.90 & $8.0^{a}$ \\
\hline$\dot{\gamma}[\operatorname{rad}(S i)]^{b}$ & 231 & 10.0 & $12 . ?$ & 44.6 & 45.3 \\
\hline$\dot{\gamma}[\operatorname{rad}(S i) / s]^{c}$ & $1.2 \times 10^{10}$ & $5 \times 10^{8}$ & $6 \times 10^{8}$ & $2.2 \times 10^{9}$ & $2.3 \times 10^{9}$ \\
\hline
\end{tabular}

$\overline{\text { ancludes } 2 \mathrm{pF}}$ from the package pin to ground (measured). $\mathrm{b}_{\text {To }}$ induce a change of $2 \mathrm{~V}$.

$c_{\text {Pulse width }}=20$ ns.

The first four rows in Table II-9 show the additive contributions of each electrode, while the last two rows indicate how the response of an electrode by 1 tself compares with the overall response. For example, the $\gamma$ tolerance of the G-K-KS structure is low compared with the total response, and 1 ts $\mathrm{Q} / \gamma$ contribution is high. Therefore, reducing the area of the G-K-KS structure would produce the largest improvement in the flip-flop $\gamma$ tolerance. On the other hand, the $\gamma$ response of the interconnect metal is about the same as the total response. Thus, reducing the area of the interconnect metal would produce little effect on the overall $\gamma$ tolerance, but would improve the flipflop's frequency response because the node capacitance would be reduced. 2. Flip-Flop Proton Dose Rate Tests. A TIC flip-flop was tested 1n a 647-MeV proton beam at the Los Alamos WNR facility. During the tests, the flip-flop was triggered continuously at a $4-\mathrm{kHz}$ rate. The outputs were fed to line drivers so that they could be monitored in the control room. 
As discussed in the previous section, the upset level of the flip-flop is expected to be determined by the total dose received in a period of time that is short compared with the flip-flop response time. In the case of $\dot{\gamma}$ upset, electrons are ejected from the substrate, and upset is caused by electron replacement current. The $\dot{\gamma}$ upset level is calculated to occur for a dose of $45 \mathrm{rad}(\mathrm{Si})$ in a short period of time. However, the proton upset mechanism should be somewhat difierent in that the protons impart less energy to the electrons and the electron motion is much less directional. Therefore, the number of ejected electrons will be lower, but the number of electron-hole pairs gentrated, and the associated conductivity effects, will be greater for protons.

The pulse width of the proton beam was adjusted until the flip-flop was at the threshold of upset, which occurred for a pulse width of 200 ns and a dose rate of $1.4 \times 10^{8} \mathrm{rad}(\mathrm{Si}) / \mathrm{s}$, or a total dose of $28 \mathrm{rad}(\mathrm{S} 1)$. Figure II-22 shows the normal waveform, and Figs. II-23 and -24 show the effect of the proton beam on the flip-flop. (In Figs. II-23 to -26 , the scope was triggered 20 us before the proton pulse.) In Fig. II-23, the flip-flop was not upset, although a comparison with $\mathrm{Fig}$. II-22 indicates that it was on the verge of being upset. In Fig. II-24, the flip-flop was upset, as it changed state when hit with the proton beam. Thus, the flip-flop's upset threshold is 28 rad(Si) delivered in $200 \mathrm{~ns}$, which is a short time compared with the flip-flop's response time.

The initial voltage step in Figs. II-23b and II-24c is caused by replacement current for the ejected electrons during the 200-ns pulse. If ejected electrons were the only radiation-induced mechanism, the off output would require about a $2-V$ step to upset the flip-flop. Since the induced step In Figs. II-23b and II-24c is no more than $1 / 2 \mathrm{~V}$, other mechanisms such as conductivity effects must be present.

The flip-flop response was also measured for a proton beam pulse width of $900 \mathrm{~ns}$ for a dose of $192 \mathrm{rad}(\mathrm{Si})$. From the results shown in Figs. II-25 and II-26, it can be seen that the higher dose drives both outputs negative. It can also be seen that the responses of the two sides are not symmetrical. This libely reduces the dose rate tolerance of the flip-flop.

To summarize, the measured proton upset level of this flip-flop is 28 rad'Si) in a short period of time $\left(1.4 \times 10^{8} \mathrm{rad}(\mathrm{Si}) / \mathrm{s}\right.$ for $\left.200 \mathrm{~ns}\right)$, as compared with the calculated gamma level of $45 \mathrm{rad}(\mathrm{Si})$. That $1 \mathrm{~s}$, for a 20 -ns pulse, the 


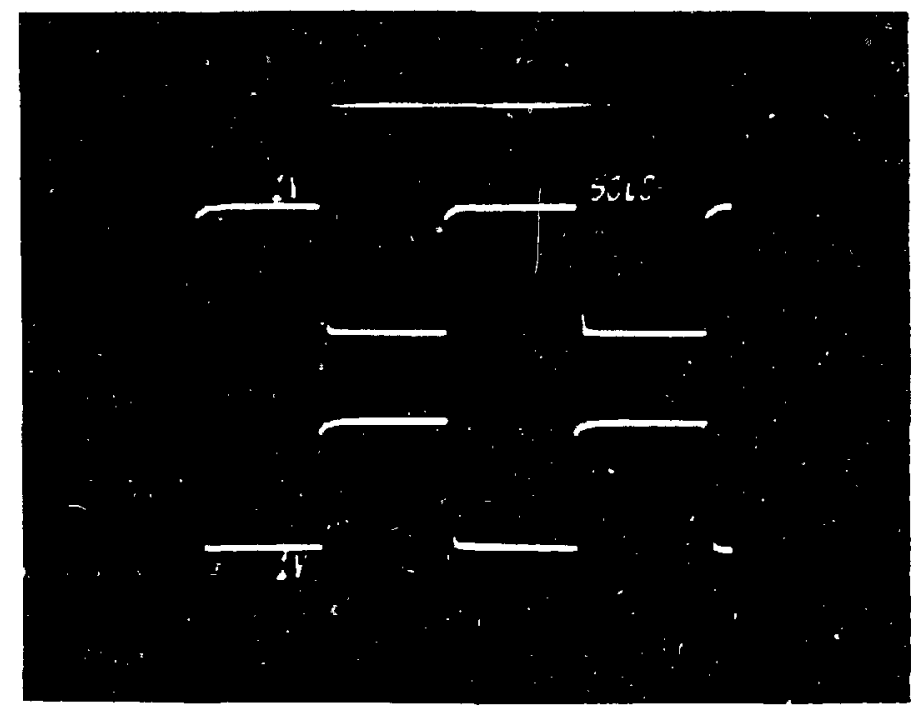

Fig. II-22, Undisturbed flip-flop waveform. 


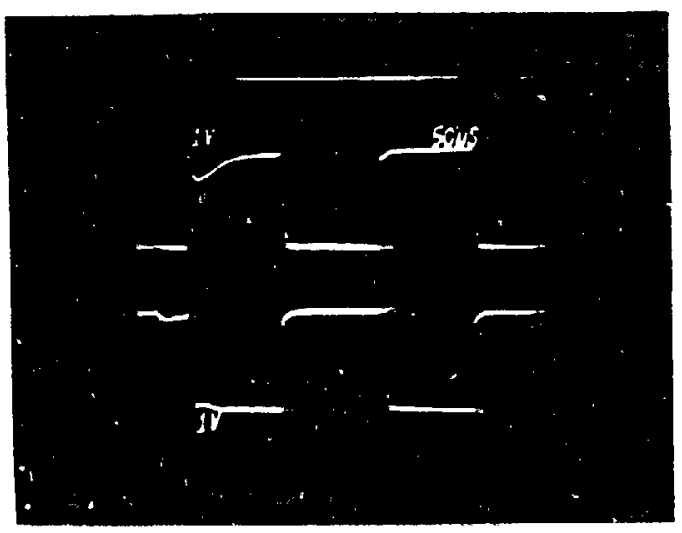

(a)

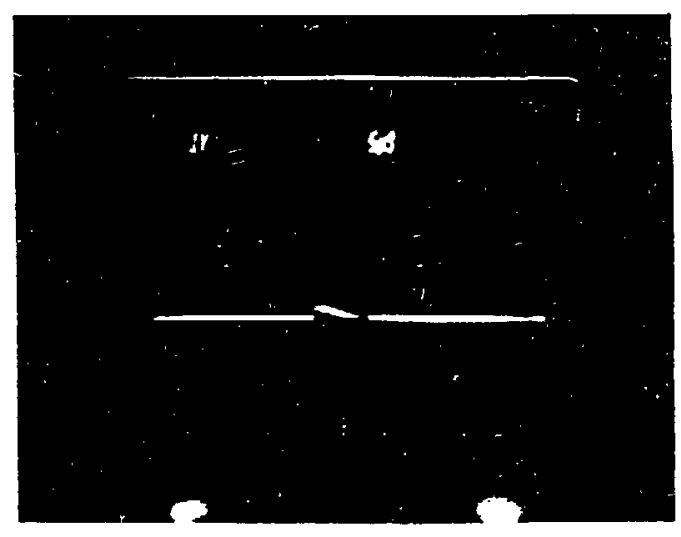

(b)

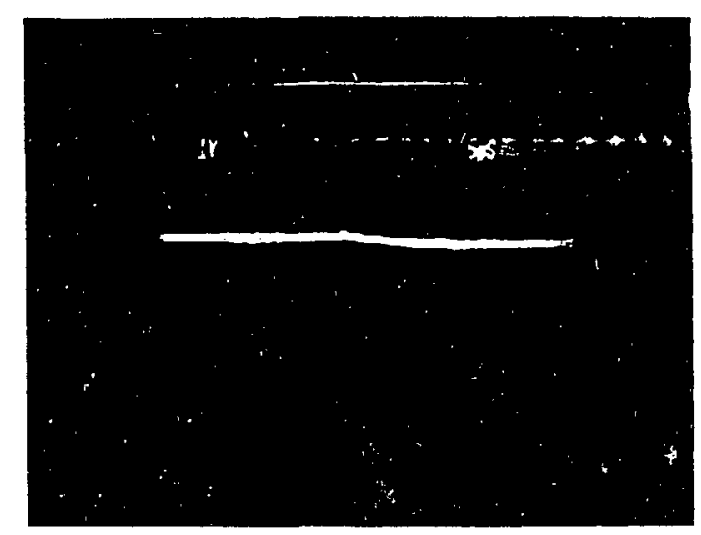

(c)

Fig. II-23. TIC flip-flop response for 200-ns proton beam pulse width, $28 \mathrm{rad}\left(\mathrm{S}_{i}\right)$, out 1 initially low, out 2 initially high. (a) Out 1 top trace, out 2 bottom trace, $50 \mu \mathrm{s} / \mathrm{div}$; (b) out 1, $50 \mu \mathrm{s} / \mathrm{div}$; (c) out $2,5 \mu \mathrm{s} / \mathrm{div}$. 


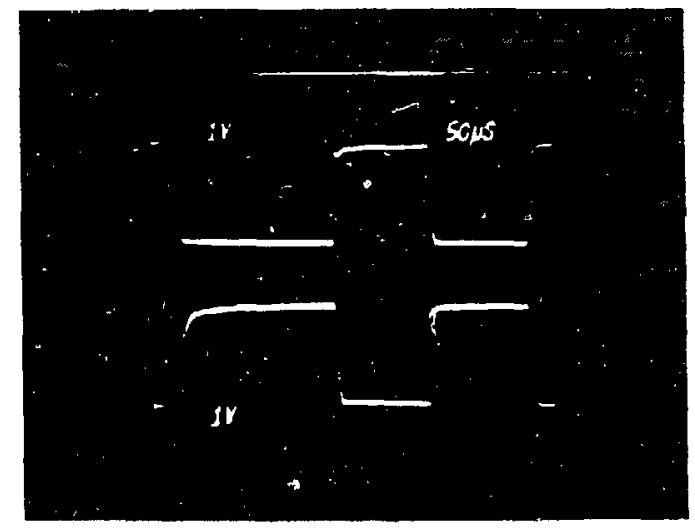

(a)

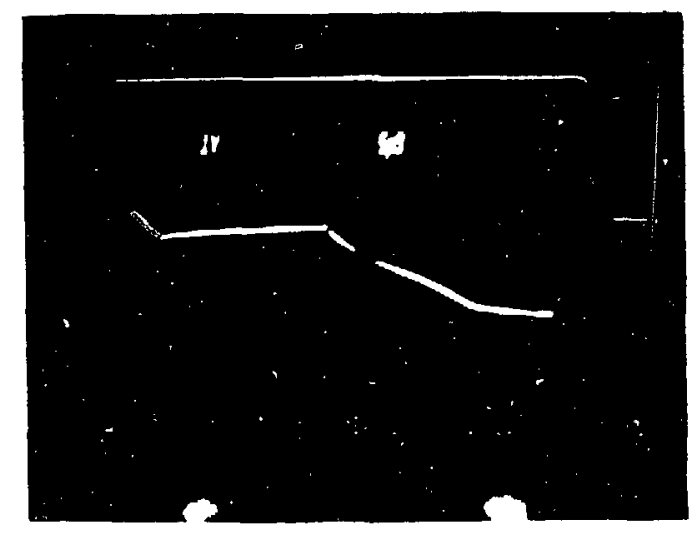

(b)

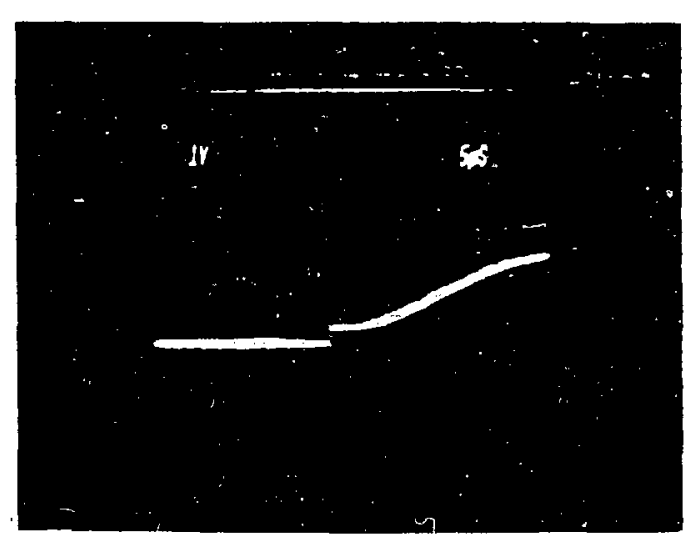

(c)

Fig. II-24. TIC flip-flop response for 200-ns proton beam pulse width, $28 \mathrm{rad}(\mathrm{Si})$, out 1 initially high, out 2 initially low. (a) Out 1 top trace, out 2 bottom trace, $50 \mu s / d i v$; (b) out $1,5 \mu \mathrm{s} / \mathrm{div}$; (c) out $2,5 \mu \mathrm{s} / \mathrm{div}$. 


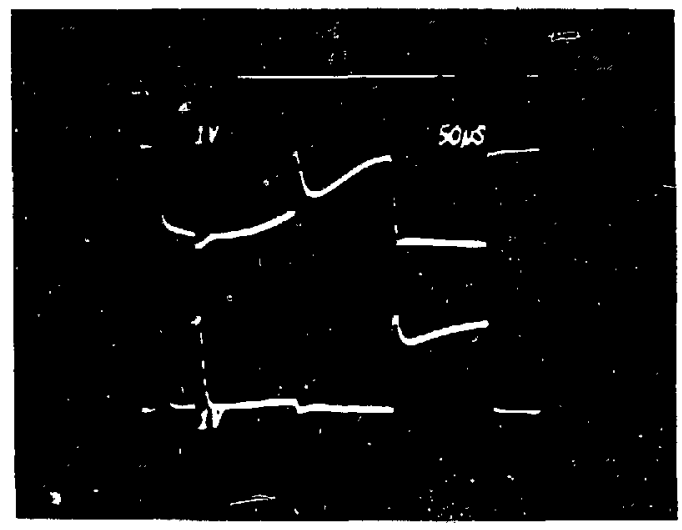

(a)

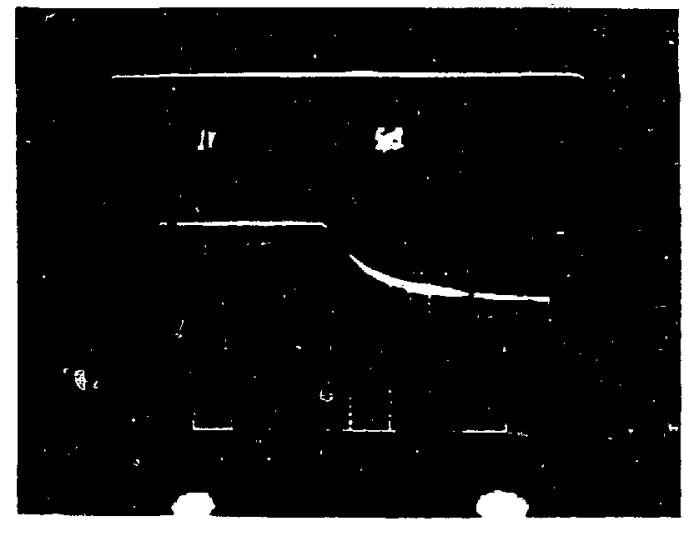

(b)

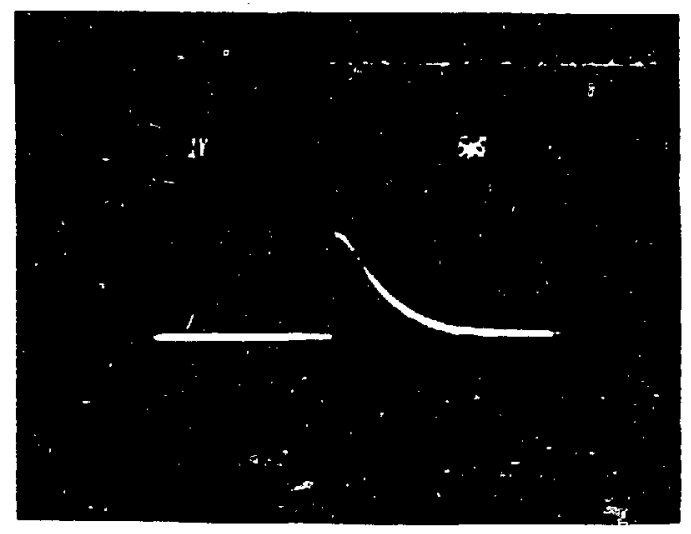

(c)

Fig. II-25. TIC flip-flop response for 900-ns proton beam pulse width, 19? rad(Si), out 1 initially low, out 2 initially high. (a) Out 1 top trace, out 2 bottom trace, $50 \mu s / d i v$; (b) out 1, $5 \mu \mathrm{s} / \mathrm{div}$; (c) out $2,5 \mu \mathrm{s} / \mathrm{div}$. 


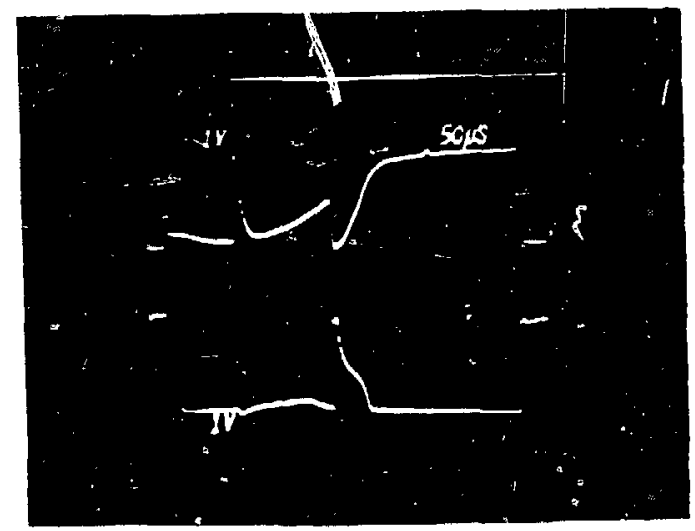

(a)

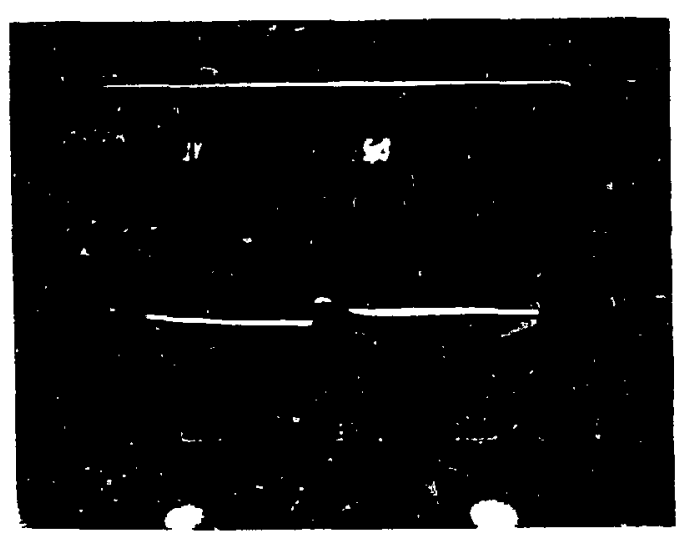

(b)

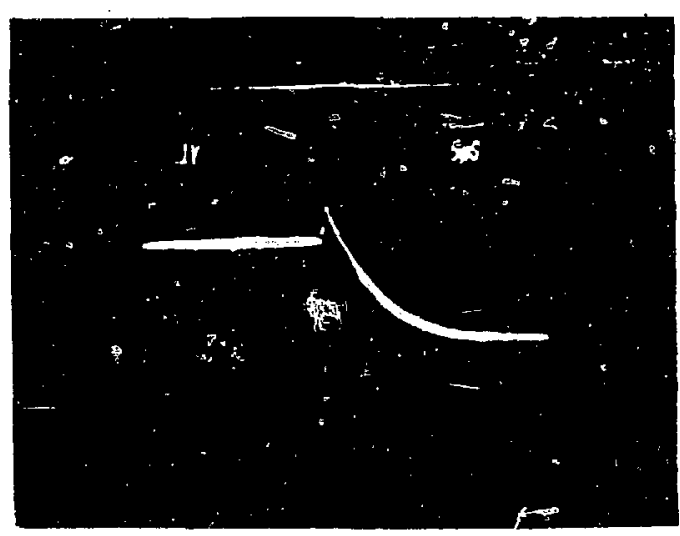

(c)

Fig. II-26. TIC I]ip-îlop response for 900-ns proton beam pulse width, $192 \mathrm{rad}(\mathrm{Si})$, out 1 initially high, out 2 initially low. (a) Out 1 top trace, out 2 bottam trace, $50 \mu \mathrm{s} / \mathrm{div}$; (b) out $1,5 \mu \mathrm{s} / \mathrm{div}$; (c) out $2,5 \mu \mathrm{s} / \mathrm{div}$. 
proton dose rate for upset is $1.4 \times 10^{9} \mathrm{rad}(\mathrm{Si}) / \mathrm{s}$, and the calculated gamma dose rate for upset is $2 \times 10^{9} \mathrm{rad}\left(\mathrm{Si}_{\mathrm{i}} / \mathrm{s}\right.$. The device, circuit, and process improvements designed to improve the TIC $\dot{\gamma}$ tolerance should produce similar improvenents in the proton dose rate tolerance. In particular, the reduction of substrate RIC shouid substantially improve the proton dose rate tolerance.

3. Projected Improvements. The radiation tolerance of a TIC circuit can be improved in four ways: (1) by reducing the size of the devices and metal interconnects, (2) by reducing the effective Lhickness of the substrate, (3) by increasing the logic voltage swing, and (4) by changing substrate materials. In this section, the radiation tolerance of the flip-flop will be recalculated both for reduced circuit size and for reduced wafer thickness in order to project transient radiation tolerances expected from circits incorporating the knowledge gained to date.

The circuit area can easily be rediced by using smaller devices and rarrower and shorter metal interconnects. The device used will be the redesigned device discussed in Section III.D. This device has a cathode wid:h of 0.8 mils and cathode length of 19.9 mils. The grid-cathode structure and the anode cf this device each have an area of $63 \mathrm{mil}^{2}$ rather than the nearly $4000 \mathrm{mil} 1^{2}$ of the test device.

The width of the interconnect metal can also be reduced. The 4-mil metal width and 4-mil spacing were used in devices tested to date in order to simplify the mask generation, not because of process limitations. Figures II-27 and -28 show the dose rate required to pruduce a $2-V$ change of potential on the metal as a function of the metal width for 10- and 1-mil substrates (it is assumed that the metal width and metal-to-ground shield spacing are the same). Also shown is the capacttance per unit length. Decreasing the metal width improves the radiation tolerance of the metal substantially. However, as was pointed out previously, decreasing the area of the metal yields diminishing returns when other parts of the circuit are dominant, although reducing the metal width still improves the frequency response by reducing circuit capacitance. Therefore, a netal width of $1 \mathrm{mll}$ will be chosen for the following calculations. This dimension is compatible with device size and required device spacing and provides only a small contribution in radiation-induced current. The layout used for the following calculations is the improved flip-flop layout discussed in Section III.D and shown in Fig. III-30. 

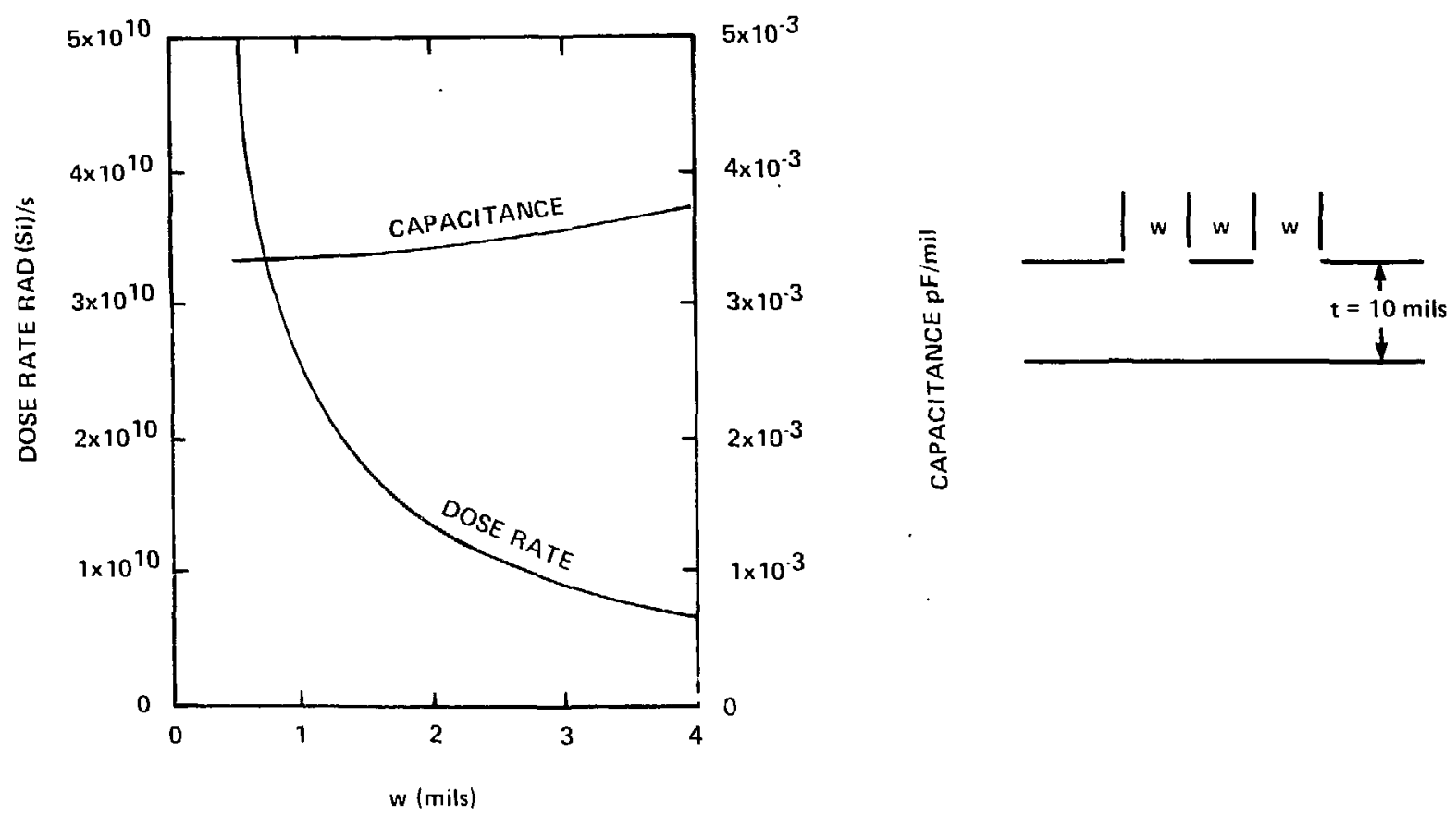

Fig. II-27. Dose rate for upset vs metal width on a 10-mil sapphire sutstrate. (2-V threshold)

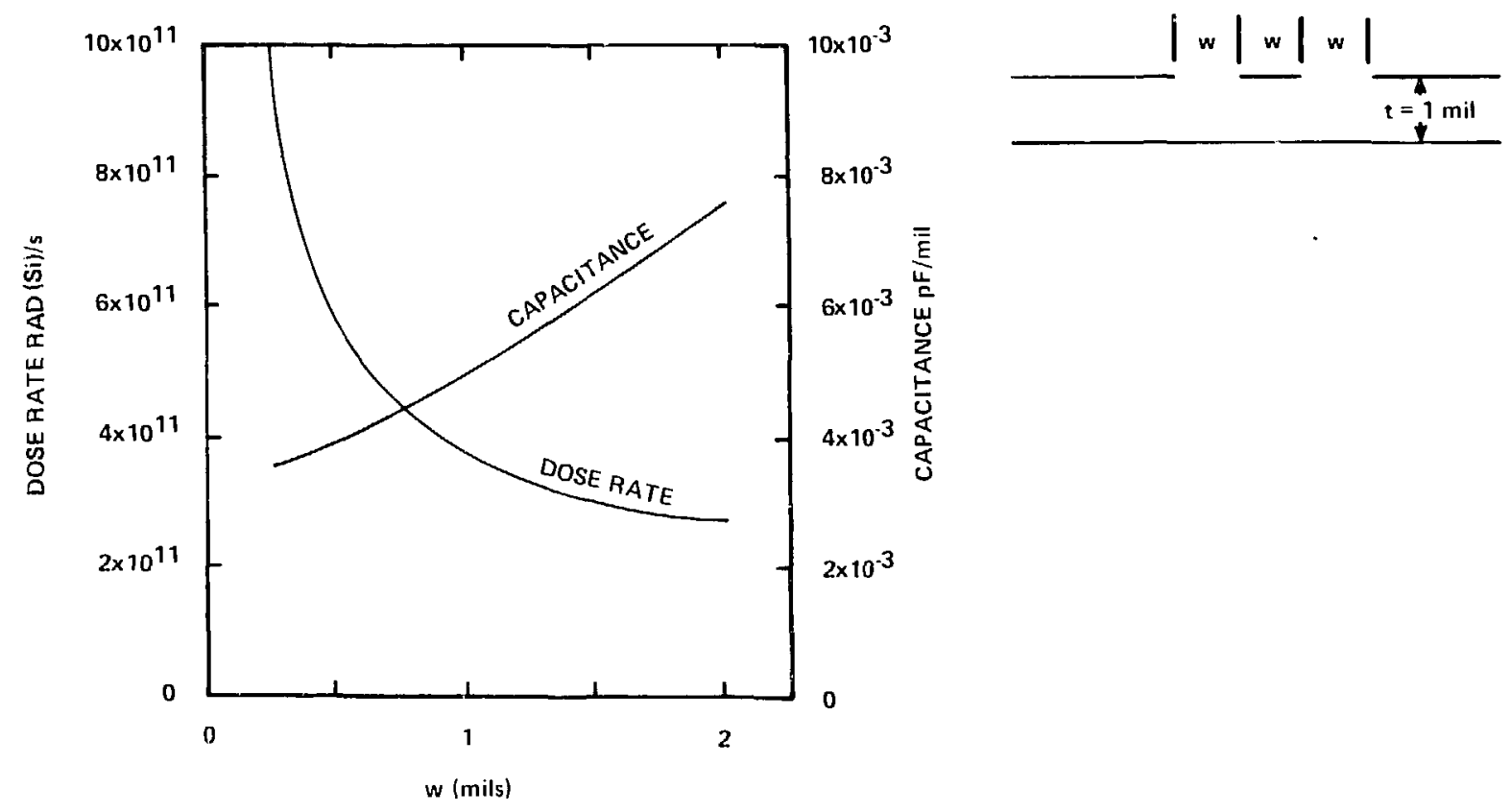

Fig. II-28. Dose rate for upset vs metal width on a 1-mil sapphire substrate. (2-V threshold) 
The greatest improvement in radiation tolerance will be obtained by reducing the thickness of the substrate. Circuits can be fabricated on substrates in the 6- to 10-mil range, but substantially thinner substrates will require other fabrication methods. As described previously and demonstrated by the last $\dot{\gamma}$ test described in Section II.D.3, a layered structure consisting of a thin insulator on a metal ground plane on a support layer has been found to be effective in decreasing the radiation-induced current of the substrate. The radiation tolerance of the improved flip-flop was calculated for substrate thicknesses ranging from $30 \mathrm{mils}$ down to 1 mil. Figure II-29 shows the calculated upset level for a $20-n$ s radiation pulse and the capacitance at the output-input node as a function of substrate thickness.

The upset level was calculated for both $2-V(\Delta V=2)$ and $20-V(\Delta V=20)$ induced excursions on the output-input node. The previous calculations were for $2 \mathrm{~V}$ because the $\log 1 \mathrm{c}$ swing of the current test flip-flop is $3-4 \mathrm{~V}$. How ever, a $\operatorname{logic}$ swing of $30-50 \mathrm{~V}$ is feasible with vacuum triodes; at this level an excursion of $20 \mathrm{~V}$ or more would be required to upset the flip-flop.

As can be seen from Fig. II-29, the node capacitance increases for thinner substrates. This improves the radiation toierance but degrades the frequency response slightly. If capacitance remaineci constant, the upset level vs thickness would be a straight line for a fixed layout.

The improved layout on 30-mil sapphire only improved the radiation tolerance from $2 \times 10^{9} \mathrm{rad}(\mathrm{Si}) / \mathrm{s}$ to $6 \times 10^{9} \mathrm{rad}(\mathrm{Si}) / \mathrm{s}$ for $\Delta \mathrm{V}=2$. However, a 10-mil substrate improved this to $2 \times 10^{10}$, and a 1 -mil substrate brought the calculated tolerance up to $4 \times 10^{11} \mathrm{rad}(\mathrm{Si}) / \mathrm{s}$ for $\Delta V=2$. (The effect of the heater as a ground plane was not included in the calculations. Including this would double the calculated tolerance.) If the flip-flop is designed with a logic swing of $30 \mathrm{~V}$, the calculated upset level for a 1-mil substrate is $4 \times 10^{12} \mathrm{rad}(\mathrm{Si}) / \mathrm{s}$.

F. Conclusions

1. The physics of the response of the TIC structure has been modeled and measured. Analyses and ohservations were found to be in good agreement.

2. Photon $(\gamma)$-induced effects in the substrate were found to be doninant in current TIC structures. Depending on substrate material, 


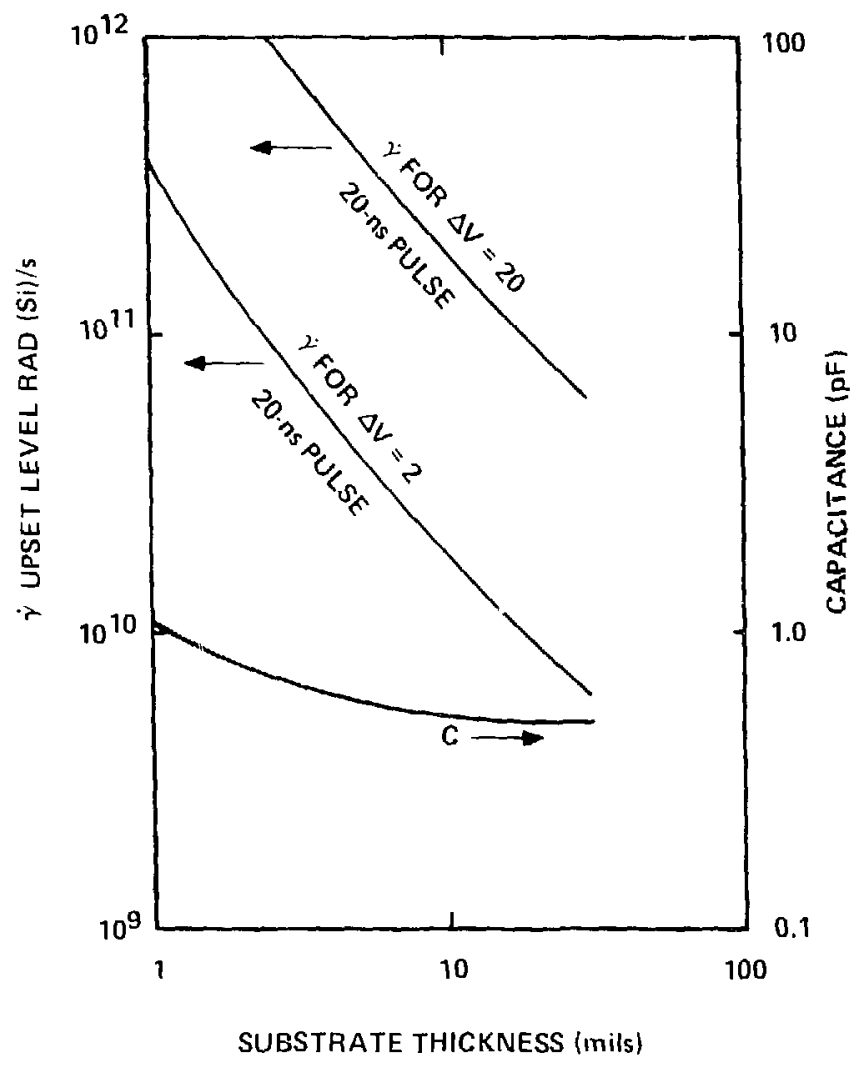

Fig. II-29. Upset level and node capacitance as a function of substrate thickness for the improved flip-flop layout. 
the dominant effect is either photoconductivity or displacement current .

3. A substrate with a ground plane and thin insulator over the ground plane was proposed to reduce the effects of the substrate described above. Preliminary tests were run that verified the effectiveness of this structure.

4. Flip-flops using the same cfrcuit tested but incorporating the improved substrate and l-mil lithography were analyzed yielding predicted upsets of between $4 \times 10^{11} \mathrm{rad}(\mathrm{S} 1) / \mathrm{s}$ and $4 \times 10^{12} \mathrm{rad}(\mathrm{Si}) / \mathrm{s}$ depending on the $\log$ ic level employed $(\Delta V=2 \mathrm{~V}$ or $\Delta \mathrm{V}=20 \mathrm{~V})$.

G. Recommendations

1. Techniques for manufacturing the improved substrate described above must be investigated.

2. Continued $\dot{\gamma}$ tests must be performed and compared with theory.

3. Extended total dose tests must be conducted to determine failure leve1s.

4. EMP tests/failure analyses must be conducted.

III. LEVEL OF INTEGRATION

A. Statement of Work from Proposa ?. March 1982)

"The electronic sophistication ald complexity of modern weapons has in recent years derived from the evolution of integrated circuitry (Fig. III-1). Clearly, by comparison, the TIC technology is in a very early stage of development both in terms of technology and investment.

"Although the ultimate performance limitations and radiation hardness of the TIC technclogy will be deperdent on the technology specific to TIC production and performance, the analogy of this technology to early integrated circuits is strong enough to base the key features of a program on the lessons learned in the development of IC technology; namely that progress has been due to improvements in four areas.

- Device processing allowing smaller devices and higher yields

- Device technulogy, allowing higher performance per device

- Larger chips, allowing more complicated functions and higher reliability 
- Clever circuit design techniques that take advantage of the particular benefits of the process and overall technology, allowing more circult sophistication, more combined functions, and less isolation between devices

The DOE investment in this technology to date (as of March 82 proposal) has been on the order of $\$ 600 \mathrm{k}$. Technology to date puts us in the 10 to 100 devices per chip regime; and current technology refined but applied in 'brute force' form to circuitry puts us in the 1000 (for analog) to 5000 (for digital) device per chip regime. (Figure III-2 compares current TIC technology to the classic silicon IC learning curve.)

"The objective of this portion of this one-year program will be to enhance assessments of possible short-and long-term levels of integration from which potential applications can be evaluated.

"Factors limiting the level of integration can be dividec into processrelated and process-1ndependent categorles. Process-related limitations are expected to be due to extraneous currents from two sources. The first is resistive leakage from element to element and the second is spurtous emission from elements such as grids, anodes, and shields, which are not intended to emit. Another fundamental process limitation is cathode photolithography. The extraneous currents determine how large a device must be for device blas currents to mask secondary currents. The cathode photolithography determines how wide the cathode stripe must be for proper delineation.

"Process-independent 1imitations are electrostatic interactions between devices and electron confinement within a given device (FIgs. III-3 and -4 respectively). Both of these effects combine to determine how far apart devices must be to ensure electrical 1solation.

"A typical present device is made with seven 1.5-m11-wide cathode stripes per device, with 1.0-mil-wide grid stripes interdigitated between cathodes. Shield electrodes are used around the grid-cathode structure to produce equipotential lines that confine electron paths within a specific device.

"Electrostatic interactions can be understood by inspecting Figs. III-3 and -5 . It is desired that the grid cathode structure GKl of a particular device not have the electric fleld at its surface appreclably modified by potentials applied to a neighboring grid cathode structure GK2, or to a neighboring anode shield SA. This is achieved by adjusting the device-to-device spacin: 


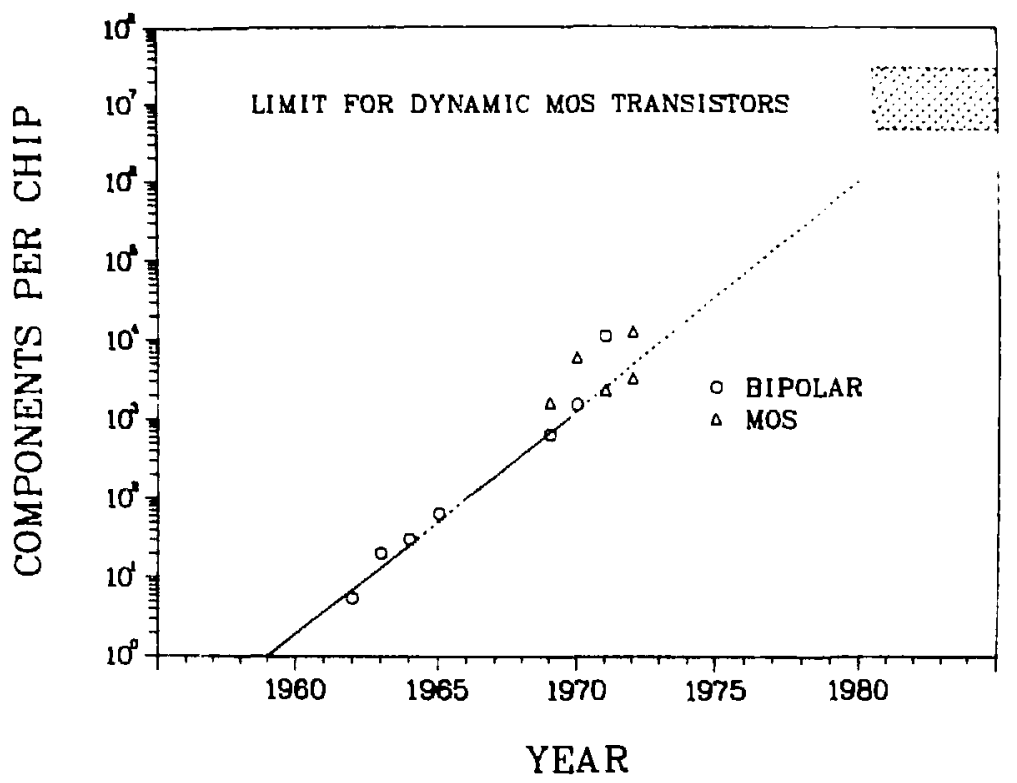

Fig. III-1. Evolution of silicon integrated circults. Progress has been due to processing, devices, larger chips, and clever circuit design techniques.

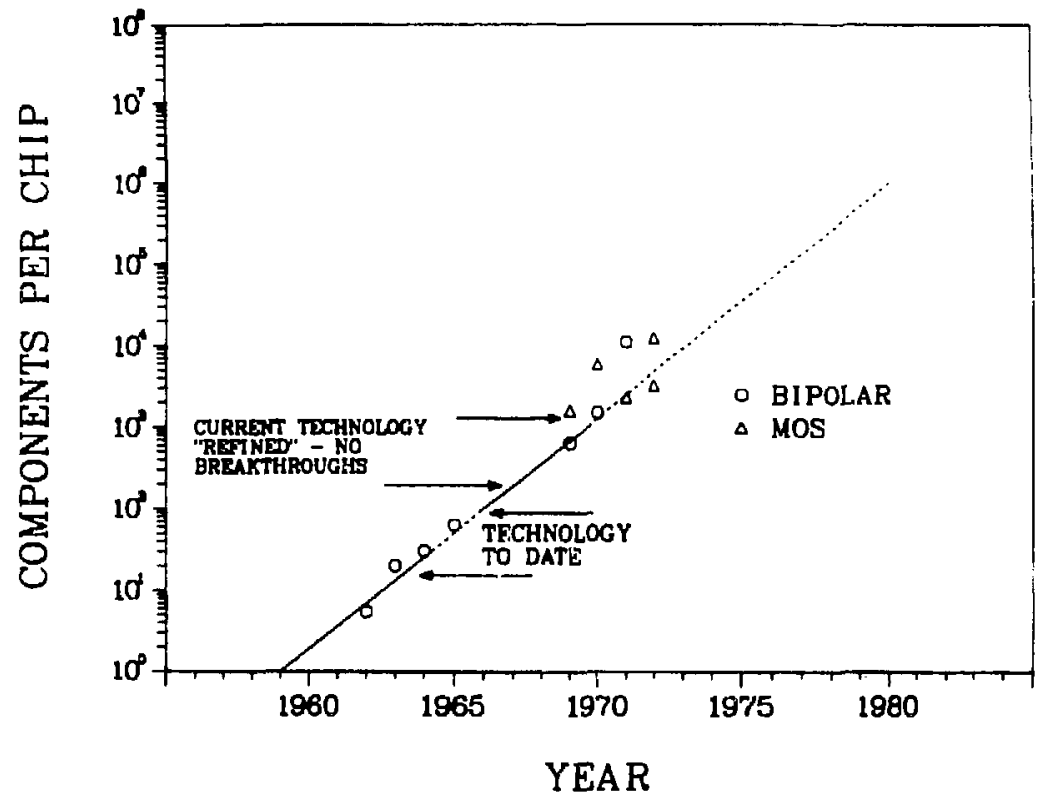

FIg. III-2. Projections made using current TIC technology. The TIC chip size is $0.19 \mathrm{in}^{2}$. 


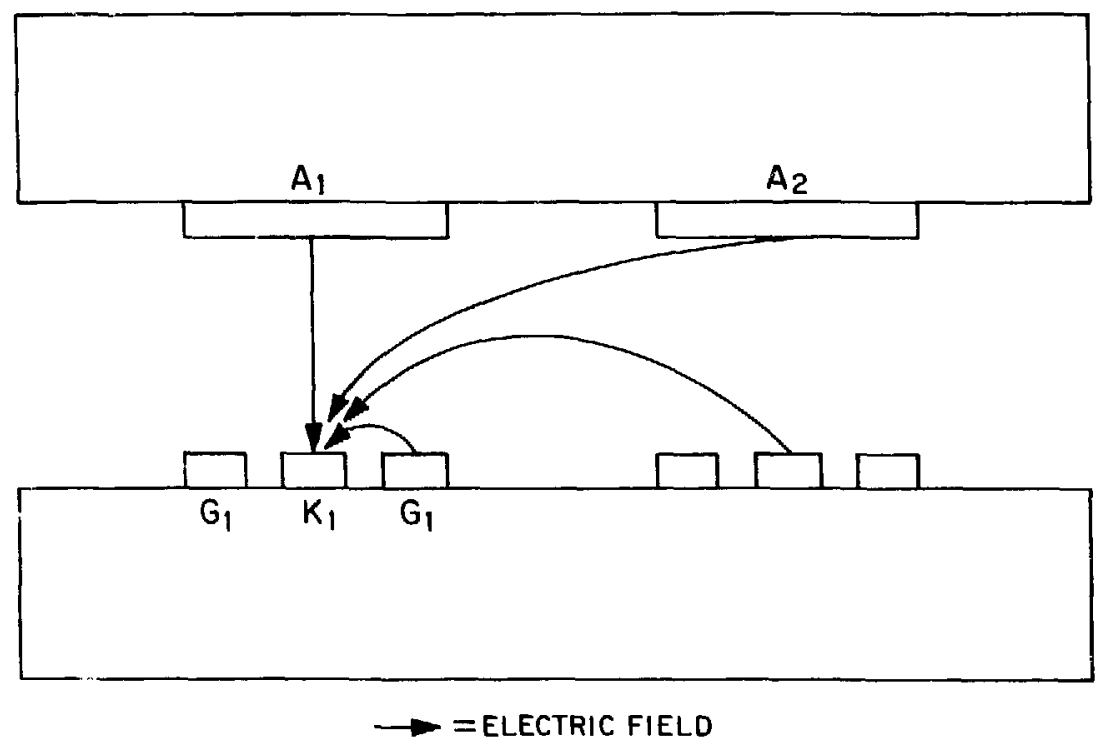

Fig. III-3. Electrostatic device interactions.

\section{ELECTRON CONFINEMENT}

- WANT TC AVOID

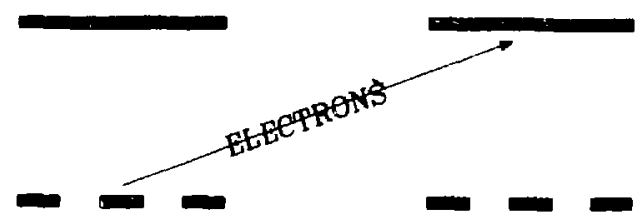

- ISE SHIELD TO FORM ELECTROSTATIC "BOTTLES"

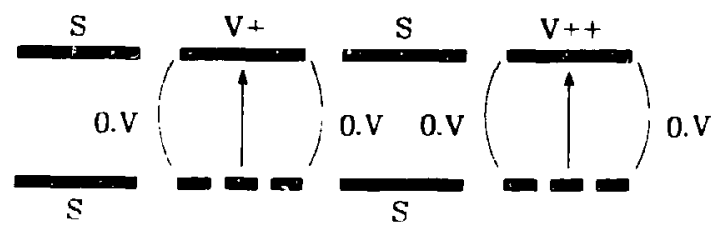

Fig. III-4. Typical interactions. 


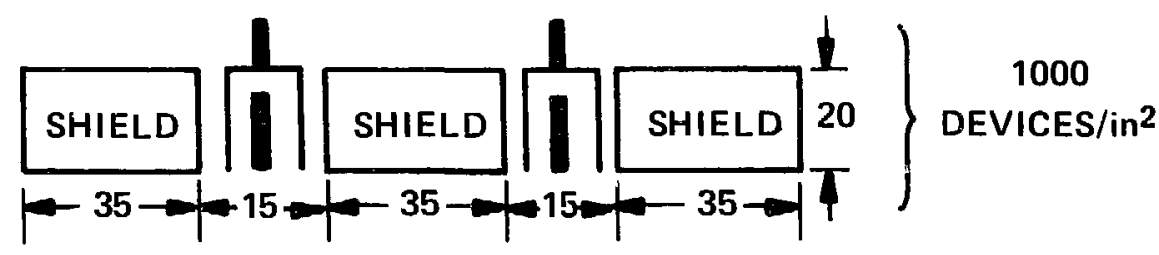

CROSS SECTIONS

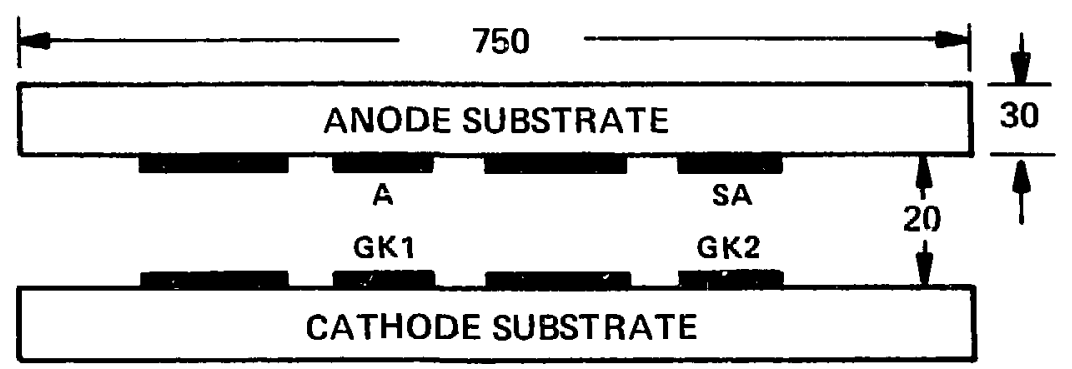

$$
\left.\begin{array}{l}
\mu_{\mathrm{GK} 1}=39 \\
\mu_{\mathrm{SA}}=11,000 \\
\mu_{\mathrm{GK} 2}=11,000
\end{array}\right\} \frac{\mu_{\mathrm{GK} 1}}{\mu_{\mathrm{SA}+\mathrm{GK} 2}}=0.007
$$

Fig. III-5. Electron confinement. Dimensions are in mils. 
to a distance at which the flelds from other elements are compatible with clrcuit requirements (e.g., low gain digital allows very close spacing, whereas high gain linear requires increased isolation). An advanced TIC circult design technique w11l undoubtedly utilize these interactions advantageously.

"The electron confinement aspect is illustrated in Fig. III-4. Electrons enitted from the cathode of a given device must be collected by the anode of that device and not attracted to nelghboring anodes that might be at different potentials. In this case, shield electrodes can ensure this. If the shield potential is properly chosen, a zero-potential line relative to the cathode potential is produced that confines the electrons to the device by an electrostatic bottle. Present devices incorporate appropriate shield electrodes to produce electron confinement.

"The simple device arrays tested to date have been at a level of integration of 122 devices/1n ${ }^{2}$. As was seen In Fig. III-5, analytical predicilons indicate that a level of 1000 devices $/ 1 \pi^{2}$ can be achleved with less than 1\% interaction between nelghboring devices, which would rapresent an acceptable level for 'stralght forward' analog clrcult design (digltal might easily allow for 5000 to 10,000 devices/ $/ \mathrm{n}^{2}$.) At this level of integration, electron confinement is also easily achieved. The reduction of leakage current to an acceptable value at this level of integration has not yet been tested. Spurious emission and methods for its suppression have been addressed in previous programs. It is not expected to be a 1imitation at this level. "Current photolithography allows cathode-to-grid spacings on the order of $0.2 \mathrm{mils}$ and $1 \mathrm{~s}$, therefore, not a 1imitation at even $100,000 \mathrm{devices} / \mathrm{in}^{2}$. The ratio of grid-cathode areas to total device/shield area for a projected minimum size device with present brute force circuit technology is $1 / 33$. Most of the device area is used by shield electrodes. Therefore, clever circuit design and/or advances in device morphology, which reduce the need for large shields, inust be developed to fully exploit the level of integration possible utilizing exlsting cathode and metal photolithography.

"Measurements must be made to quantify amounts and locations of sources of leakage currents and spurious emission as a function of activation techniques and as a function of time. Techniques will be investigated to improve results.

"No activities are proposed in cathode delineation because present techniques are adequate. 
"A mask set will be generated and devices fabricated to measure interactions and electron confinement. The masks will include devices with one, three, and six cathode stripes. A four-device nearest neighbor array will be used (Fig. III-6). Electron confinement will he measured as a function of electrode bias voltages. Interactions will he measured and their effects evaluated for simple two- and four-device circuits such as simple gain stages, cathode followers, and differential amplifiers. Effects of reducing device geometry on device parameters such as $\mu, g_{m}$, etc., will also be evaluated."*

B. Modification to the Statement of Work

Because the generation of artwork and mask making for new test structures is time consuming and costly relative to the budget for this program and because an integrated flip-flop or memory element fabricated using TICs was required to check transient radiation upset predictions, the Statement of Work was modified as indicated below.

1. Fabricate and test simple circuit, i.e., gain stages with masks on hand and compare the test results with interaction predictions based on two-dimensional Laplace-equation computer codes. Analytic circuit models incorporating electrostatic feedback terms were to be developed and used to compare the predicted with the observed circuit performance.

2. Build a first completely integrated circuit using TICs, which woıld force verification of expected performance levels.

3. Quantify sources of parasitic resistive grid-to-cathode leakage and emission from noncathode elements.

4. Improve fabrication processes to minimize leakage and spurtous emission. This aspect was considered critical to achieving a high level of integration.

5. Evaluate, using masks on hand, the four nearest neighbor interactions as described in the March 1982 statement of Work.

\section{Process Dependent Factors Influencing Level of Integration}

1. Resistive Leakage. TIC devices incorporate photolithographically delineated thin films on sapphire substrates. The spacing between thin-film

\footnotetext{
* End March 1982 Statement of Work.
} 
elements such as grids and cathodes can currently be as narrow as $5 \mu \mathrm{m}$ $(0.2 \mathrm{mil})$. Resistive leakage between such elements can he detrimental to efficient circuit operation; therefore, quantifying the amount and sources of leakage and improving fabrication techniques to minimize leakage have recently been major activities of this program. The test vehicle used is the dual triode shown ia Fig. III-7. Each triode has ten 100-mil x 1.5-mil cathode lines for a total cathode area of $1500 \mathrm{mils}^{2}$. The grid-to-cathode spacing is 0.3 mils, and the total grid-cathode close proximity length is $2000 \mathrm{mils}$. This test structure was designed to provide an extensive grid-to-cathode length, which allows for easily measurable resistances for very small amounts of leakage-causing residue.

From the outset, the cathode-coating/photoresist combination was strongly suspect as a possible source of leakage. This combination is a mixture of standard vacuum tube harium-strontium-calcium carbonate powder and negative photoresist. Verification of this mixture and the associated processing as the leakage source was made by assembling dual triode substrates without cathode material or photoresist and then processing them through the normal vacuum bakeout and activation cycle, heating both substrates to more than $900^{\circ} \mathrm{C}$. No measurable leakage was observed. However, at this point in time, grid-to-cathode leakages as 1 ow as $100 \mathrm{k} \Omega$ were commonplace in the test structures with cathode/photoresist material. This same type of test, when conducted with only the negative photoresist binder portion of the cathodecoating mix, indicated that the negative photoresist binder (no added carbonates) was the principal source of the observed leakage. The negative resists used are basically cyclized rubber derivative with a sensitizer additive. (Positive resists cannot be used because they contain sulphur compounds that react with barium to "poison" cathode emission.) Observations during the activation cycle show that, at approximately $700^{\circ} \mathrm{C}$, leakage started to form, and at that time, various hydrocarbon outputs were observed on a mass spectrometer. For completeness, several brands of negative resist were evaluated with little or no difference observed.

A series of tests was then performed ro determine the extent to which the vacuum pumping path and temperature variation across the substrate governed the magnitude and location of hydrocarbon deposits. In the first tests, only the grid-cathode suhstrate (Fig. III-7a) was used, and cathode coating 


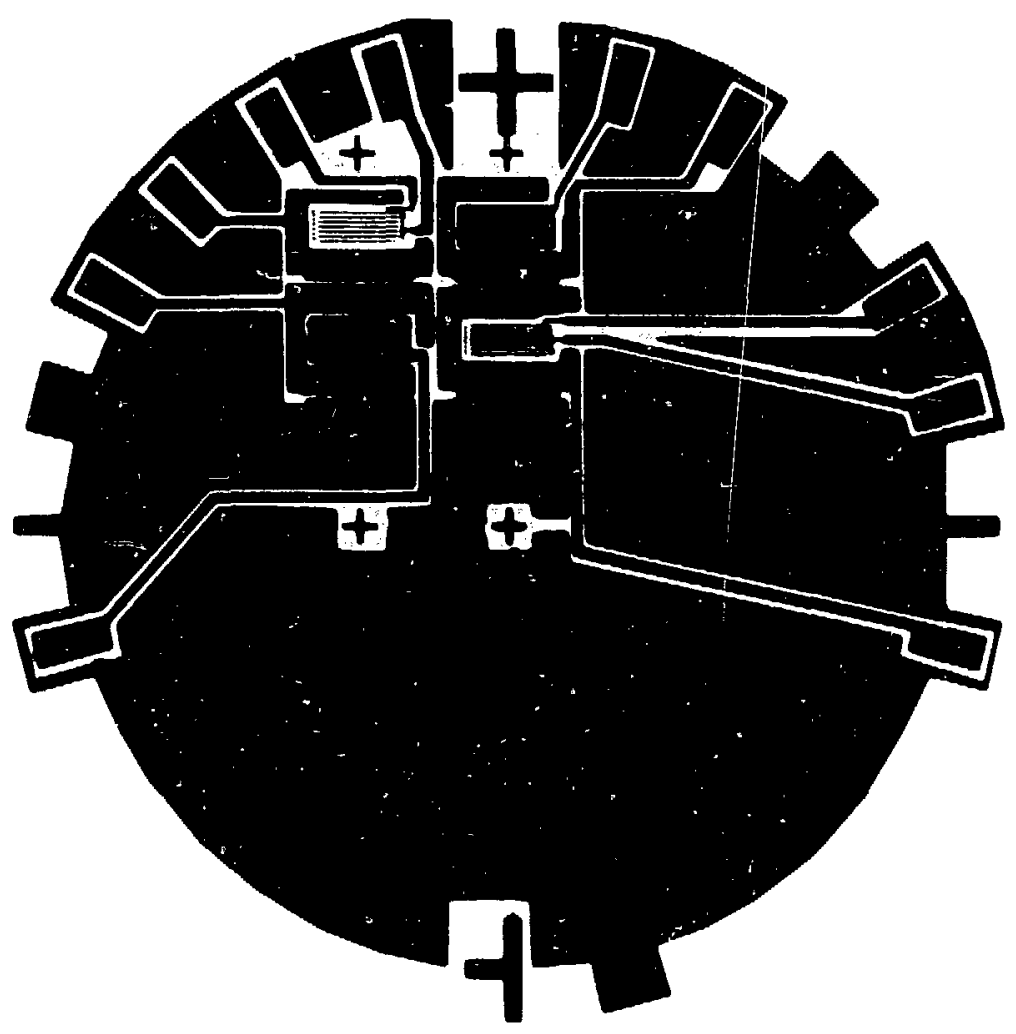

Fig. III-6. Nearest neighbor arrays.

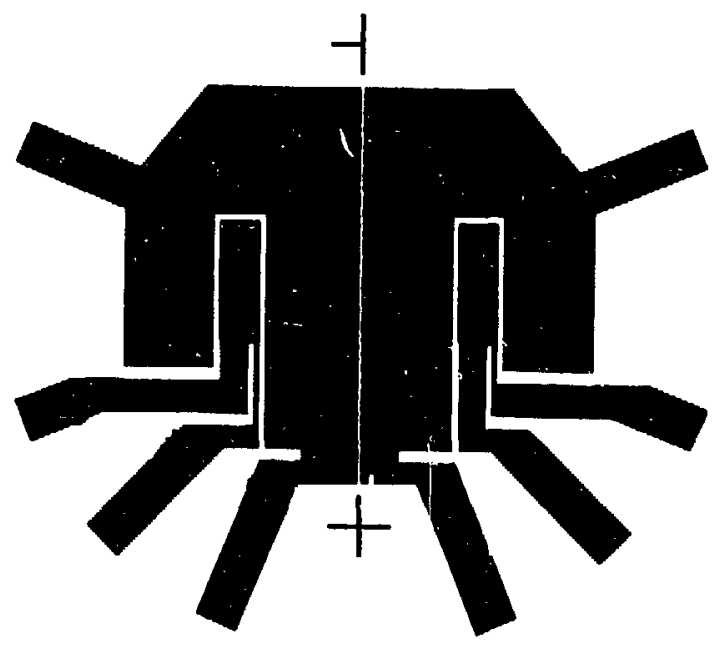

(a)

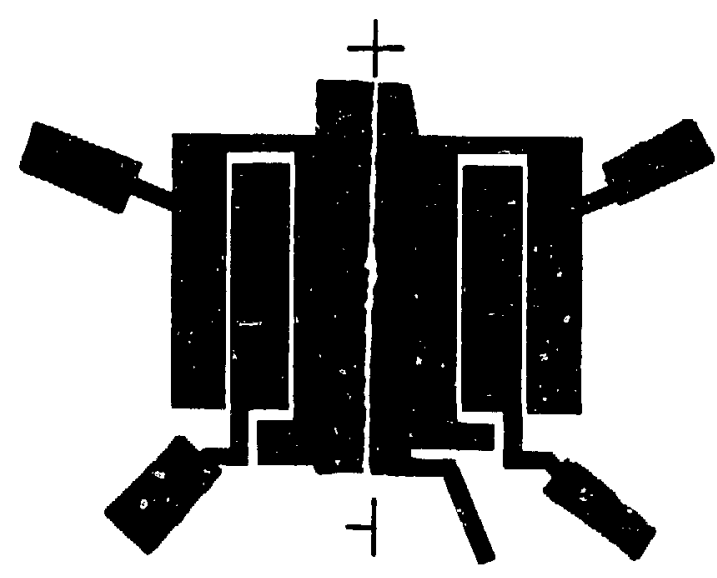

(b)

FIg. III-7. Dual trlode for leakage evaluation. 
was applied to only one triode. A small-diameter nickel wire was positioned over this device to serve as an anode with approximately 100 -mil vertical spacing. Therefore, this device had essentially an unrestricted pumping path to the vacuum pump. Grid-cathode leakage on both triodes was monitored during the activation cycle. Typical results are shown in Fig. III-8.

These data show that with unrestricted pumping, the leakage on the cathode-coated device stabilized at $u 3 \mathrm{M} \Omega$ after $3 \mathrm{~h}$ at temperature and also indicate that some of the hydrocarbon residue had reached the uncoated device.

This test was then repeated using the regular anode substrate in place of the nickel wire with a 40-mil separation hetween substrates. This provides the restricted pumping typical of TICs. Results are shown in Fig. III-9.

It is obvious from this test that restricted pumping during activation enhances the deposition of leakage-causing materials. This test was performed with both substrates heated simultaneously. The anode-to-anode shield leakage was in the megohm range. Additional tests were performed with the anode substrate heater turned off. Hydrocarbons were observed to condense on the relatively cool surface, promoting an order of magnitude increase in anode-anode shield leakage. The heater pattern used on the aforementioned substrates is shown in Fig. III-10.

The current assembly technique for the two substrates uses three $40-x$ 50-mil platinum straps bonded to each substrate at $120^{\circ}$ intervals. The substrates are then aligned with respect to each other. By viewing the "cross" and "tee" alignment keys shown on the circuit patterns (Fig. III-7), the heater windows permit viewing these keys. Nickel shims welded to the straps govern the substrate separation. With the substrates aligned and spaced by the shims, the corresponding straps are welded togethor external to the substrates. $U_{n^{-}}$ fortunately, these straps also create a heat sink for three areas of the substrates. Temperature measurements indicated a $40-50^{\circ} \mathrm{C}$ differential from the substrate center to the area of a strap with a corresponding potential for in-creased leakage between elements in this area.

2. Resistive Leakage - Improvements to Date. Based on the measurements and mechanisms observed in the tests described above, three obvious approaches to reduce the leakage were investigated.

o Minimize the amount of photoresist used in the cathode mixture.

o Reduce the effects of the poor pumping path.

- Redesign the heater to provide more uniform substrate temperature. 


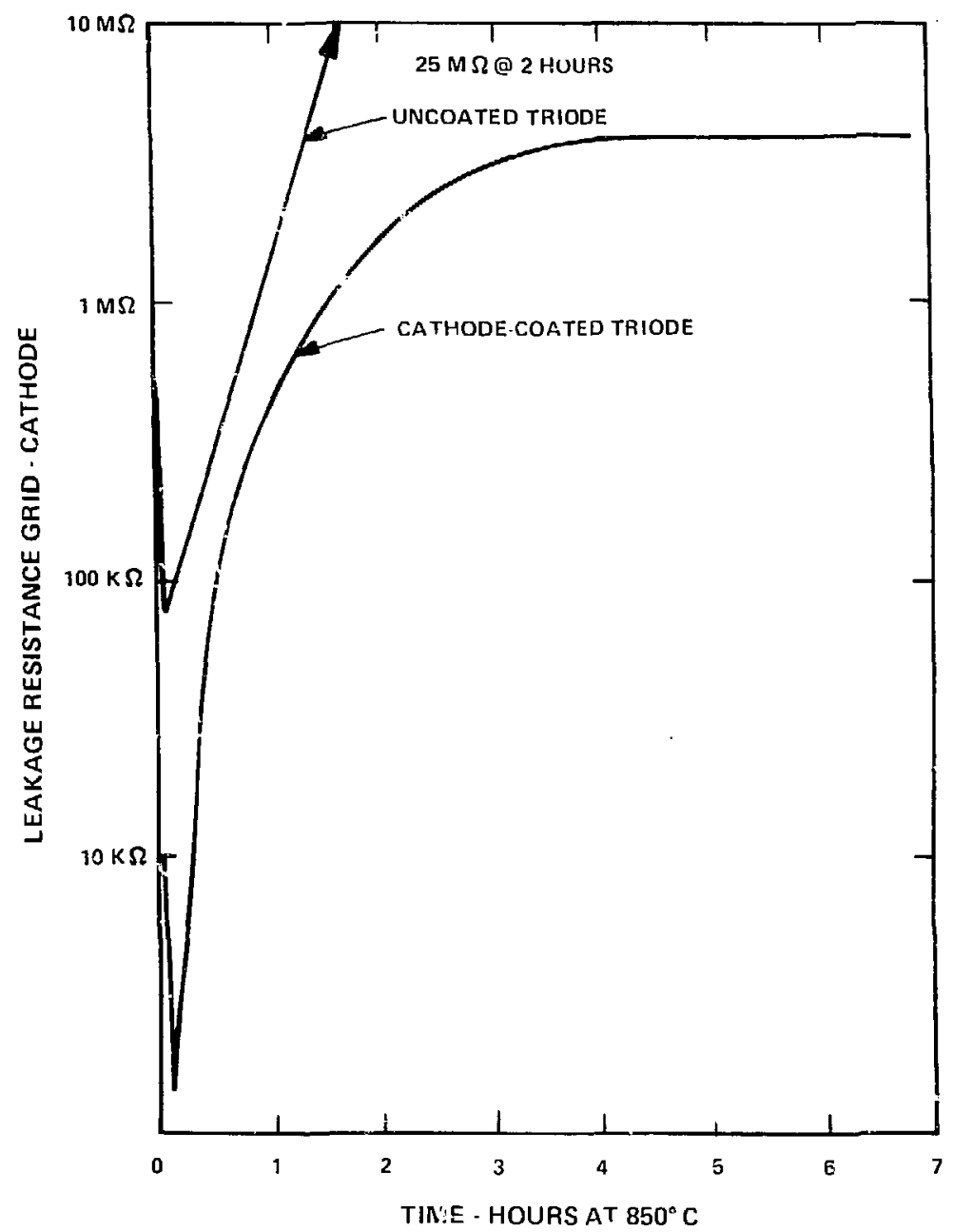

Fig. III-8. Laakage vs time for a triode with an unrestricted pumping path. 


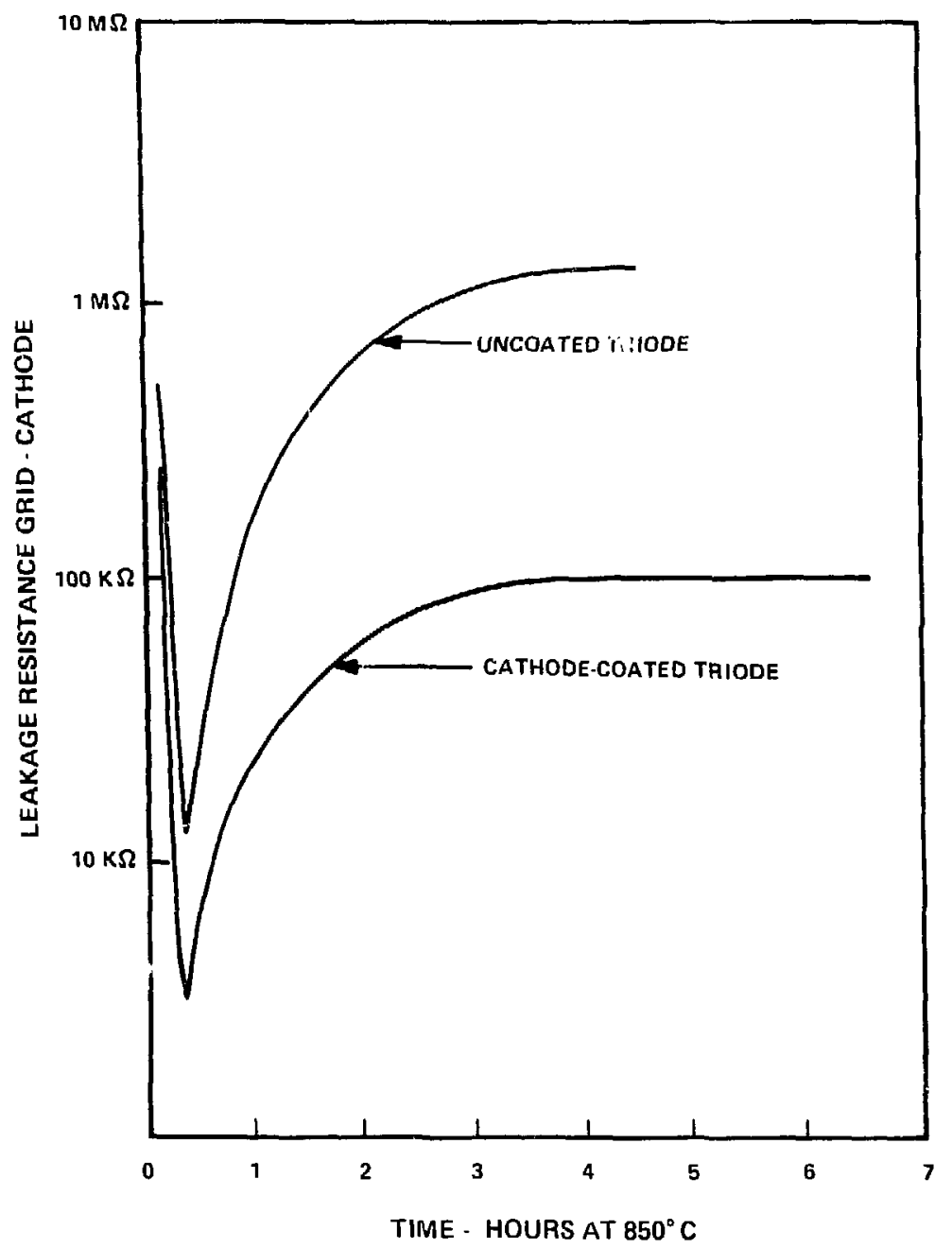

Fig. III-9. Leakage vs time for a triode w1th a restricted pumping path. 
Two 1imitations imposed on a reduction of photoresist used in the mixture are (1) a minimum quantity is required to define photolithographic lines and (2) a minimum quantity is necessary to serve as a binder for the cathode powder. an evaluation of the powder-resist mixture used in the aforementioned tests indicates that additional thinning of the resist would not be practical. However, other modifications of the coating process that result in a ret decrease in photoresist are believed worthwhile; they are listed below.

1. A decrease in the coating thickness as applied to the substrate. Because the powder-resist mixture is applied by spinning, an increase tn spin speed accomplishes this. The cathode thickness was reduced by approximately $30 \%$.

2. A decrease in the polymerization of the photoresist. Unpolymerized resist should be removed by developer. Also, polymerization increases the length of hydrocarbon chains and the difficulty in vacuum pumping; therefore, the ultraviolet exposure time of the resist was reduced to the minfmum for acceptable line delineation. Also, emulsion photomasks were substituted for metal-on-glass photomasks. The emulsion surface reduces light scattering during exposure.

3. An improvement in the developing and postdevelopment process to minimize surface contaminants and insure removal of all unpolymerized resist. A three-bath development sequence was initiated--two developer baths followed by a butyl-acetate rinse, all incorporating ultrasonic agitation. This process was then followed by a 30-min, $120^{\circ} \mathrm{C}-a 1 r$ postbake and a $10-\mathrm{min}$ sputter-etch in argon.

The effects of the poor pumping path were alleviated by incorporating a much longer pumping time before activation $(72 \mathrm{~h})$. This is followed by a preactivation bakeout at $400^{\circ} \mathrm{C}$ for $15 \mathrm{a}$. The substrates are then heated to $850^{\circ} \mathrm{C}$ to complete the activation process. Experiments were performed to vary the bakeout time and temperature and also the rate of heating to $850^{\circ} \mathrm{C}$. The times, temperatures, and rates appear to be optimum.

The heater was redesigned using a computer analysis to provide a more uniform wafer temperature, compensating for strap losses, etc. The revised pattern is shown in Fig. III-11.

A number of dual triodes were made using the aforementioned process modifications. The grid-cathode leakage distribution (after stabilizing at $850^{\circ} \mathrm{C}$ ) obtained in these tests is shown in F1g. III-12. These data averaged 


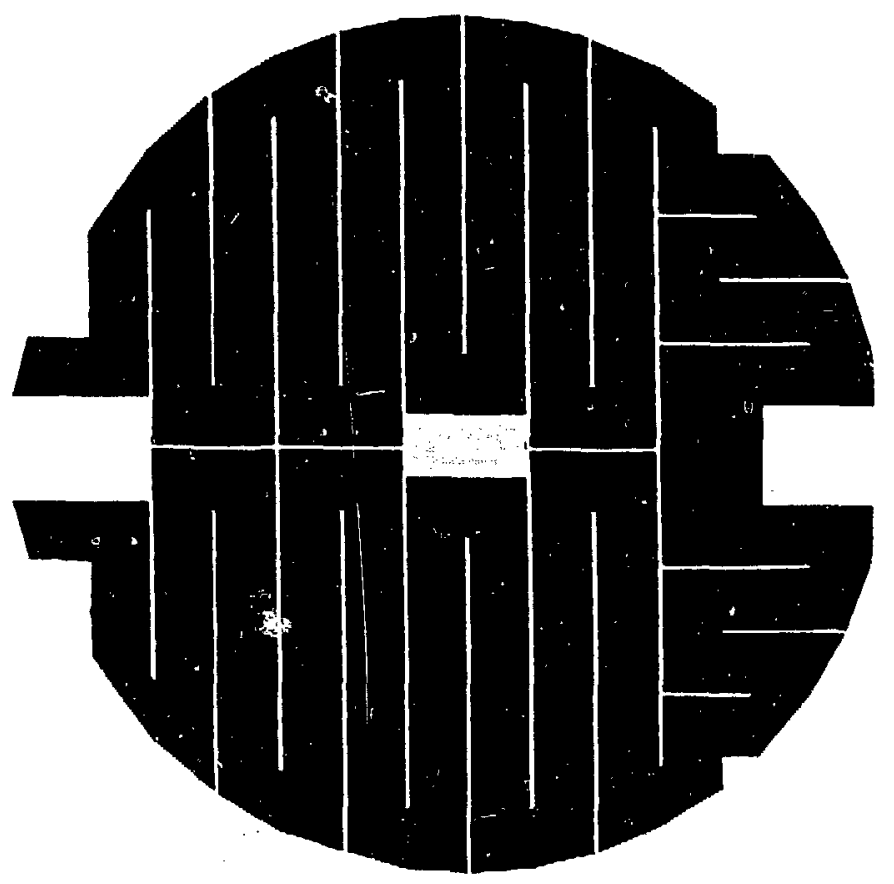

Fig. III-10. Original substrate heater design.

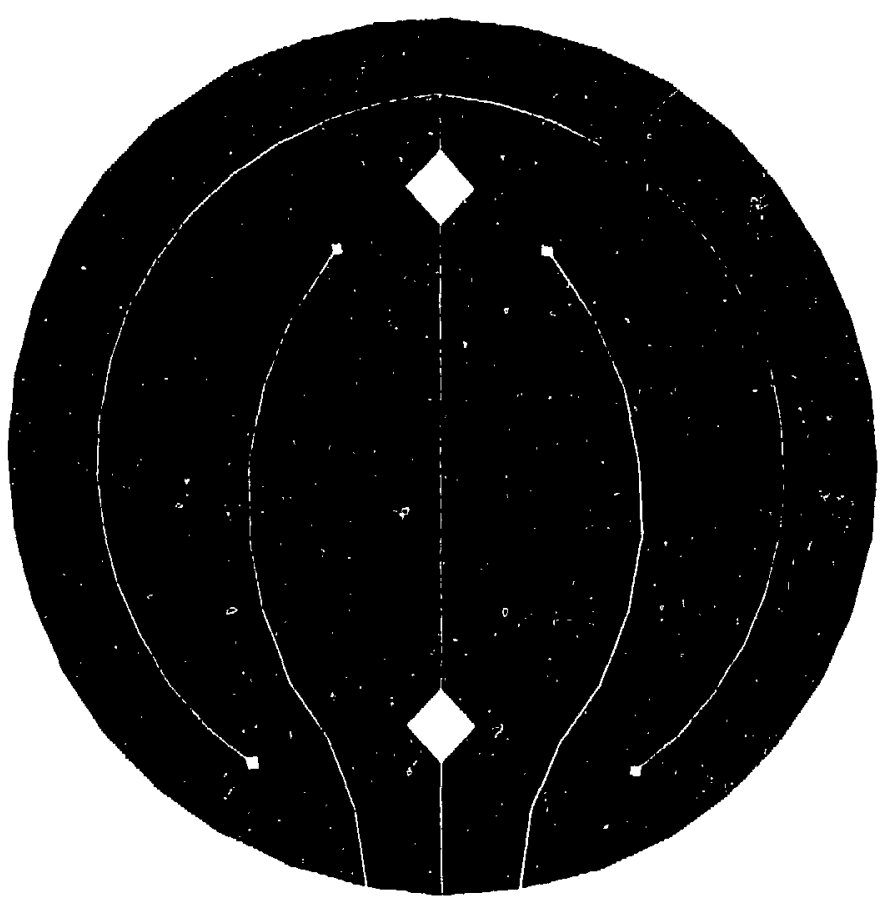

FIg. III-11. Revised substrate heater design. 
$960 \mathrm{k} \Omega$. While this is a considerable improvement over the previous 100-k $\Omega$ level, the distribution shown in Fig. III-12 indicates further effort is required for ultimate Jevels of integration. However, this leakage level has been 1mproved stificiently to permit the effective operation of circuits with device densities in the 1000 to 10,000 devices $/ \mathrm{In}^{2}$ regime.

3. Kesist1ve Leakage - Future Improvements. A significant Improvement could be made if $1 \mathrm{t}$ were possible to heat individual substrates (with coated cathodes) to $850^{\circ} \mathrm{C}$ in a vacuum before they were assembled as pairs of substrates and mounted in the device package. This vacuum firing could be performed in a vacuum oven, essentlally corresponding to the "unrestricted pumping path" test of Fig. III-8. Unfortunately, the conventional cathode material, barium carbonate, is reduced to BaO during this temperature cycle. BaO, if exposed to alr, reacts with the molsture in the alr to form barlum hydroxide that, as a lcw melting compound, induces excessive sintering and fusion of the cathode coating, with loss of emission. Therefore, activation, assembly, and packaging would have to be accomplished under vacuum (a technique employed effectively by Plessey a number of years ago for similar reasons in fabrication of vacuum tubes for transoceantc cables). In principle, this technique should be applicable though not approprlate for a laboratory-scale R\&D effort.

A more promising approach, therefore, might be the use of barium aluminate as a cathode material. The key factor pertaining here is its ability to withstand repeated exposure to air after activation without deterioration. Coppola and Hughes ${ }^{3}$ have shown the behavior of a pressed cathode containing barium aluminate under conditions of repeated air exposure (FIg. III-13). As shown, the cathode was able to obtain the inttial emission level through five cycles. The TIC would require only one cycle to complete processing. TIC cathodes would be activated in a vacuum system with an unrestricted pumping path, then assembled. Preliminary work performed at Los Alamos using bariun aluminate has also shown promise, although much more work must be done to create a cathode material with proper characteristics for application to the TICs. 4. Spurtous Emission. Spurious emission is defined as emission from elements other than the cathode. Because all elements, Including the wires bonded to the substrates, are at or near cathode temperature in the TIC assembly, the possibility for cimission extsts if barlum or barium oxide is present on the element. Barium or barlum oxide may be evaporated from the cathode material during activation or over life. It may also be left on the substrates 


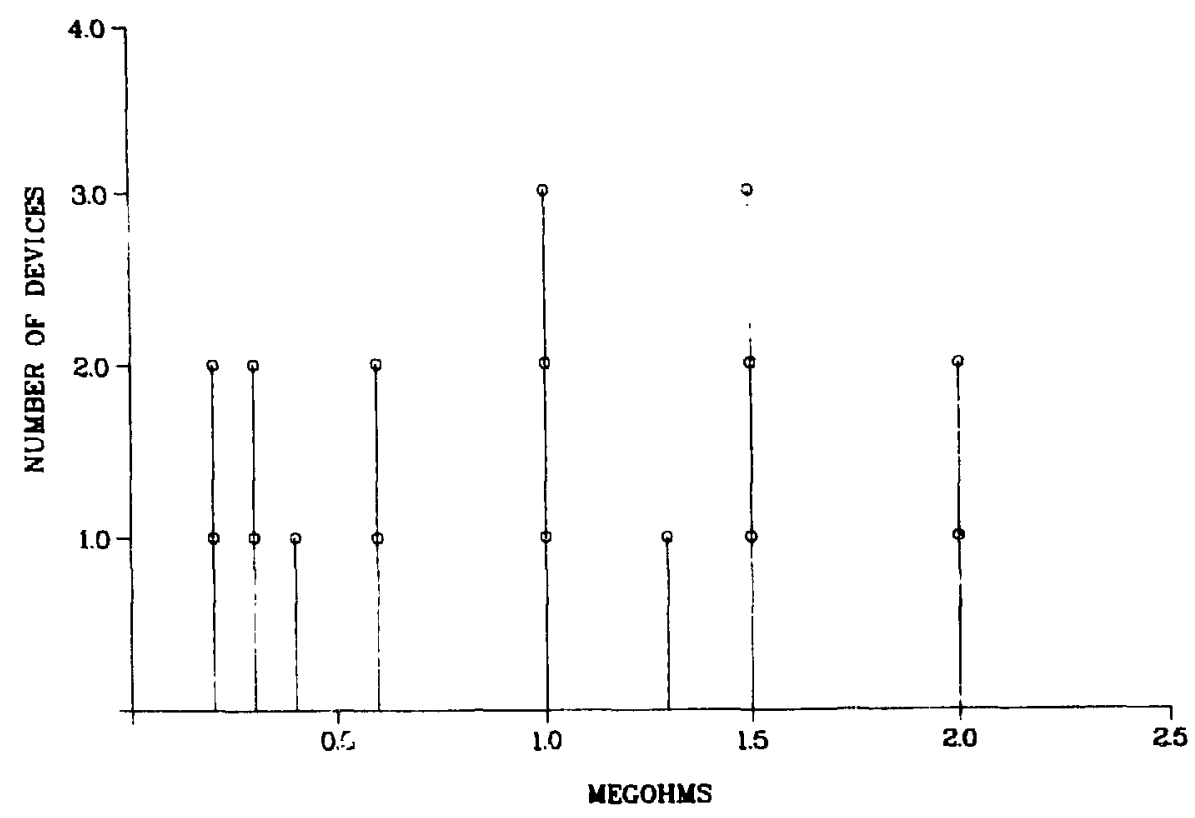

Fig. III-12. Grid-to-cathode leakage distribution.

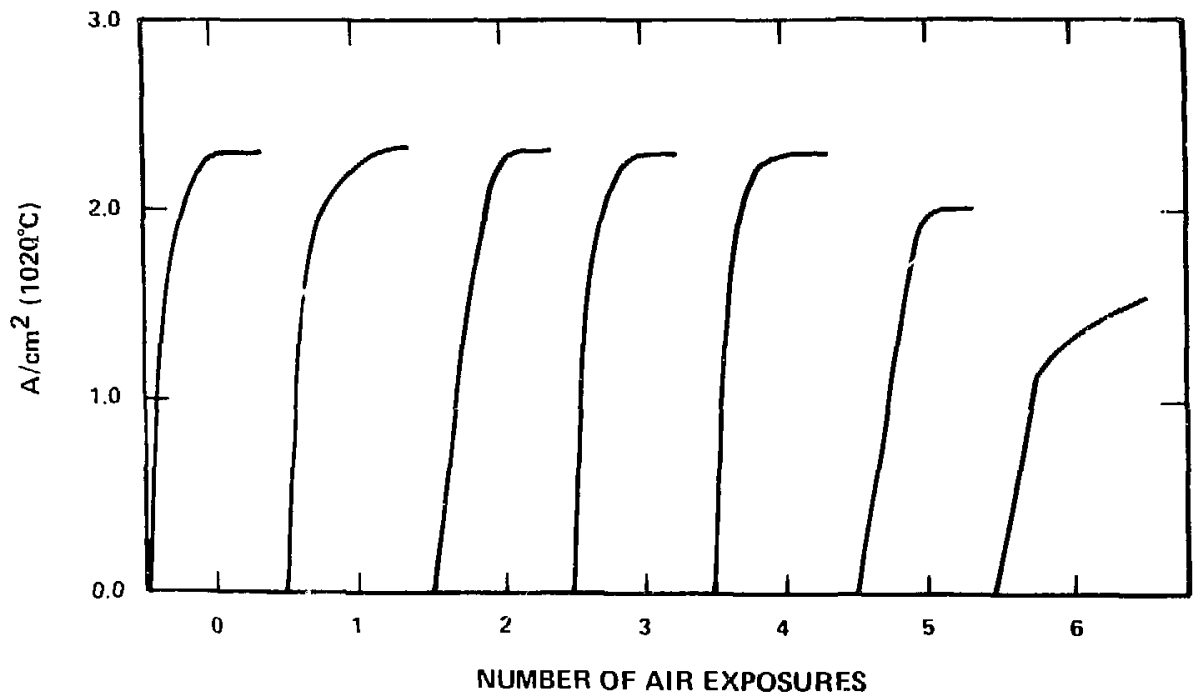

Fig. III-13. Behavior of a pressed cathode containing bartum aluminate under conditions of repeated air exposure. 
as a result of incomplete development and rinse. In genural, all of the improvements incorporated in the process to reduce leakage also act to reduce spurious emission. The use of titanium as the upper layer of grids, anodes, shields, etc., also helps. Hot ticanium reacts with barlum to form barfum titanate; it also reduces $\mathrm{BaO}$ and absorbs the oxygen. The platinum bond pads and bond wires remain a problem. Sowever, by reducing their area and shielding by a ground plane, their effects can be minimized. It is also possible to use titanium bond wires or NiTi-brazed lead frames. As with leakage, the spurious emission effects have been sufficlently controlled to permit circuit operation at levels of integration exceeding several thousand devices per square inch.

5. Conclusions on Process Dependent Factors Influencing Level of Integration. Recently a major effort has been made to reduce the parasitic resistive leakage between elements. Experiments confirm that the major source of leakage is residue from the hydrocarbons present in the photoresist that is used as a photosensitive binder to define the cathode pattern. Leakage has been experimentally observed to be increased by the poor pumping path caused by the closely spaced sapphire substrates, by nonuniform heating of the substrates, and by excessive polymerization of the photoresist.

A number of experiments were performed that have resulted in several process modifications to reduce the leakage. The modifled sequence with the largest effect is to (1) minimize the amount of photoresist used in the cathode mixture, (2) do a 10-minute sputter etch to remove surface contamination after the normal photoresist developing techniques are completed, (3) use a much longer pumplng time $(72 \mathrm{~h})$ to remove as many volatiles such as photoresist solvents before activating at high temperature and thereby reduce the effects of the poor pumping path, and (4) bake at $400^{\circ} \mathrm{C}$ for $15 \mathrm{~h}$ before activation to drive off as many remaining volatiles as possible.

In addition, the heater was redesigned to provide a more uniform substrate temperature. This approach minimizes the condensation of hydrocarbons on the cooler areis and reduces edge element leakage.

Spurious emission from electrodes such as grids, anodes, shields, and ground planes is caused by cathode materlal being deposited on the electrodes during the cathode activation process. Emission is minimized by using titanium as the top layer for these electrodes because cathode mate:ial on titanium produces a short-lived cathode. On the other hand, platinum with deposited 
cathode material produces a much better parasitic cathode. Spurious emission was further reduced by minimizing the platinum area used for bond pads. Cathodes are activated and the devices are aged for several hours until the spurious emission is reduced to a negligible level by the chemical reaction of the titanium with the cathode materials.

The interelectrode leakage resistances were measured on a number of test devices with typical values ranging from several megohms upward. Most of the leakage paths were geometrically dominated by laakage from the interconnect metalization from device to bond pad, not the device itself. Therefore, the internaily connected devices of actual integrated circuits are expected to have substantially higher leakage resistances.

While these problems appear to be solved for simple TICs, leakage and spurious emission nust be continuously monitored as TICs become more complex. The additional cathode area required by more complicated circuits, smaller lines and spacings, and process changes made to enhance other parameters all. could contribute to increased sensitivity to leakage and emission.

D. Process Indeperdent Factors Influencing Level of Integration

1. Device and Circuit Modeling/Verification of Effects. Recause of the nature of TICs and the complex interaction between devices, a substantial device modeling and circuit analysis capability is required to accurately predict performance of a moderately complex TIC. A TIC device has characteristics that are very similac to a conventional vacuum triode. The major difference is that the TIC device, when used in an integrated circuit, can be affected by parasitic electrostatic interactions that can modify the expected device current. Previous analyses and experiments have suggested that the TIC device characteristics can be described by

$$
i_{P}=k\left(v_{G}+v_{P} / \mu+\Sigma v_{S} / \mu_{S}\right)^{3 / 2},
$$

$$
\text { where } \begin{aligned}
{ }_{\mathrm{i}} & =\text { anode current, } \\
{ }_{\mathrm{K}} & =\text { perveance, } \\
\mathrm{v}_{\mathrm{G}} & =\text { grid-to-cathode voltage, } \\
\mathrm{v}_{\mathrm{P}} & =\text { aiode-to-cathode voltage, } \\
\mathrm{v}_{\mathrm{S}} & =\text { voltage on another electrode } \mathrm{s} \text { in the circuit, } \\
\mu & =\text { the triode amplification factor, and }
\end{aligned}
$$


$H_{S}$ tescribes the effect of electrode $S$ on the tube characteristics The variational anode current is

$$
d i_{P}=\frac{\partial i_{P}}{\partial v_{G}} d v_{G}+\frac{\partial i}{\partial v_{P}} d v_{P}+\frac{\partial i_{P}}{\partial v_{S}}=g_{m} d v_{G}+\frac{1}{r_{P}} d v_{P}+g_{m s} d v_{S} \text {, }
$$

where, for simplicity, it is assumed that only the grid, anode, and one additional shield electrode influence the anode current. Then

$$
\begin{aligned}
& \mathrm{g}_{\mathrm{m}}=\partial \mathrm{i}_{\mathrm{P}} / \partial \mathrm{v}_{\mathrm{G}}=1.5 \mathrm{~K}\left(\mathrm{v}_{\mathrm{G}}+\mathrm{v}_{\mathrm{P}} / \mu+\mathrm{v}_{\mathrm{S}} / \mu_{\mathrm{S}}\right)^{1 / 2}=1.5 \mathrm{k}^{2 / 3_{\mathrm{i}_{\mathrm{P}}}^{1 / 3},} \\
& \frac{1}{\mathrm{r}_{\mathrm{p}}}=\partial \mathrm{i}_{\mathrm{P}} / \partial \mathrm{v}_{\mathrm{P}}=\mathrm{g}_{\mathrm{m}} / \mu, \text { and } \\
& \mathrm{g}_{\mathrm{ms}}={ }^{2} \mathrm{i}_{\mathrm{P}} / \partial \mathrm{v}_{\mathrm{S}}=\mathrm{g}_{\mathrm{m}} / \mu_{\mathrm{S}} \text {, or } \\
& \mathrm{g}_{\mathrm{m}} \mathrm{r}_{\mathrm{p}}=\mu \text { and } \\
& \mathrm{g}_{\mathrm{ms}} \mathrm{r}_{\mathrm{p}}=\mu / \mu_{\mathrm{S}} .
\end{aligned}
$$

These equations give rise to the linear equivalent circuits shown in Fig. III-14.

Equation (III-1) can also be lised to calculate the gain and Ac bias of the $\mu / 2$ gain stage shown in Fig. III-15. Note that the calculations include the effects of the ground shield and the effects of the anode and cathode shields of both devices. From Eq. (III-1),

$$
\begin{aligned}
& i_{\mathrm{P} 1}=\mathrm{K}_{1}\left(\mathrm{v}_{\mathrm{G} 1}+\mathrm{v}_{\mathrm{P} 1} / \mu_{1}+\mathrm{v}_{\mathrm{Pl}} / \mathrm{u}_{\mathrm{S} 1}+\mathrm{v}_{\mathrm{PP}} / \mu_{\mathrm{P} 1}\right)^{3 / 2} \text { and } \\
& i_{\mathrm{P} 2}=\mathrm{K}_{2}\left[\left(\mathrm{v}_{\mathrm{PP}}-\mathrm{v}_{\mathrm{P} 1}\right) / \mu_{2}-\mathrm{v}_{\mathrm{Pl}} / \mu_{\mathrm{G}} \cdot \mathrm{v}_{\mathrm{Pl}} / \mu_{\mathrm{S} 2}\right]^{3 / 2},
\end{aligned}
$$

where $\mu_{1}$ and $\mu_{2}$ are the amplification factors of the bottom and top triodes, respectively. If $i_{P 1}=i_{P 2}$, then Eqs. (III-8 and -9) can be solved for the anode voltage $v_{P 1}$ 


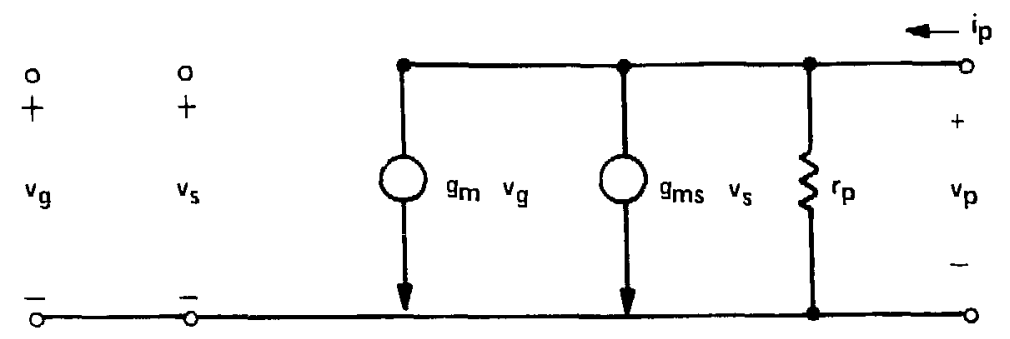

(a)

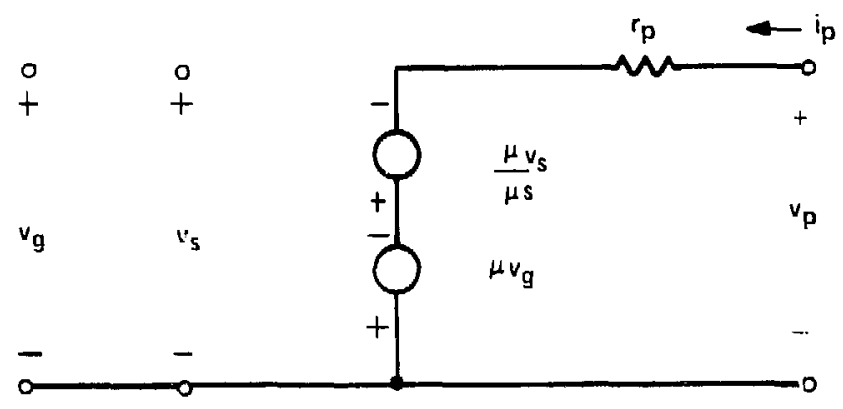

(b)

Fig. III-14. Linear equivalent circuits for a TIC gain device. (a) Controlled current source. (h) Controlled voltage source.

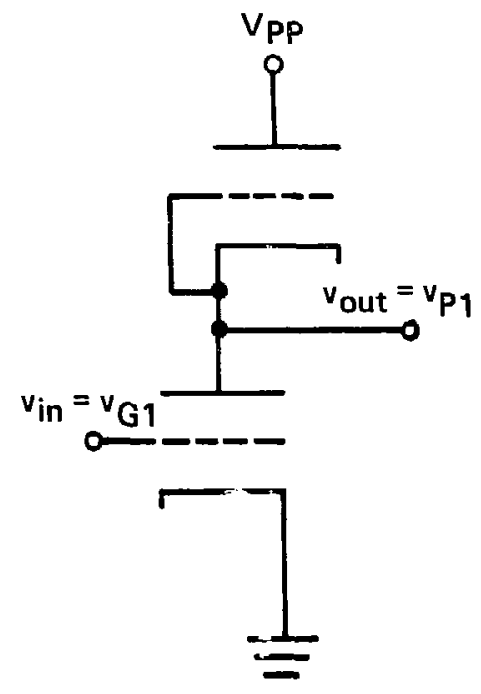

(a)

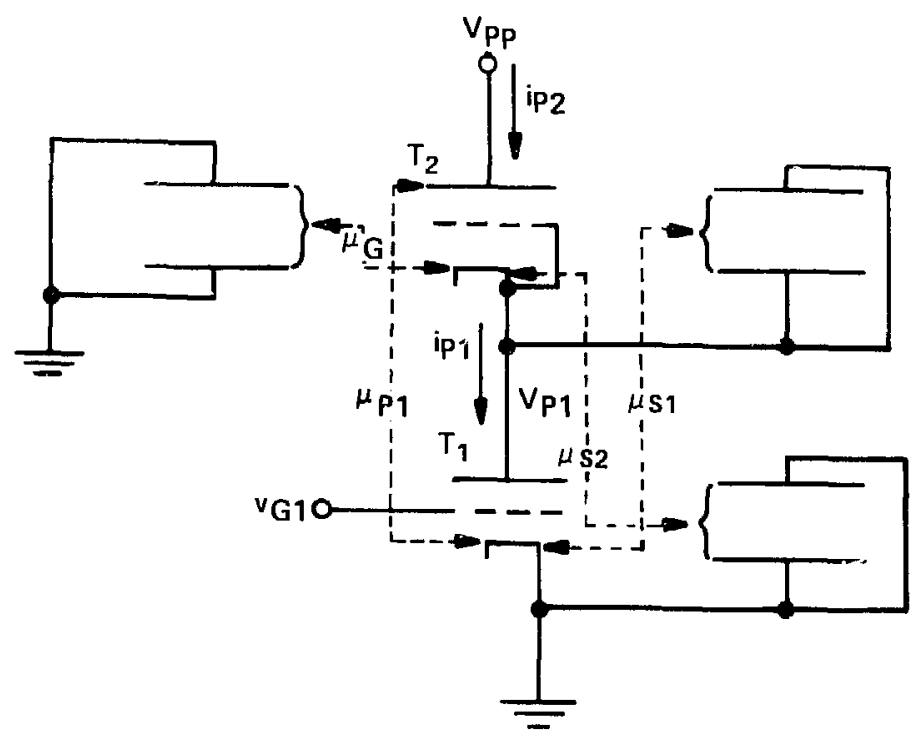

(b)

Fig. III-15. TIC gain stages. (a) $\mu / 2$ with active load. (b) $\mu / 2$ including ground, anode, and cathode shields. 


$$
v_{P 1}=\frac{-v_{G 1}+v_{P P}\left(\gamma / \mu_{2}-1 / \mu_{P 1}\right)}{1 / \mu_{1}+1 / \mu_{2}+\gamma\left[1 / \mu_{2}+1 / \mu_{S 1}+1 / \mu_{G}\right]},
$$

where $\gamma=\left(K_{1} / K_{2}\right)^{2 / 3}$. The small signal voltage gain is

$$
G_{v}=-1 / D
$$

and the de bias voltage is

$$
\mathrm{V}_{\mathrm{Pl}}=\mathrm{V}_{\mathrm{PP}}\left(\gamma / \mu_{2}-1 / \mu_{\mathrm{P} 1}\right) / \mathrm{D},
$$

where

$$
D=1 / \mu_{1}+1 / \mu_{S 1}+\gamma\left(1 / \mu_{2}+1 / \mu_{S 2}+1 / \mu_{G}\right)
$$

If Tube 1 and Tube 2 in Fig. III-15 are identical, then $\gamma=1$ and $\mu=\mu_{1}=\mu_{2}$. Then, if $\mu_{S 1}, \mu_{S 2}$, and $\mu_{G}$ are large, $G_{v}=-\mu / 2$ and $v_{P I}=v_{P P} / 2$.

As an example, two 60-mil-long test devices were placed end-to-end on the same substrate pair. The measured $\mu$ 's are

$$
\begin{aligned}
& \mu_{1}=\mu_{2}=23, \\
& \mu_{G}=64, \\
& \mu_{S 1}=348, \\
& \mu_{S 2}=344, \text { and } \\
& \mu_{P 1}=1254 . \text { For } v_{P P}=200 \mathrm{~V}, \text { the measured and calculated gain and dc }
\end{aligned}
$$

levels are

$\begin{array}{ccc} & \text { Calc } & \text { Meas } \\ \mathrm{G}_{\mathrm{v}} & -9.2 & -9.5 \\ \mathrm{~V}_{\mathrm{P} 1} & 78.7 \mathrm{~V} & 83.4 \mathrm{~V} .\end{array}$

Note that the interactions have a substantial effect, for without them the gain $\mathrm{G}_{\mathrm{v}}$ and the bias point $\mathrm{V}_{\mathrm{P} 1}$ would be -11.5 and $100 \mathrm{~V}$.

2. Device Interactions As stated in the March 1982 Statement of Work, two types of device-to-device interactions are important in the TICs: electron interactions and electrostatic interactions. Electron interactions occur when electrons are not confined to the appropriate device (or devices). For 
proper operation of an integrated circuit using TICs, electrons emitted from the cathode of a given device must be collected by the anode of that device and not attracted to neighboring electrodes that might be at different potentials. Electrons can be confined to the appropriate device by means of shield electrodes. If the shield potential is properly chosen, a zero potential line (with respect to the cathode) is formed that confines the electrons to that device. In effect, this zero potential line forms an electrostatic bottle. Electrostatic interactions are illustrated in Figs. III-3 and -5 . It is desired that the grid-cathode structure GK of a particular device not have the electric fields at its surface appreciably modified by potentials applied to a neighboring grid cathode structure GK2 or by a neighboring anode or anode shield. This can be achieved by adjusting device-to-device spacing to a distance at which the fields from other elements are compatible with circuit requirements. That is, low gain digital circuitry would allow relatively close spacing, whereas high gain linear circuitry would require increased isolation. In evaluating the relative importance of these two effects, it should be noted that electron containment can be achieved with the appropriate potential on a shield whose width is comparable to the device electrode widths, whereas electrostatic interactions decrease continuously with increasing shield width. Therefore, a thorough understanding of electrostatic interactions vs geometry will be required to accurately project future levels of integration. For this reason, a number of devices were fabricated and the electrode interactions were measured. These measurements were then compared with computer calculations; agreement was found to be good. As a result, the computer calculations can now be used to determine the reguired shielding for the needed degree of isolation. However, a limitation should be noted; that is, the computer code solves the two-dimensional form of Laplace's equation so that only the interactions between adjacent devices such as devices $a$ and $d$ or $b$ and $c$ in Fig. III-16, with electrode lengths much greater than electrode widths, can be calculated. A three-dimensional code will be required to calculate interactions between diagonal or end-to-end devices such as illustrated in Fig. III-16 or between devices with other aspect ratios.

The four-device nearest-neighbor array shown in Fig. III-16 was used to measure the device interactions. Electrostatic interactions were characterized as they were in the previous section in terms of the electrode $\mu^{\prime} s$, where the $\mu$ of electrode $i$ with respect to the cathode of device $j, \mu_{1 j}$, is defined as 

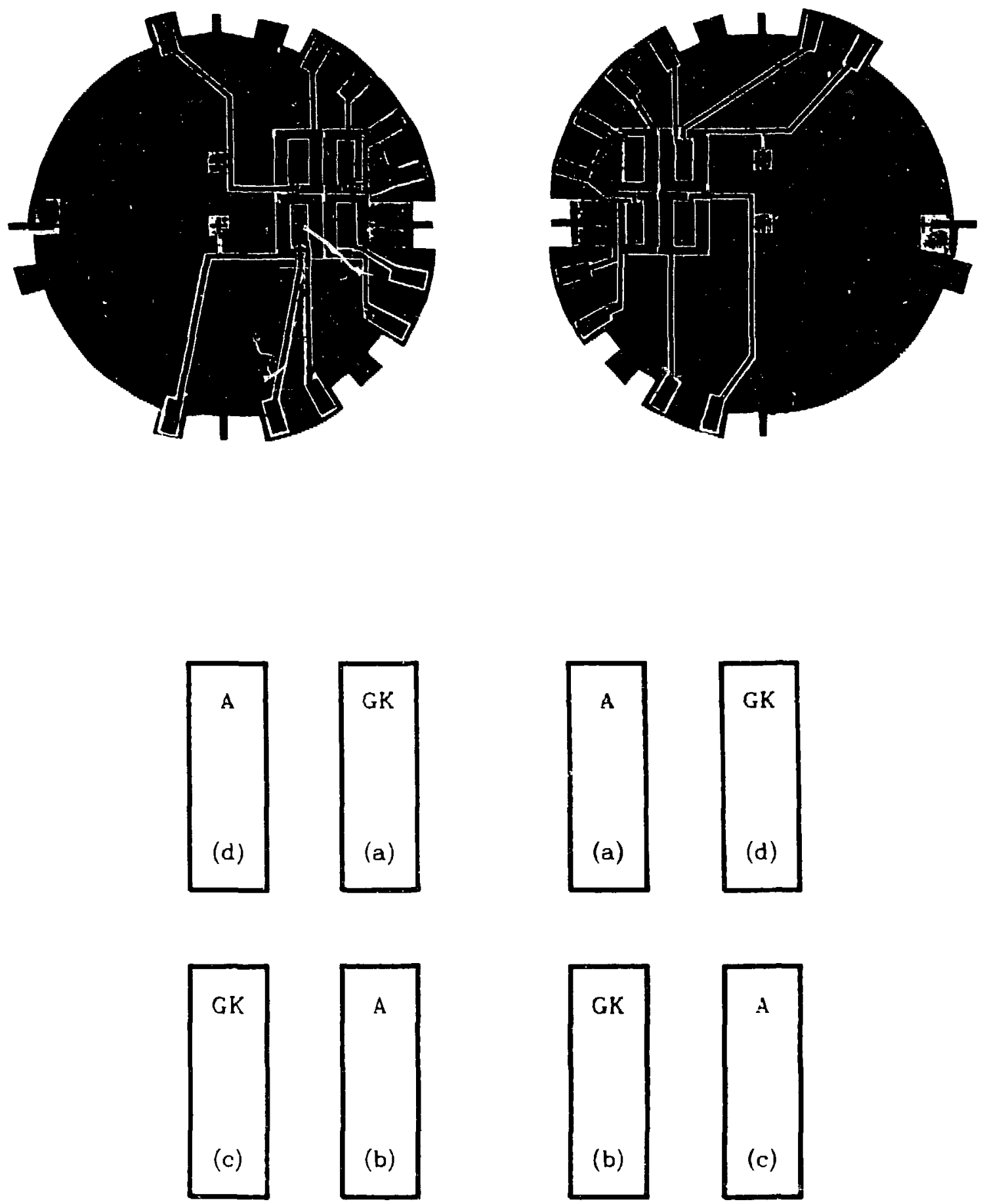

Fig. III-16. Four-device, nearest-neighbor array to evaluate device interactions. 
$\mu_{i j} \equiv-\frac{\partial v_{i}}{\partial v_{G j}}$

The small signal open circuit voltage gain of a conventional triode is

$$
\mu \equiv-\frac{\partial v_{p}}{\partial v_{G}}
$$

or in the notation of Eq. (III-14), the gain of triode $j$ is

$$
\mu_{j} \equiv u_{P_{j}}=-\frac{\partial v_{P j}}{\partial v_{G j}} .
$$

The interaction of electrode $i$ with device $j$ is characterized by the relative influence of electrode $i$ compared with grid $j$ or

$$
\frac{\mu_{j}}{\mu_{i j}} .
$$

If a device has two electrodes, $a$ and $b$, it is said to have $1 \%$ interaction with device 1 if

$$
\mu_{1}\left(\frac{1}{\mu_{a 1}}+\frac{1}{\mu_{h 1}}\right)=0.01 \text {. }
$$

The electrode $\mu^{\prime} s$ that affect the gain of the basic $\mu / 2$ gain stage are shown in Fig. III-17. In order to simplify the gain equation, the $\mu$ 's of the anode shield and cathode shield can be combined into a single $\mu$, i.e.,

$$
\begin{aligned}
& \frac{1}{\mu_{\mathrm{S} 21}} \equiv \frac{1}{\mu_{\mathrm{AS} 21}}+\frac{1}{\mu_{\mathrm{KS} 21}}, \\
& \frac{1}{\mu_{\mathrm{S} 12}} \equiv \frac{1}{\mu_{\mathrm{AS} 12}}+\frac{1}{\mu_{\mathrm{KS} 12}} .
\end{aligned}
$$




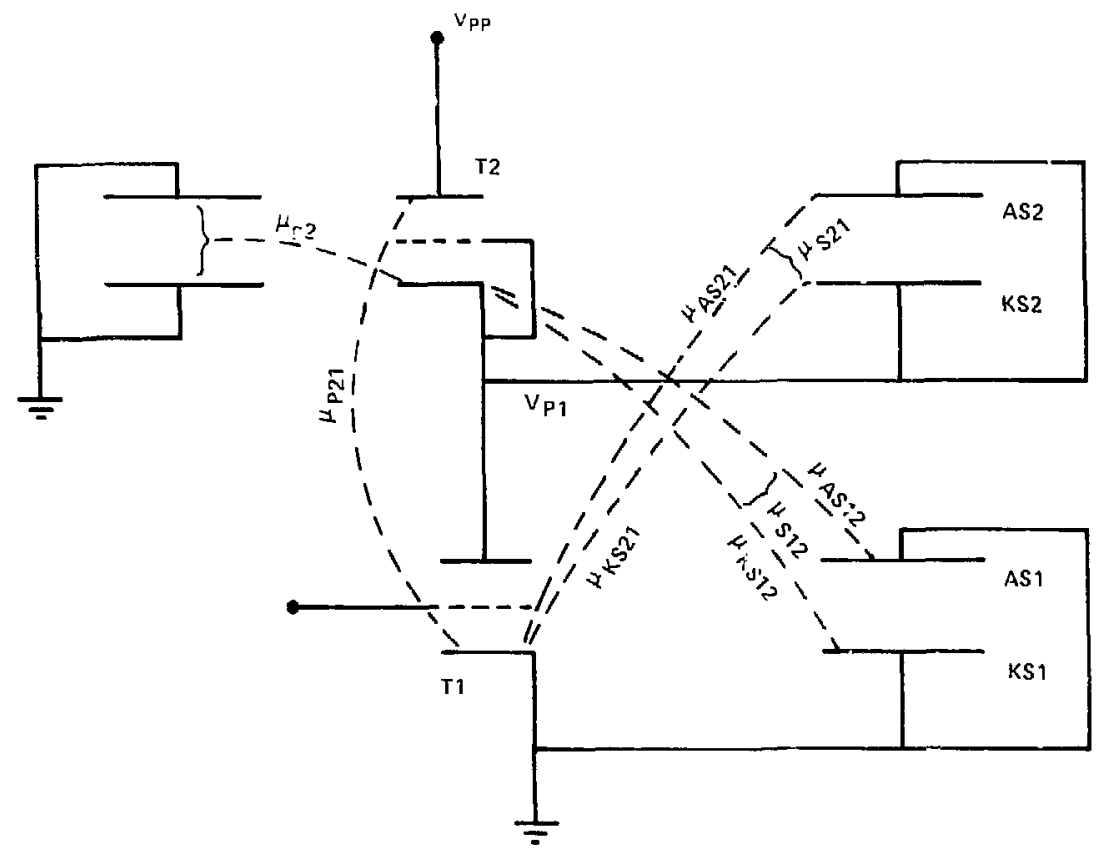

Fig. ILI-17. Basic TIC gain stage showing device interactions that affect the voltage gain. $\mathrm{T} 1$ is the gain scage and $\mathrm{l} 2$ is the load cevice. 
A number of device arrays were fabricated and the interelectrode $\mu$ 's were measured. The devices were operated in a bell jai on the vacuum system because the bell jar could accommodate up to 26 conner-ans to the device (the header for the vacuum package has only 11 pins). The disadvantage of leaving the devices on the vacuum system is the short device lifetime of one or two days.* Once the device was activated and aged enough to stabilize its characteristics, there was not enough time remaining to make all the measurements desired.

The arrays fabricated and tested are listed below.

A. 4-device array, 50-mil anode-cathode spacing, 7 cathode stripes

B. 4-device array, 40-mil anode-cathode spacing, 3 cathode stripes

C. 4-device array, 25-mil anode-cathode spacing, 7 cathode stripes

D. 2 devices separated by $120 \mathrm{mils}, 25$-mil anode-cathode spacing, single cathode stripi

Device array A was tested as a basic gain stage (gain device and load device as shown in Fig. III-17). The following configurations of the gain and load devices were tested to determine how device location and orientation affect device interactions (devices $a, b, c$, and $d$ are identified $\pm n$ Fig. III-16).

1. Adjacent devices (maximum interaction), load device outside (sees less ground plane, $\mu_{\mathrm{G} 2}$ larger) $\mathrm{a}=$ load device, $\mathrm{d}=$ gain device

2. Adjacent devices (maximum interaction), load device inside (sees more ground plane, $\mu_{\mathrm{G} 2}$ smaller, gain less than configuration 1 ) $\mathrm{d}=$ load device, $\mathrm{a}=$ gain device

3. Devices end-to-end, load device outside (less interaction than configurations 1 and 2) $a=$ load device, $b=$ gain device

4. Devices end-to-end, load device inside (lower $\mu_{\mathrm{G} 2}$, lower gain than configuration 3 )

$\mathrm{d}=$ load device, $\mathrm{c}=$ galn device

5. Diagonal devices, load device outside (the least interaction) $a=$ load device, $c=$ gain device

\footnotetext{
FTis is because of the large volume of the vacuum system compared with a package. In a practical sense, the vacuum system looks like an infinite source of water that slowly poisons the cathode, as described in a later section.
} 
6. Diagoral devices, load device inside

$\mathrm{d}=$ load device, $\mathrm{b}=$ gain device

The measured values of the interelectrode $\mu$ 's shown in Fig. III-17 are given in Table III-1 for the six configurations. In addition, the calculated voltage gain $\mathrm{G}_{\mathrm{v}}$ and the gain normalized to $\mu / 2, \mathrm{G}_{\mathrm{v}} /(\mu / 2)$, are given (array $\dot{A}$ did not live long enough in the bell jar to measure the gain of all configura-tions). Since the basic gain stage would have a voltage gain of $\mu / 2$ without interaction, the value of $G_{v} /(\mu / 2)$ is a measure of the degree of interacion for each configuration. Note that, as expected, adjacent devices have the most interaction, end-to-end devices have less, and diagonal devices have the least interaction.

TABLE III-1

INTERACTIUNS FOR 4-DEVICE ARRAY A

(device $\mu=50$ )

\begin{tabular}{|c|c|c|c|c|c|c|c|c|}
\hline $\begin{array}{l}\text { Config- } \\
\text { uration } \\
\end{array}$ & $\mu_{\mathrm{G} 2}$ & $\mu_{\mathrm{AS}} 21$ & $\mu_{\mathrm{KS} 21}$ & $\mu_{\mathrm{AS} 12}$ & $\mu_{\mathrm{KS} 12}$ & ${ }^{{ }^{\mu} 21}$ & $\mathrm{G}_{\mathrm{v}}$ & $\mathrm{G}_{\mathrm{v}} /(\mu / 2)$ \\
\hline 1 & 83 & 238 & 366 & 218 & 344 & 1130 & 14.8 & 0.592 \\
\hline 2 & 61 & 218 & 344 & 238 & 366 & 1100 & 13.9 & 0.556 \\
\hline 3 & 83 & 418 & 1640 & 396 & 1530 & 1730 & 17.0 & 0.680 \\
\hline 4 & 61 & 522 & 366 & 516 & 360 & 728 & 14.9 & 0.596 \\
\hline 5 & 83 & 2200 & 3220 & 3700 & 2380 & $>5000$ & 18.7 & 0.748 \\
\hline 6 & 51 & 4160 & 2460 & 2480 & 2940 & $>5000$ & 17.3 & 0.692 \\
\hline
\end{tabular}

Table III-2 compares interactions of the four different arrays. A con-parison of device test structures $A$ and $C$ shows that smaller anode-cathode spacing reduces interaction (and reduces device gain). However, array $B$ with 40-mil spacing has even lower interactions (and higher sain) than array $C$ with 25-mil spacing. This is because the cathode width of array B ( 3 stripes) is less than that $r^{r}$ array $C$ (7 stripes). For a given spacing, a narrower cathode reduces the interations because there is less cathode area to interact with. The gain of the widely spaced array $D$ is $93 \%$ of $\mu / 2$. This gain reduction is almost entirely due to the effects of the ground shield rather than device-to-device interactions. 
BASIC GAIN STAGE INTERACTIONS OF DIFFERENT DEVICE ARRAYS

(Arrays A, B, and C use two devices placed end-to-end.

Array D uses two adjacent devices spaced 120 mils apart.)

\begin{tabular}{|c|c|c|c|c|c|c|c|c|c|}
\hline Device & $\underline{\mu}$ & ${ }_{\mathrm{G}} \mathrm{Z}$ & ${ }^{\mu} \mathrm{AS} 21$ & $\mu_{\mathrm{KS} \text { 2 I }}$ & ${ }^{\mu} \mathrm{AS} 12$ & $\mathrm{U}_{\mathrm{KS} 12}$ & ${ }^{\prime} E 21$ & $\mathrm{G}_{\mathrm{v}}$ & $\mathrm{G}_{\mathrm{v}} /(11 / 2)$ \\
\hline A & 50 & 61 & 522 & 366 & 516 & 360 & 728 & 14.9 & 0.596 \\
\hline B & $3 j$ & 83 & 860 & 6.28 & 814 & 700 & 1308 & 13.3 & 0.760 \\
\hline C & 23 & 64 & 798 & 654 & 730 & 574 & 1254 & 9.2 & 0.800 \\
\hline$D$ & 25 & 188 & $30 \quad 000$ & 1428 & 25000 & 25000 & $>30000$ & 11.6 & 0.929 \\
\hline
\end{tabular}

Finally, the two-dimensional Laplace code was used to calculate interelectrode $\mu^{\prime} s$. Because the code is two-dimensional, the results are accurate only for electrodes with a large length-to-width ratio. As can he seen Erom Fig. III-16, this is reasonable only for interactions hetween adjacent devices ( $a$ and $d$ or $b$ and $c$ ). Calculated and measured values for adjacent devices with a 50-mil anode-to-cathode spacing are given in Table III-3 as well as calculated values for 40-, 30-, and 20-mil spacing. The agreement hetween measured and calculated values is quite good. It is also apparent from Table III-3 that, as the anode-cathode spacing is decreased, the degree of isolation improves while the voltage gain decrases.

TABLE III-3

IN'CERELECTRODE $\mu^{\prime}$ S FOR DIFEERENT ANODE-CATHODE SPACING

\begin{tabular}{|c|c|c|c|c|c|}
\hline & & - Cat ho & cing & & \\
\hline & 50 & 50 & 40 & 30 & 20 \\
\hline & Muas & $\underline{\mathrm{Ca} \mathrm{Lc}}$ & Calc & Calc & $\mathrm{Ca} 1 \mathrm{c}$ \\
\hline$\mu$ & 50 & 55 & 39 & 25 & 14 \\
\hline$\mu_{A S} \perp 1$ & 61 & 56 & 47 & 41 & 39 \\
\hline$\mu_{K S} \perp 1$ & 12 & 10 & 11 & 12 & 14 \\
\hline$\mu_{\text {AS } 21}$ & 218 & 246 & 333 & 573 & 1888 \\
\hline$\mu_{K S} 21$ & 344 & 323 & 391 & 610 & 1890 \\
\hline HP2 1 & 1098 & 935 & 1675 & 4628 & $27 \quad 400$ \\
\hline
\end{tabular}


3. Projected Level of Integration - Current Technology As was pointed out in the March 1982 proposal, an Integration level of $1000 \mathrm{devices} / \mathrm{In}^{2}$ can be obtained with less than $1 \%$ interaction between adjacent devices. The analysis at that time assumed vertical devices with a 1.5- x 10-mil cathode and a cathode-anode spacing of $20 \mathrm{mils}$. However, a number of design tradeoffs and considerations are involved that merit a more thorough examination. For example, it was pointed out in Section III.D.2 that decreasing the anode-cathode spacing essentially trades gain for isolation. Decreasing cathode width while maintaining other electrode dimensions increases device gain and maintalns about the same degree of 1solation. Decreasing the size of the anode and cathode shields or returning them to a constant potential (rather than the cathode potential) increases isolation and can maintain device gain (depending on nearby electrode potentlals).

Because of the tradeoffs, a number of device configurations were analyzed with the 2-D Laplace code. The results of Section III.D.2 Indicate that the results should be good for interactions between adjacent devices but of course, a 3-D code is required to obtain interactions between diagonal or endto-end devices.

The basic structure analyzed is shown in FIg. III-18. The interactions between the electrodes of device 2 on the right and device 1 on the left are calculated. It is assumed that all of the device on the right is at signal potentlal; 1.e., grid, cathode, cathode shield, anode, and anode shield are all at signal potential. If the shields are connected to a constant potential, the effective device width (for signal analysis purposes) is reduced and the interaction is reduced. For generality, the interactions will be c:lculated without regard to how the devices are interconnected. However, it should be noted that the relative importance of the interactions is determined by the way in which the devices are connectc: . For example, if the anode and cathode shields of device 2 are returned to the cathode of device 2 , and the anode of device 1 is connected to the cathode of device 2 (as in the basic gain stage) or the grid of device 2 (as in cascaded gain stages), tien the interaction frow the cathode, grid, and shlelds of device 2 to device 1 is negative feedback. That is, the effect of this interaction is to reduce the gain of device 1 , as shown by the analysis of the basic gain stage in Section III.D.1. (The measured device-to-device interactions are over $6 \%$, which would have reduced the 


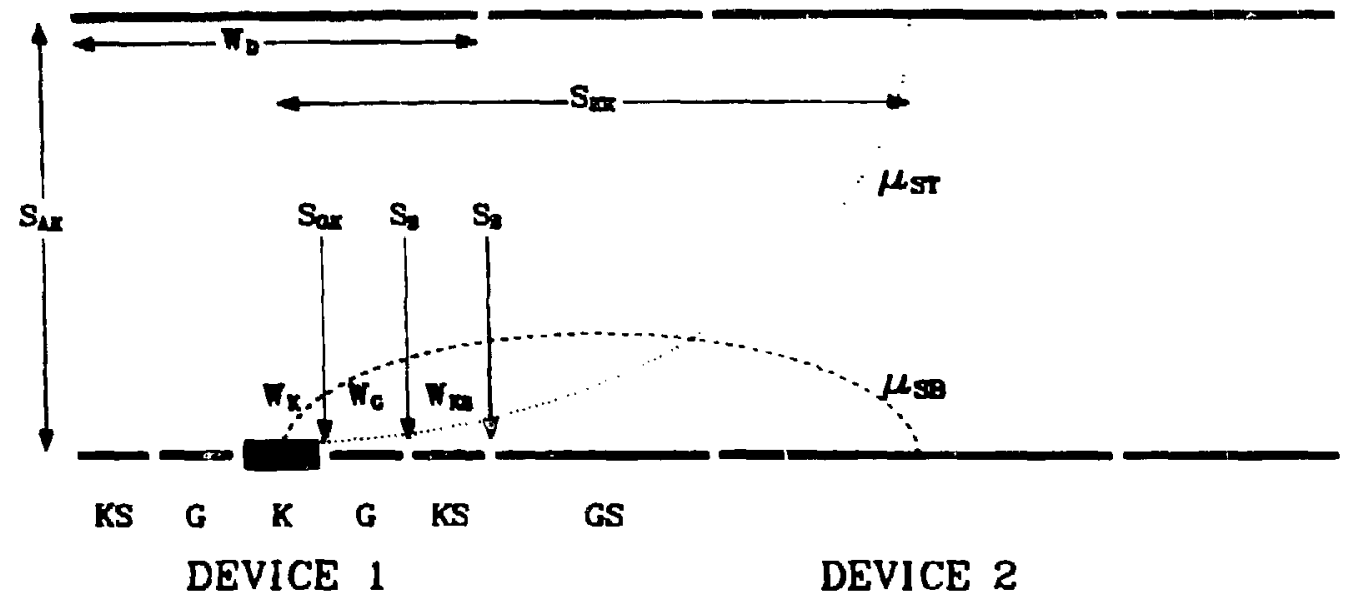

$$
\begin{gathered}
S_{S}=1, S_{G K}=0.2 \\
W_{D}=W_{K}+2\left(S_{G K}+W_{G}+S_{S}+W_{K G}\right) \\
=W_{K}+2.4+2\left(W_{K}+W_{K S}\right)
\end{gathered}
$$$$
\text { Cathode height }=0.2 \text { mils }
$$

Fig. III-18. Structure for calculating adjacent device interactions. Dimensions are in mils. 
gain from 11.5 to 10.8. However, feedback from ground shield to load device further reduced the gain to 9.2.$)$

For the structure of Fig. III-18, a nominal device was assuned to have the dimensions given in Table III-4. Then $S_{K K}$ was varied for the nominal device and for different values of $\mathrm{W}_{\mathrm{K}}, \mathrm{W}_{\mathrm{KS}}$, and $\mathrm{S}_{\mathrm{AK}}$. Table III-5 shows some of the results for the nominal $\mathrm{S}_{\mathrm{KK}}$ of $40 \mathrm{mils}$. The percent interaction is calcu lated from

$$
\text { interaction }=100 \frac{\mathrm{H}}{\mu_{\mathrm{S}}} \text { percent, }
$$

where

$$
\frac{1}{\mu_{S}}=\frac{1}{\mu_{S B}}+\frac{1}{\mu_{S T}} \text {. }
$$

TABLE III-4

NOMINAL DEVICE DIMENSIONS IN MILS

$\begin{array}{llr}\text { Cathode width } & \mathrm{W}_{\mathrm{K}} & 1.0 \\ \text { Grid width } & { }_{\mathrm{W}} & 1.0 \\ \text { Cathode shield width } & \mathrm{W}_{\mathrm{KS}} & 2.8 \\ \text { Shield spacing } & \mathrm{S}_{\mathrm{S}} & 1.0 \\ \text { Grid-cathode spacing } & \mathrm{S}_{\mathrm{CK}} & 0.2 \\ \text { Device width } & { }_{\mathrm{W}} & 11.0 \\ \text { Cathrde-cathode spacing } & \mathrm{S}_{\mathrm{KK}} & 40 \\ \text { Anode-cathode spacing } & \mathrm{S}_{\mathrm{AK}} & 30\end{array}$


TABIE III-5

SUMMARY OF ISOLATION CALCUIATIONS FOR $\mathrm{S}_{\mathrm{KK}}=40 \mathrm{~m} 11 \mathrm{~s}$

\begin{tabular}{|c|c|c|c|c|}
\hline${ }^{W_{K}}$ & $\mathrm{~S}_{\mathrm{AK}}$ & ${ }^{\mathrm{W}} \mathrm{D}$ & 11 & $\begin{array}{c}\text { Percent } \\
\text { Interaction }\end{array}$ \\
\hline 1 & 30 & 11 & 28 & 6.3 \\
\hline 0.5 & 30 & 11 & 40 & 6.4 \\
\hline 1 & 30 & 13 & 27 & $\overline{7} .2$ \\
\hline 1 & 30 & 11 & 28 & 6.3 \\
\hline 1 & 30 & 9 & 28 & 5.5 \\
\hline 1 & 30 & 7 & 26 & 4.4 \\
\hline 1 & 30 & 3.4 & 28 & 2.6 \\
\hline 1 & 20 & 11 & 18 & 0.1 \\
\hline 1 & 30 & 11 & 28 & 0.3 \\
\hline 1 & 40 & .11 & 37 & 15 \\
\hline
\end{tabular}

From Table III-5, it can be seen that reducing the cathode width results in a substantial increase in voltage gain with no increase in interaction (i.e., $\mu_{S}$ increased by the same factor as $\mu$ ). Reducing the device width by reducing the anode and cathode shield widths reduces device interaction. For $W_{D}=3.4$, which corresponds to no anode shield or cathode shield (or shields connected to a constant potential), the interaction has been reduced from $7.2 \%$ to $2.6 \%$. This may well be the most common case because it corresponds to a grounded cathode stage. Further, it may be appropriate to connect most of the shields to a fixed potential. Finally, Table III-5 shows clearly that reducing the anode-to-cathode spacing amounts to trading gain for isolation.

Figures III-19 and -20 show the isolation $\mu$ as a function of cathodecathode spacing for varying device widths and varying anode-cathode spacing, while Figs. III-21 and -22 show the corresponding percent interaction. Figures III-21(a) and $-22(a)$ are appropriate for digital circuit interactions and most linear circuit interactions, while the expanded scales of Figs. III-21(b) and $-22(b)$ are appropriate for critical interactions in linear circuits.

The end-to-end device interactions cannot be calculated with the 2-D Laplace code; however, Fig. III-16 and Table III-1 in Section III.D. 2 indicate that, for the end-to-end device, isolation is higher than for adjacent devices even though the end-to-end spacing is about half that of the adjacent devices. 


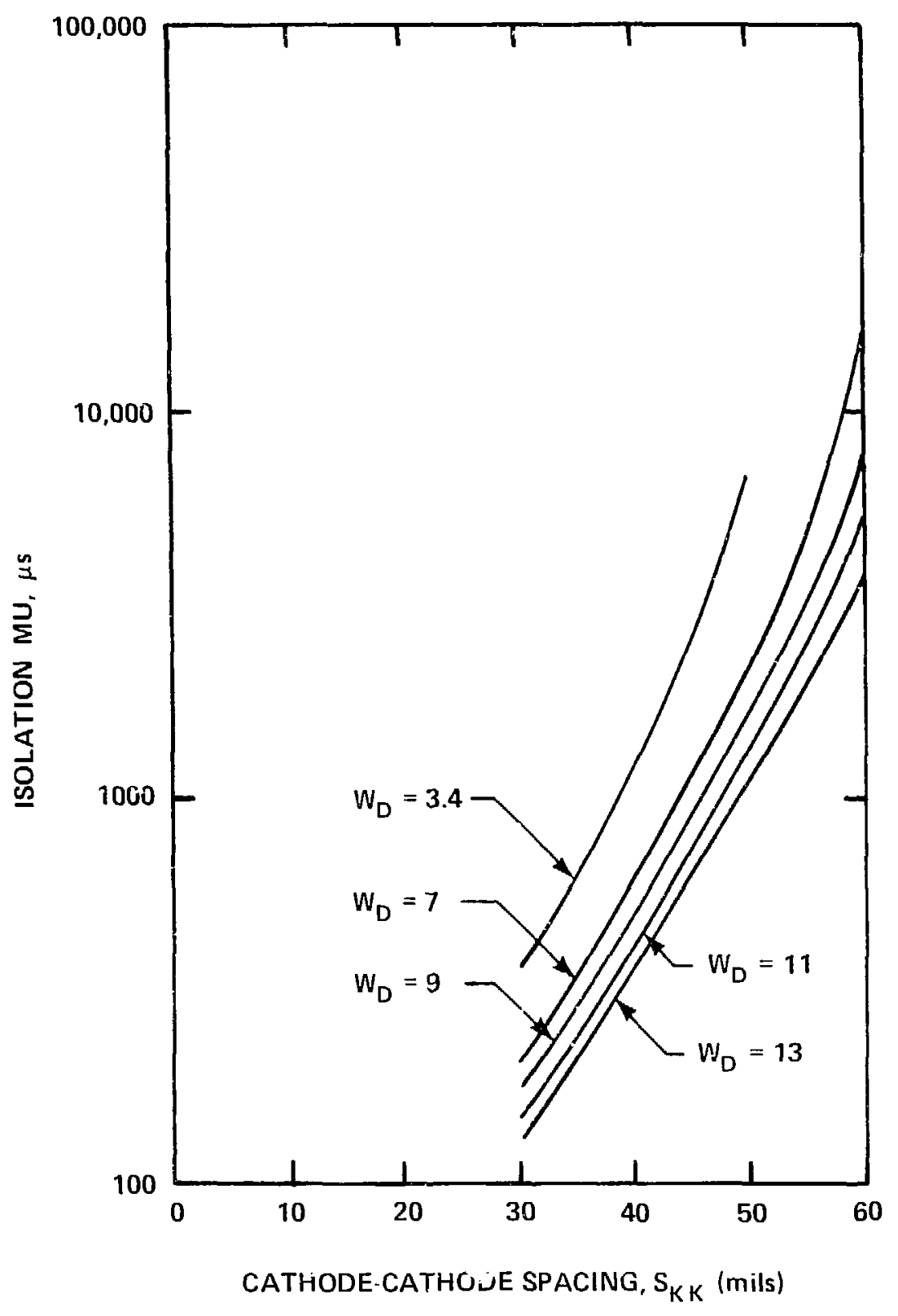

Fig. III-19. Isolation $\mu\left[\mu_{S}=\left(\mu_{S B} \mu_{S T}\right) /\left(\mu_{S B}+\mu_{S T}\right)\right]$ for varying device width: ( 10 ). 


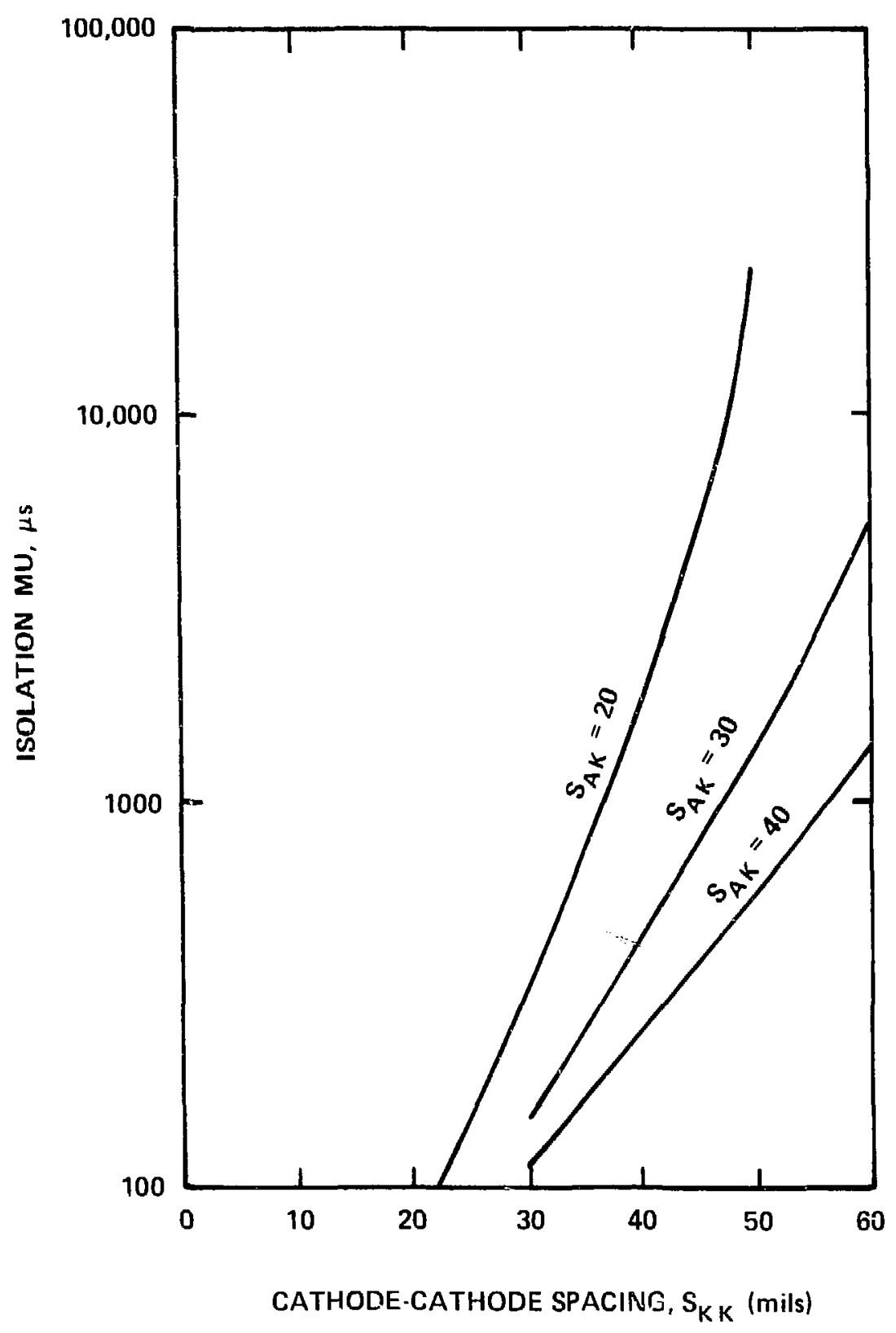

Fig. III-20. Isolation $\mu$ for varying anode-to-cathode spacings. 


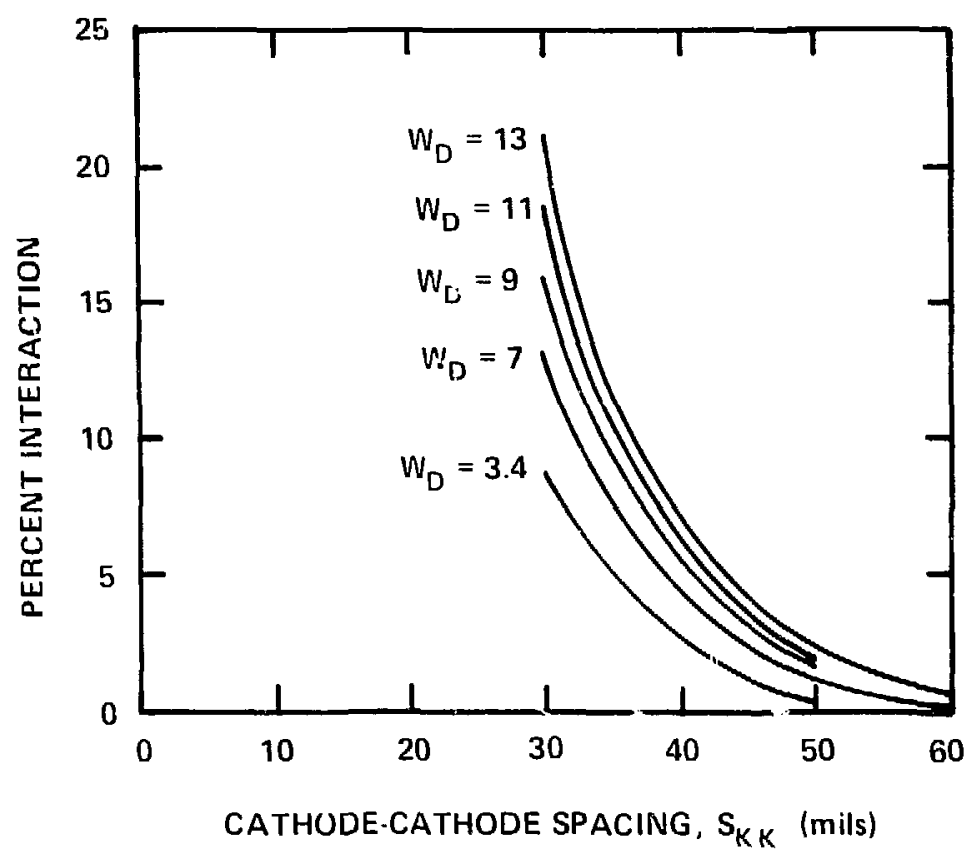

(a)

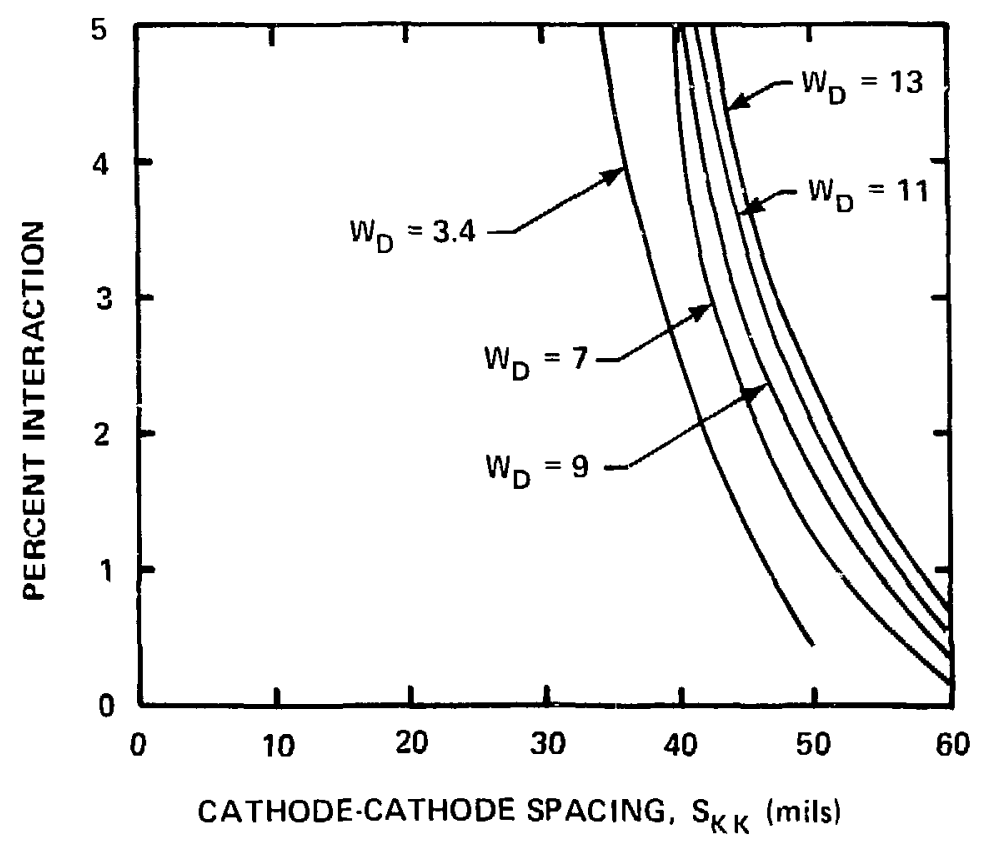

(b)

Fig. III-21. Percent interaction for different device widths. 


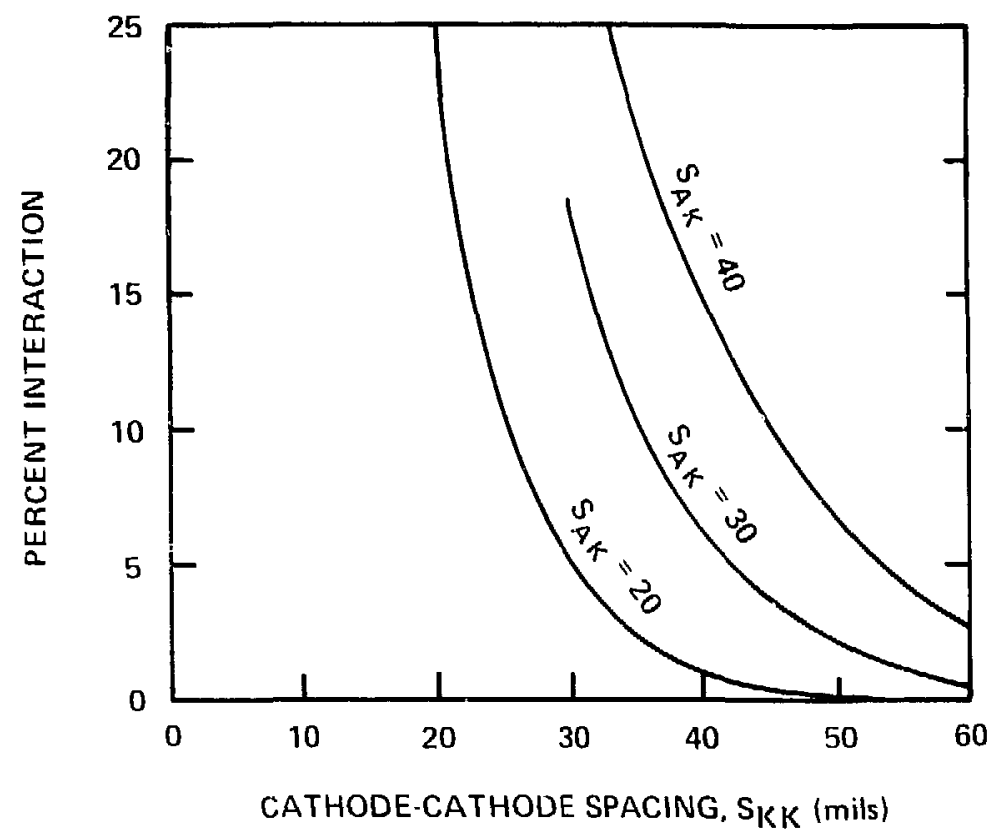

(a)

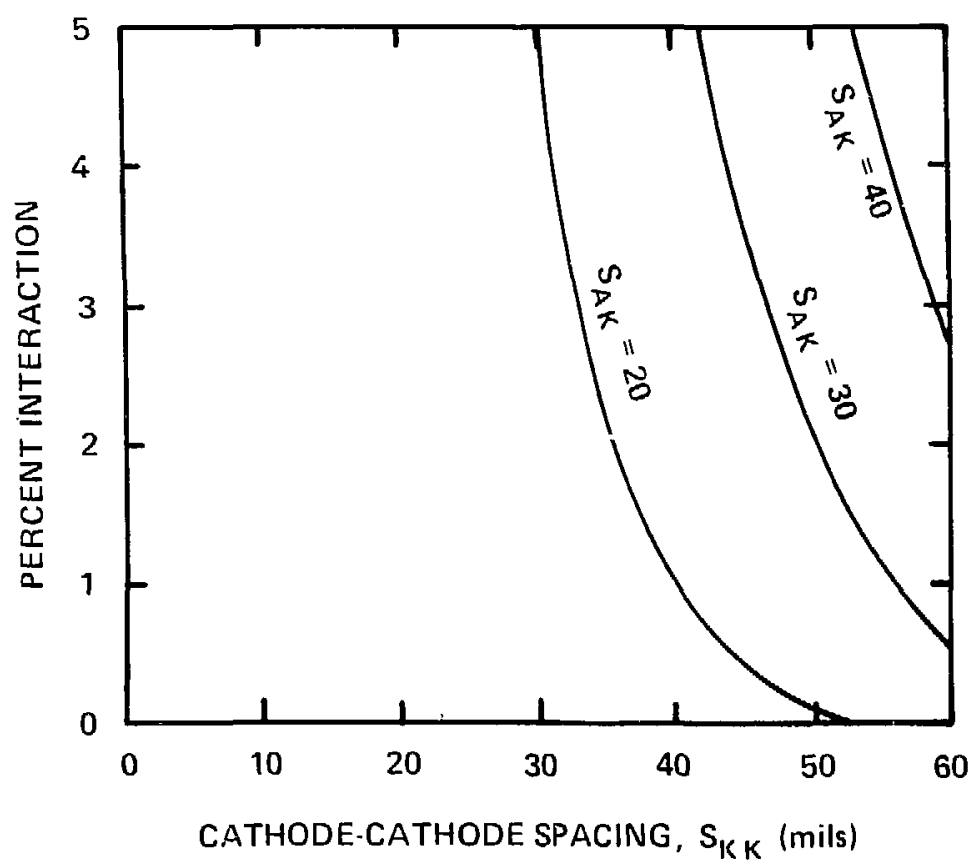

(b)

Fig. III-22. Percent interaction for different anode-to-cathode spacings. 
This isolation would be substantially higher if the cathodes were reduced from seven 1.5 -mil stripes to one 1 -mil stripe, a $10.5: 1$ reduction in the length of the edge. If a 10-mil separation adequately isolates end-to-end devices and if the cathode is 10 mils long, then $S_{K K}=50$ results in 1000 devices $/ \mathrm{In}^{2}$.

Table III-6 lists the gain, percent interaction, and level of integration for some of the configurations. With a 10-mil cathode stripe, 20-mil anode-cathode separation allows 1670 devices $/ 1 n^{2}$ for $5.4 \%$ inieraction and 1250 devices/in ${ }^{2}$ for $1 \%$ interaction, but at reduced gain. An anode-cathoda spacing of $30 \mathrm{mils}$ with the nominal device provides improved gain at 1250 devices/in ${ }^{2}$ but increases the interaction to $6.3 \%$. An interesting configuration would be a 0.5-mil-wide cathode and a 20-mil anode-cathode spacing. The 0.5-mil cathode would improve the gain, and the 20 -mil anode-cathode spacing would provide a high degree of isolation.

\section{TABLE III-6}

GAIN, PERCENT INTERACTION, AND LEVEL OF INTEGRATION FOR SEVERAL DEVICE CONFIGURATIONS

\begin{tabular}{|c|c|c|c|c|c|c|}
\hline $\begin{array}{l}\text { Cathode } \\
\text { Length } \\
\end{array}$ & $\mathrm{S}_{\mathrm{AK}}$ & $\mu$ & $\mathrm{W}_{\mathrm{D}}$ & $\mathrm{S}_{\mathrm{KK}}$ & $\begin{array}{l}\text { Percent } \\
\text { Interaction }\end{array}$ & Devices/in ${ }^{2}$ \\
\hline 10 & 40 & 37 & 11 & 50 & 6.5 & 1000 \\
\hline 5 & 40 & 37 & 11 & 50 & 6.5 & 2000 \\
\hline 10 & 30 & 28 & 11 & 40 & 6.3 & 1250 \\
\hline 5 & 30 & 28 & 11 & 40 & 6.3 & 2500 \\
\hline 10 & 30 & 28 & 3.4 & 30 & 8.7 & 1670 \\
\hline 5 & 30 & 28 & 3.4 & 30 & 8.7 & 3330 \\
\hline 10 & 30 & 28 & 3.4 & 50 & 0.5 & 1000 \\
\hline 5 & 30 & 28 & 3.4 & 50 & 0.5 & 2000 \\
\hline 10 & 20 & 18 & 11 & 30 & 5.4 & 1670 \\
\hline 5 & 20 & 18 & 11 & 30 & 5.4 & 3330 \\
\hline 10 & 20 & 18 & 11 & 40 & 1.0 & 1250 \\
\hline 5 & 20 & 18 & 11 & 40 & 1.0 & 2500 \\
\hline
\end{tabular}

\footnotetext{
a 10 -mil cathode and 10-mil isolation shield or 5-mil cathode and 5-mil isola* tion shield.
} 


\section{Design/Fabrication of an Integra:ad clrcuit}

a. Initial Design of an Integrated Flip-Flop The flip-flop shown in Fig. III-23 was chosen as the first completely integrated circuit to be desizzed and fabricated in the TIC technology. As can be seen in Fig. III-23, this circult uses a total of 10 devices; the layout has been arranged for expediency (See Section 4.b of this section) to separate the devices enough tc minImize interactions. Figure III-24 shows the clrcuit broken down into its basic circuit components (a mask for manufacturing the circuit in this fashion was created first in order to test each of the independent circuit elements).

The test circuit then consists of two gain stages (T1, T2 and T6, T7) and two leveI shifters ( $T 3, T 4, T 5$ and $T 8, T$, T10) that can be connected 1n a number of ways. For example, a gain stage can be connected to a level shift to provide a logic inverter whose dc oucput level is compatible with the input of a similar stage as is required for logic circuits and dc-coupled ampliflers. When two Inverters are cascaded with the output of the second connested to the input of the Ilrst, i inifir Flp-flop is toriued.

The level shift circuit has a galn of approximately $1 / 2$ and incorporates a cathode follower in order to prevent loading of the gain stage by the level-shift circuit. For simplicity, no provisions are included for triggerIng or for logic input, and no attempt has been made to optimfze device or clrcult performance. The dc levels at the input of each inverter are approximate $1 \mathrm{y}+1$ and $-3 \mathrm{~V}$.

Figures III-25 and -26 are photographs of the masks for the two flipflop substrates. The circult has been laid out so that ali the points indicated In FIg. III-24 can be brought out or so that some can be connected internally. If desired, the flip-flop can be completely connected internally. The options are obtained by selectively opening some of the metal interconnections on the rasks; examples can be seen in Figs. III-25 and -26 .

Several of these circults have been fabricated and tested as gain stages, logic fnverters, and flip-flops. FIgure III-27 shows the output waveform of a flip-flop when it is triggered by externally generated pulses (this circult was operated in a bell jar, and the long external connections required latroduced substantial capacitance, which caused the siow speed shown in the figure). Figure III-28 is a photograph showing both flip-flop substrates. The exercise of designing and testing the clrcult proved to be enlightening in a number of ways. 


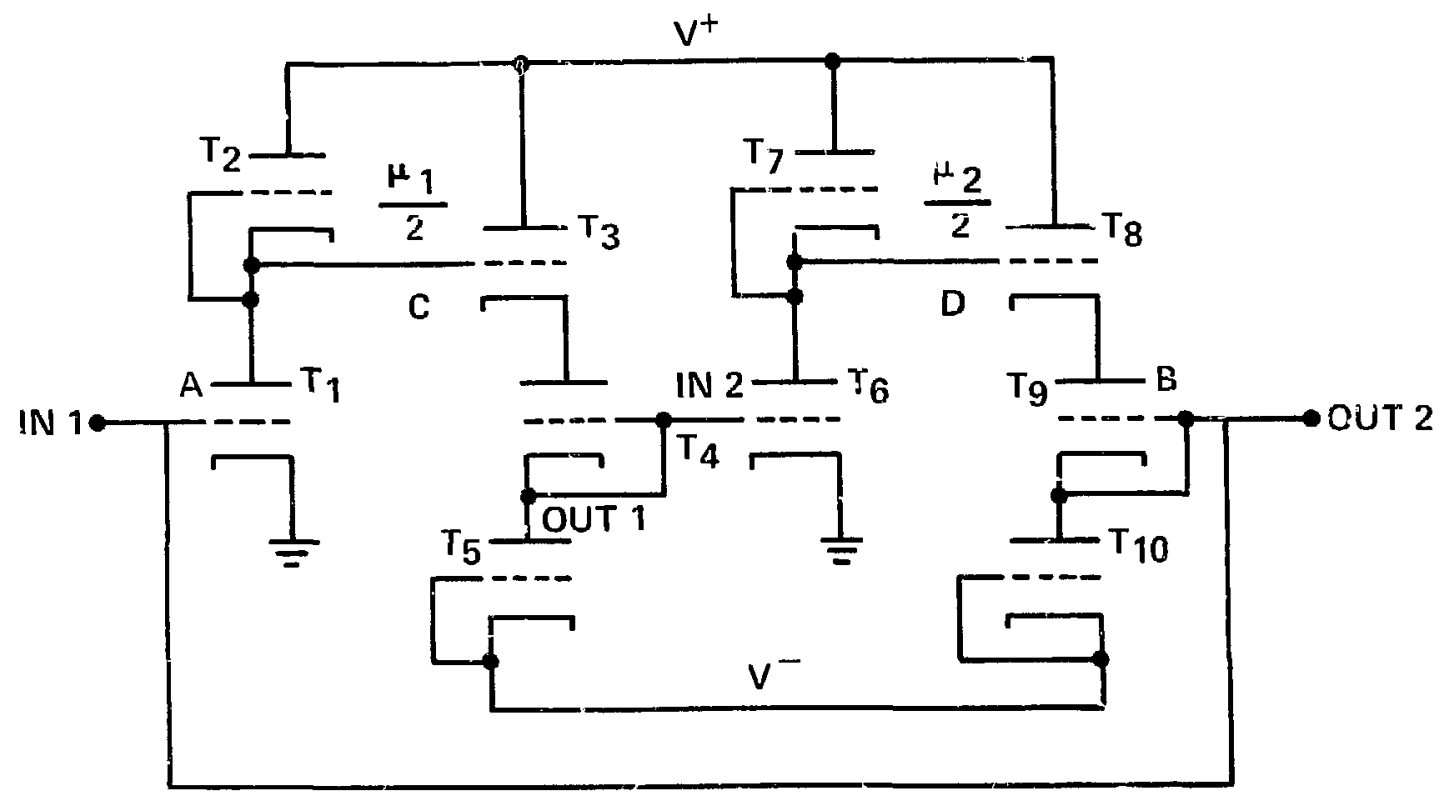

Fig. III-23. Circuit diagram of the fully interconnected flip-flop.

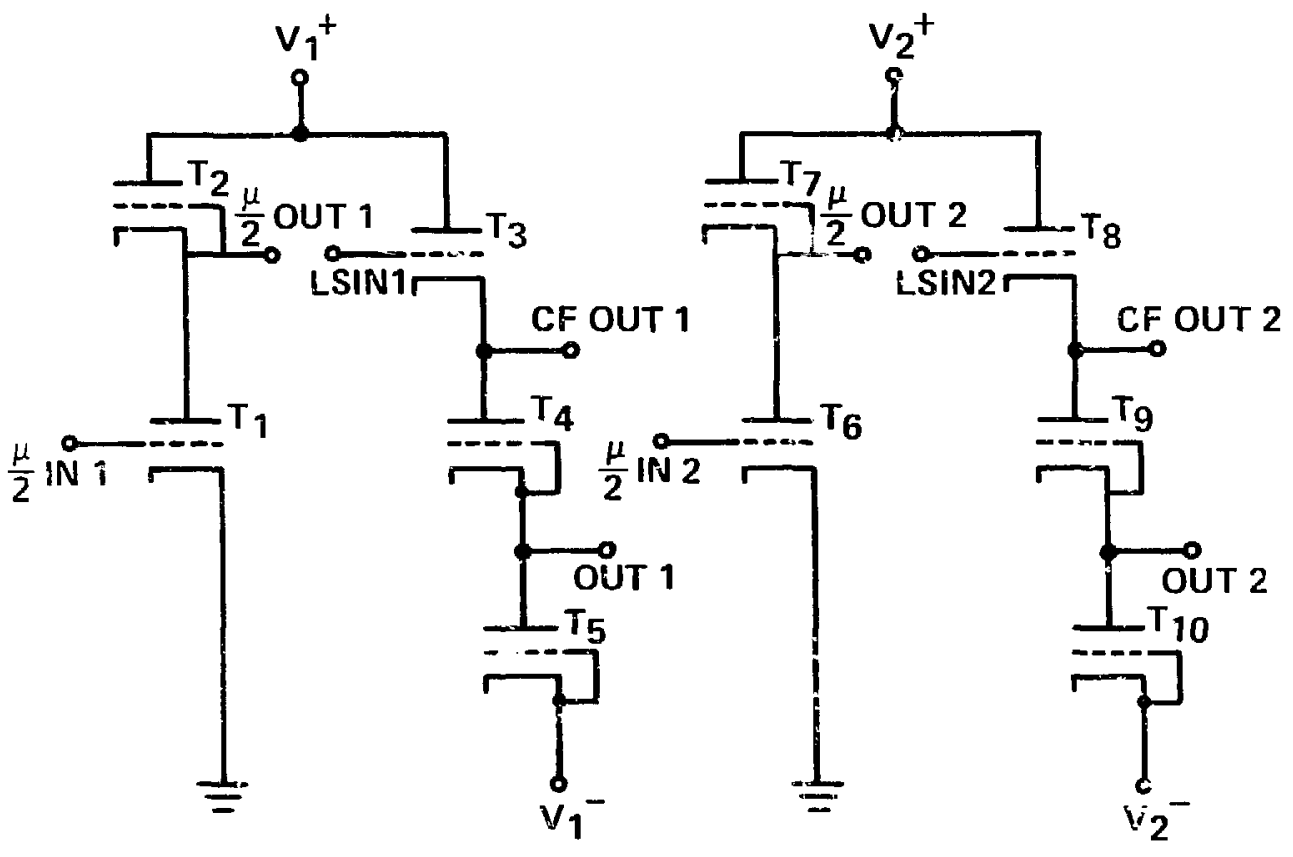

Fig. ilI-24. Flip-flop circuit diagram showing basic circuit components. 


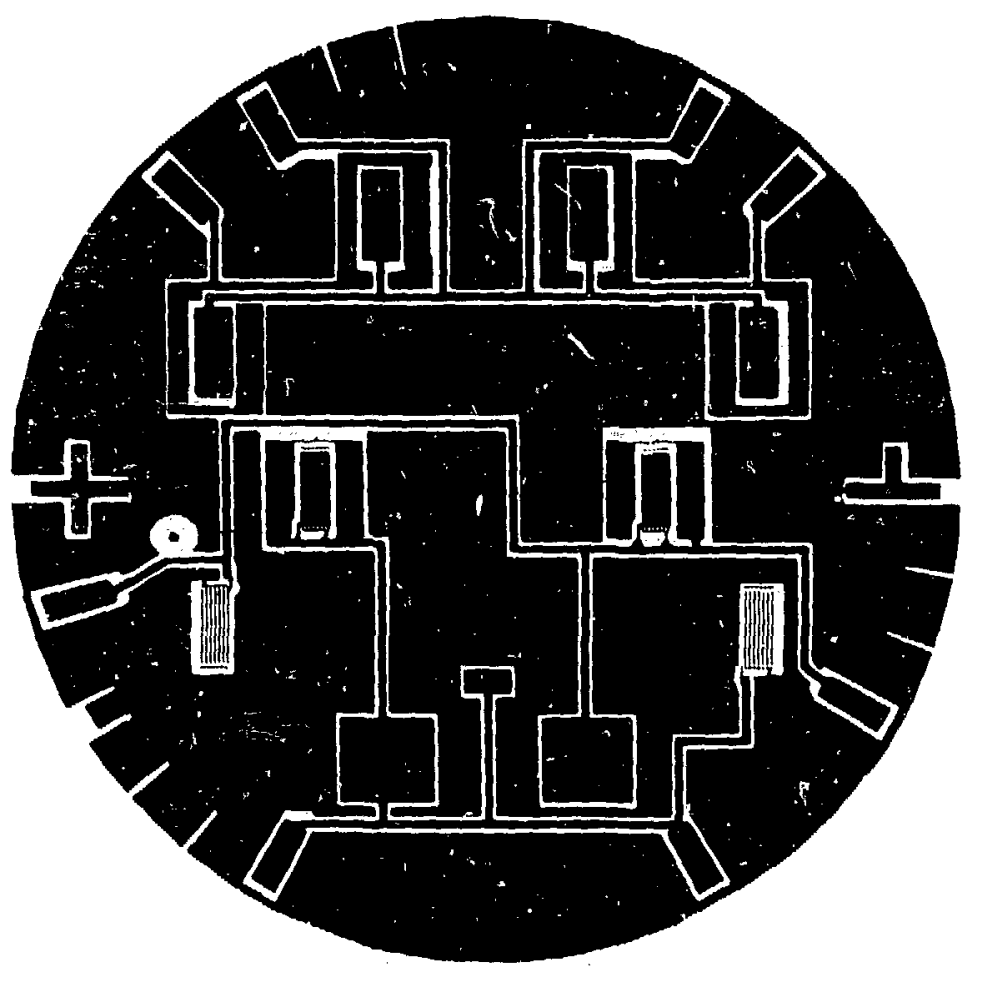

Eig. III-25. Mask for blue substrate.

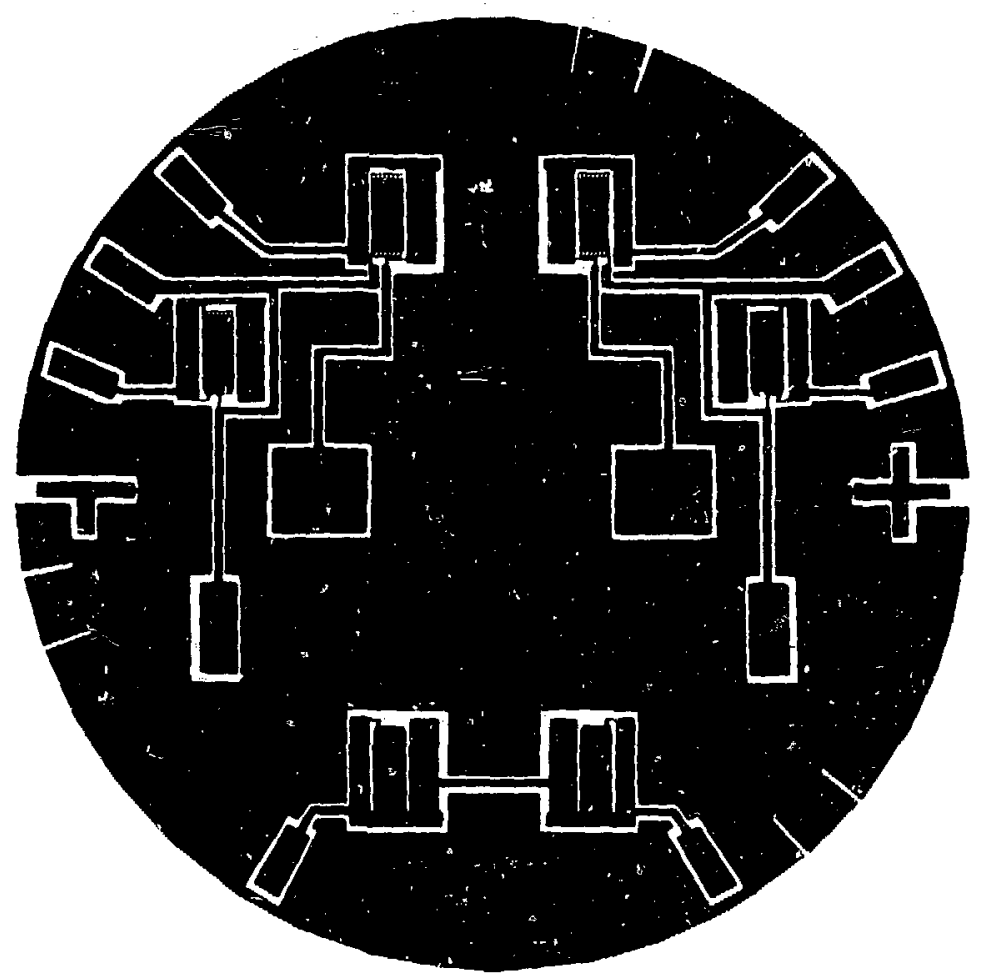

Fig. III-26. Mask for red substrate. 


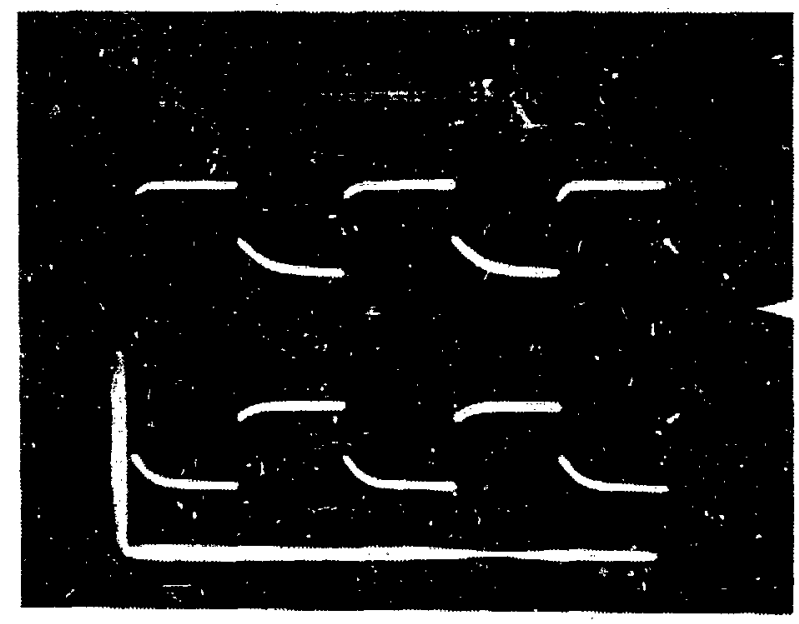

Fig. III-27. Flip-flop waveform.

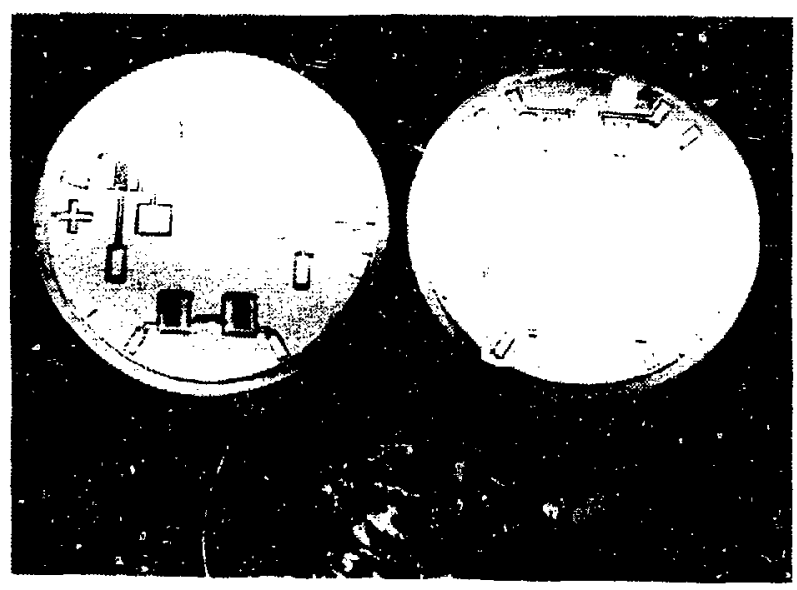

Fig. III-28. Two flip-flop substrates. 
1. The circuit worked as predicted.

2. The improved processing yielded leakages and spurious emission levels in the circuit that were immeasurably low.

3. The interactions from the shield to the devices had to be measured experimentally (the two-dimensional computer simulation, which works well for long, thin structures, was found to be difficult to apply to the complex geometries of an actual circuit).

4. The level shift stage as created gives up over half of the voltage galn; therefore, devices or clrcuits that behave like current sources will ultimately be required to increase the level shift gain to nearly $I$, or devices that operate at a high positive grid voltage could be used either for the basic gain stage or as levelshifting cathode followers.

b. An Improved Fllp-Flop Layout because an adequate layout and mask generation facility was not readily avallable, * the flip-flop masks had to be created in a ratiner cumbersome manner. Device masks with the critical $0.3-\mathrm{mil}$ grid-cathode spacing have been manufactured previously by a mask house. These are large devices with seven cathode stripes, each $1.5 \times 55$ mils. A method had also been devised whereby devices could be placed in any of 24 fixed locations. Then the devices could be interconnected by generating metal artwork on an avallable low-precision system (4-mil lines and spaces). Because of the unnecessarily large devices and the lack of flexibllity in placing the devices, the test flip-flop consumes much more area than necessary; the level of intcgration corresponds to about 50 devices/in ${ }^{2}$ of active area.

Because of the above restrictions, the test flip-flop gives no real indication of the attainable level of integration. The analysis discussed in Section III.D.3 predicts 1000 devices $/ 1^{2}{ }^{2}$ with less than $1 \%$ interaction between adjacent devices. In order to partially verify this, the flip-flop was redesigned using the current TIC technology but with redesigned devices, flexible placement, and 1-m1l lines and spaces for metal interconnect.

The redesigned device has a single cathode stripe, and its basic configuration is shown in Fig. III-29. The cathode is 0.8 mils wide, the grid is

*The cost of having this work done by an outside mask house was considered beyond the means of the program. 


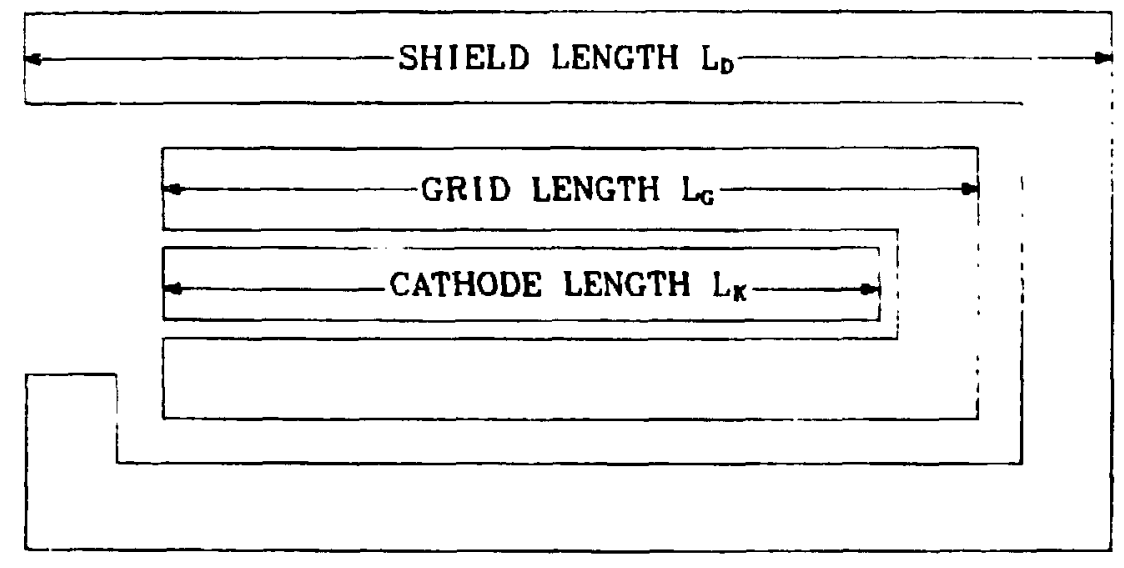

Fig. III-29. Redesign of the cathode-grid-cathode shield structure for the improved flip-flop layout. 
$0.9 \mathrm{mils}$, and the grid-cathode of acing is $0.2 \mathrm{mils}$. The total device width $W_{D}$ is 6 mils including shield.*

For a given overall device length $L_{D}$, the cathode length $L_{K}$ and grid length $\mathrm{L}_{\mathrm{G}}$ are

$$
\begin{aligned}
& \mathrm{L}_{\mathrm{K}}=\mathrm{L}_{\mathrm{D}}-4.1 \text { and } \\
& \mathrm{L}_{\mathrm{G}}=\mathrm{L}_{\mathrm{D}}-3 .
\end{aligned}
$$

The length of the corresponding anode $\mathrm{L}_{A}$ and width of the anode $\mathrm{W}_{\mathrm{A}}$ are

$$
\begin{aligned}
& \mathrm{L}_{A}=\mathrm{L}_{G} \text {, nd } \\
& \mathrm{W}_{\mathrm{A}}=3,
\end{aligned}
$$

and the anode shield is identical to the cathode shield.

For the flip-flop, a device length of $24 \mathrm{mils}$ is used. The grid length, cathode length, and cathode area $A_{k}$ are

$\mathrm{L}_{\mathrm{G}}=21 \mathrm{mils}$,

$i_{K}=19.9 \mathrm{mils}$, and

$A_{K}=15.9 \mathrm{mils}^{2}$.

While this device has not heen fahricated and tested hecause of the lack of artwork facilities, it is helieved to he a conservative design for tho following reasons.

1. The current processing technology has demonstrated cathode widths of $0.5 \mathrm{mil}$ or less; $0.8 \mathrm{mil}$ is, therefore, easily attainable $(0.5-\mathrm{mil}$ cathodes have heen successfully delineaced hut not tested in devices).

2. A number of single carhode stripe devices have heen fahricated (using the standard device hut coating only 1 cathode stripe) and tested. The characteristics of these devices are hasically the

The T"mil-wide cathode shield is to provide some isolation hetweon the cathode and ground shield, thiat is, to reduce the hiasing effect of the grnund shield on the cathode. Additional shielding hy the ground shield is required to reduce device-to-device interactions. 
same as the multicathode stripe devices, but thov operate at a lower current level. The single stripe devices have a cathode area of $1.5 \times 55=82.5 \mathrm{mil}^{2}$.

3. Diodes have been fabricated with a cathode area of only $25 \mathrm{mil}^{2}$. These diodes operate at -urrent levels sufficlently high to drive external clrcultry. Even smaller cathodes can be used to drive off-chip; if the device drives only other on-chip devices, the cathode could be much smaller.

A possible flip-flop layout is shown in Fig. III-30; this layout permits the devices to be interconnected as a flip-flop without crossovers. The dotted area would malntain as much space between adjacent flip-flops as that maintained between adjacent devices. The area enclosed by the dotted rectangle Is $9180 \mathrm{mils} \mathrm{s}^{2}$, which corresponds to 1089 devices $/ \mathrm{in}^{2}$.

The analysis discussed in Section III.D. 3 used a cathode-to-cathode spacing to cathode width ratio of 50:1 to maintain interaction between adjacent devices at less than $1 \%$ and a cathode leigth of $10 \mathrm{~m} 11 \mathrm{~s}$. The layout of F1g. III-30 has a cathode spacing to cathode width ratio of 37.5 , resulting in more interaction between adjucent devices, which is allowable for a digltal circuit. On the other hand, the devices used for the flip-flop layout have a cathode length of 19.9 mils rather than $10 \mathrm{mlls}$. It is projected that devices with $0.5-\mathrm{mll} \times 10-\mathrm{m} 11$ cathodes could easily be fabricated; use of these devices would further reduce the total flip-flop area substantially.

\section{Level Shifting in a Single Device (a feasibility experiment)}

The basic inverter circuit used for the TIC flip-flop requires five devices--two for the basic gain circuit and three to level shift its output. The dc transfer characteristic of the basic gain stage is shown in Fig. III-31(a). because the low output of the gain stage is over $40 \mathrm{~V}$ and because the gain stage requires a negative voltage to turn it off, the output of the gain stage must be shifted lownward to provide an output that is dc-compatible with the input of a similar stage. The output of the complete inverter is shown by the solid curve in Fig. III-31(b). If the inverter is driving a similar stage, the load stage draws grid current at about $2.3 \mathrm{~V}$. This 1 imfts the positive output of the inverter and is showin by the dashed curve of Fig. III-3l(b). It is erident that the output of the complete inverter is compatible with the Input of a similar inverter, but the level shift circuit adds three more devices and reduces both the gain and logj.c swing of the inverter. 


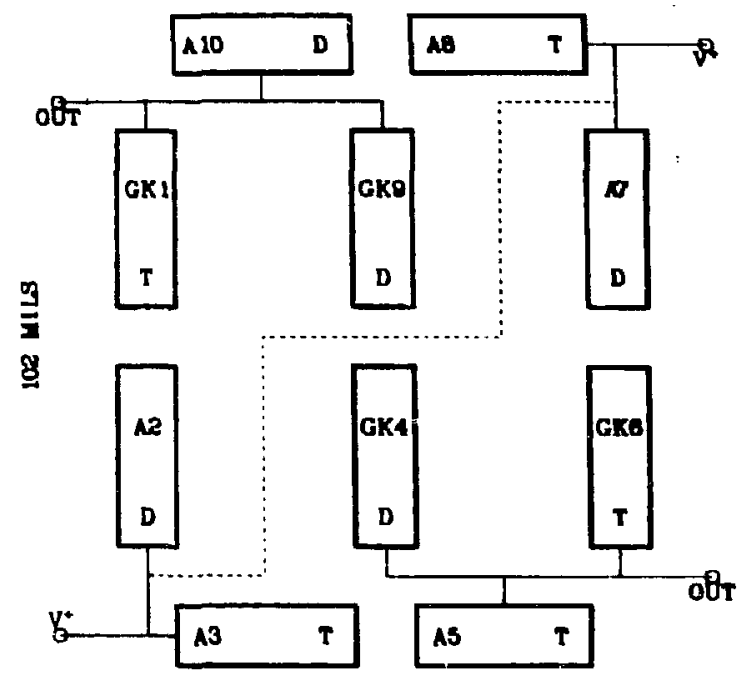

90 UILS

BLUE SUBSTRATE

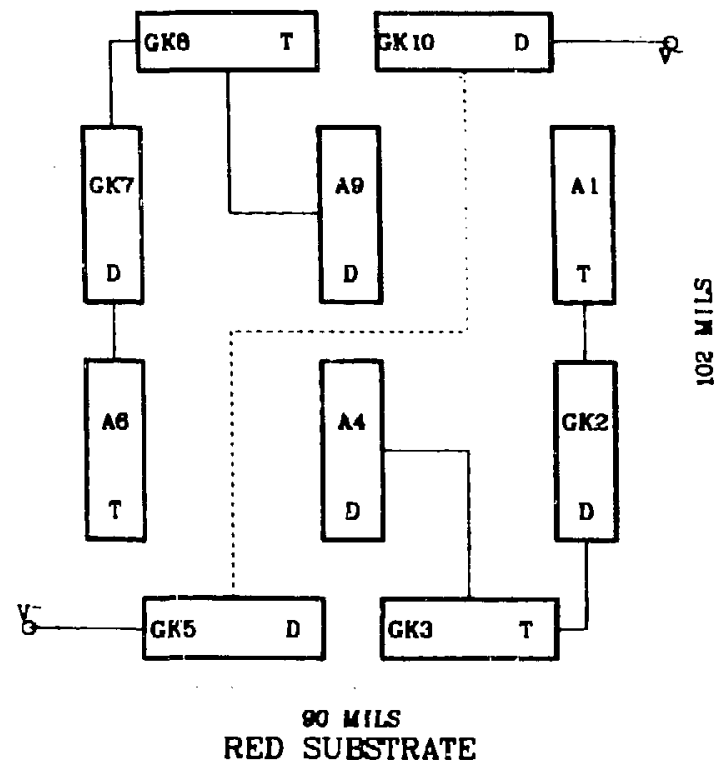

Fig. III-30. Improved f1ip-flop layout. Total area is $9180 \mathrm{mils}^{2}$ ylelting 1089 devices/in ${ }^{2}$. 


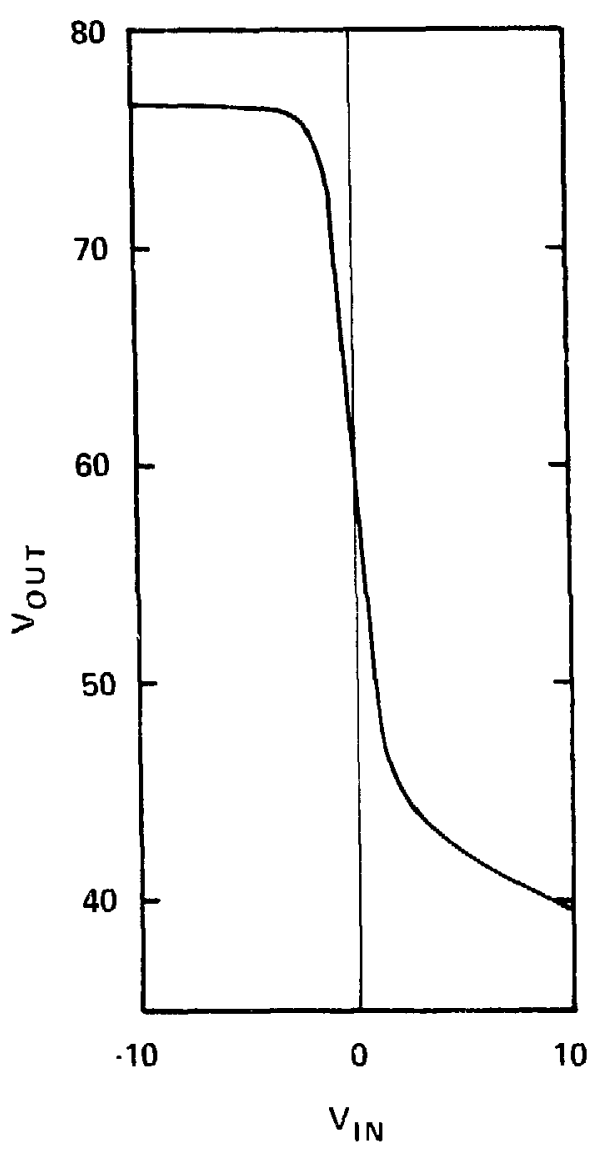

(a)

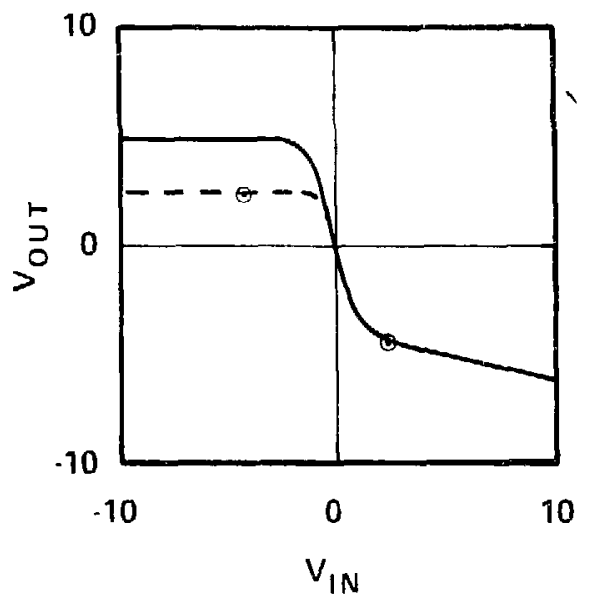

(b)

Fig. III-31. DC transfer characteristics of the (a) basic gain stage and (b) complete inverter.

ANODE

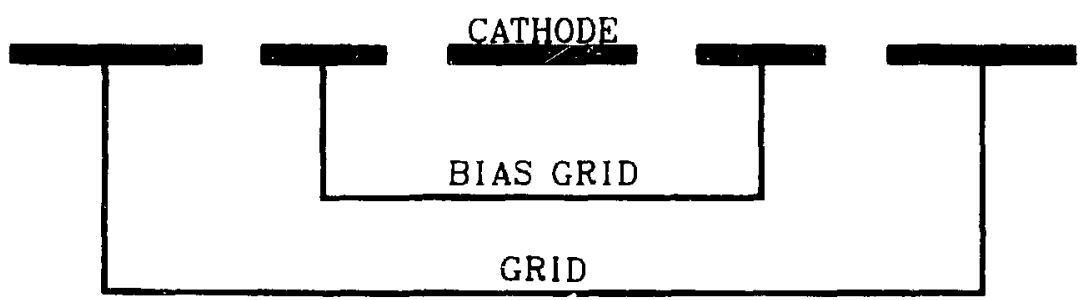

Fig. III-32. Proposed level shift device. 
One way to reduce the inverter device count and to perhaps improve the gain and logic swing is to introduce an additional set of grids in the gain device as shown in Fig. III-32. If a negative voltage is applied to the bias grid, the device could be cut off with a positive grid voltage. A higher grid voltage would then turn the device on. The hias grid is closer to the cathode in order to prevent the grid from drawing grid current with a positive hias.

An existent test device was modified as shown in Fig. III-33 to test this concept. Only the center cathode stripe had cathode coating. The two innermost $1-m i$ ? grids were used as bias grids, and the next two cathode stripes were used as grids. The remaining grids and cathodes were shorted together to form the shield. This device would be expected to have low gain because the 1 mil bias grids and $0.3-m i l$ spacing force the grids to be 1.6 mils away from the cathode.

The transfer characteristics of this device with a $1-M \Omega$ resistive load and a 25-V supply are shown in Fig. III-34. As can be seen, the output is compatible with the input of a similar device (the operating points are circled); the logic swing is larger than that of the flip-flop inverter; and the gain is low because of large grid-cathode separation. This device shows feasibility For an improved inverter with a device count of only 2. However, more suitable devices with narrower bias grids and higher gain need to be tested with active loads while driving similar stages.

It is also expected that such a device could be used as a cathode follower, which operates at a large positive grid voltage. Using such a device may obviate the need for the diodes used in level-shifting diodes, such as those employed in the test flip-flop.

6. Current Source Devices. Often in the design of circuits, it is useful to have a device whose current is virtually independent of anode voltage. Such a device is referred to as a current source and is useful. in such circuits as active loads, level shifters, and differential amplifiers. As was observed in the design of the test flip-flop, one-half of the voltage gain was lost in bringing the output voltage back to ground through a string of diodes. Professors Douglas Hamilton and William Kerwin and graduate students Lazaro Hong and Dan Schoenerman at the University of Arizona ( $U$ of $A$ ) under sponsorship of the National Science Foundation have been investigating advanced TIC device morphologies. This program was developed in cooperation with Los Alamos and has 
ANODE (Va)

C.ATHODE

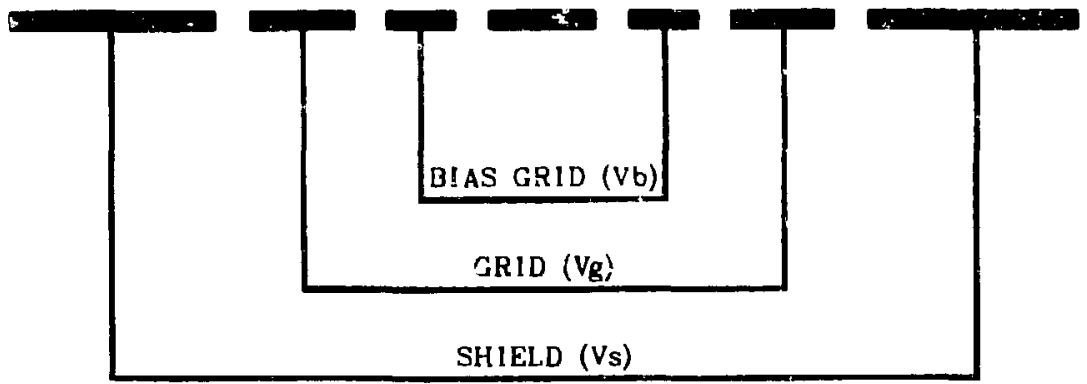

Fig. III-33. Leve1 shift test device.

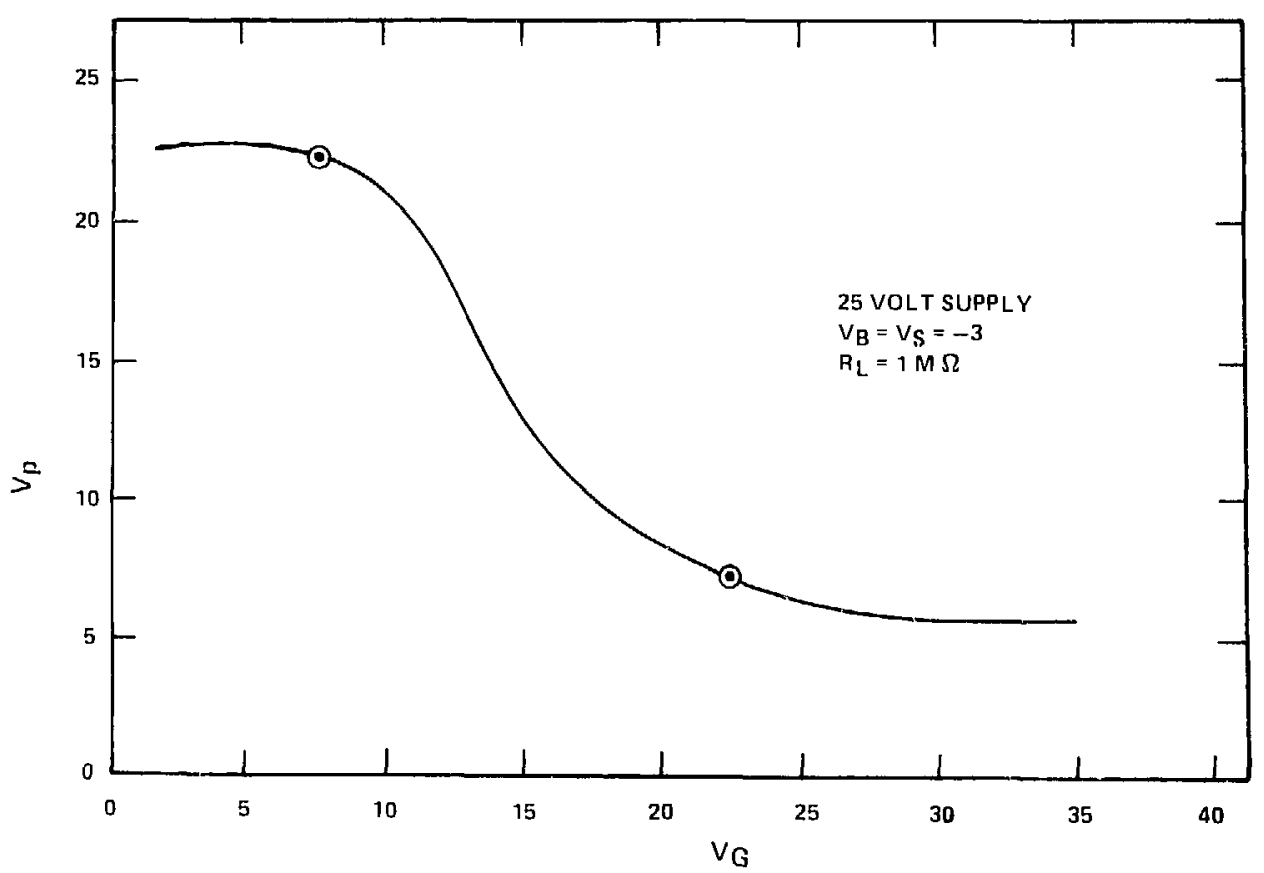

Fig. III-34. Transfer characteristics of the leve1 shift test device. 
been directed at augmenting the Los dlamos technology base. One structure proposed by Hong and being investigated at the $U$ of $A$ is the current source device as shown in FIg. III-35. This structure relies on several principles for operation.

1. To achieve current source operation, the fleld from the anode as seen by the cathode must be small so that influence of changing anode voltage is small.

2. As a result of 1 , the electron transport from cathode to anode must be facilitated by fields Induced by eleccrodes other than the anode.

3. I ens structures can be designed that provide the flelds necessary to accompl1sh 2 .

FIgure III-36 shows a computer-generated map of constant fleld lines for a device with lens 2 at $+100 \mathrm{~V}$ and lens 1 at $-100 \mathrm{~V}, \operatorname{grids}$ at $-1 \mathrm{~V}$, and anode at $+10 \mathrm{~V}$. Note that the lens structure creates the desired electron transport. Figure III-37 is an example of measured characteristics of a test device. The slope of the characteristics is primarily due to parasitic leakage present In devices fabricated at the $U$ of $A$.

These devices show great promise as current sources, although much work remains to be dore. Principally, because the device relles on the operation of the lens structure, evaluations must be made of the effects on the device operation as the cathode voitage is varied with respect to the fixed lens potentlals. A1so, a general set of design rules for creating a current source with desired characteristics must be developed.

However, the $U$ of A structure shows promise for enhancing the TIC capability and should be invesigated further as part of any continuing program.

E. Conclusions

The work performed on this phase of the project (augmented with DOE, Basic Energy Sciences support and NSF support at the University of Arizona) demonstrates that integrated circuits using the TIC technology are possible. Test circuits performed as expected, and improved processes were developed that greatly reduced parasitic currents.

This work confirms previous analyses that integrated circuits with device counts of between 1000 and $10,000 / \mathrm{in}^{2}$ are likely in the near term and that devices with improved functionallty (current sources, level shift devices) are likely in the future. However, the experience also pointed out the need 
SHIELD

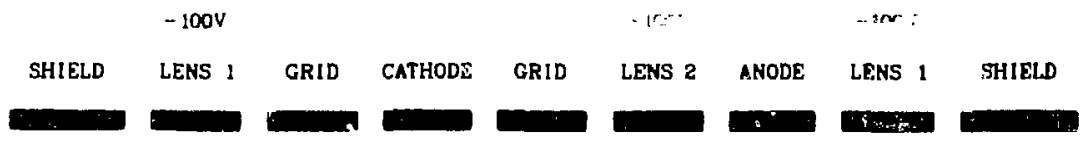

Fig. III-35. Monoplanar TIC current source developed and tested at the University of Arizona.

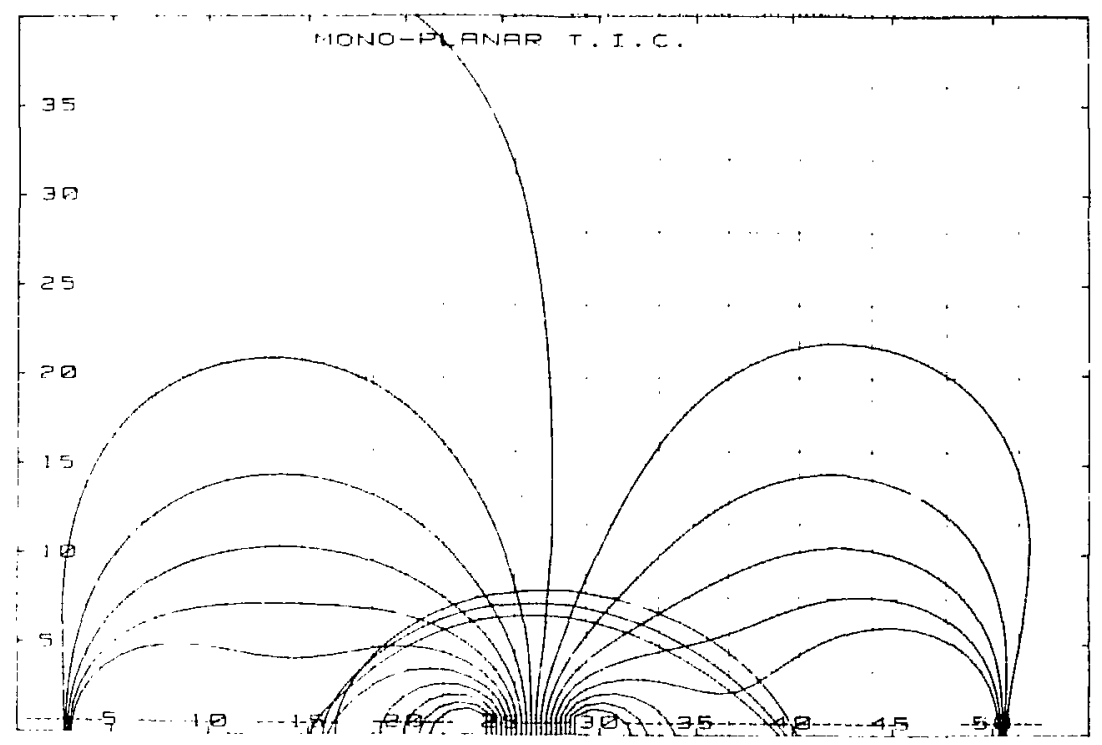

Fig. III-36. Constant field lines and clestron trajectories for the monoplanar current source. 


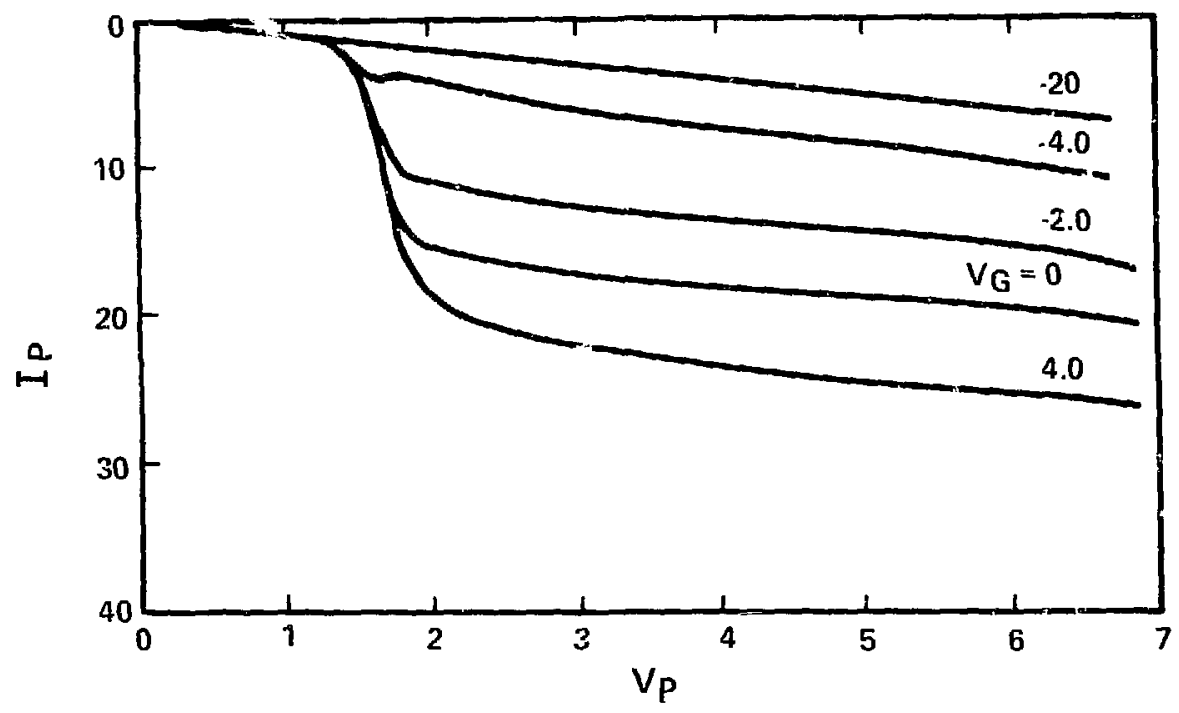

Fig. III-37. Measured response of the monoplanar current source. 
for better 3-D analysis Laplace codes in order to better predict performance and the need for better $\mathrm{CAD}$ tools to improve turnaround on masks.

F. Recommendations

1. In any continuation of TIC technology development, a substantial investment is required in circuit sechnology.

2. CAD support tools should be used and improved 3-D Laplace codes should be developed.

3. F periments with advanced device morphologies should be continued to Improve functionality per device.

4. Enhanced processing techniques stouid be investigated including smaller 1ithography (both cathode and 1fne), impreved cathodes (higher current density at long life), resistors, capacitors, and metalization crossovers.

IV. POWER REQUIREMENTS

A. Statement of Work from Proposal (March 1982)

"Presert test devices and circuits are fabricated on substrates having a heater element on the reverse side of the substrate. Two substrates are presently packaged in an evacuated glass envelope (FIg. IV-1). (Metal packages are used for high-temperature tests.) Present heater power in the glass envelope is $15 \mathrm{~W}$ per 0.75 -in.-diam substrate pair, with the substrates at $750^{\circ} \mathrm{C}$ and the envelope at $25^{\circ} \mathrm{C}$ ambient. No he $t$ radiation shields are used, and no attempt has been made to minimize conductive losses through bonding wires and substrate supports.

"Calculations show that more than an order of magnitude reduction can be achieved by using a package designed with appropriate heat radiation shields, by reducing conduction losses through use of thinner wires and by packaging many substrates in the same envelope. Specifically, analysis shows that for eleven 0.75--in.-diam substrate patrs in the same envelope with appropriate shields between substrate stack and envelope, the power required would be approximately $1.14 \mathrm{~W} /$ substrate pair (a similar result can be achieved by using a single pair (f 2-in.-diam wafers). If a nominal level of integration (e.g., 1000 devices $/ \mathrm{in}^{2}$ ) is achleved, there would be 4859 devices in the package, each requiring $2.58 \mathrm{~mW}$ of heater power per device. The total heater power for the 
4859 devices would be $12.54 \mathrm{~W}$. This assumes no power dissipation in the devices; in reality, device dissipation would allow further reduction of heater power. Therefore, a package containing several substrates with hect: rs and heat shields will bs designed and fabricated. Heater power required to maintain the substrates at $750^{\circ} \mathrm{C}$ will be measured for several different envelope temperatures. Results will. verify calculations and will provide direction for future package development."

B. Theoretical Ana1ysis and Experimenta1 Results

Two mechanisms account for the total internal heat loss. The first is direct thermal radiation from the sapphire substrates according to the StefanBoltzmann law:

$$
P_{1}=\text { e } A \sigma\left(T_{1}^{4}-T_{2}^{4}\right) \text {, }
$$

where $P_{1}$ is the radiated power in $W$, e is the emissivity of sapphire at $T_{1}$, $A$ is the area of the sapphire in $\mathrm{cm}^{2}, \sigma$ is the Boltzmann constant $\left(5.7 \times 10^{-12}\right.$ $\left.W / c m^{2} K^{4}\right), T_{1}$ is the temperature of the sapphire $(K)$, and $T_{2}$ is the temperature of the outer envelope $(K)$. The second mechanism is conduction through the stipport wires and leads:

$$
P_{2}=k\left(A_{1} / \ell\right) \Delta T \text {, }
$$

where $\mathrm{P}_{2}$ is the power conducted in $\mathrm{W}, \mathrm{k}$ is the thermal conductivity $(0.91$ $\left.W / \mathrm{cm}^{\circ} \mathrm{C}\right), \mathrm{A}_{1}$ is the cross-section area of the lead $\left(\mathrm{cm}^{2}\right), \ell$ is the lead length, and $\Delta \mathrm{T}$ is the temperature differential $\left({ }^{\circ} \mathrm{C}\right)$.

Since the sapphire is normally at about $1073 \mathrm{~K}\left(800^{\circ} \mathrm{C}\right)$, according to Wien's Displacement Law, the peak radiation occurs at

$$
\lambda_{\max } \mathrm{T}=2880 \mu \mathrm{m} \mathrm{K}
$$

or $\lambda_{\max }=2.68 \mu \mathrm{m}$. At this wavelength the glass outer package used for current prototype devices is essentially black and absorbs nearly all the radiation emitted by the sapphire substrates. The sapphire itself has an emissivity of about 0.5 at this temperature. For an area of $6.52 \mathrm{~cm}^{2}$ including the edges of 
the 30-mil-thick sapphire, the total radiation is $P_{j}=0.5(6.52)\left(5 . x_{10}^{-12}\right)$ $\left(1073^{4}-400^{4}\right)=24 \mathrm{~W}$. When two support leads, four heater lends, and three circuit leads are "ncluded, $P_{2}=2 \mathrm{~W}$. The total theoretical heat loss is, therefore, $26 \mathrm{~W}$ with the radiation term by far dominant.

Experimentally, the heat loss was initially measured as helween 26 and $28.1 \mathrm{~W}$, depending on whether the themocouple or optical temperature reading was used. The outside envelope temperature was measured at $127^{\circ} \mathrm{C}$. At this temperature, using an emissivity of 0.9 for the envelope, an area of $9 \mathrm{l} \mathrm{cm}^{2}$, and a hackground temperature of $300 \mathrm{~K}$, the external huih radiation $\mathrm{P}_{3}$ is $7.3 \mathrm{~W}$. The rest of the heat loss must he hy external conduction and convection. For an approximately uniform surface temperature, this is

$$
\theta \simeq 60 / \mathrm{A}^{1 / 2}
$$

where $\theta$ is in ${ }^{\circ} \mathrm{C} / \mathrm{W}$ and $\mathrm{A}$ is the area in $\mathrm{cm}^{2}$. For $\mathrm{A}=91 \mathrm{~cm}^{2}, \theta=6.3^{\circ} \mathrm{C} / \mathrm{W}$.

Since the net heat loss to be aucounted for is $\mathrm{P}_{1}+\mathrm{P}_{2}-\mathrm{P}_{3}=18.7 \mathrm{~W}$, then the external temperature would theoretically be $6.3 \times 1.8 .7=117^{\circ} \mathrm{C}$ above ambient or $142^{\circ} \mathrm{C}$. The actual measured temperature was $127^{\circ} \mathrm{C}$.

Next, a similar assembly was built (Fig. IV-2), but the enveiope was internally coated with gold (emissivity $\simeq 0.05$ at $1100 \mathrm{~K}$ ) to provide a highly reflective surface to reduce the radiative transfer from the sapphire substrates. To allow for the fact that the ends were not coated, an effective envelope emissivity of 0.06 was used. The heat transfer was then approximated to first order by using the analytic equation for heat transfer between two concentric spheres.

$$
Q_{1}=\frac{e_{1} e_{2}}{e_{2}+e_{1}\left(1-e_{2}\right)\left(r_{1} / r_{2}\right)^{2}} \sigma\left(T_{1}^{4}-T_{2}^{4}\right)
$$

where

$$
\begin{aligned}
& \mathrm{Q}_{1}=\text { heat flow, } \mathrm{W} / \mathrm{cm}^{2}, \\
& \mathrm{e}_{1}=\text { emissivity of } \mathrm{T}_{1} \text { surface, } \\
& \mathrm{e}_{2}=\text { emissivity of } \mathrm{T}_{2} \text { surface, } \\
& \mathrm{r}_{1}=\text { radius of inner sphere, } \mathrm{cm},
\end{aligned}
$$




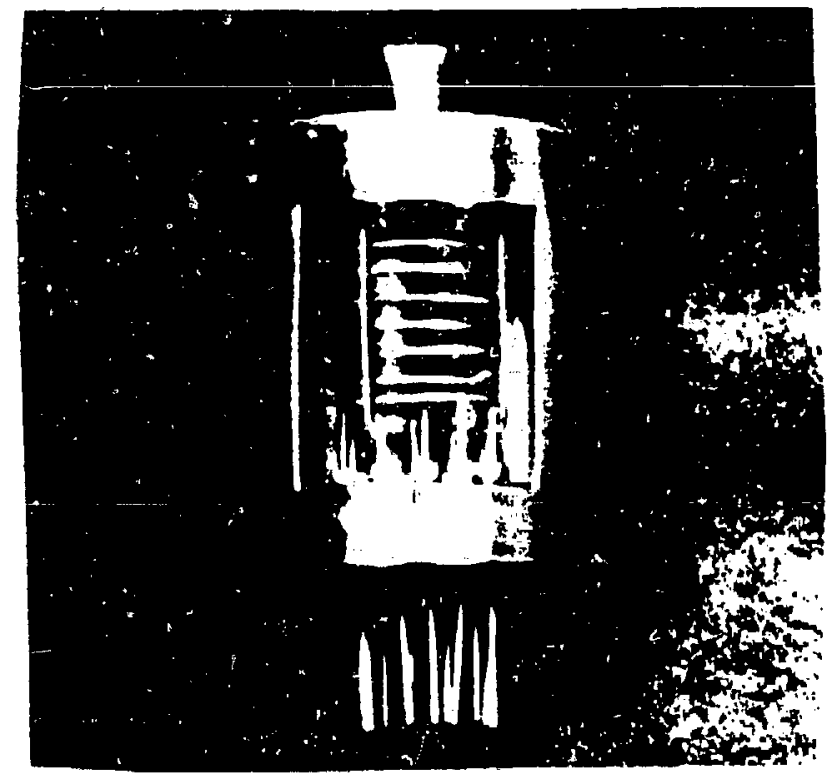

Fig. IV-1. Clear glass envelope.

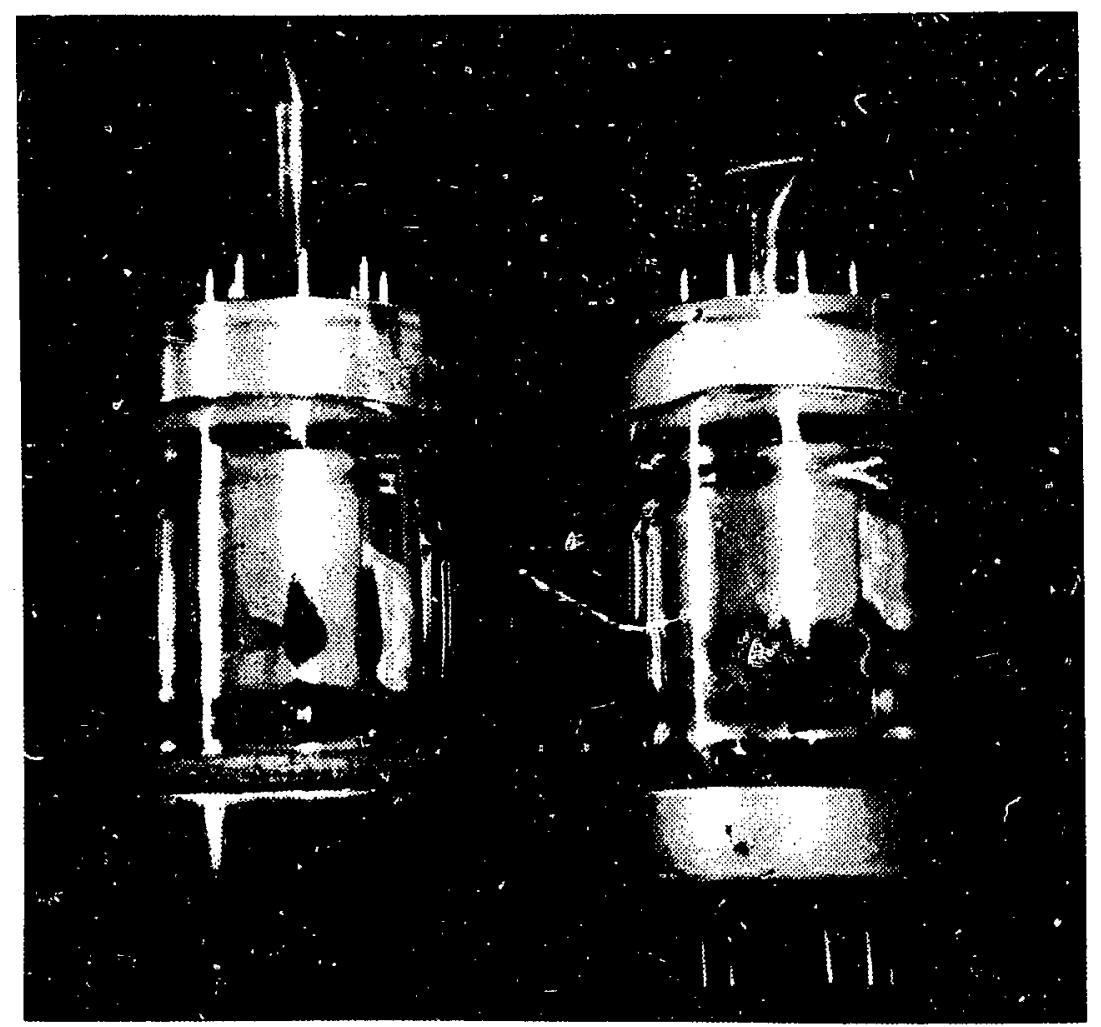

Fig. IV-2. Envelope coated with silver (left) and gold (right) to reduce heat loss and power requirements. 


$$
\begin{aligned}
& r_{2}=\text { radius of cuter sphere, cm, } \\
& \sigma=\text { Boltzmann's constant, } \\
& \mathrm{T}_{1}=\text { inner sphere temperature, and } \\
& \mathrm{T}_{2}=\text { outer sphere temperature. }
\end{aligned}
$$

An equivalent radius $r_{1}$ was found by equating the sphere area to the sapphire area, and an equivalent radjus $r_{2}$ was found hy similarly equating the envelope a rea to that of a sphere. The result for $\mathrm{T}_{1}=1073 \mathrm{~K}, \mathrm{~T}_{2}=400 \mathrm{~K}, \mathrm{e}_{1}=0.5$, $e_{2}=0.06, r_{1}=0.72 \mathrm{~cm}$, and $r_{2}=2.69 \mathrm{~cm}$ was $Q_{1}=2.33 \mathrm{~W} / \mathrm{cm}^{2}$ or a power of $15.2 \mathrm{~W}$ for a sapphime area of $6.52 \mathrm{~cm}^{2}$. When a conduction heat $\mathrm{flow}$ of $2 \mathrm{~W}$ is included, a total heat loss of $17.2 \mathrm{~W}$ is predicted. The optically measured heater power was $18 \mathrm{~W}$ while the thermocouple readings indjcated $16 \mathrm{~W}$. The measured reduction in heater power was more than $30 \%$, as predicted hy analysis.

The next test was the addition of two more sapphire substrates immediately adjacent to and coaxial with the original device substrates. These were gold plated on the inner surface to shield hoth faces. In addition, the device substrates were now mounted horizontally. In this case, the formula for radiative transfer between parallel planes was used to calculate the heat flow

$$
\mathrm{Q}_{2}=\frac{\mathrm{e}_{1} \mathrm{e}_{2}}{\mathrm{e}_{2}+\mathrm{e}_{1}\left(1-\mathrm{e}_{2}\right)} \sigma\left(\mathrm{T}_{1}^{4}-\mathrm{T}_{2}^{4}\right) \text {, }
$$

where

$$
\begin{aligned}
& \mathrm{Q}_{2}=\text { heat flow, } \mathrm{W} / \mathrm{cm}^{2}, \\
& \mathrm{e}_{1}=\text { emissivity of } \mathrm{T}_{1} \text { surface, } \\
& \mathrm{e}_{2}=\text { emissivity of } \mathrm{T}_{2} \text { surface, } \\
& \mathrm{\sigma}=\text { Boltzmann's constant, } \\
& \mathrm{T}_{1}=\text { temperature of surface } 1 \text { in } \mathrm{K} \text {, and } \\
& \mathrm{T}_{2}=\text { temperature of surface } 2 \text { in } \mathrm{K} .
\end{aligned}
$$

In addition, the temperature of the shields $\mathrm{T}_{\mathrm{s}}$ could be calculated because at equilibrium, $Q_{2}=Q_{3}$, where $Q_{3}$ is the heat radiated from the shields and $i: i$

$$
Q_{3}=\sigma e_{3}\left(T_{s}^{4}-T_{2}^{4}\right)
$$

where $e_{3}$ is the outer sapphire surface emissivity $(0.5)$ and $\mathrm{T}_{2}$ is the envelope 
temperature. This resulted in $\mathrm{T}_{\mathrm{s}}$ being $616 \mathrm{~K}$. With this temperature reduction, the total radiation, not including the edges of the shields, was expected to be $Q_{3}=0.5\left(5.7 \times 10^{-12}\right)\left(616^{4}-400^{4}\right) \mathrm{W} / \mathrm{cm}^{2}$. For an area of $6.52 \mathrm{~cm}^{2}$, the power radiated was $\mathrm{P}_{4}=2.4 \mathrm{~W}$. When we add in the edge and conduction 10 sses, the total heat loss is $7.5 \mathrm{~W}$. The measured power required was $13.9 \mathrm{~W}$. This was a measured improvement over the clear envelope of about $47 \%$, again as predicted by theory. The discrepancy is probably due to the shield being only as large as the device substrates and belng spaced away from tilem. Thus, srme surface radiation would : :ot be stopped by the shield.

The next test attempted to simplify the system by using a low-emissivity gold coating on the device substrates themselves. An $\mathrm{SiO}_{2}$ layer was used to avoid shorting out the heater. The results were excellent while on the vacuum pump, but the system failed as soon as the tube was pinched off because of conduction caused by the gas given off from the sputtered $\mathrm{SiO}_{2}$. This experitient sinowed promise, and a more appropr fate insulator material and deposition technique should he investigated as part of any follow-on TIC prograr.

Another Lust was made using 0.018-in.-thick, 1-in.-diam nickel disks that were gold plated on the inside in place of the tigo extra sapphire wafers. The resuit was a total power of $12.1 \mathrm{~W}$. There were st:111 edge losses and the ni.ckel was not highly polished so that the gold plating was not entirely effective. A high-emissivity coating is also required on the outside surface of the nickel.

Future tests should contain two end heaters and shields but with a stack of five device substrates in between and a gold-plated envelope. Temperature will be measured near the center of the stack and on the heater substrate.

C. Conclusions

The total power required for the clear envelope and unshialded device substrates is adequateiy explained theoretically. The effect of reflective shielding internally and of added shields outside the sapphire substrates is also reasonably in accord with the theory, allowing for unavoldable losses in the experimerital arrangement. The total power was reduced from 24-28 $b$ unshielded to $12.1 \mathrm{~W}$ with the best heat shield. From these resuits $1 \mathrm{t}$ appears practical that, with additional work, the total power required can be reduced to below $10 \mathrm{~W}$ without adding any additional shields. These results verify the previous (March 1982 proposal) prediction that, at the level of integration of 
1000 devices $/$ in $^{2}$ with multiple substrates, $2.5 \mathrm{~mW}$ of heaier power per device will be achievable. Because the power per substrate stays constant, independent of the number of devices, at 10,000 devices/in ${ }^{2}$, the heater power per device would be $0.25 \mathrm{~mW}$.

D. Recommerdacions

1. Work should be continued to solve the problems of placing an insulating material over the heater without trapping gas. Then a low-emissivity coating can be applied to the insulating layer. This coating must be smooth to better than $1 \mathrm{\mu m}$.

2. For lorig-term use at high temperature, the vapor pressure of gold is too high. A literature search shows that rhodium is satisfactory. After this heater coating has been worked out, an additional nickel shield could be added with an internal coating of rhodium and an external coating of oxide for high emissivity. Hafnium oxide is excellent, but nickel oxide is reasonably good and could be formed on the nickel after the rhodium plating on the other side. The rhodium and the oxide layer should be 3 un thick. Also, the edges of the device substrates need to be covered with $3 \mu \mathrm{m}$ of rhodium.

3. After the materials/processes supporting the approach outlined above are cumpleted and tested, a complete TIC package should be designed and tested. This package should include not only thermal design but also shock and vibration features.

\section{DEVICE SPEED/BANDWIDTH}

A. Statement of Work from Proposai-(March 1982)

"A common figure of merit for comparing device speed is the gainbandwidth product (GBP) that is custrmarily characterized as the ratio of the transconductance to an equivalent load capacitance. Figure V-1 shows a general case applicable for any three-terminal electronic device. Here the equivalent capacitance $C_{e q}$ is the sum of the output capacitance of the device and the input capacitance of the following device, together with any parasitic capacitance. Therefore, the GBP is

$$
\mathrm{GBP}=\mathrm{g}_{\mathrm{m}} / 2 \pi \mathrm{C}_{\mathrm{eq}},
$$


where $g_{m}$ is the transconductance of the device (recall, $g_{m}$ is a function of the current at which the device is operated as wall as the device geometry). For present TIC devices, the dominant capacitance is the grid-cathode capacitance because of the proximity of those two electrodes and because the sapphire substrate has a relative dielectric constant of 10 . The GBP was not important for the applications previously addressed, so it has not been measured. However, the following data are available.

- Using measured values of $\mathrm{g}_{\mathrm{m}}$ and calculated values of the gridcathode capacitance, an estimate of the GBP of present devices has been shown to be $30 \mathrm{MHz}$.

- A sinusoidal oscillator was fabricated with an oscillation frequency of $5 \mathrm{MHz}$ and was tested at $500^{\circ} \mathrm{C}$.

"Measurements of GBP will be made on a number of devices $n f$ iticicent geometries to determine the limits of the present technology and how these limits are related to device geometry and processing constraints. These measurements will also be compared with theoretical analyses to evaluate the capability of the analytical methods for predicting device performance."

B. Modifications to the Scatement of Work

Because of the number of technical issues to be addressed within the scope of the program and because of the time and cost involved in generating new masks for test structures, it was decided that an analytical approach to the bandwidth/speed issue would be taken in order to bound the expected performance range and highlight parametric relationships. A detailed computer analysis to more accurately evaluate space-charge-limited device performance and a thorough measurement and characterization effort should be undertaken as part of any continued TIC development effort.

\section{Theoretical Analysis of GBP}

Scaling of TIC devices should improve the GBP as should operating the devices at the highest possible current density. For purposes of analysis, the geometry assumed for the device is shown in Fig. V-2. As can be seen, both cathode and anode are raised, permitting emission from the side of the cathode. It is assumed that means are available to prevent emission from all cathode surfaces except the side facing the anode. If necessary, a shield plane can be located some distance above the substrate. 


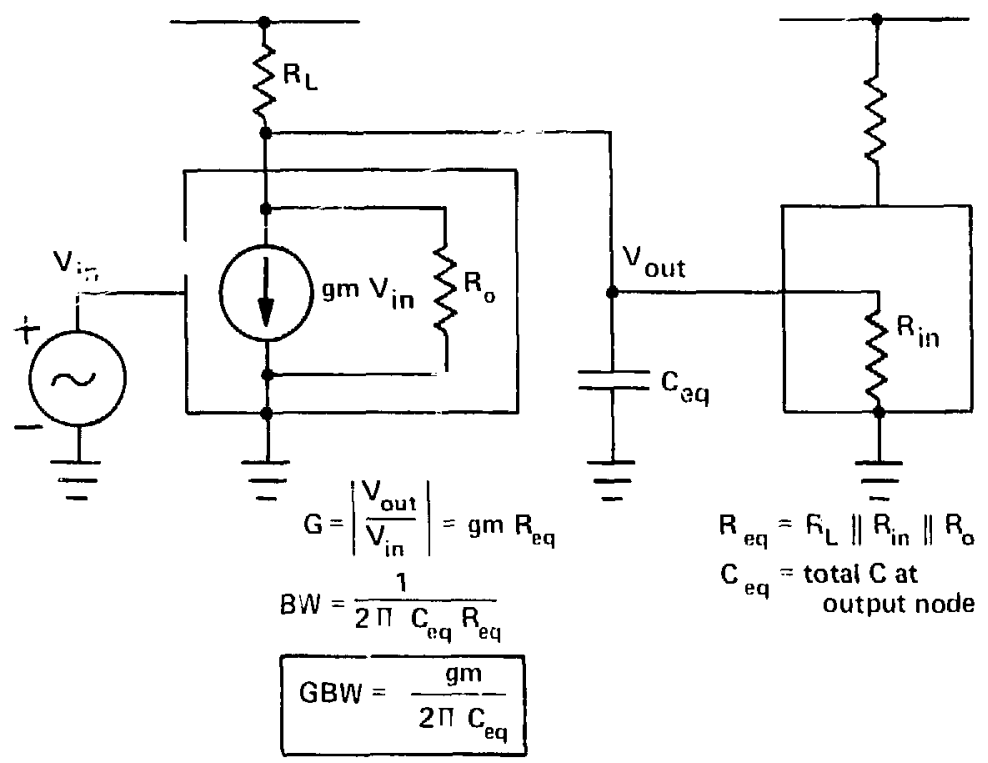

Fig. V-1. Gain-bandwitth product for a three-terminal device.
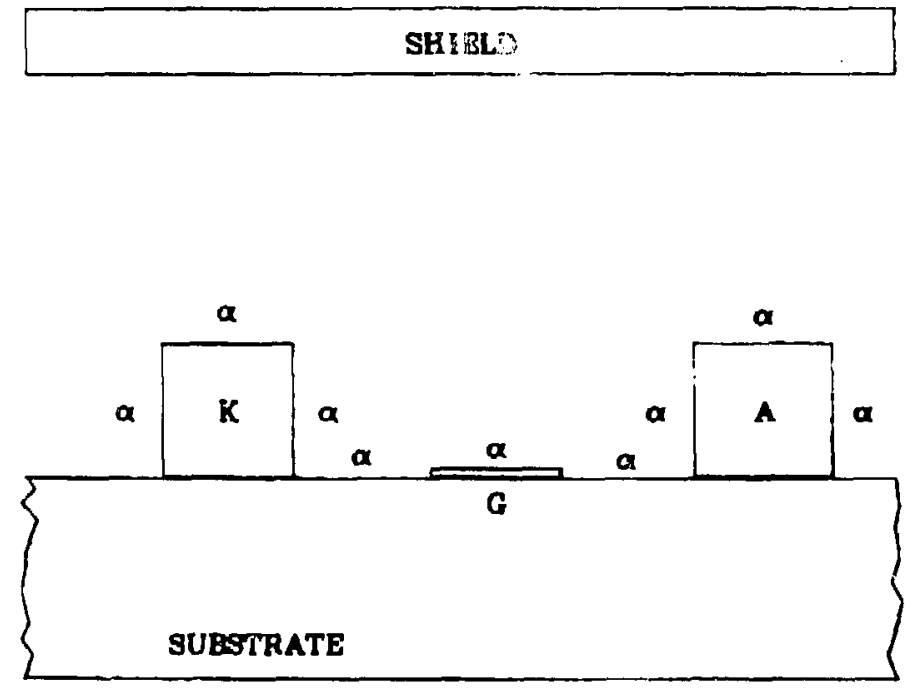

Fig. V-2. Planar device used in GBP calculations. 
The following assumptions and approximations are then made. Current is assumed to be space-charge limited. Photolithography imposes a minimum feature size linitation $\alpha$. All current flow is assumed to be one dimensional between the cathode and anode. The device can be analyzed as though it were a parallel-plane triode with a grid located some effective distance from the cathode and normal to the current flow. The effective distance of the grid from the cathode is approximately $\alpha$. No fringing effects contribute either to interelectrode capacitance or to the amplification factor $\mu$. Spangenberg's equation ${ }^{5}$ for current in a paralle1-plane triode applies, subject to the above assumptions. Wolfe's results for capacitance ${ }^{6}$ are used where applicable. Work functions are neglected. (In a practical sense, the work functions offset the bias voltages of the grid and anode relation to the cathode by the difference between the work function of the metal and that of the cathode.)

If the dimensional dependence of perveance is taken j.nto account, the current in a parallel-plane triode ${ }^{5}$ can be written as

$$
i_{P}=\frac{A_{k} b\left(v_{G}+v_{P} / \mu\right)^{3 / 2}}{\left(\alpha^{4 / 3}+d^{4 / 3} / \mu\right)^{3 / 2}},
$$

where

$$
\begin{aligned}
& A_{k}=\text { cathode area, } \\
& b=2.34 \times 10^{-6}, \\
& v_{G}=\text { grid-cathode voltage, } \\
& v_{P}=\text { anode-cathode voltage, and } \\
& d=\text { distance from anode to cathode. }
\end{aligned}
$$

From this, the transconductance can be determined by

$$
g_{m} \equiv \frac{\partial \dot{A}_{P}}{\partial v_{G}}=\frac{3}{2} A_{k} b \frac{\left(v_{G}+\frac{v_{P}}{\mu}\right)^{1 / 2}}{\left(\alpha^{4 / 3}+\frac{d^{4 / 3}}{\mu}\right)^{3 / 2}}
$$

This can be written in terms of the current density $J$ as 


$$
g_{m}=\frac{1.5 A_{k} b^{2 / 3} J^{1 / 3}}{\left(\alpha^{4 / 3}+d^{4 / 3} / \mu\right)}
$$

Formulation in terms of $J$ is useful because it may be desirable to operate the cathode so that some acceptable $J_{\max }$ is maintained. By substituting $A_{k}=\alpha L_{k}$, where $L_{k}$ is the length of the cathode stripe and $d=3 \alpha$,

$$
g_{\mathbb{m}}=\frac{2.63 \times 10^{-4} L_{k} J^{1 / 3}}{\alpha^{1 / 3}(1+4.33 / \mu)}
$$

Wolfe's results, ${ }^{6}$ with suitable approximations, show that the capacttances per unit length as defined in $\mathrm{Fig} . \mathrm{V}-3$ are $C_{\lambda 6} \simeq 0.688 \varepsilon_{0}, C_{\lambda 7} \simeq 0.780 \varepsilon_{0} \varepsilon$, and the grid-cathode capacitance, $C_{\text {eq }}$, for $E=10 \mathrm{is}$

$$
\mathrm{C}_{\mathrm{eq}} \simeq\left(\mathrm{C}_{\lambda 6}+\mathrm{C}_{\lambda 7}\right) \mathrm{L}_{\mathrm{k}}=7.51 \times 10^{-13} \mathrm{~L}_{\mathrm{k}} \text { farads, }
$$

where $\mathrm{L}_{k}$ is now in centimeters.

With the above results for $g_{m}$ and $C_{e q}$, the GBP can be written as

$$
G B P=\frac{5.58 \times 10^{7} J_{\text {max }} 1 / 3}{\alpha^{1 / 3}(1+4.33 / \mu)},
$$

where $J$ is in $\mathrm{A} / \mathrm{cm}^{2}$ and $\alpha$ is in $\mathrm{cm}$. For $J_{\max }=0.200 \mathrm{~A} / \mathrm{cm}^{2}, \alpha=10^{-4} \mathrm{~cm}$ and $\mu=3$; the GBP is $288 \mathrm{MHz}$. This is, of course, a low $\mu$ case. If $\mu=30$ and the other values are unchanged, the GBP is $614 \mathrm{MHz}$. As expected, the GBP is a weak function of $\mu$.

By solving $\mathrm{Eq}$. $(\mathrm{v}-3)$ for $\left(\mathrm{v}_{\mathrm{G}}+\mathrm{v}_{\mathrm{P}} / \mu\right)$, setting $\mathrm{v}_{\mathrm{G}}=0$, and inserting the appropriate relationship for $\mu$, an anode voltage $v_{P}=66 \mathrm{mV}$ is required to obtain $0.200 \mathrm{~A} / \mathrm{cm}^{2}$ for $\mathrm{n}=1(\mu=3)$.

From Spangenberg, ${ }^{4}$ the transit time for electrons to traverse the region from cathode to anode is approximated by

$$
\tau_{t}=3 \mathrm{~d} / \mathrm{v}_{\mathrm{P}},
$$


where $v_{P}$ is the velocity of electrons at the anode. If the initial velocity is zero, then from energy considerations

$$
v_{P}=\left[(2 e / m) v_{P}\right]^{1 / 2}
$$

For $\alpha=10^{-4} \mathrm{~cm}$ and $V_{\mathrm{F}}=1 \mathrm{~V}, \tau_{\mathrm{t}}$ is found to be $15 \mathrm{ps}$. Preliminary computer modeling including actual electron trajectories, space charge, and geometry indicates a transit time of approximately $34 \mathrm{ps.} \mathrm{One} \mathrm{set} \mathrm{of} \mathrm{computer} \mathrm{simula-}$ tion results is shown in Fig. V-4. (The transit time from the simulaticn is a factor of 2 higher than the idealized theoretical problem hut lends credence to the assumptions made. As will be shown in the following, transit time does not represent a general limitation in small TIC devices.) A 15-ps transit time corresponds roughly to a cutoff frequency of

$$
\mathrm{f}_{\mathrm{T}}=2.2 /\left(2 \pi \tau_{t}\right)=23.2 \times 10^{9} \mathrm{~Hz} .
$$

If the grid-cathode leakage sheet resistance $\rho_{\mathrm{s}}$ is $10^{9} \Omega / \mathrm{sq}$, the leakage current will be $1 \mathrm{nA} / \mathrm{V}$ per uni- length. At a cathode current density of $0.200 \mathrm{~A} / \mathrm{cm}^{2}$, the emission current will be $2 \mathrm{nA}$ per unit length for a cathode height of $1 \mathrm{~m}$. This underscores the necessity of insuri $\mathrm{gg}$ minimum grid-tocathode leakage current and operating the cathode at the largest allowable current density.

This therretical reasoning gives comparative results, indicating the factors on which GBP depends. In Tables $V-1$ and -2 , it is seen that operation at higher anode voltages and, consequently, at large current densities is desirable for a large GBP. It should be noted that TIC cathodes routinely approach current densities of $20 \mathrm{~A} / \mathrm{cm}^{2} \mathrm{dc}$ in test devices. Notice that in all cases above, the limitation imposed hy transit time is substantially above that imposed by $\mu \mathrm{m} / \mathrm{C}$.

Figure $V-5$ presents data similar to Table $V-1$ in graphical form. 

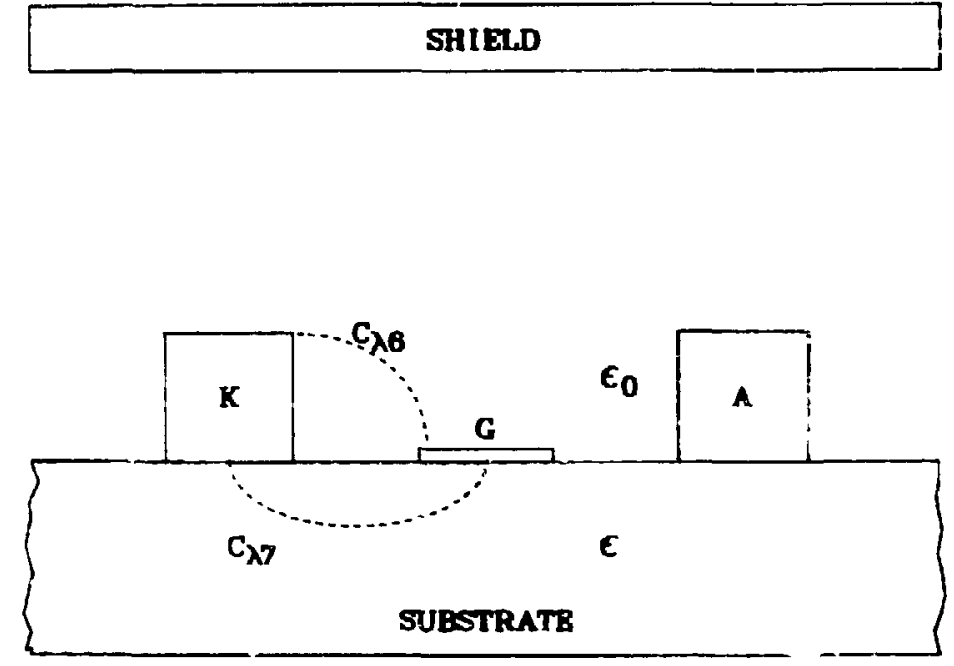

Fig. V-3. Capacitances in a planar device.

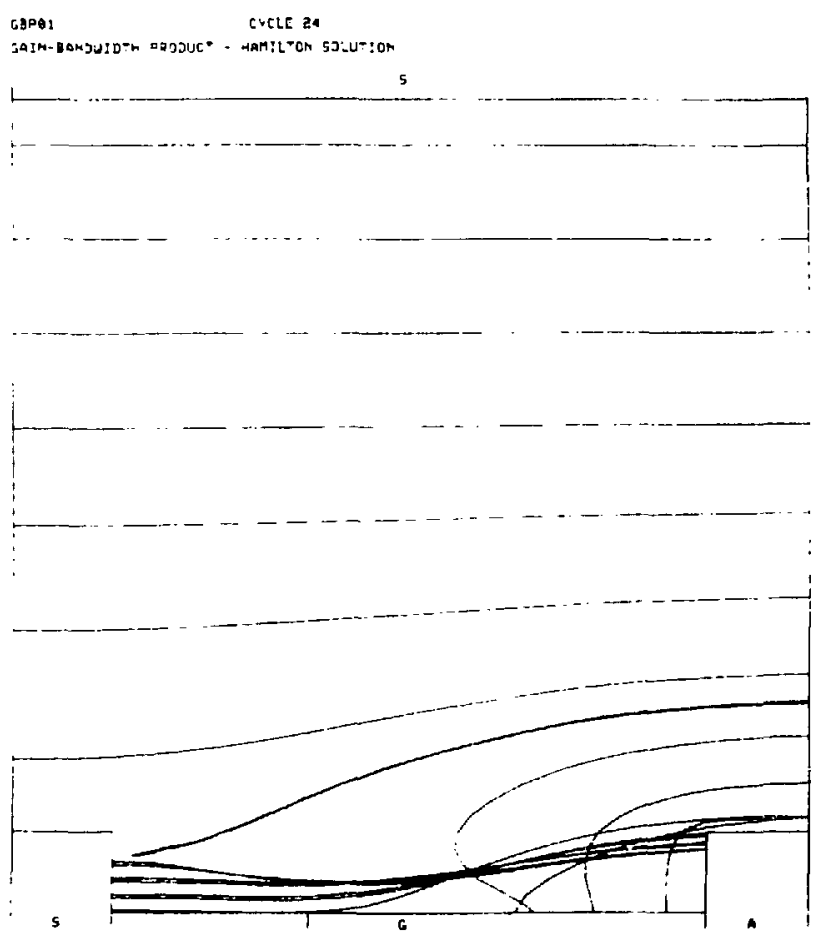

Fig. V-4. Computer simulation showing equipotentials and electron trajectories of the $1-\mu \mathrm{m}$ theoretical device for the GBP calculation. Cathode is to the left, anode is to the right, grid is along the bottom, and reneller is along the top. Potentials used: cathode $0 . ? \mathrm{v}$, anode $1.0 \mathrm{~V}$, grid $0.01 \mathrm{~V}$, repeller $-2.25 \mathrm{~V}$. E1ectron transit time was $34.2 \mathrm{ps}$. 


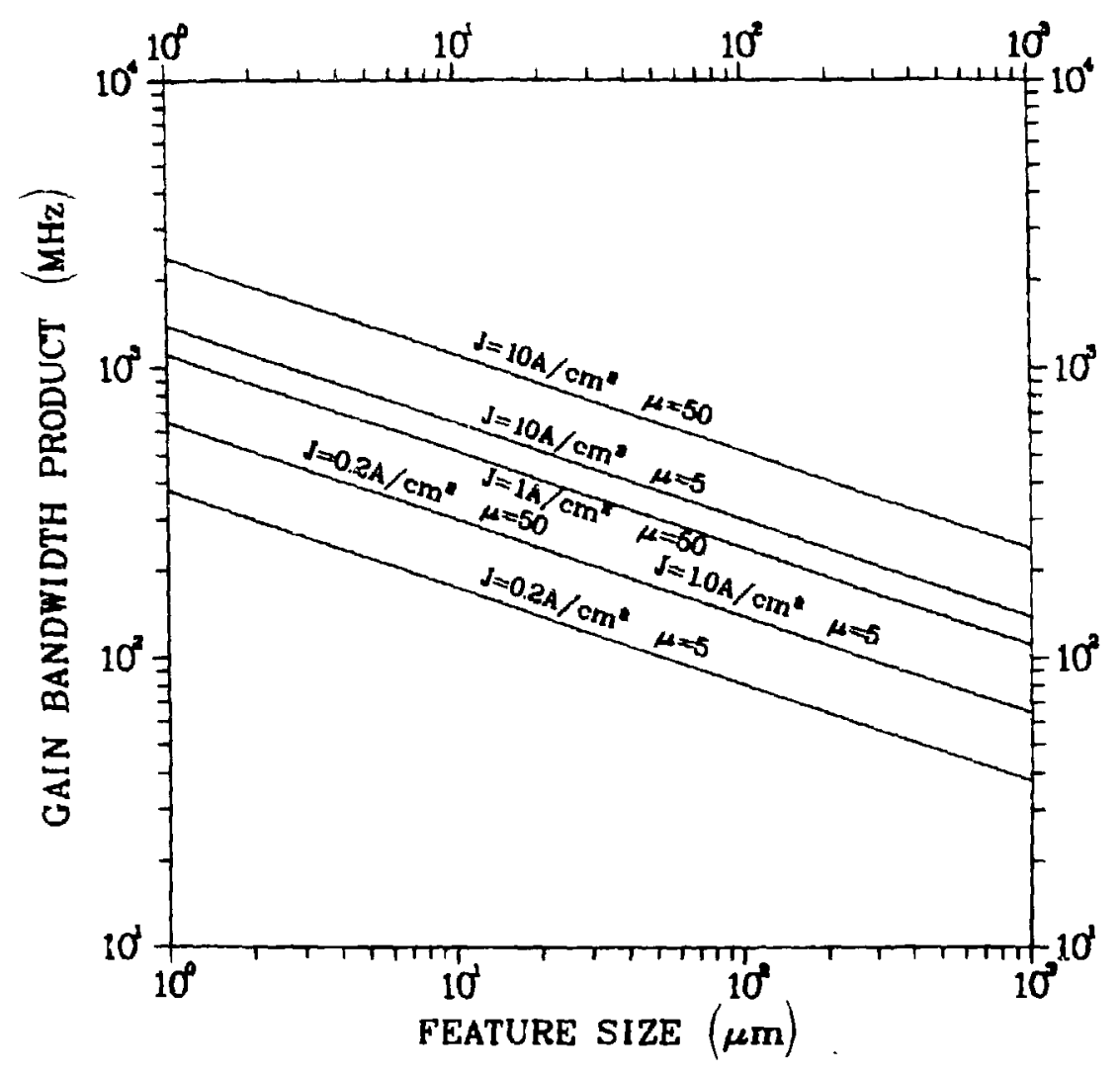

Fig. V-5. GBP as a function of feature size. 
TABLE $V-1$

GAIN-BANDWIDTH PRODUCT IN MEGAHERTZ VS DEVICE FEATURE SIZE $(\alpha)$ AND CURRENT DENSITY ( $\mathrm{J}$ )

\begin{tabular}{|c|c|c|c|c|c|c|}
\hline \multirow[t]{2}{*}{$\alpha(\mu \mathrm{m})$} & \multicolumn{2}{|c|}{$\mathrm{J}=0.2 \mathrm{~A} / \mathrm{cm}^{2}$} & \multicolumn{2}{|c|}{$\mathrm{J}=1 \mathrm{~A} / \mathrm{cm}^{2}$} & \multicolumn{2}{|c|}{$\mathrm{J}=10 \mathrm{~A} / \mathrm{cm}^{2}$} \\
\hline & $\mu=5$ & $\mu=50$ & $\mu=5$ & $\mu=50$ & $\mu=5$ & $\mu=50$ \\
\hline 10,000 & 17.5 & 30.0 & 30.0 & 51.4 & 64.6 & 111 \\
\hline 5000 & 22.1 & 37.9 & 37.8 & 64.7 & 81.4 & 139 \\
\hline 2500 & 27.8 & 47.7 & 47.6 & 81.6 & 103 & 176 \\
\hline 2000 & 30.0 & 51.4 & 51.3 & 87.9 & 111 & 189 \\
\hline 1000 & 37.8 & 64.7 & 64.6 & 111 & 139 & 238 \\
\hline 500 & 47.6 & 81.6 & 81.4 & 139 & 175 & 300 \\
\hline 200 & 64.6 & $i 1 \mathrm{i}$ & 111 & 189 & 238 & 408 \\
\hline 100 & 81.4 & 139 & 139 & 238 & 300 & 514 \\
\hline 50 & 103 & 176 & 175 & 300 & 378 & 647 \\
\hline 20 & 139 & 238 & 238 & 408 & 513 & 879 \\
\hline 10 & 175 & 300 & 300 & 514 & 646 & 1107 \\
\hline 5 & 221 & 379 & 378 & 647 & 814 & 1395 \\
\hline 2 & 300 & 514 & 513 & 879 & 1105 & 1893 \\
\hline 1 & 378 & 647 & 646 & 1107 & 1392 & 2385 \\
\hline
\end{tabular}

TABLE $\quad \mathrm{V}-2$

GAIN-BANDWIDTH PRODUCT CALCULATIONS FOR $1-\mu$ m-FEATURE SIZE

\begin{tabular}{|c|c|c|c|c|c|c|}
\hline $\begin{array}{r}\mathrm{V}_{\mathrm{P}} \\
(\mathrm{V})\end{array}$ & $\begin{array}{c}\mathrm{J} \\
\left(\mathrm{A} / \mathrm{cm}^{2}\right) \\
\end{array}$ & $\underline{\mu}$ & $\begin{array}{l}\mathrm{g}_{\mathrm{m}} / \mathrm{L}_{\mathrm{k}} \\
(\mu \mathrm{S} / \mathrm{cm}) \\
\end{array}$ & $\begin{array}{c}\mathrm{GBP} \\
(\mathrm{GHz}) \\
\end{array}$ & $\begin{array}{c}\tau_{t} \\
(p s) \\
\end{array}$ & $\begin{array}{c}f_{t} \\
\left(\mathrm{GH}_{z}\right) \\
\end{array}$ \\
\hline 1.000 & 11.70 & 3 & 5289 & 1.100 & 15 & 23.2 \\
\hline 1.000 & 1.16 & 30 & 5211 & 1.100 & 15 & 23.2 \\
\hline 0.310 & 0.20 & 30 & 2900 & 0.618 & 27 & 13.1 \\
\hline 0.066 & 0.20 & 3 & 1363 & 0.283 & 58 & 6.0 \\
\hline
\end{tabular}


D. Enhanced Processing

If a process analogous to a "self-aligned" IC process is developed, the effective spacing between the grid and cathode could be reduced in the manner shown in Fig. V-6. For this case, in which minimum spacing of 0.1 is assumed,

$$
g_{m}=\frac{1.5 b^{2 / 3} L_{k} J^{1 / 3}}{\alpha^{1 / 3}(0.05+1.28 / \mu)}
$$

and

$$
\mathrm{C}_{\text {eq }}=(1.98+2.82 \varepsilon) \mathrm{E}_{\mathrm{o}} \mathrm{L}_{\mathrm{k}} .
$$

For $J=0.200 \mathrm{~A} / \mathrm{cm}^{2}$ and $\alpha=10^{-4} \mathrm{~cm}$, the GBP is $0.42 \times 10^{9} \mathrm{~Hz}$ for $\mu=3$ and $1.74 \times 10^{9} \mathrm{~Hz}$ for $\mu=30$.

Use of a self-aligned process with smaller grid-cathode spacing would increase the GBP, but nut by an order of magnitude. It would, however, significantly increase the leakage current. Operation at the largest allowable cathode current density not only would improve the GBP but also would improve the ratio of cathode current to leakage current.

Table V-2 also shows that $g_{m}$ is not changed by an order of magnitude for any of the conditions calculated, and it seems evident that refinement of the approximations will not result in drastic alteration of the obtainable $g_{\mathrm{m}}$. Therefore, to make significant improvement of the GBP by process variations would require a modification that reduces $\mathrm{C}_{\text {eq }}$. A more likely approach, however, would be to include grooves in the substrate to reduce the interelectrode capacitance (Fig. V-7). Table V-3 shows the calculated effects on interelectrode capacitance vs depth of groove using the notation in Fig. V- 8 . 


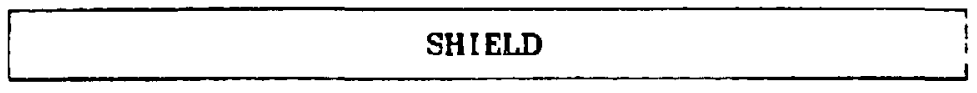

$\alpha$

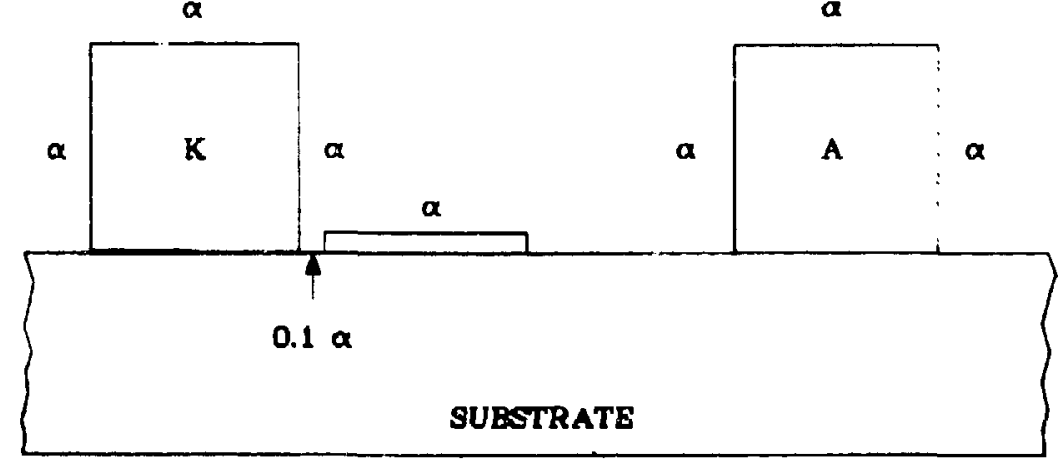

Fig. V-6. Reduction of grid-cathode spacing in self-aligning planar device.

\section{SHIELD}

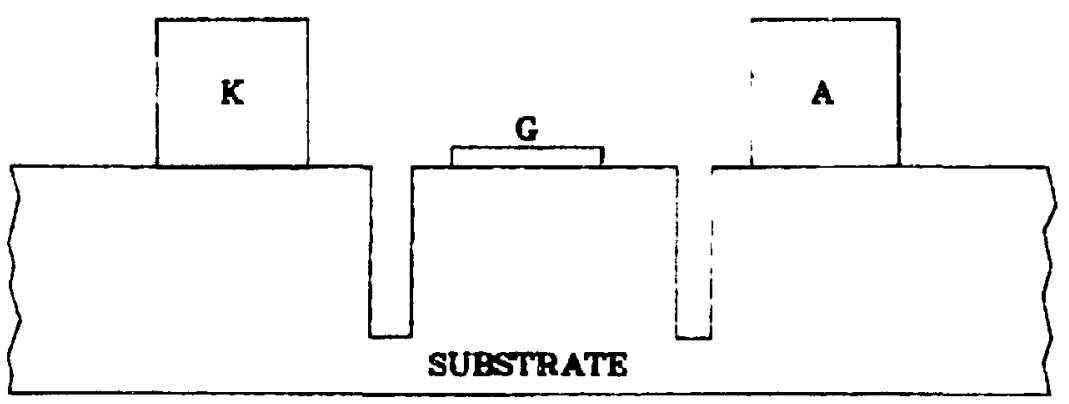

Fig. V-7. Grooved planar device to reduce gridcapacitance cathode. 


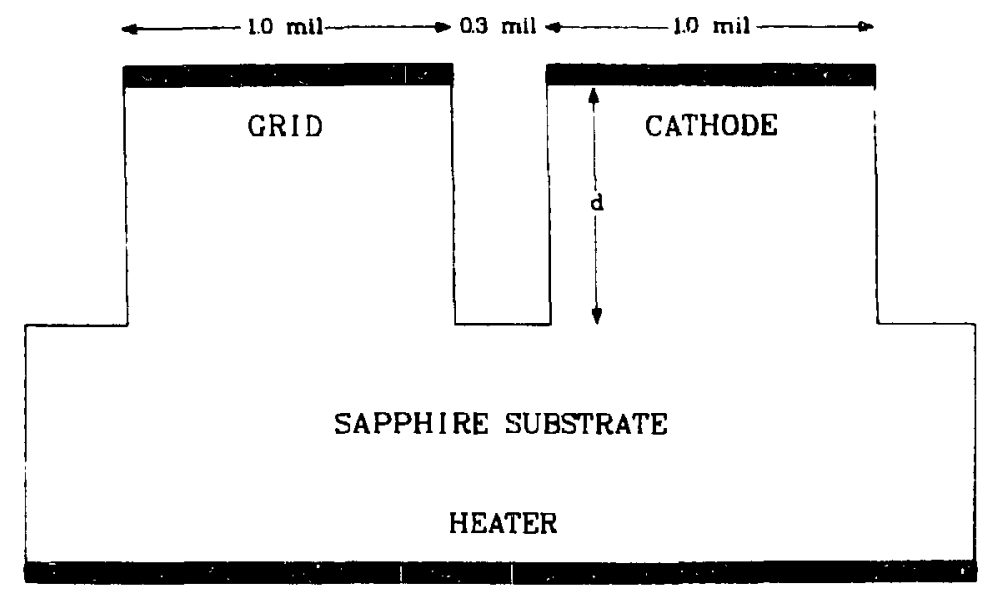

Fig. V-8. Reference figure for depth of groove vs capacitance calculation. 
TABLE V-3

CAPACITANCE OF GROOVED SAPPHIRE NORMALIZED TO UNGROOVED

\begin{tabular}{ccc}
$\mathrm{d}(\mathrm{m})$ & $\begin{array}{c}\text { Grid-Cathode } \\
\text { Normalized Capacitance } \\
\text { no groove }\end{array}$ & $\begin{array}{c}\text { Gain-Bandwidt h } \\
\text { Improvement Factor }\end{array}$ \\
\cline { 2 - 3 } 1 & 1.0 & -- \\
5 & 0.82 & 1.22 \\
10 & 0.58 & 1.72 \\
12.7 & 0.43 & 2.33 \\
19 & 0.38 & 2.63 \\
25.4 & 0.29 & 3.45
\end{tabular}

E. Conclusions

As can be seen from Table $V-1$, TIC devices with gain-bandwidth products on the order of $100 \mathrm{MHz}$ can be designed with current technology. Higher current densities of $10 \mathrm{~A} / \mathrm{cm}^{2}$ such as those commonly observed in TIC test devices but not characterized for lifetime under those conditions would increase frequency responses of devices achievable with current technology to over $500 \mathrm{MHz}$. Smaller feature sizes or grooved substrates could be expected to increase these frequencies to gigahertz levels.

F. Recommendations

1. As can be seen from Tables $V-1$ and $V-2$ and Fig. V-5, the speed of the devices can be greatly enhanced by running at higher current densities. Therefore, understanding the effects of high current density operation on cathode lifetime is important. A continuation of the characterization described in Section VI.B should be part of any continuing TIC program.

2. Ways of improving the processing and lithography of cathodes should be investigated in order to minimize spacing between grid and cathode.

3. Processing techniques for grooving substrates as part of the process should be investigated (including perhaps the use of different substrate materials). 
4. Although Los Alamos has developed and routinely used computer codes to predict the performance of TIC devices, a new code should be developed with adjustable meshing contours to more accurately describe the rapid variation in potential occurring near the cathode of a planar device.

5. A variety of TIC structures should be fabricated and tested to verify the GBW calculations, as descrihed in the Appendix.

6. The models described in the preceding section do not include the cathode dynamics. Thermionic cathodes have been historically observed to provide substantially (sometimes orders of magnitude) more current in the "pulsed" mode or during transient operation. This effect has also been observed in the TICs. TIC cathodes must, therefore, be thoroughly characterized and modeled for transient operation.

VI. LIFE AND RELIABILITY

A. Statement of Work from Proposal (March 1982)

"Devices have been operated continuously with substrates at $750^{\circ} \mathrm{C}$ and envelopes at $500^{\circ} \mathrm{C}$ ambient for 13,000 hours. During that time, no degradation of device dc characteristics was observed. After 13,000 hours a pin seal on the package falled and the test was terminated." No further activity in this area was proposed under this program.

B. Experimental Program for Another Sponsor - High Current Density Cathodes

An industrial sponsor of this technology (with interest in a very different set of commercial devices that utilize TIC cathodes and fabrication processes) has requested that Los Alamos investigate life and reliability issues as related to the cathode. The approach to these tests is surinarized in this section along with preliminary cathode current data.

Current density is basically a measurement of cathode efficiency at a given temperature. The higher the current density, the 1 arger $g_{m} / C$; or conversely, a smaller cathode area can produce equivalent $g_{m}$ with a corresponding reduction in capacitance and increase in packing density. Temperature might also be lowered for a high current density cathode, reducing heater power requirements and promoting increased lifetime. Conventional receiving tubes were designed to operate at $100 \mathrm{~mA} / \mathrm{cm}^{2}$ to achieve optimum life with carbonate 
cathode material on nickel Dase metal (with BaO reducing agents incorporated in the base metal). With the advent of the barium aluminate dispenser cathodes in 1955, current densities of $2 \mathrm{~A} / \mathrm{cm}^{2}$ at $1000^{\circ} \mathrm{C}$ were achieved with up to $10 \mathrm{~A} / \mathrm{cm}^{2}$ at $1200^{\circ} \mathrm{C}$. These cathodes were made by impregnating a porous tungsten plug with barium aluminate powder. The barium necessary for activation is generated by reaction with tungsten.

Under industrial sponsorship, experiments on cathode 11 fe vs current. density have recently been inftlated at Los Alamos. Test diodes have been fabricated and tested using the TIC standard tungsten thin-film base, regular (Ba, Sr, Ca) carbonate-photoresist as cathode material, and a 5- x 5-m11 cathode area. Emission levels of $10 \mathrm{~A} / \mathrm{cm}^{2}$ or greater at $800^{\circ} \mathrm{C}$ have routinely been observed (FIg. VI-1). The anode consists of titanlum sheet mounted $5 \mathrm{mils}$ above the cathode. Figure VI-2 shows a test pattern used to test four diodes simultaneously. Flgure VI-3 shows the same structure with one anode welded in position on the sapphire substrate. The titanium sheet has folded up "wings" to provide additional tinermal dissipation in the anode.

It is belleved that the carbon in the photoresist acts as a reducing agen.t for these cathodes. The following reactlons may occur:

At $600^{\circ} \mathrm{C}, \mathrm{BaCO}_{3}+\mathrm{C}=\mathrm{BaO}+2 \mathrm{CO}$.

At $850^{\circ} \mathrm{C}, \mathrm{BaO}+\mathrm{C}=\mathrm{Ba}+\mathrm{CO}$.

A more efficient reaction may take place in the TIC cathode because the carbon is avallable in the mixture; whereas in the standard receiving tube cathodes, reducing agents were diffused from the base metal (nlckel), and thus, barlum conversion was limited by the rate of diffusion at a specific temperature.

High current Ilfe tests us ing this structure will be started in the near future. (Previous 11 fe tests on TIC devices were conducted at approximately $200 \mathrm{~mA} / \mathrm{cm}^{2}$.) Also, no attempt has been made to date to fabricate a trlode for operation at these levels. Future planning includes work on both these 1tems using the four-device structure shown in Fig. IV-1 to evaluate the cathode 1ifetime as a function of current density for a given temperature. Multiple tests will be performed to determine the effect of teinperarure.

C. Conclusions

The TIC devices are routinely producing currant densitles approaching $20 \mathrm{~A} / \mathrm{cm}^{2}$ at $800^{\circ} \mathrm{C}$ as compared with the older figures of mertt of $100 \mathrm{~mA} / \mathrm{cm}^{2}$ in conventional oxide-coated vacuum tube cathodes. This could have a large impact 


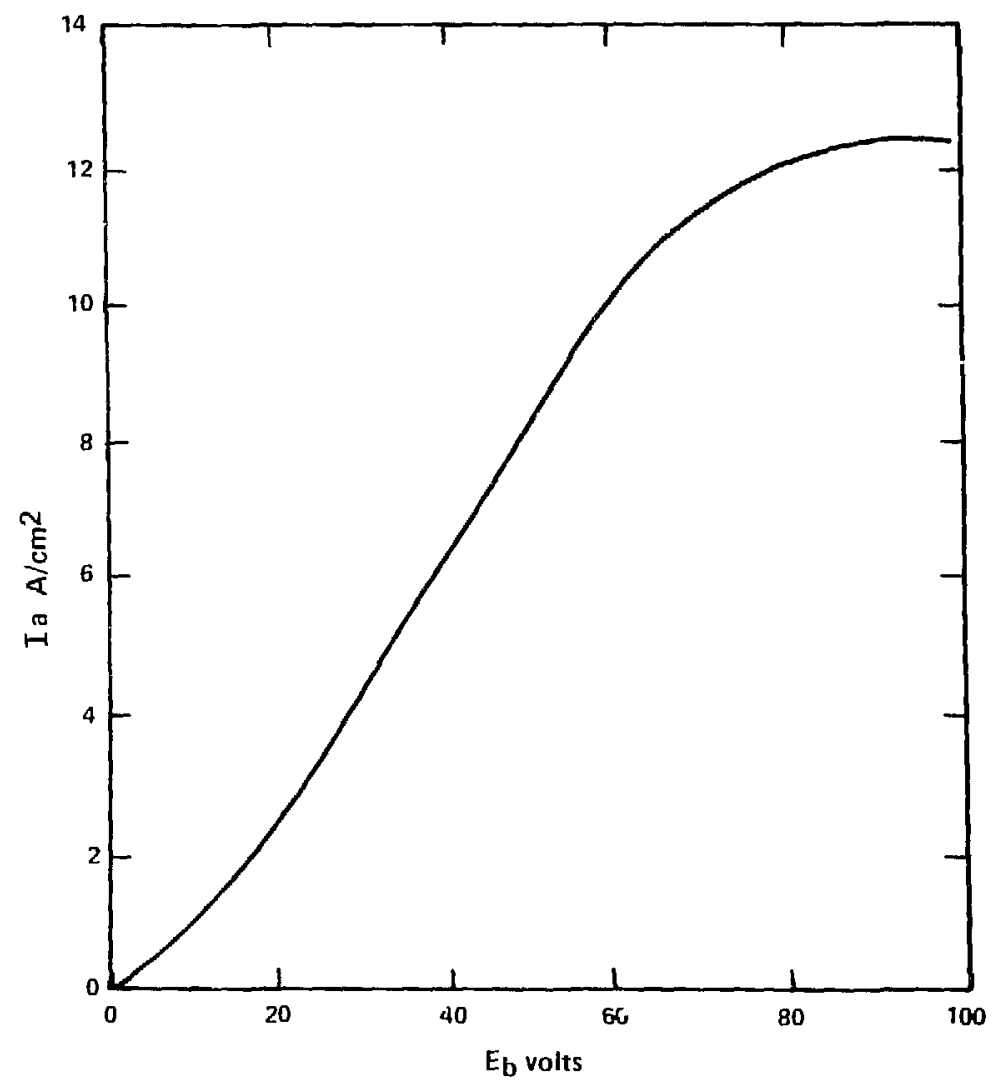

Fig. VI-1. Diode characteristics at $800^{\circ} \mathrm{C}$. 


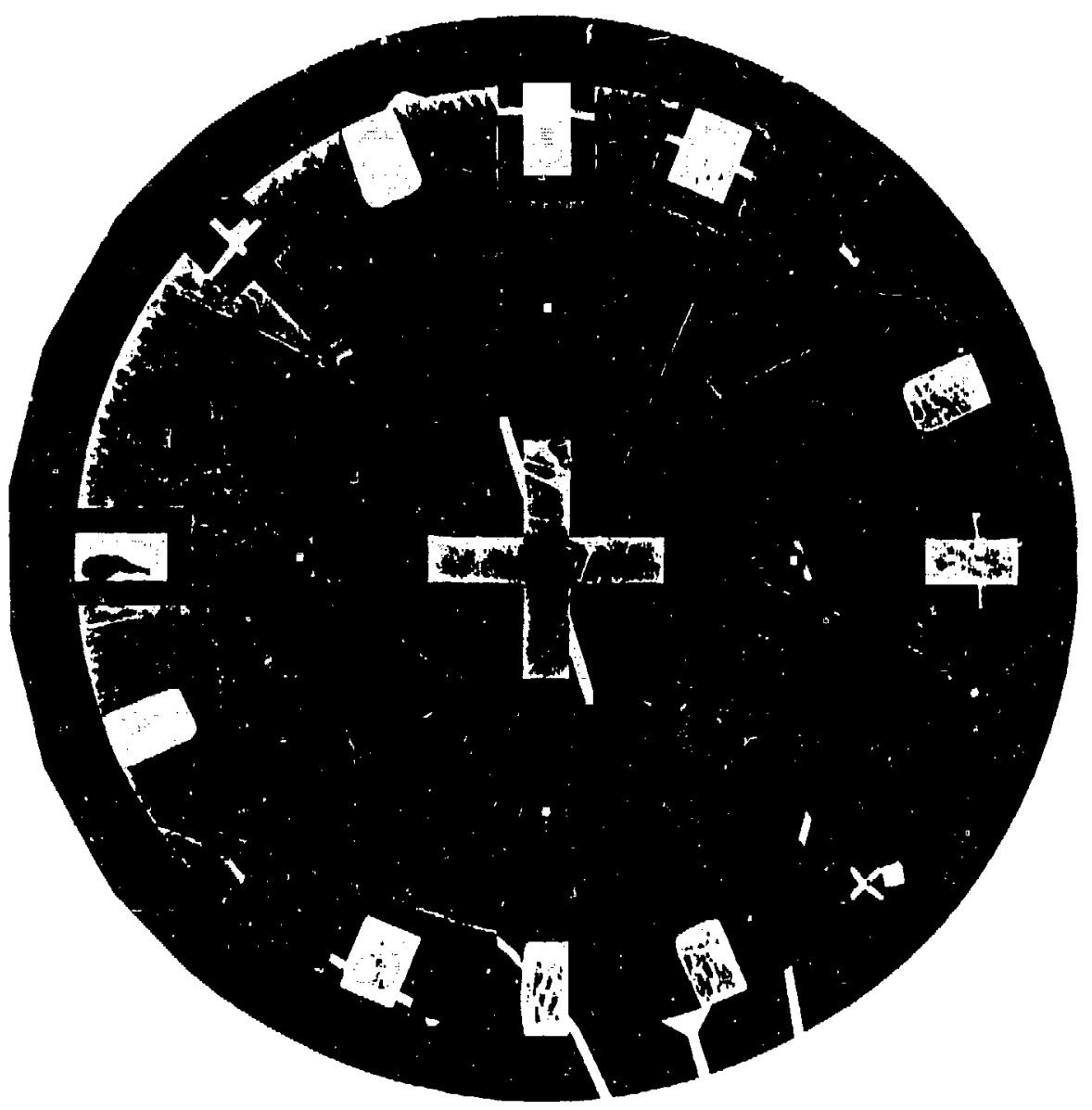

Fig. VI-2. Cathode substrate.

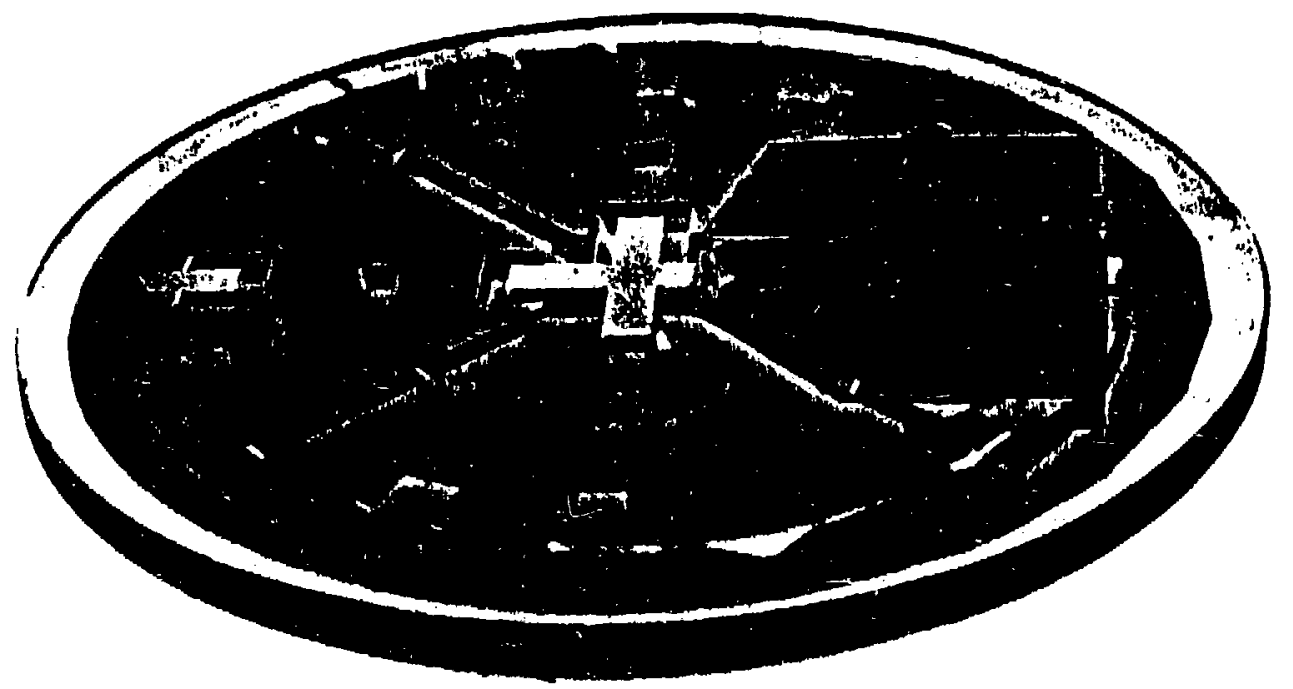

Fig. VI-3. Substrate with one anode welded in position above the cathode. 
on both functionality and speed of TIC circults if long lifetime can also be demonstrated under these conditions.

D. Recommendations

1. At a very minimum, life vs current density and life vs substrate temperature experiments should be continued for existing cathode techntques.

2. Advanced, more durable cathodes as described above should be explored as part of any long-term TIC program.

VII. POWER DEVICES

A. Background

The TICs could be of interest as triode power switches or power diodes for many systems such as the space reactor because of their high tolerance to total radiation dose. This preliminary evaluation addresses this application as requested at a meeting between Los Alamos personnel and an SP-.LO0 contractor infliated at the request of the contractor.

It must be mentioned at the outset that the TICs have been developed as small signal linear or low power digital devices, not as high current or power devices. Therefore, a complete evaluation for power applications would require a substantial effort in power device design as well as power device fabrication and evaluation in order to verify performance. In addition, package design is an important consideration. Because the device must ie packaged to withstand shock and vibration and because the devices operate at $700-900^{\circ} \mathrm{C}$, therma1 radiation characteristics and thermal capabilities of the package are important. Further: 1ifetime data vs current density and operating temperature are not available at this time, although preliminary tests are currently under way as described in section VI.

B. Analysis of Two Conflgurations

Two possibilities are considered for handling 2-kW increments from the source (power and operating voltage was supplied by the SP-100 contractor). Th.2 first is as a conventional switch where most of the $2 \mathrm{~kW}$ would be dissipated in a load resistor. In the second possibility, the entire $2 \mathrm{~kW}$ would be dissipated in a metal anode, which is part of the device. That is, the device 
would be connected directly across the source and there would be no load resistor. The device would be designed so that in the on state the device current would be $2000 /$ (source voltage).

The first design using the conventional low-power switch shows some promise even for a source voltage as low as $100 \mathrm{~V}$. However, it should be noted that, because the total cathode area is proportional to the total current, device size is reduced and device design is simplified as the source voltage 18 increased and device current is decreased. Therefore, higher source voltages are more favorable to the devices.

The evaluation of the low-power switch is based on the worst case of 100-V source and 20-A switch current. As indicated below, there are insufficlent data to justify detailed calculations or evaluation of other source voltages, although as described later, higher voltage operation at lower current simplifies device design.

As a starting point, a current density of $1 \mathrm{~A} / \mathrm{cm}^{2}$ would require $20 \mathrm{~cm}^{2}$ of active cathode area, and an "on" voltage of $5 \mathrm{~V}$ would require that the device be capable of dissipating $100 \mathrm{~W}$. Although a triode is being evaluated, the diode current density equation can be used to calculate the approximate anode-to-cathode spacing:

$$
\mathrm{J}=2.335 \times 10^{-6} \mathrm{v}^{3 / 2} / \mathrm{s}^{2},
$$

where $\mathrm{S}$ is the anode to cathode spacing in centimeters.

Using the above conditions, the required spacing is $5.1 \times 10^{-3} \mathrm{~cm}$ or $2 \mathrm{mils}$. Since substrate-to-substrate spacings of $2 \mathrm{mils}$ cannot be maintained with the vertical triode structure ( $g r 1 d$ and cathode on one substrate and anode above on another substrate), the vertical trlode probably cannot be used. However, the planar triode (cathode, grid, and anode on the same substrate) would allow an anode-to-cathode spacing of $2 \mathrm{mils}$.

Equation ( $\left.V_{i}^{i}-1\right)$ was derived for a vertical structure and should only be used as an approximation for a planar device. However, assume that a cur-. rent density of $1 \mathrm{~A} / \mathrm{cm}^{2}$ can be obtained from a multiple device planar triode with a cathode-to-anode spacing (center-to-center) of 2 mils. Figure VII-1 shows a single device of this type. It must be emphasized that there is very little data on planar devices of this geometry and that the following calculations require experimental verification. 
SHIELD
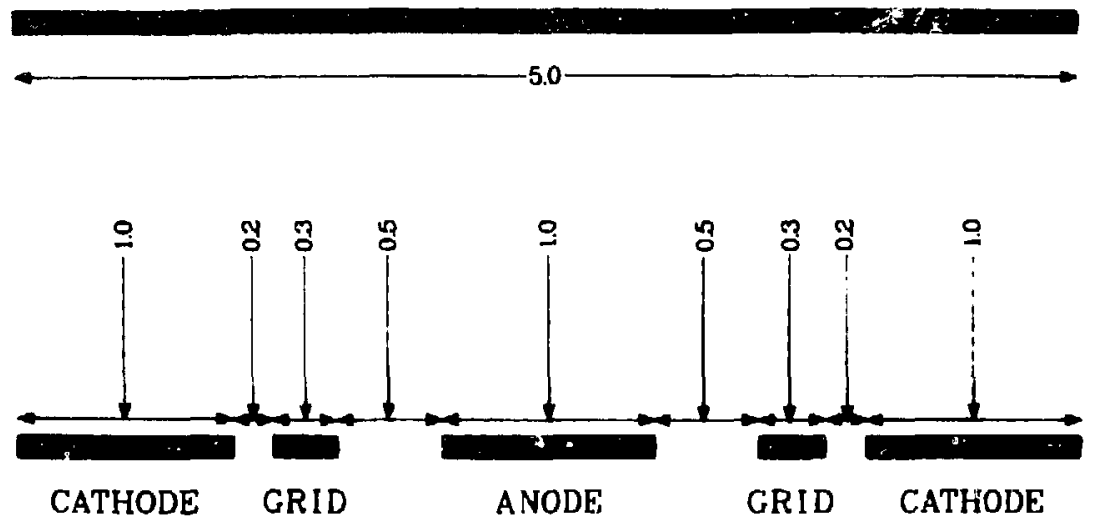

Fig. VII-1. Space power reactor planar triode dimensions. 
From Fig. VII-1, the total device area is four times the cathode area or $80 \mathrm{~cm}^{2}$. Four 2.2-in.-diam substrates would supply this device area with $200 \mathrm{mils}$ around the outer edge of each substrate for bonding and mounting.

The total power radiated from a pair of 0.75-in.-diain by 0.03-in.-thick substrates operating at $800^{\circ} \mathrm{C}$ can be reduced to below $10 \mathrm{~W}$ by the methods used in Section IV. The ratio of the edge area to total substrate area is

$$
A_{e} / A_{t}=4 t /(d+4 t),
$$

where $t$ is the substrate thickness and $d$ is the substrate diameter. For $d=$ $0.75 \mathrm{in}$. and $t=0.03 \mathrm{in.}, \mathrm{A}_{\mathrm{e}} / \mathrm{A}_{\mathrm{t}}=0.14$. Then for a total power of $10 \mathrm{~W}$, the power radiated from the two substrate edges is approximately $1.4 \mathrm{~W}$, and the power radiated from the two substrate surfaces is approximately $8.6 \mathrm{~W}$ or $1.5 \mathrm{~W} / \mathrm{cm}^{2}$. These data are used to calculate the heater power required becatze heater power has not been measured for 2.2-in substrates or for a stack cf more than tho substrates.

For a stack of four 2.2-in substrates, the surface power radiated from the two end substrates would be $74 \mathrm{~W}$. The ratio of the total edge area to the two end surfaces for 30 -mil-thick substrates is 0.11 . The power radiated from the four edges is $\mathrm{P}_{\mathrm{e}}=8.1 \mathrm{~W}$, and the total power radiated is $\mathrm{P}_{t}=82 \mathrm{~W}$. Thus, an estimate of the heater power required to maintain the four substrates at $800^{\circ} \mathrm{C}$ is $82 \mathrm{~W}$. Lhis can be reduced by additional shieluing or by reducing the standby temperature. For example, a standby temperature of $700^{\circ} \mathrm{C}$ would reduce the estimated heater power to $55 \mathrm{~W}$.

The voltage gain of the device in Fig. VII-1 is estimated to be about 4 . The device would be turned on with about $+2 \mathrm{~V}$ and turned of $\mathrm{f}$ with $-25 \mathrm{~V}$. The input power is determined primarily by the grid-to-cathode leakage resistance, which is quite high. It is estimated that the power gain would be $>1000$.

These values are based on preliminary calculations of planar device characteristics. At Los Alamos, only a few planar devices have been characterized and no power devices have been characterized. One small signal device that has been characterized has geometry similar to that of the device in Fig. VII-1 but with substantially different electrode dimensions. Its characteristics were voltage gain $=4$ and current density $=100 \mathrm{~mA} / \mathrm{cm}^{2}$ at $5 \mathrm{~V}$ and 300 $\mathrm{mA} / \mathrm{cm}^{2}$ at $10 \mathrm{~V}$. These current densities would be increased if the anode-tocathode spacings were reduced to $2 \mathrm{mils}$. 
A second possible device for this application would dissipate the entire $2 \mathrm{~kW}$ in the anode. Preliminary calculations indicate that this concept has possibilities for source voltages above $200 \mathrm{~V}$. For example, with a source voltage of $400 \mathrm{~V}$, the device would be designed so that in the "on" state the device current would be $5 \mathrm{~A}$ at $400 \mathrm{~V}$ anode to cathode. The metal anode would have to be designed to radiate $2 \mathrm{~kW}$; this could be done at relatively high temperatures (perhaps $>1000^{\circ} \mathrm{C}$ ). Before further work is done on this concept, it must be determined if it offers any system advantages or would even be compatible with the system.

For example, consider switching 5 A from a $400-\mathrm{V}$ source. If a vertical triode with a 100-mil anode-to-cathode spacing is used, the current density calculated from Eq. (VII-1) is $289 \mathrm{~mA} / \mathrm{cm}^{2}$. Current vertical devices have a device-to-cathode area ratio of $2: 1$ and a voltage gain of about 50 with 100-mil anode-to-cathode spacing. Thus, a cathode area of $17 \mathrm{~cm}^{2}$ and a device area of $34 \mathrm{~cm}^{2}$ are required. The device would consist of a $2-i n$ substrate on each end of a common anode. The size and shape of the anode could be adjusted to accommodate the required radiated thermal power.

C. Conclusions

Because of the small cathode-to-anode distances achievable in the planar device form of TIC technology, power devices with high stand-off and low forward drop in the on state (as compared with conventional vacuum devices) may be possible. Also, power devices may have important properties for space reactors in their ability to withstand total dose environments and may be useful adjuncts to TICs with applications mentioned in Section VIII.

\section{Recommendations}

1. Power devices should be designed and tested in order to augment the capabilities of TICs in controlling power.

2. Current density vs life tests must he conducted in order to properly evaluate the technology for possible high-power applications. 
VIIT. APPLICATIONS

A. Approach

Since the general rationale for this project is to evaluate applicability of TIC technology to weapons systems and concurrently to develop insights for guiding future TIC development programs, broad discussions with both governmental agencles and industry (Ref. Section VIII.B) have been Inftiated. Based on those discussions, varying emphasis has been given to the types and defth of the technicai evaluations performed. Additionally, based on sponsor guidance suggesting the importance of applications, a small amount of funding from the program ( $\$ 30 \mathrm{k}$ ) has been set aside for a contract to one of several companies to perform an independent evaluation of the TIC technology vs applications. After the competitive RFP process, $R \& D$ Associates (RDA) has been selected to carry out this analysis. Also, since beam weapons represent an important possible threat in the fucure, Dr. George Messenger has been retained by Los Alamos as a consultant to evaluate and report upon the threat posed to electronics by beam weapons and to evaluate the TIC technology as related to that emerging weapons concept.

The first phase of understanding potentlal TIC applications was to initiate a broad-based set of discussions with both industry and military personnel. Because TICs represent a new concept to most of the military weapons systems communty, it was expected that these discussions would inftiate dialog that would, in general terms, define possible applications and/or technological 1ssues that should be further addressed in this program. More detalled assessments would be left to RDA and Dr. Messenger.

B. Discussions/Presentations/Meetings

For brevity, the discussions, presentations, and meetings to date are listed in Tables VIII-1 and VIII-2. Table VIII-3 is an additional list of requests for data from industry (visits to several of these organizations have been promised in the next few months). 
TABLE VIII-1

MEETINGS

\begin{tabular}{|c|c|c|c|}
\hline General Meetings & Sponsor & Presenter & Location \\
\hline $\begin{array}{l}\text { Space-Based Space } \\
\text { Surveillance Tech- } \\
\text { nology Briefing to } \\
\text { Industry }\end{array}$ & $\begin{array}{l}\text { AF Space Tech- } \\
\text { nology Center }\end{array}$ & J. B. McCormick & $\begin{array}{l}\text { Alr Force Weapons } \\
\text { Laboratory }\end{array}$ \\
\hline $\begin{array}{l}\text { Hardened Electronics } \\
\text { and Radiation Tech- } \\
\text { nology Conference }\end{array}$ & DNA/Oak Ridge & G. Messenger ${ }^{a}$ & Oak Ridge \\
\hline $\begin{array}{l}\text { Solid-State Vacuum } \\
\text { Tube Technology Seminar }\end{array}$ & $\mathrm{JPL}^{\mathrm{b}}$ & J. B. McCormick & JPL \\
\hline $\begin{array}{l}\text { Neutral Beam Technical } \\
\text { Interchange Meeting }\end{array}$ & $\begin{array}{l}\text { AF Space Tech- } \\
\text { nology Center }\end{array}$ & $\begin{array}{l}\text { J. B. McCormickc } \\
\text { G. Messenger }\end{array}$ & $\begin{array}{l}\text { Alr Force Weapons } \\
\text { Lahnratory }\end{array}$ \\
\hline
\end{tabular}

\footnotetext{
autstanding paper award; subject: Susceptibility of Exo-Atmospheric Electronic Systems to Neutral Beam Weapons.

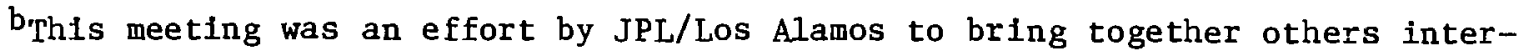
ested in vacuum tube technology to begin sharing data/objectives.

CTwo papers: "Thermionic Integrated Circults for Hardening Electronic Systems," coauthored by B. McCormick and G. Messenger, and "Pulsed Neutral Beams to Enhance Dose Rate Failure Mechanisms" by G. Messenger.
} 
TABLE VIII-2

APPLICATIONS DISCUSSIONS

Name

Prof. Pat Parker Admiral Bob Monroe Brig. Gen. James L. Crouch Al Devitt

Lt. Col. James Hayes

Dr. Richard L. Wagner

Capt. Jim patton

Jin Ramsey

Maj. Ron Lord

Vincent Hungerford

Bill Yeckley

Dick Montgomery

Robert D. Castater

Francis O'Mera

James Vinarski

Dr. Theodore M. Hardebeck

Gene Schroeder

Henry Gray

Mike Gauthier

Jim Graf

Nick Yaru

Dick Richmond

Jim Raymond

Dr. Larry Gray

Mike Gordon

Rao Yadaval11

Dale Vaslow

Al Lieber

Comdr. Al Hughes

Capt. Blodinger

Walt Ware

Phil Jessen

Khosrow Bahrami

Mr. Bob Kupperman

Dr. Howard Phillips

Dr. Frank Rose

Capt. Bud Powers

Lt. Col. Brown
Organization

Navy Postgraduate School

Los Alamos consultant

Data Systems HQ/SAC

" "

" "

Assistant to the Secretary of Defense (Atomlc Energy)

Naval Ocean Systems Center

BMO, Norton AFB

Naval Ordnance Station

JPL-Army Advisory Group

Chlef of Science \& Research, $\mathrm{HQ} / \mathrm{SAC}$

Chlef, Operations Analysis, $\mathrm{HQ} / \mathrm{SAC}$

Operations Analysis, HQ/SAC

Operation Analysis, HQ/SAC

Applied Research, HQ/SAC

Naval Research Iaboratory

JPL-Rad Hardness Group,

SP-100 Program

JPL, SP-100 Program

Sr. Vice President, Hughes

Alrcraft

Hughes Aircraft - Combat

Information, Surveillance

and Sensor Systems

Mission Research Corporation T

Nava1 Ocean Systems Center T.

Martin Marietta IA

GA Technologies T

Navy

DNA

Mission Research Corporation " " "

JPL, Space Reactor Program

Los Alamos consultant

Aerospace Corporation

Naval Surface Weapons Center

Navy, PM-23

DNA, Albuquerque
LA

Location

$(\mathrm{T}=$ Ther $\epsilon$ )

$\underline{(L A=\text { Los Alamos })}$

$\mathrm{T}$

LA

LA

IA

LA

LA

$\mathrm{T}$

LA

$T$

LA, T

IA, T

$\mathrm{T}$

$T$, LA

LA

IA

LA

$T$, LA

$\mathrm{T}$

LA, T

$\mathrm{T}$

$\mathrm{T}$

$\mathrm{T}$

T

LA, T

LA, T

$\mathrm{T}$

LA

$\mathrm{T}$

LA 
Name

Maj. Rolfes

Larry Darda

Tom Bristol

Ken Downing

Bob Hengsteback

Leroy Lakin

Al Lepis

H. T. Peterson

Bob Reeves

B111 Sagey

Joe Santana

Wayne Schenet

John Singleton

Maj. Swenson

Dan Payton

Representative

Maj. Mike Starch

Maj. Lou Mills

Capt. Bruce ThIeman

Maj. Steve Parker

Thomas Jorgensen

Warren Lee

Capt. Leo Florence

Roger David

Joe Mulcahy

Ray Tang

Steve Wfarfield

BIll Wri ht

Maj. Joel Benson

Maj. Nathan Mathewson

Col. Joe Jarboe

Col. Rod Bartholemew

Col. Tom Hohman

Col. Jerry Mason

Col. John Bates

Col. Mike Burke

Col. Dave Carlson

John Bayless

Dr. Signor 1
Organization

"

Hughes Alrcraft, Space \& $T$

Communications

Hughes Aircraft, Ground T

Systems Div.

Hughes Alrcraft T

" " T

" "

" "

" " " T

" " T

" $"$ " T

" $"$ T

" "

" " T

AF Space Technology Center T

AF Weapons Laboratory $T$

a jet engine manufacturer ${ }^{a} \quad$ LA

$\mathrm{HQ} / \mathrm{SAC} / \mathrm{XPQM}$

" $"$ T

" $"$ " T

" " T

" DEXT T

" NRA T

" XPXS T

" XPXF T

" XOBM $T$

Hughes Alrcraft $T$

" " $"$ T

Academy of Health Sclence,

US Army

AF Systems Command LA

" " " LA

" " " " LA

" " " LA

$"$ " " LA

" " " LA

" " " IA

TRW T

Defense Communications Agency $\mathrm{T}$

a Name deleted because proprietary contract with Los Alamos is being negotiated to evaluate jet englne requirements. 
TABLE VIII -3

\section{REQUESTS FOR DATA}

$\begin{array}{ll}\text { Name } & \text { Organization } \\ \text { Carl Casiky } & \text { RCA }^{\text {a }} \\ \text { Joe Veltri } & \text { Sperry Research } \\ \text { Vince Teofilo } & \text { Lockheed } \\ \text { Truman Nybakken } & \text { Delco Systems } \\ \text { Bill Flemming } & \text { TRW }^{\text {a }} \\ \text { D. L. Beeqley } & \text { Lockheed }\end{array}$

avisits/discussions have been requested and will be initiated as time pertits.

C. Conclusions

As can be seen from the preceding section, there have been a substantial number of discussions regarding the TICs. Because the TICs are in a developmental stage, many of the discussions were followed with "what if" questions or both sides. From these discussions some general trends are emerging.

First, word of the technology is spreading rapidly, and as a result, people are contacting Los Alamos for information and briefings. Because military systems and their operational envelopes are designed with existing/ verifi $i$ d hardware, personnel/organizations most curious about the TICs are generally those who are working on future systems. The ability of the TICs to survive and possibly operate through a wide range of radiation and hightemperature environments is stimulating those people to broaden their concept of possible missions and capabilities of future systems. New threats such as beam weapons, lasers, and enhanced effects weaponry as well as new strategies such as flexible response during nuclear conflict, air 1and 2000, and nuclearreactor-powered satellites present the possibilities for environments through which conventional electronics will have difficulty surviving and for which the penalty for electronic failure is large. 
The concept of utilizing the TICs in conjunction with shielded semiconductors has been universally supported as the appropriate approach for employment of the TICs. As a result, TICs with small- to medium-scale level of integratiou have been projected to be extremely useful; projected heater powers of a couple of milliwatts per device are acceptable; and speeds and bandwidths projected suggest a diversity of applications. Concern for EMP is large. High-temperature operation is appealing for a number of applications, and power devices using TIC technology would complement TICs in providing a full systems capability.

As described early in this report, a number of applications have been thought to show promise. A few are listed below.

o Launch control for hard mobile missile - BMO, Norton AFB

D Selective hardening of satellites - Hughes Aircraft, Air Force Systems Command

- Hardened RPVs and battlefield sensors - AF Systems Command, Hughes Aircraft, Mission Research Corporation

- Reactor safety, military, and nonmilitary - GA Technologies, Inc.

- Arming, fuzing, and terminal guidance - Sandia National Laboratories, Naval Weapons Systems Center

- Hardened controls/power devices for both space and terrestrial reactors - JPL, GA Technologies, Inc., Lockheed, Martin Marietta, GE

- Hardened $C^{3} I$ - Defense Communications Agency, Strategic Air Command, JPL

o Jet engine instrumentation/control ("fly by wire") - Strategic Air Command, a jet engine manufacturer*

Two recurring themes in the discussions to date are - Timeliness of the availability of TIC devices (How soon?) o Concern For validation (How can delay from R\&D to fielding be minimized?)

Both of these are important issues in structuring a TIC program and are reflected in the recommendations of Section I.E.

\footnotetext{
* Name deleted because proprietary contract with Los Alamos is being negotiated to evaluate jet engine requirements.
} 
D. Recommendations

There is 11ttle doubt after the discussions held to date that if the TICs fulfill current technical expectations they will find applications in a number of military systems. Therefore, an aggressive TIC development program is recommended even before completion of detailed analyses by RDA and Dr. Messenger. In general, this conclusion not only derives from the interest exhibited to date but also because of the breadth of applications discussed, which are within the capabilities of a projected generic TIC technology. It must be emphasized, however, that this program not only should be a technological program but should include funding for continued applications evaluations and discussions with industrial and governmental personnel responsible for planning and developing future generations of military hardware. In this manner, as the technical performance is verified, the way can be paved for an orderly transition of this technology from the lab to the fleld.

\section{REFERENCES}

1. R. W. Klaffky, B. H. Rose, A. N. Goland, and G. J. Dienes, "RadiationInduced Conductivity of $\mathrm{Al}_{2} \mathrm{O}_{3}$ : Experjment and Theory," Physical

Review B 21-8, 3610-3614 (1980).

2. R. W. Klaffky, "Radiation-Induced Conductivity of $\mathrm{Al}_{2} \mathrm{O}_{3}$," In "Special Purpose Materials," US Department of Energy Annual Progress Report, October 1, 1979, DOE/ER-0048/1 (Apr11 1980).

3. P. P. Coppola and R. C. Hughes, "A New Pressed Dispenser Cathode," Proc. of the IRE (March 1956), pp. 351-359.

4. J. E. Beggs, "Characteristics of Electron Tubes Having Clean Electrodes," InE Transactions of Electron Devices (April 1958), p. 56.

5. Karl Spangenberg, Vacuum Tubes (McGraw H111, New York, 1948), pp. 185-186.

6. P. N. Wolfe, "Capacitance Calculations for Several Simple Two-Dimensional Geometrles," Journal: Proc. of the IRE, October 1962, pp. 2131-2132. 


\section{APPENDIX}

TIC Speed/Bandwidth Test Structures and Plans

Two test patterns need to be fabricated for measurement of the GBP and for verification of predictions. One would be a spiral single-stripe cathode device and the other would be an interdigitated device. Both would have the same cathode area for a given cathode width. Measurements should first be made on a dummy substrate with a heater, but no device pattern, mounted in a header. A substrate with both heater and device can then be measured. All measurements would be made both hot and cold. For ease of mask making, the test devices will be rectangular as shown in Fig. A-1. To minimize the effects of pin capacitance, wherever possible a blank pin would be left between pins used for connections. If adjacent pins must be used, then device eîectrodes already having high capacitance would be connected to adjacent pins. Figure A-2 shows possible pin cholces.

For the spiral single-stripe cathode, as large a cathode area as possible must be obtained while maintaining the same line widths and spacings as would be used in an actual small-geometry, single-stripe device. The spiral would be in the form of a scuare 384 mils on a side (Fig. A-3). For a 1.5-milwide cathode, the length of the cathode is $2550 \mathrm{mils}$ and the cathode area is 3825 sq mils. The first leg and corner of the spiral are shown in Fig. A-4(a). The dimensions of the lines and spacings to be used in this example are: grid (G) width, $1 \mathrm{mil}$; cathode (K) width, $1.5 \mathrm{mils}$; grid-to-cathode (G-K) spacing, 0.25 mils; cathode shield (KS) width, 36 mils; cathode shleld-to-grid (KS-G) spacing, 4 mils; anode (A) width, 4 mils; anode-to-shield (AS) spacing, 36 mils; and anode shield-to-anode (AS-A) spacing, 4 mils. The first leg and corner of the anode are shown in Fig. A-4(b).

If an interdigitated structure of 29 cathode stripes (each $1.5 \times 88$ mils) is used, the cathode area is $38 \mathrm{~L} i \mathrm{sq}$ mils. Figure A-5(a) shows this configuratton using 1-mil grid stripes and 1-mil spaces between the ends of grids and cathodes. The anode substrate is shown in Fig. A-5(b).

The following test procedure would then be implemented. Durmy substrates with heaters for both anode and cathode world be made and mounted on headers sealed in ersvelopes. Substrates would not have device patterns but 
would Include all bonding pads and interconnection metal up to the device terminals. Several headers would then be measured to see if they have the same pin capacitance. Both hot and cold capacitance measurements would be made. Next, substrates having heaters and device patterns would be mounted on headers and sealed in envelopes. Both hot and cold capacitance measurements would again be made. On the hot measurements, the cathode may have to be blased so it is cut off. On all measurements, a guard voltage would be applied to all but the two terminals being measured and to the ring. Finally, transconductance measurements would be made.

If $\left[\mathrm{Y}_{1 \mathrm{~T}}\right]$ is the indefinite admittance matrix for the total configuration of the header, wiring, and substrates with the device; [Y $Y_{1 D}$ ] is the indefinite admittance matrix for the header, wirlng, and dummy substrates; and $\left[\mathrm{Y}_{\mathrm{il}}\right]$ is the indefinitive admittance matrix for the intrinsic device, then

$$
\left[\mathrm{Y}_{i \mathrm{~T}}\right]=\left[\mathrm{Y}_{\mathrm{iD}}\right]+\left[\mathrm{Y}_{\mathrm{iI}}\right]
$$

or

$$
\left[Y_{i 1}\right]=\left[Y_{i T}\right]-\left[Y_{i D}\right]
$$

Once [ $\left.\mathrm{Y}_{\mathrm{il}}\right]$ is known, the device is completely characterized for small-signal operation, no matter what terminal connections are used. It should be noted that even for small-signal operation, the device has six effective terminals: anode, anode shield, cathode, cathode shield, grid, and heater. (For smallsignal operation, both heater terminals are assumed to be electrically the same.) The process can then be repeated for a variety of expected geometries. 


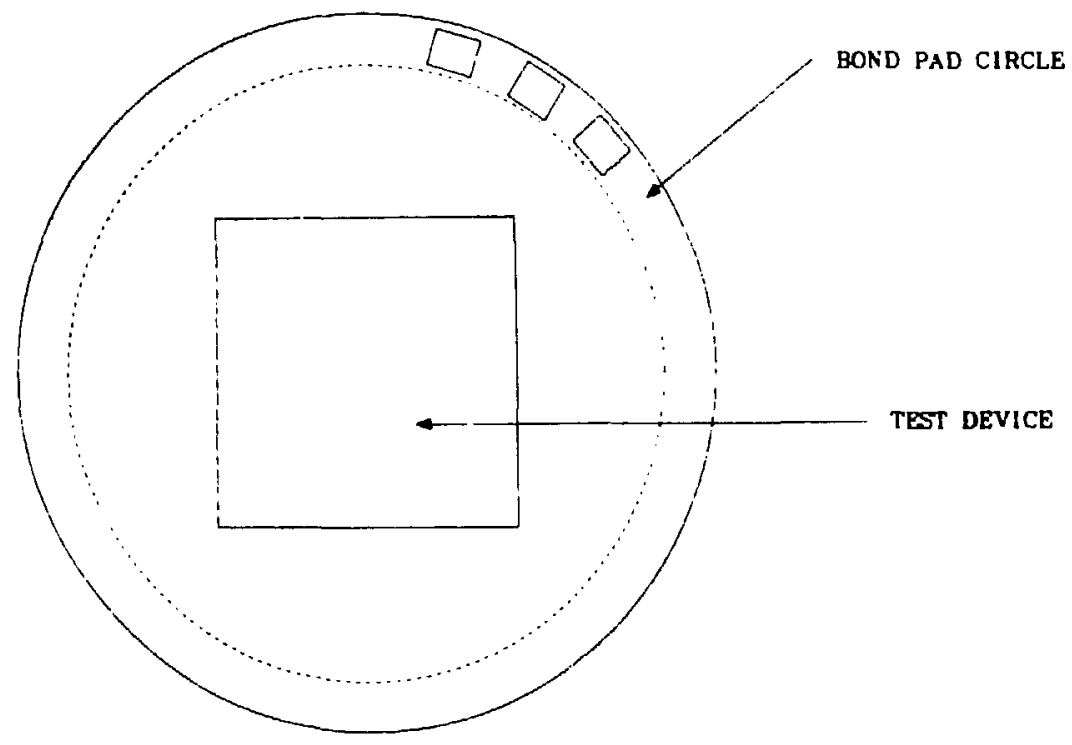

Fig. A-1. Substrate layout of GBP test device.

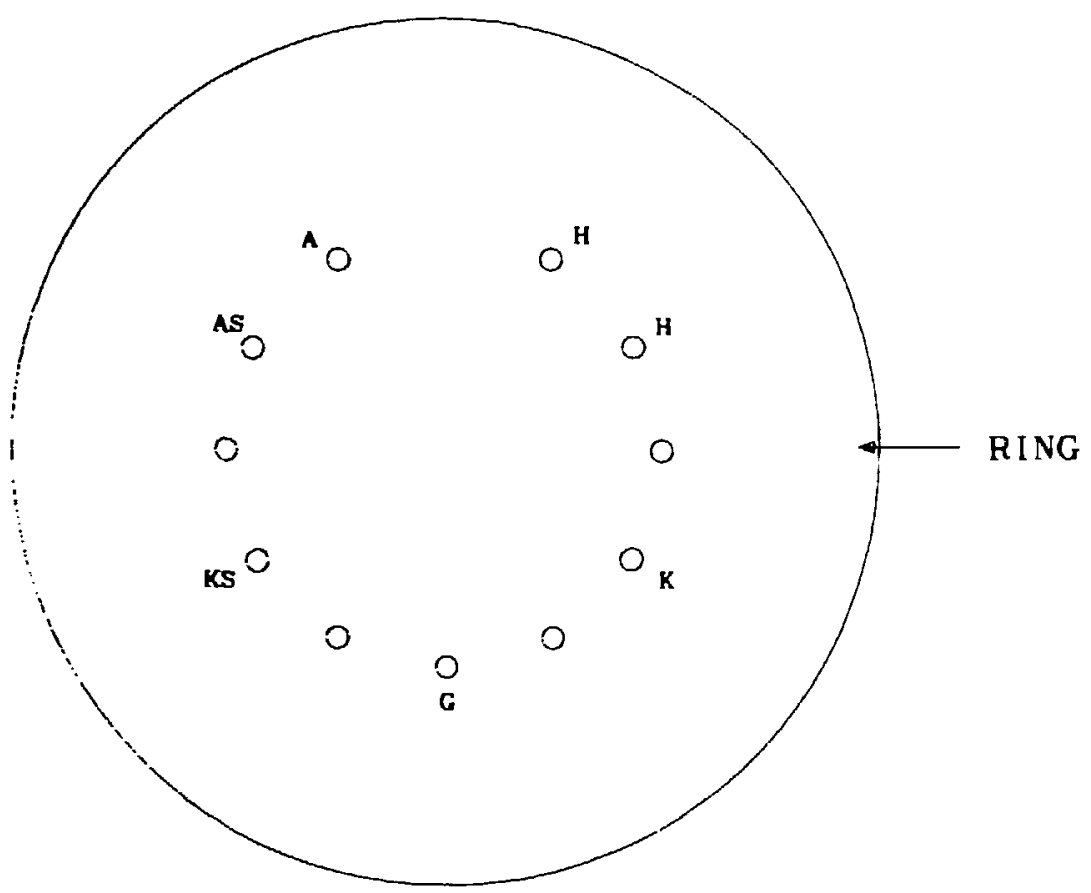

Fig. A-2. Pin choices for GBP test device. 


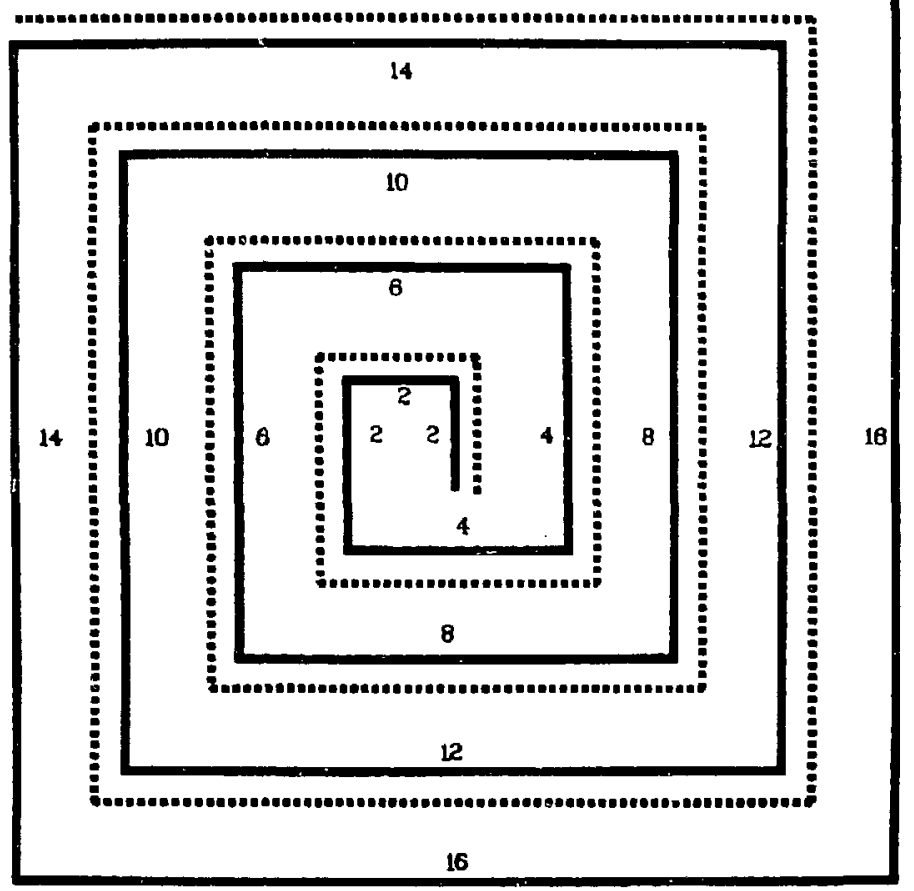

Fig. A-3. Cathode length, splral GPB test device. 


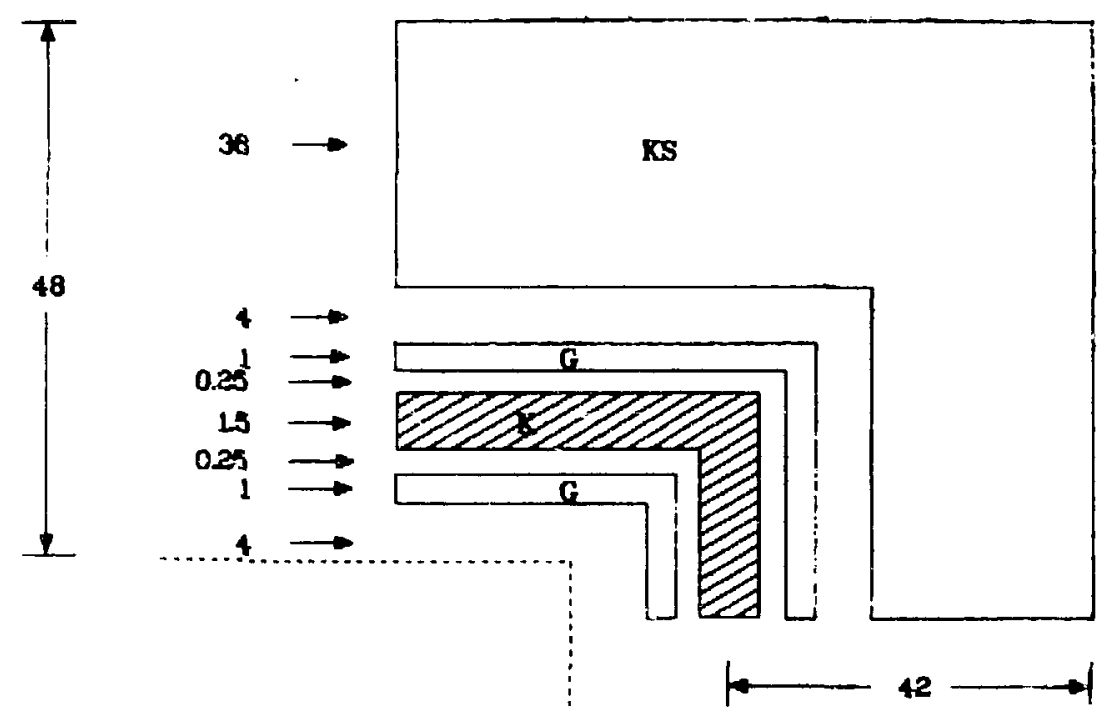

(a)

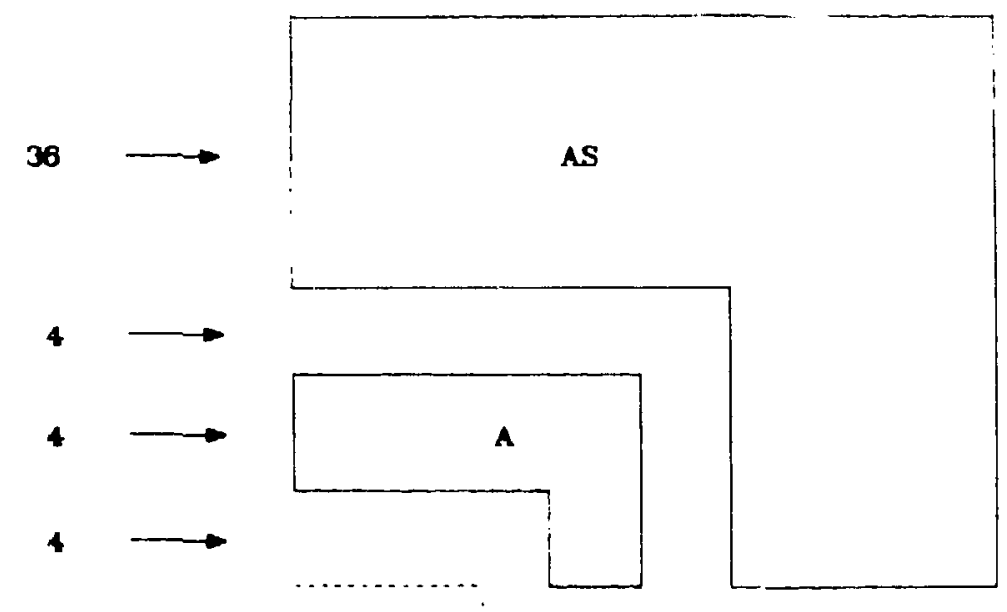

(b)

Fig. A-4. Example of spacing for single-stripe cathore. (a) Grid-cathode structure. (b) Anode structure. 


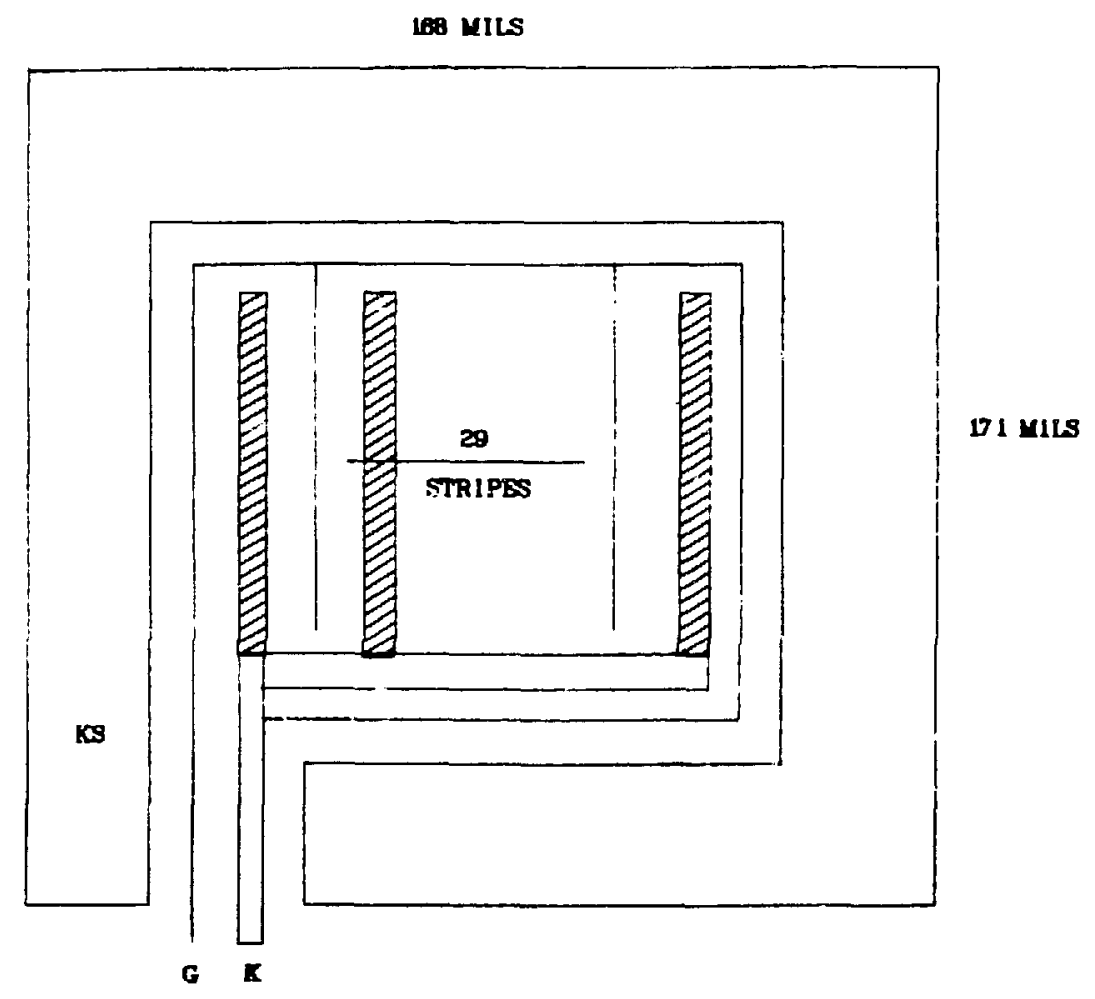

(a)

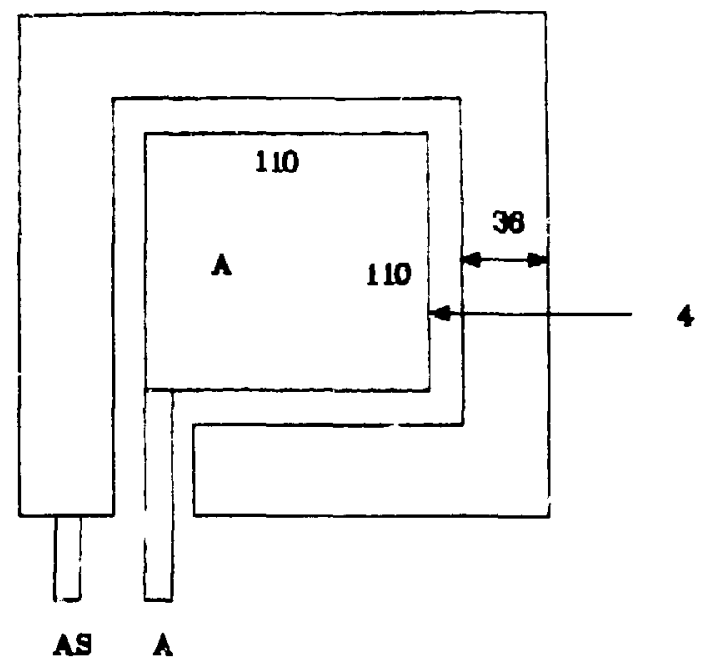

(b)

Fig. A-5. Structure of interdigitated GBP test device. (a) Grid-cathode shield. (b) Arode shield. 